EXPERIMENTAL AND NUMERICAL INVESTIGATION OF BIOMASS MECHANICAL PRE-PROCESSING

A Dissertation
presented to
the Faculty of the Graduate School
at the University of Missouri-Columbia
In Partial Fulfillment
of the Requirements for the Degree
Doctor of Philosophy
Br. Ali Bulent Koc, Dissertation Supervisor
JUL 2014
by LIU


The undersigned, appointed by the dean of the Graduate School, have examined the dissertation entitled

\section{EXPERIMENTAL AND NUMERICAL INVESTIGATION OF BIOMASS MECHANICAL PRE-PROCESSING}

presented by Bo Liu,

a candidate for the degree of doctor of philosophy of Bioengineering, and hereby certify that, in their opinion, it is worthy of acceptance.

Assistant Professor Ali Bulent Koc

Professor P. Frank Pai

Associate Professor Rob Myers

Associate Professor William Jacoby 


\section{ACKNOWLEDGEMENTS}

First, I offer my gratitude to my advisor, Dr. Ali Bulent Koc, who has supported me throughout my dissertation with his patience and knowledge. He has been supportive and has given me the freedom to pursue different projects and ideas without objection. He always encourages and expects me to think more independently about the experiments and results from an innovate aspect.

I also want to thank all the committee members, their guidance and advice helped me clarify my research goals and resolve difficulties on my path to finish this dissertation. I would like to give special thanks to Professor Frank Pai, he kindly allowed me to use his lab equipment and helped me to solve some technical problems I met.

In regards to the universal testing machine, I thank Dr. Sheila Grant who allowed me to use the testing equipment in her lab to finish some of the experimental tests. I would also like to thank Mr. David Grant for his kindness and help for making the experimental research progress much smoother.

I would also like to thank all the technical staff in the department who spent their time on manufacturing parts, experimental platform to make the experiments in this research to be possible.

Finally, I want to thank my family who always support me from heart. I could not finish this dissertation without their help and understanding. 


\section{TABLE OF CONTENTS}

ACKNOWLEDGEMENTS .......................................................................... ii

TABLE OF CONTENTS .............................................................................. ii

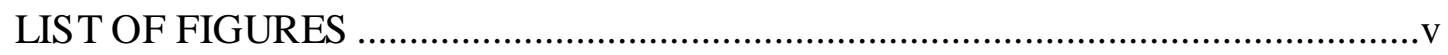

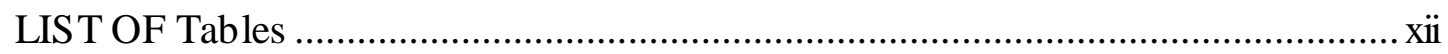

LIST OF NOMENCLATURE....................................................................... xiii

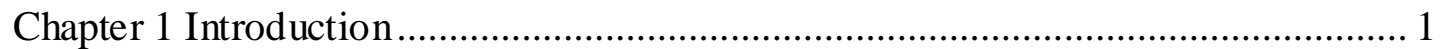

1.1 Using biomass as a sustainable energy source ............................................ 2

1.2 Clas sification of biomass ........................................................................ 3

1.2.1 Conventional biomass resources ......................................................... 4

1.2.2 Plantation-grown biomas s................................................................ 4

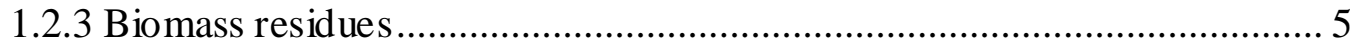

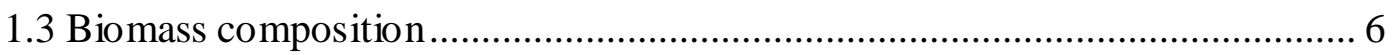

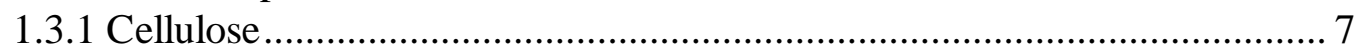

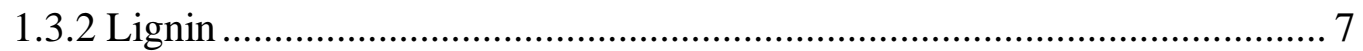

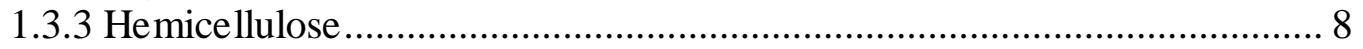

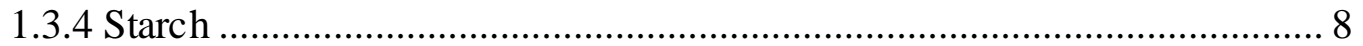

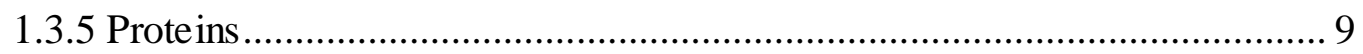

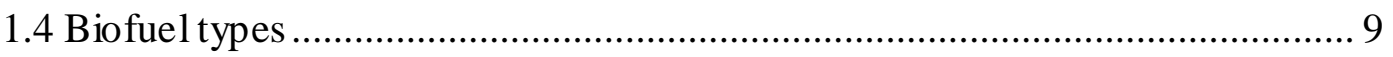

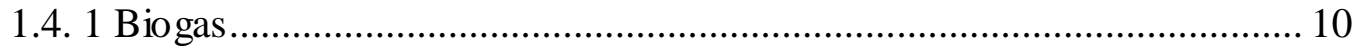

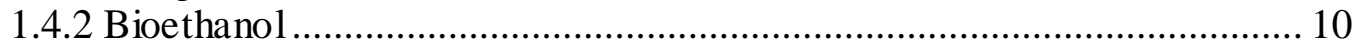

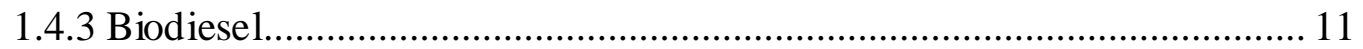

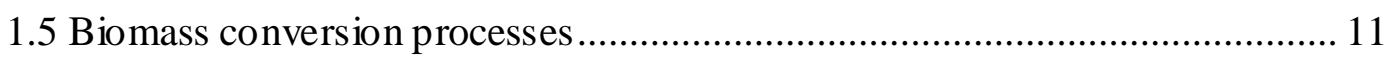

1.5.1 Thermochemical conversion ............................................................. 12

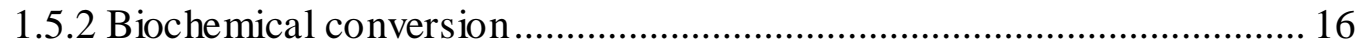

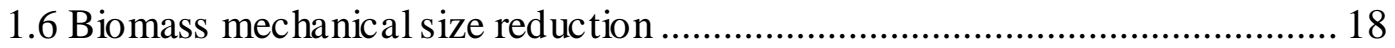

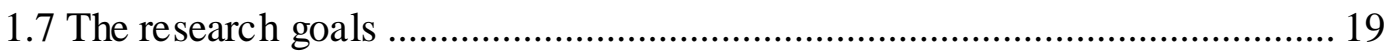

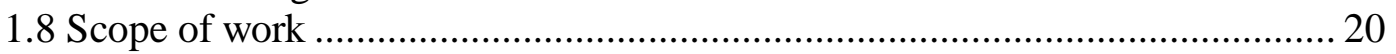

Chapter 2 Mechanical Properties Determination of S witchgrass and Miscanthus .... 22

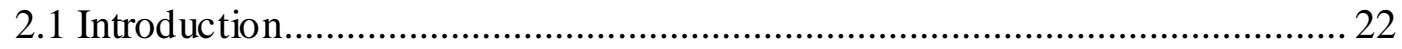

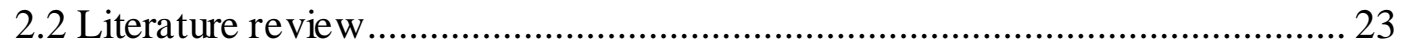

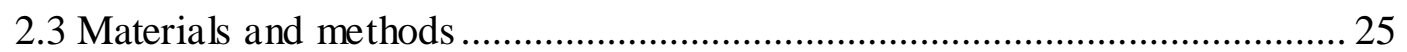

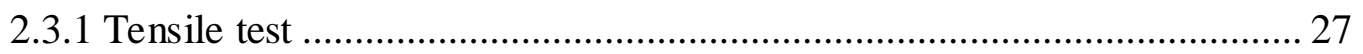

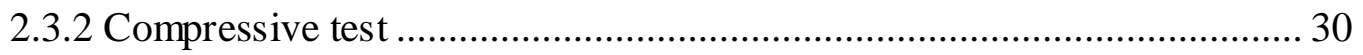

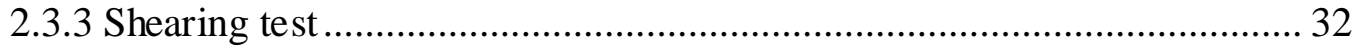

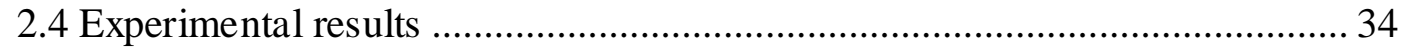

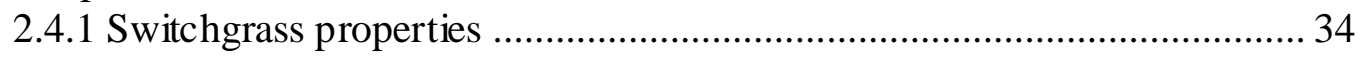

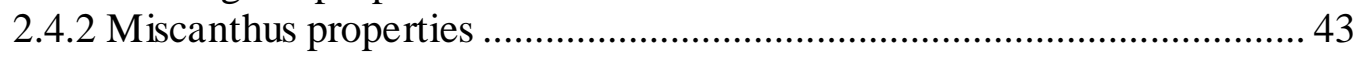

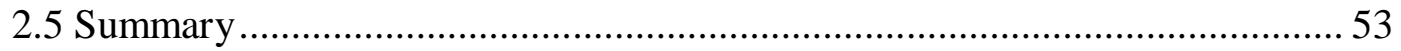

Chapter 3 Biomass Experimental Pre-processing System Development .................. 54

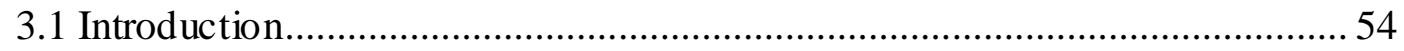




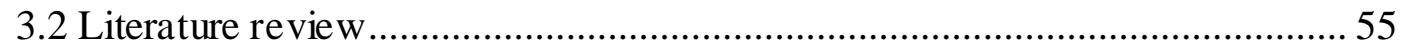

3.3 Development of a biomass experimental pre-processing system..................... 57

3.3.1 Design of a linear cutting platform ........................................................ 57

3.3.2 Development of a data acquisition and control system ............................ 58

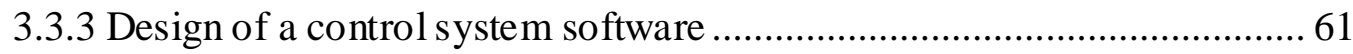

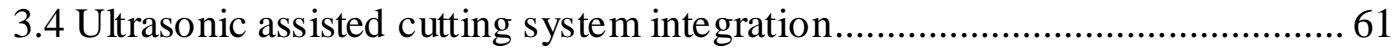

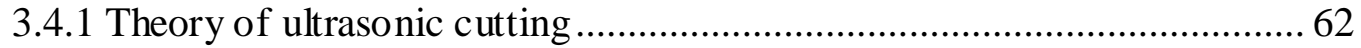

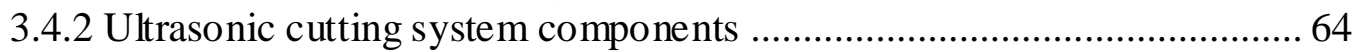

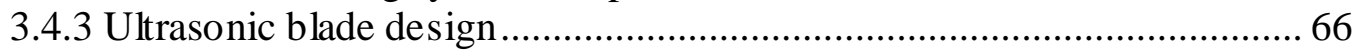

3.4.4 Experimental modal analysis of blade ................................................... 82

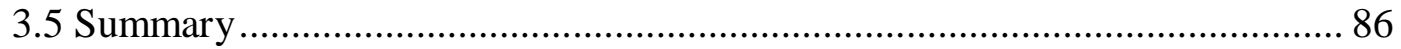

Chapter 4 Finite Element Analysis of Biomass Mechanical Pre-processing ............ 88

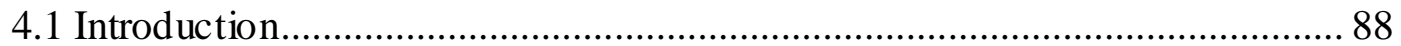

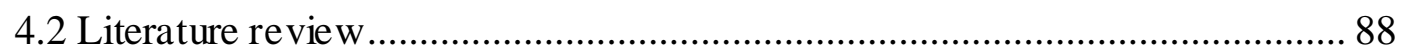

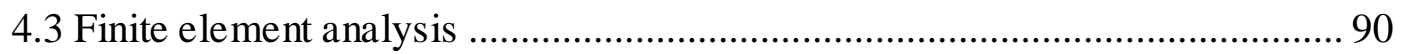

4.3.1 Material properties ………………………………………………..... 91

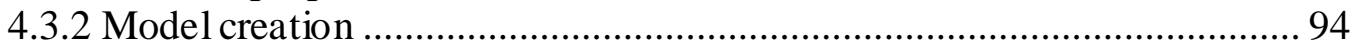

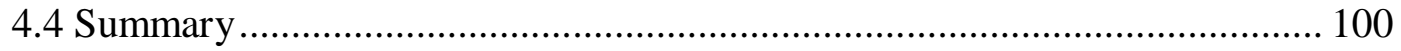

Chapter 5 Experimental and Finite Element Analysis of Biomass Cutting............. 102

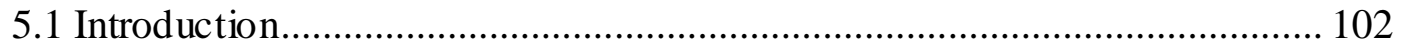

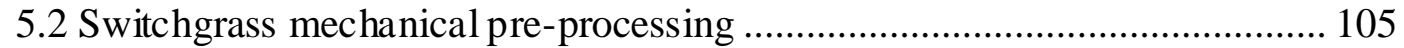

5.3. Miscanthus mechanical pre-processing ..................................................... 117

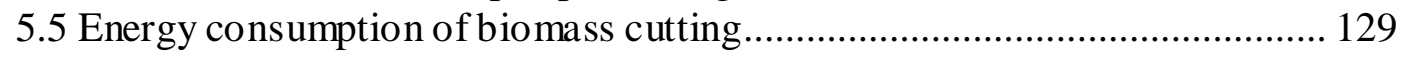

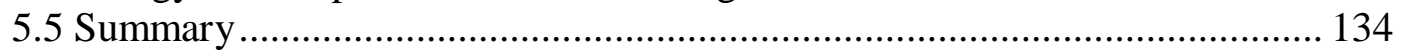

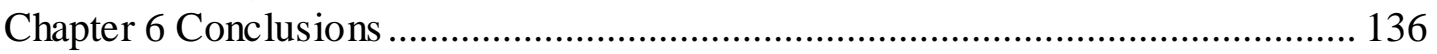

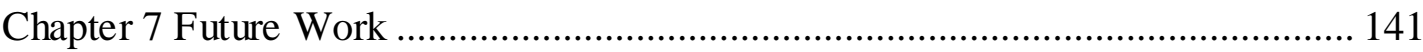

7.1 Determination of biomass mechanical properties ............................................. 141

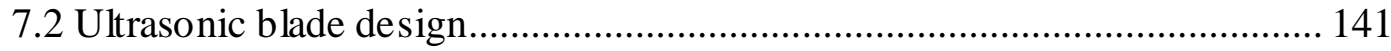

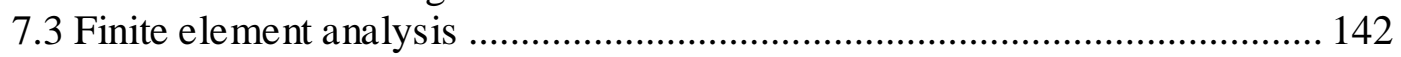

7.4 Cutting experiments and equipment design ................................................. 143

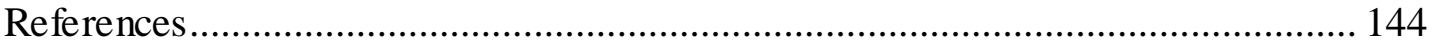

Appendix I. Schematic diagram of the wireless energy monitoring circuit ............ 151

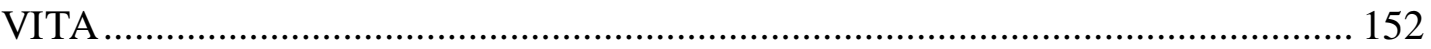




\section{LIST OF FIGURES}

Figure 1-1. Structure of lignocellulosic biomass with cellulose, hemicellulose, and lignin represented (Alonso, Wettstein, \& Dumesic, 2012).

Figure 1-2. Products of thermal conversion of biomass according to available technologies and feedstock (Sohi, Krull, Lopez-Capel, \& Bol, 2010) ............................ 13

Figure 1-3. Schematic diagram of biomass biochemical conversion (Damartzis \&

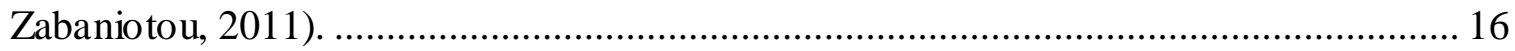

Figure 2-1. Experimental setup for biomass mechanical property determination. .......... 26

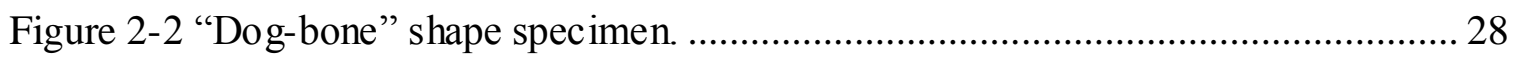

Figure 2-3. Specimen test preparation for tensile test on longitudinal direction (along

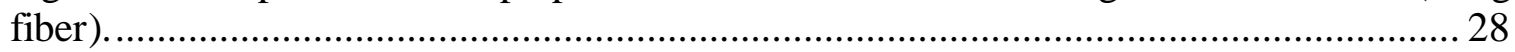

Figure 2-4. Specimen preparation for tensile tests on trans verse direction (cross fiber). . 29

Figure 2-5 Specimen preparation for compressive test on transversal direction. 31

Figure 2-6. Specimen preparation for compressive test on longitudinal direction (along fiber).

Figure 2-7. Specimen preparation for compressive tests on transversal direction (cross fiber). 32

Figure 2-8. Specimen preparation for shearing test on longitudinal direction (along fiber). 33

Figure 2-9. Specimen preparation for shearing test on transversal direction (cross fiber).

Figure 2-10. Tensile strength of switchgrass (9.8\% w.b.) longitudinal direction. 35

Figure 2-11. Young's modulus of switchgrass (9.8\% w.b.) longitudinal direction. 35

Figure 2-12. Compressive strength of switchgrass (9.8\% w.b.) longitudinal direction.... 36

Figure 2-13. Shearing strength of s witchgrass (9.8\% w.b.) longitudinal direction. ......... 36

Figure 2-14. Shear modulus of switchgrass (9.8\% w.b.) longitudinal direction. ............. 36

Figure 2-15. Tensile strength of switchgrass (9.8\% w.b.) transversal direction. .............. 37

Figure 2-16. Young's modulus of switchgrass (9.8\% w.b.) trans versal direction. ........... 37 
Figure 2-17. Compressive strength of switchgrass (9.8\% w.b.) trans versal direction. ..... 38

Figure 2 - 18 . Shearing strength of switchgrass (9.8\% w.b.) trans versal direction. ........... 38

Figure 2-19. Shear modulus of switchgrass $(9.8 \%$ w.b.) trans versal direction ................ 38

Figure 2-20. Tensile strength of switchgrass (14.6\% w.b.) longitudinal direction........... 39

Figure 2-21. Young's modulus of switchgrass (14.6\% w.b.) longitudinal direction. ....... 39

Figure 2-22. Compressive strength of switchgrass (14.6\% w.b.) longitudinal direction. . 40

Figure 2-23. Shearing strength of s witchgrass (14.6\% w.b.) longitudinal direction. ....... 40

Figure 2-24. Shear modulus of switchgrass (14.6\% w.b.) longitudinal direction. ........... 40

Figure 2-25. Tensile strength of switchgrass (14.6\% w.b.) transversal direction............ 41

Figure 2-26. Young's modulus of switchgrass (14.6\% w.b.) transversal direction. ......... 41

Figure 2-27. Compressive strength of switchgrass (14.6\% w.b.) transversal direction.... 42

Figure 2-28. Shearing strength of s witchgrass (14.6\% w.b.) transversal direction. ......... 42

Figure 2-29. Shear modulus of switchgrass (14.6\% w.b.) trans versal direction. ............ 42

Figure 2-30. Tensile strength of miscanthus (10.2\% w.b.) longitudinal direction. .......... 43

Figure 2-31. Young's modulus of miscanthus (10.2\% w.b.) longitudinal direction. ....... 43

Figure 2-32. Compressive strength of miscanthus (10.2\% w.b.) longitudinal direction. . 44

Figure 2-33. Shearing strength of miscanthus (10.2\% w.b.) longitudinal direction. ........ 44

Figure 2-34. Shear modulus of miscanthus (10.2\% w.b.) longitudinal direction. ............ 44

Figure 2-35. Tensile strength of miscanthus (10.2\% w.b.) trans versal direction. ........... 45

Figure 2-36. Young's modulus of miscanthus (10.2\% w.b.) transversal direction. ........ 45

Figure 2-37. Compressive strength of miscanthus (10.2\% w.b.) trans versal direction .... 46

Figure 2-38. Shearing strength of miscanthus (10.2\% w.b.) transversal direction .......... 46

Figure 2-39. Shear modulus of miscanthus (10.2\% w.b.) transversal direction ............... 46

Figure 2-40. Tensile strength of miscanthus (15.1\% w.b.) longitudinal direction ........... 47

Figure 2-41. Young's modulus of miscanthus (15.1\% w.b.) longitudinal direction ........ 47 
Figure 2-42. Compressive strength of miscanthus (15.1\% w.b.) longitudinal direction .. 48

Figure 2-43. Shearing strength of miscanthus (15.1\% w.b.) longitudinal direction ......... 48

Figure 2-44. Shear modulus of miscanthus (15.1\% w.b.) longitudinal direction ............. 48

Figure 2-45. Tensile strength of miscanthus (15.1\% w.b.) trans versal direction. ........... 49

Figure 2-46. Young's modulus of Miscanthus (15.1\% w.b.) transversal direction. ......... 49

Figure 2-47. Compressive strength of miscanthus (15.1\% w.b.) trans versal direction. ... 50

Figure 2-48. Shearing strength of miscanthus (15.1\% w.b.) transversal direction. ......... 50

Figure 2-49. Shear modulus of miscanthus (15.1\% w.b.) transversal direction. .............. 50

Figure $3-1$. Schematic diagram of the experimental cutting system............................57

Figure 3-2. Designed experimental linear cutting system. ...................................... 58

Figure 3-3. Schematic diagram of the control and data acquisition system development 59

Figure 3-4. Recorded voltage and current information (ultrasonic generator deactivated).

Figure 3-5. Recorded voltage and current information (ultrasonic generator activated).. 60

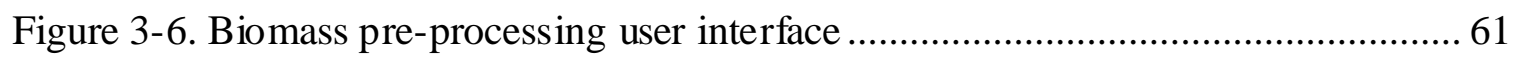

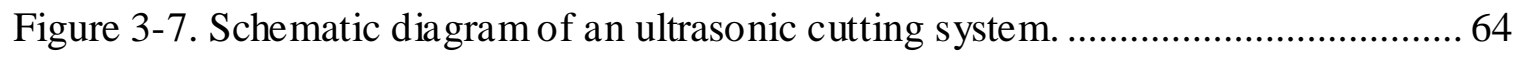

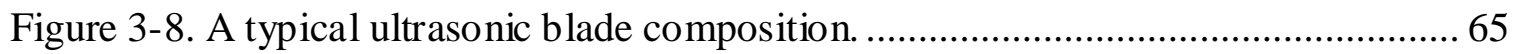

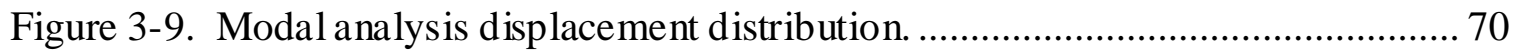

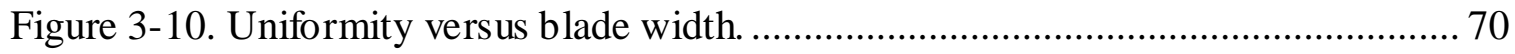

Table 3-11. Tip vibration amplitude control using a slot or groove. ............................. 71

Figure 3-12. Main effect plots for means of slot parameters. .................................... 75

Figure 3-13. Main effect plots for means of groove parameters................................. 75

Figure 3-14. Interaction plots for means of slot parameters. ..................................... 76

Figure 3-15. Interaction plots for means of groove parameters.................................. 76

Figure 3-16. First ultrasonic blade design: (a) blade design and (b) finite element mesh.77 
Figure 3-17. Second ultrasonic blade design: (a) blade design and (b) finite element mesh.

Figure 3-18. Third ultrasonic blade design: (a) blade design and (b) finite element mesh. 81

Figure 3-19. Polytec PS V-200 scanning laser vibrometer. 85

Figure 3-20. Manufactured blades: (a) first design (b) second design and (c) third design. 85

Figure 3-21. Polytec PS V-200 scanning laser vibrometer software. ................................. 86

Figure 4-1. Guillotine cutting configuration of bio mass. ............................................... 91

Figure 4-2. Simplified biomass stem structure. ……………………………………..... 92

Figure 4-3. Sliding friction experiments: (a) Experiment setup and (b) Schematic

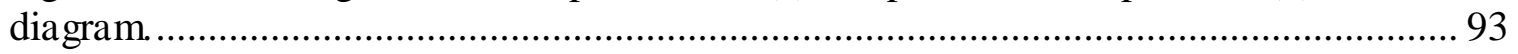

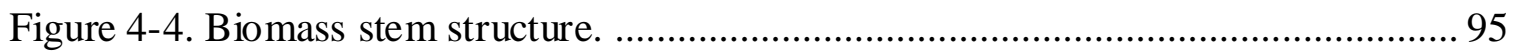

Figure 4-5. Typical uniaxial stress-strain response of brittle and ductile material.......... 96

Figure 4-6. A typical tensile test of miscanthus specimen............................................. 96

Figure 4-7. Element deletion in the model........................................................................ 99

Figure 4-8. Finite element analysis model of biomass cutting. ...................................... 100

Figure 5-1. Biomass cutting parameters configuration. ……………………………..... 103

Figure 5-2. Monitored biomass cutting performances................................................... 104

Figure 5-3. Switchgrass cutting blade profile 1 at $3 \mathrm{~mm} / \mathrm{s}$ cutting speed, $90^{\circ}$ cutting angle and with conventional cutting method: (a) force vs. displacement, and (b) cutting energy vs. displacement. 105

Figure 5-4. Switchgrass cutting blade profile 1 at $30 \mathrm{~mm} / \mathrm{s}$ cutting speed, $60^{\circ}$ cutting angle and with ultrasonic cutting method: (a) force vs. displacement, (b) cutting energy vs. displacement. 106

Figure 5-5. Switchgrass cutting with blade profile 1 at $300 \mathrm{~mm} / \mathrm{s}$ cutting speed, $45^{\circ}$ cutting angle and with conventional cutting method: (a) force vs. displacement and (b) cutting energy vs. displacement. ................................................................................... 106

Figure 5-6. Switchgrass cutting with blade profile 2 at $3 \mathrm{~mm} / \mathrm{s}$ cutting speed, $60^{\circ}$ cutting angle and with ultrasonic cutting method: (a) force vs. displacement and (b) cutting energy vs. displacement. 107 
Figure 5-7. Switchgrass cutting with blade profile 2 at $30 \mathrm{~mm} / \mathrm{s}$ cutting speed, $45^{\circ}$ cutting angle and with conventional cutting method: (a) force vs. displacement and (b) cutting energy vs. displacement. 107

Figure 5-8. Switchgrass cutting with blade profile 2 at $300 \mathrm{~mm} / \mathrm{s}$ cutting speed, $90^{\circ}$ cutting angle and with ultrasonic cutting method: (a) force vs. displacement and (b) cutting energy vs. displacement. 108

Figure 5-9. Switchgrass cutting with blade profile 3 at $3 \mathrm{~mm} / \mathrm{s}$ cutting speed, $45^{\circ}$ cutting angle and with conventional cutting method: (a) force vs. displacement and (b) cutting energy vs. displacement. 108

Figure 5-10. Switchgrass cutting with blade profile 3 at $30 \mathrm{~mm} / \mathrm{s}$ cutting speed, $90^{\circ}$ cutting angle and with ultrasonic cutting method: (a) force vs. displacement and (b) cutting energy vs. displacement. 109

Figure 5-11. Switchgrass cutting with blade profile 3 at $300 \mathrm{~mm} / \mathrm{s}$ cutting speed, $60^{\circ}$ cutting angle and with conventional cutting method: (a) force vs. displacement and (b) cutting energy vs. displacement. ......................................................................... 109

Figure 5-12. Switchgrass main effect plots for experimental max. cutting force. .......... 110

Figure 5-13. Switchgrass interaction plot for experimental max. cutting force. ............ 110

Figure 5-14. Switchgrass main effect plots for experimental average cutting force. ..... 111

Figure 5-15. Switchgrass interaction plot for experimental average cutting force. ........ 112

Figure 5-16. Switchgrass main effect plots for experimental cutting energy. ............... 112

Figure 5-17. Switchgrass interaction p lot for experimental average cutting force......... 113

Figure 5-18. Switchgrass main effect plot for simulated max. cutting force.

Figure 5-19. Switchgrass interaction plot for simulated max. cutting force.................. 114

Figure 5-20. Switchgrass main effect for simulated average cutting force. .................. 114

Figure 5-21. Switchgrass interaction plot for simulated average cutting force. ............. 115

Figure 5-22. Switchgrass main effect plots for simulated cutting energy. .................... 115

Figure 5-23. Switchgrass interaction plot for simulated cutting energy....................... 116

Figure 5-24. Miscanthus cutting with blade profile 1 at $3 \mathrm{~mm} / \mathrm{s}$ cutting speed, $90^{\circ}$ cutting angle and with conventional cutting method: (a) force vs. displacement and (b) cutting energy vs. displacement. 117 
Figure 5-25. Miscanthus cutting with blade profile 1 at $30 \mathrm{~mm} / \mathrm{s}$ cutting speed, $60^{\circ}$ cutting angle and with ultrasonic cutting method: (a) force vs. displacement and (b) cutting energy vs. displacement.

Figure 5-26. Miscanthus cutting with blade profile 1 at $300 \mathrm{~mm} / \mathrm{s}$ cutting speed, $45^{\circ}$ cutting angle and with conventional cutting method: (a) force vs. displacement and (b) cutting energy vs. displacement.

Figure 5-27. Miscanthus cutting with blade profile 2 at $3 \mathrm{~mm} / \mathrm{s}$ cutting speed, $60^{\circ}$ cutting angle and with ultrasonic cutting method: (a) force vs. displacement and (b) cutting energy vs. displacement.

Figure 5-28. Miscanthus cutting with blade profile 2 at $30 \mathrm{~mm} / \mathrm{s}$ cutting speed, $45^{\circ}$ cutting angle and with conventional cutting method: (a) force vs. displacement and (b) cutting energy vs. displacement.

Figure 5-29. Miscanthus cutting with blade profile 2 at $300 \mathrm{~mm} / \mathrm{s}$ cutting speed, $90^{\circ}$ cutting angle and with ultrasonic cutting method: (a) force vs. displacement and (b) cutting energy vs. displacement.

Figure 5-30. Miscanthus cutting with blade profile 3 at $3 \mathrm{~mm} / \mathrm{s}$ cutting speed, $45^{\circ}$ cutting angle and with conventional cutting method: (a) force vs. displacement and (b) cutting energy vs. displacement. 120

Figure 5-31. Miscanthus cutting with blade profile 2 at $300 \mathrm{~mm} / \mathrm{s}$ cutting speed, $90^{\circ}$ cutting angle and with ultrasonic cutting method: (a) force vs. displacement and (b) cutting energy vs. displacement.

Figure 5-32. Miscanthus cutting with blade profile 3 at $300 \mathrm{~mm} / \mathrm{s}$ cutting speed, $60^{\circ}$ cutting angle and with conventional cutting method: (a) force vs. displacement and (b) cutting energy vs. displacement.

Figure 5-33. Miscanthus main effect plots for experimental max. cutting force. 122

Figure 5-34. Miscanthus interaction plot for experimental max. cutting force. 123

Figure 5-35. Miscanthus main effect plots for experimental average cutting force. ...... 123

Figure 5-36. Miscanthus interaction plot for experimental average force. 124

Figure 5-37. Miscanthus main effect plots for experimental cutting energy. 124

Figure 5-38. Miscanthus interaction plot for experimental cutting energy. 125

Figure 5-39. Miscanthus main effect plots for simulated max. cutting force. 125

Figure 5-40. Miscanthus interaction plot for simulated max. cutting force. 126

Figure 5-41. Miscanthus main effect plots for simulated average cutting force. 126 
Figure 5-42. Miscanthus interaction plot for simulated average cutting force.

Figure 5-43. Miscanthus main effect plots for simulated cutting energy. 127

Figure 5-44. Miscanthus interaction plot for simulated cutting energy. 128

Figure 5-45. Average cutting force of switchgrass cutting with $90^{\circ}$ cutting angle. 130

Figure 5-46. Total energy consumption of switchgrass cutting with $90^{\circ}$ cutting angle. 130

Figure 5-47. Average cutting force of switchgrass cutting with $60^{\circ}$ cutting angle. ....... 130

Figure 5-48. Total energy consumption of switchgrass cutting with $60^{\circ}$ cutting angle. 131

Figure 5-49. Average cutting force of switchgrass cutting with $45^{\circ}$ cutting angle.

Figure 5-50. Total energy consumption of switchgrass cutting with $45^{\circ}$ cutting angle. 131

Figure 5-51. Average cutting force of miscanthus cutting with $90^{\circ}$ cutting angle.

Figure 5-52. Total energy consumption of miscanthus cutting with $90^{\circ}$ cutting angle. 132

Figure 5-53. Average cutting force of miscanthus cutting with $60^{\circ}$ cutting angle.... 132

Figure 5-54. Total energy consumption of miscanthus cutting with $60^{\circ}$ cutting angle. 133

Figure 5-55. Average cutting force of miscanthus cutting with $45^{\circ}$ cutting angle......... 133

Figure 5-56. Total energy consumption of miscanthus cutting with $45^{\circ}$ cutting angle. 133

Figure 6-1. Miscanthus cross-section structure

Figure 6-2. Cross section of cut switchgrass stems by: (a) conventional cutting method and (b) ultrasonic cutting method. 139

Figure 7-1. Thermal damage on biomas s cross-section area. 143 


\section{LIST OF TABLES}

Table 2-1. Linear regression analysis of mechanical properties of switchgrass. 52

Table 2-2. Linear regression analysis of mechanical properties of miscanthus. 52

Table 3-1. Tool steel DC53 material properties 69

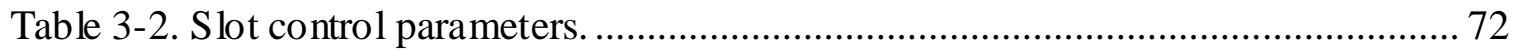

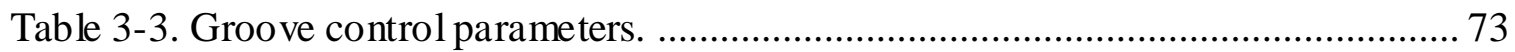

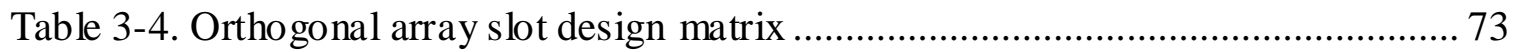

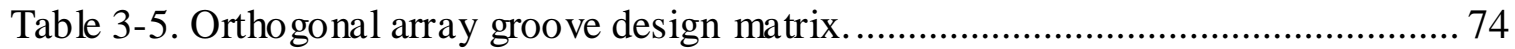

Table 3-6. Model shapes and natural frequencies of the first design. ............................. 77

Table 3-7. Model shapes and natural frequencies of the second design......................... 79

Table 3-8. Model shapes and natural frequencies of the third design .......................... 81

Table 3-9. Natural frequencies of experimental and simulation modal analysis results. . 84

Table 4-1. Biomass friction coefficient with blade (DC53 steel). ............................... 94

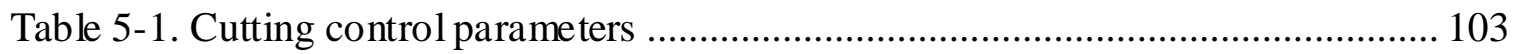

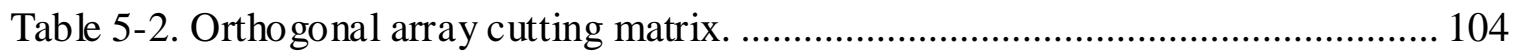

Table 5-3. Orthogonal array cutting experiment................................................. 105

Table 5-4. Switchgrass cutting performances with different cutting parameters. .......... 111

Table 5-5. ANOVA table for switchgrass cutting performance. .................................. 117

Table 5-6. Miscanthus cutting performances with different cutting parameters ........... 122

Table 5-7. ANOVA table for miscanthus cutting performance. ............................... 128 


\section{LIST OF NOMENCLATURE}

\begin{tabular}{|c|c|}
\hline$\delta_{t}$ & : Tensile strength \\
\hline$F_{t}$ & : Tensile force \\
\hline$A_{t}$ & : Failure area with tensile tests \\
\hline$L$ & : Length \\
\hline$\Delta L$ & : Change of length \\
\hline$F$ & : Force \\
\hline$A$ & : Area \\
\hline E & : Young's modulus \\
\hline$\sigma$ & : Stress \\
\hline$\varepsilon$ & : Strain \\
\hline$\delta_{c}$ & : Compressive strength \\
\hline$F c$ & : Compressive force \\
\hline$A c$ & : Failure area with compressive tests \\
\hline$\delta_{s}$ & : Shear stress \\
\hline$t_{c}$ & : Critical t statistic \\
\hline$S_{y x}$ & : Standard error of the estimate \\
\hline$x_{i}$ & : Given value of $x$ \\
\hline $\bar{x}$ & : Average of the $x$ values \\
\hline$n$ & : Number of data points \\
\hline$R^{2}$ & : coefficient of determination \\
\hline$P$ & : Power \\
\hline$V_{r m s}$ & : Root mean squared voltage values \\
\hline
\end{tabular}


$I_{r m s} \quad$ : Root mean squared current values

$\cos (\phi)$ : Power factor

$u_{m} \quad$ : Material displacement

$A_{m} \quad$ : Material vibration amplitude

$v_{m} \quad$ : Material vibration amplitude

$a_{m} \quad$ : Material acceleration

$F_{m} \quad:$ Force on material

$u_{b} \quad$ : Blade tip displacement

$A_{b} \quad$ : Blade tip vibration amplitude

$v_{b} \quad:$ Blade tip vibration amplitude

$A_{b} \quad$ : Blade tip acceleration

$v_{\text {rel }} \quad$ : Relative speed

$F_{R} \quad$ : Average friction force

$F_{C} \quad:$ Coulomb friction force

$\omega \quad:$ Angular velocity

$\theta \quad$ : Phase angle

c : Acoustic speed

$f \quad$ : Frequency

$\rho \quad$ : Density

$N \quad$ : Diameter radio

$K_{1}, K_{2} \quad$ : Constants

[M] : Mass matrix

[C] : Damping matrix 


\begin{tabular}{|c|c|}
\hline$[K]$ & : Stiffness matrix \\
\hline$[F]$ & : Force vector \\
\hline$u$ & : Displacement \\
\hline$\dot{u}$ & : Velocity \\
\hline$\ddot{u}$ & : Acceleration \\
\hline$\lambda$ & : Eigenvalue \\
\hline$\{\phi\}$ & : Eigenvector \\
\hline$u_{\min }$ & : Minimum displacement \\
\hline$u_{\max }$ & : Maximum displacement \\
\hline$F_{F}$ & : Friction force \\
\hline$F_{N}$ & : Normal force \\
\hline$\mu_{s}$ & : Coefficients of static friction \\
\hline$\mu_{d}$ & : Coefficients of dynamic friction \\
\hline$\sigma_{i j}$ & : Stress components on $i$ surface in $j$ direction \\
\hline$X_{T}$ & : Allowable tensile strengths in $X$ material directions \\
\hline$Y_{T}$ & : Allowable tensile strengths in $Y$ material directions \\
\hline$Z_{T}$ & : Allowable tensile strengths in $Z$ material directions \\
\hline$X_{C}$ & : Allowable compressive strengths in $X$ material directions \\
\hline$Y_{C}$ & : Allowable compressive strengths in $Y$ material directions \\
\hline$Z_{C}$ & : Allowable compressive strengths in $Z$ material directions \\
\hline$S_{i j}$ & : Allowable shear strengths on $i$ surface in $j$ direction \\
\hline$A_{0}, A_{n}$ & : Constant \\
\hline $\mathrm{B}_{0}$ & : Constant \\
\hline
\end{tabular}




$\begin{array}{ll}\text { FEA } & \text { : Finite Element Analysis } \\ \text { w.b. } & \text { : Wet Basis } \\ \text { WPF } & \text { : Windows Presentation Foundation } \\ \text { OATS } & \text { : Orthogonal Array Testing Strategy } \\ \text { FFT } \quad \text { : Fast Fourier Transform } \\ \text { DFT : Digital Fourier Transform } \\ \text { UC } \quad \text { : Ultrasonic Cutting } \\ \text { CC } \quad \text { : Conventional Cutting } \\ \text { ANOVA : Analysis of Variance }\end{array}$




\section{CHAPTER 1 INTRODUCTION}

From transportation tools to cell phones, air conditioning to baking, energy is important in every aspect of people's lives. As more and more human activities and life demands depend on energy sources, energy will play an important role in the world's future. Generally, Energy sources can be grouped into three major categories: fossil fuels (natural gas, coal and petroleum), renewable sources (wind, solar, biofuels and etc.) and nuclear sources (Evans, Strezov, \& Evans, 2009; Parikka, 2004). The interests of using renewable energy resources have been increasing in the past decades because of the exhausting fossil fuel resources and potentially problematic nuclear resources (Markvart, 2000). The renewable energy share of total consumed energy use in the United States is expected to increase from 9 percent in 2012 to 12 percent in 2040, and a large portion of the total consumed energy use is expected to come from biomass sources (DOE, 2014).

Biomass is a biological material derived from living organisms, such as plants and microalgae. As one of the renewable energy sources, biomass materials store chemical energy by absorbing the energy from the Sun via the process of photosynthesis, and the stored energy can be converted to other usable forms such as methane gas, ethanol and biodiesel or directly to heat (McKendry, 2002a). Biomass fuels or biofuels are technogenic solid, liquid or gaseous fuels generated from biomass resources via processing of its natural constituents (Vassilev, Baxter, Andersen, \& Vassileva, 2010). Because of its sustainable and environment-friendly attributes, biomass has become an attractive renewable energy source to produce biofuels (BEC). 


\subsection{Using biomass as a sustainable energy source}

Biomass has potential to be a sustainable fuel source that provides numerous benefits compared to other energy sources, when it is correctly managed and well used. Biomass crops have the effect of taking in carbon dioxide and releasing oxygen into the environment through the natural photosynthesis process of plants (Whitmarsh, 1999). Fossil fuels are also derived from biological materials, however, the carbon dioxide absorbed in these materials has lasted over many millions of years, the combustion products of fossil fuels released to the atmosphere will contribute to increasing carbon dioxide concentrations in a short time, and this process is believed to accelerate the global warming (Cox, Betts, Jones, Spall, \& Totterdell, 2000). While biomass crops are converted to energy, they only produce a fraction of the carbon emissions of fossil fuels (Hall, Mynick, \& Williams, 1991). The world now is facing challenges of reducing and eliminating wastes permanently generated by energy conversion processes. Biomass residues, co-products and wastes, which are not used for energy generation or some other desired applications, will eventually rot. The use of biomass energy sources also offers economic incentives to protect biodiversity and preserve woodlands (Anderson \& Fergusson, 2006). Many biomass fuel processing methods have presented cost effective ways of acquiring energy compared to oil supplies (Galbe, Sassner, Wingren, \& Zacchi, 2007). Not every country in the world has its own supply of oil, and many countries mostly rely on the oil sources from other countries which can produce and refine fossil oil. The world is facing the crisis of fossil fuel depletion, and eventually the fossil fuels will be depleted by the soaring energy demands (Singh \& Singh, 2010). Therefore, exploring alternative energy sources that are cost effective and environmentally friendly 
is the only choice left for human beings to solve the crisis of fossil fuel depletion and environmental degradation (Chynoweth, Owens, \& Legrand, 2001).

Biomass crops can be planted locally that can help the local economy and provide job opportunities in all the processes of converting biomass to end-use energy. The world's population has been significantly increased in the past century because of the improved healthcare and increased food production (Fuller, Scherer, \& Pomroy, 2003). With the global population explosion, food shortage and energy consumption needs are two controversial problems the world is facing. Biomass includes energy crops that do not necessarily compete with food in the food chain (Shi, Wang, Duan, Link, \& Morreale, 2012).

However, there is a concern that the growing bioenergy market will affect the present land use patterns and compete for land and cause higher prices of agricultural commodities and/or a significant reduction in food production (Ignaciuk, Vöhringer, Ruijs, \& van Ierland, 2006). Biomass crops are considered to be occupying land which could have been utilized in growing food crops. Hunger is still a big issue that many nations are facing nowadays. Dealing with energy, food and environment is one of the most challenging problems that the people on this planet are facing in the future. Dramatic improvements are needed in policy and technology to reconfigure agriculture and land use to meet global demand for both food and biofuel feedstock (Tilman et al., 2009).

\subsection{Classification of biomass}

The general classification of biomass materials for energy includes: wood and woody biomass from forestry, energy crops, agricultural residues, food waste, industrial waste 
and co-products. Based on biomass use and applications, biomass also can be categorized in conventional biomass resources, plantation biomass and biomass waste/residues (Jaya Shankar Tumuluru, Sokhansanj, Wright, Boardman, \& Yancey, 2011).

\subsubsection{Conventional biomass resources}

Conventional biomass resources cover a wide range of materials, such as woody biomass, agricultural residues and food wastes. Woody biomass is one of the major biomass resources available in large quantities in various regions of the world (Parikka, 2004). Woody biomass is an important energy carrier contributing substantially to cover energy demands in many parts of the world (Parikka, 2004). Woody biomass is usually larger and structurally stronger and denser than agricultural biomass and has higher lignin content (higher energy density) than agricultural biomass (Zhu \& Pan, 2010). Shortrotation intensive culture can provide lots of opportunities for producing woody biomass. Wood fuels can be derived from conventional forestry practice, for example trimming, as part of the management of woodland to improve the production of high quality timber for wood products and optimization of biodiversity (Lehoux, Marier, D`Amours, \& Beaulieu, 2012).

\subsubsection{Plantation-grown biomass}

Plantation-grown biomass consists of energy crops, aquatic biomass and agricultural residues. Energy crops are grown specifically for biofuel production and offer high energy output with low inputs (McKendry, 2002a). Although energy crops contribute a small proportion to the total energy produced from biomass each year, this proportion is expected to increase over the next few decades (Sims, Hastings, Schlamadinger, Taylor, 
\& Smith, 2006). Energy crops have different forms and can be converted to a great number of products, such as ethanol, methanol, and biodiesel or used as solid biomass for combustion. Perennial grasses like switchgrass and miscanthus are less expensive to produce because they do not have to be replanted each year, and they are considered to be promising sources of cellulosic ethanol. Fast-growing woody crops, such as poplar, willow, are also attractive options because of harvesting and storage advantages (Zhuang, Qin, \& Chen, 1999).

\subsubsection{Biomass residues}

Biomass residues mainly include agricultural, forestry, fishery and livestock residues. Great amounts of biomass residues, co-products and wastes that could potentially become available at relatively low cost, and many of these have energy contents that can be exploited. Residues from industrialized farming, forests, food and fiber processing operations are currently collected worldwide and used in modern bioenergy conversion plants (Sims et al, 2006). Agricultural residues cover a wide variety of biomass kinds, and the energy conversion technologies and handling methods vary from kind to kind.

The major division of biomass wastes are the residues that are predominantly dry or wet (nee'Nigam \& Pandey, 2009). Many agricultural and livestock residues can be potentially used for energy applications and these residues and wastes usually have relatively high water content when collected. The high moisture contents make wet biomass waste energetically inefficient to use for direct combustion or gasification and costly to transport. Therefore, it is usually preferred to have high moisture content 
biomass waste processed near the origins or used in an aqueous environment (nee'Nigam \& Pandey, 2009).

\subsection{Biomass composition}

As mentioned in previous sections, there are numerous types of biomass resources, and the biomass composition is widely diverse. However, there are some shared primary components in most of the biomass materials, such as lignin, starch, cellulose, hemicellulose, and proteins (Amon et al., 2007; Callé \& Rosillo-Calle, 2007). Different kinds of biomass have different ratios of each of these components. For instance, grains mainly contain starch, while trees mainly consist of cellulose, lignin and hemicellulose (Alriols, Tejado, Blanco, Mondragon, \& Labidi, 2009). M Thomas, Van Vliet, and Van der Poel (1998) identified some of the important ingredients of biomass, including starch, protein, sugar and non-starch polysaccharides (NSP), fat, fiber, inorganic matter, and water. Cellulose, lignin and hemicellulose are the most important components (shown in Figure 1-1) for biomass fuel production.

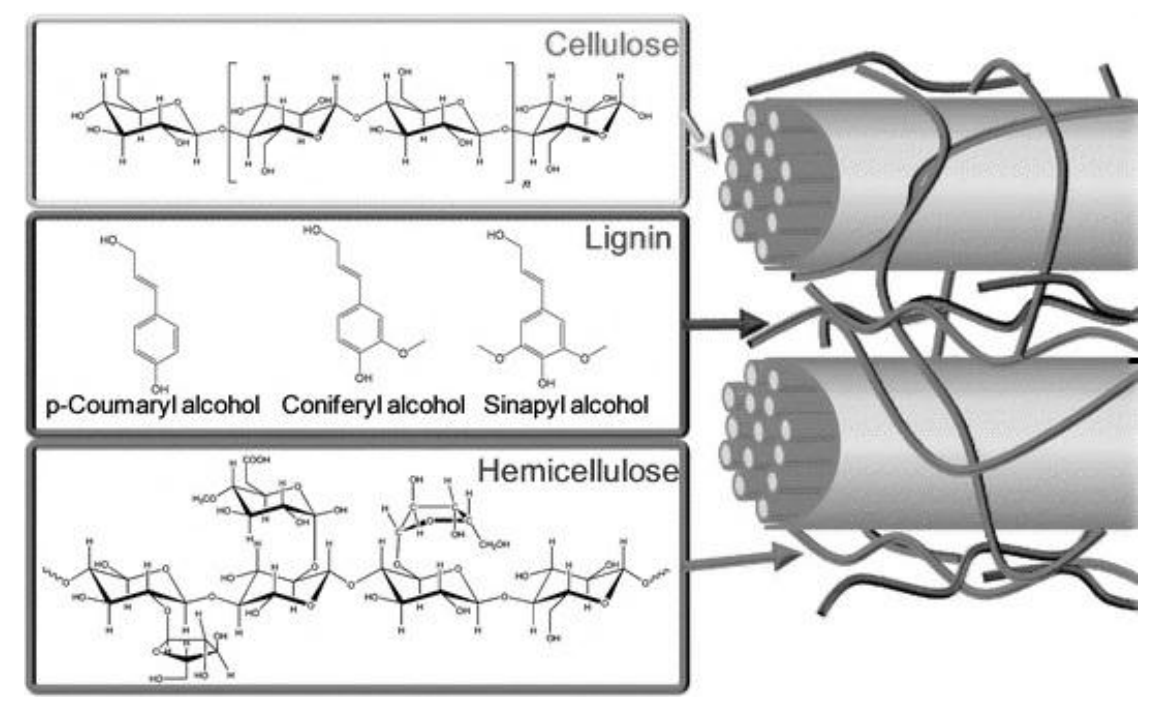

Figure 1-1. Structure of lignocellulosic biomass with cellulose, hemicellulose, and lignin represented (Alonso, Wettstein, \& Dumesic, 2012). 


\subsubsection{Cellulose}

Cellulose is the primary component of nearly every natural, free-growing plant, tree, and bush, in meadows and forests with little agricultural effort. Cellulose is a linear homopolysaccharide of d-glucopyranose units. Natural cellulose is a semicrystalline polymer with crystalline sections formed by polymer alignment and held together by strong chemical bonding and interactions (S. R. Collinson \& W. Thielemans, 2010). Unlike the starch plants (for instance, corn) used to make most ethanol nowadays, cellulose is not used for food, and it can be grown with less agricultural effort. Cellulosic ethanol is expected to be less expensive and more energy-efficient than today's ethanol because it can be made from low-cost feedstock, such as sawdust, forest thinning, waste paper, grasses, farm residues (corn stalks, wheat straw, rice straw, and etc.), and energy crops like switchgrass, miscanthus and other perennial grasses which are considered to be promising sources of bioenergy (Schmer, Vogel, Mitchell, \& Perrin, 2008).

\subsubsection{Lignin}

Lignin is a naturally occurring macromolecule following cellulose as the second major component in biomass materials. It is found as a cell wall component in all vascular plants and in the woody stems of arborescent angiosperms (hardwoods) and gymnosperms (softwoods) and thus coexists with cellulose (S. Collinson \& W. Thielemans, 2010). Lignin permits adhesion in the wood structure and acts as a rigidifying and bulking agent (Adapa, Karunakaran, Tabil, \& Schoenau, 2009; Angles, Ferrando, Farriol, \& Salvadó, 2001). The lignin content in woody stems varies between $15 \%$ and $40 \%$ where it works as water sealant and plays an important role in controlling water transport through cell walls. Lignin can protect plants against biological attack by 
hampering enzyme penetration, and act as permanent glue binding cells together in the woody stems, and thus providing the stems' rigidity and impact resistance (Wool \& Sun, 2011). As lignin is a hydrophobic material and cellulose is a hydrophilic material, the compatibility between the two is obtained through hemicellulose, which contains both hydrophilic and hydrophobic sections (S. R. Collinson \& W. Thielemans, 2010).

\subsubsection{Hemicellulose}

The hemicelluloses found in the cell wall are heteropolysaccharide, or the combination of many sugars other than just glucose. Hemicelluloses have a random amorphous structure and are comprised of several polysaccharides. The amorphous structure of hemicelluloses is due to branching and is more easily hydrolyzed or can be dissolved in alkali solution (Wyman et al, 2005). Studies on utilization of hemicelluloses from cereal straws have shown that they have the potential to be fermentation feedstock in production of xylitol. Properties of hemicelluloses being worthy of exploiting are their ability to serve as adhesives, thickener, stabilizers, film formers and emulsifiers (Sun, 2009). Some research results indicate that natural bonding may occur due to the adhesive degradation products of hemicelluloses which are believed to be involved in regulation of wall elongation and modification. Wall elongation and modification are thought to have a strong effect on the interactions between cellulose microfibrils (Wyman et al., 2005).

\subsubsection{Starch}

Starch is a naturally occurring blend of two polymers: amylose and amylopectin, and both of them are $\alpha$-d-glucopyranose polymers (S. R. Collinson \& W. Thielemans, 2010). Starch is one of the most common carbohydrates contained in biomass. Starch undergoes 
gelatinization, pasting, and retrogradation reactions, of which gelatinization plays the most important role during pelletization (Kaletunc \& Breslauer, 2003). Gelatinization of starch is an irreversible process and is mainly influenced by the densification process variables of heat, water, shear, and residence time (Menno Thomas, Huijnen, van Vliet, van Zuilichem, \& van der Poel, 1999). During feeding and biomass pelletization processes, starch not only acts as a binder but also as a lubricating agent, and helps to ease the flow of materials through the pellet mill or extruder.

\subsubsection{Proteins}

Agricultural products can contain substantial amounts of proteins. Proteins, such as potato proteins, proteins from cereals, soybeans, collagen and gelatine are being used in food and feed as well as in various non-food or technological applications (Mulder, 2010). Protein in biomass is heated during the densification process and undergoes denaturation leading to the formation of new bonds and structures with other proteins, lipids and starch available in biomass and improves the binding capacity ( $\mathrm{M}$ Thomas et al., 1998).

\subsection{Biofuel types}

Biofuels are produced from living organisms or from metabolic by-products for energy use. Biofuels are originally derived from the photosynthesis process; therefore they can be referred to as solar energy sources. The major biofuel types include biogas, bioethanol and biodiesel, and the following sections will discuss these different types of biofuels. 


\subsection{Biogas}

Biogas typically includes a mixture of gases produced by breaking down organic matter in the absence of oxygen. Biogas productions from biomass are of growing importance as they offer considerable environmental benefits (Angelidaki et al., 2009). Biogas, as a renewable energy source, is produced by anaerobic digestion with anaerobic bacteria or fermentation of biodegradable materials such as manure, sewage, plant materials and crops (Bisen, Debnath, \& Prasad, 2012). The primary contents of biogas include methane, carbon dioxide and may have small amounts of hydrogen sulphide, moisture and siloxanes. Biogas has been widely used to generate heat for heating, cooking and powering vehicles (Abdulkareem, 2005).

\subsubsection{Bioethanol}

As one of the modern forms of biomass energy, bioethanol produced from biomass has the potential to be a sustainable biofuel resource and a fuel oxygenate to replace gasoline (Searchinger et al., 2008). Ethanol is an alternative fuel produced from starch contained in grains such as corn, grain sorghum, barley and sugarcane through a fermentation and distillation process that converts starch to sugar and then to ethanol (Prasad, Singh, \& Joshi, 2007). Most ethanol produced in the United States is made from corn because its low-cost source of starch can be easily converted into sugar, then fermented and distilled into ethanol (Yacobucci, 2007). In most cases, ethanol is used as a fuel additive to reduce vehicles' carbon monoxide and other smog-causing emissions. Ethanol can be blended with gasoline to create E85, a blend of 85 percent ethanol and 15 percent gasoline for flex-fuel vehicles. 


\subsubsection{Biodiesel}

Biomass can be used to produce low-molecular-weight organic liquids, which can be used by vehicles. It is used as an additive to reduce vehicle emissions or in its pure form as a renewable alternative fuel for diesel engines. Biodiesel is made by combining alcohol such as methanol with vegetable oil, animal fat, or recycled cooking greases (Gerpen, 2005). Because the great molecular similarities of biodiesel to paraffinic diesel fuel compounds, this alternative fuel has a chance of fulfilling the demands of diesel engines as fuel. Although biodiesel has cold flow issues, they can be avoided by using fuel-line or in-tank heaters by storing the related equipment in heated areas or by insulating fuel lines and filters. Essentially no engine modifications are required to substitute biodiesel for diesel fuel that can maintain the engine performance. In addition, biodiesel is better than diesel fuel in terms of sulfur content, flash point, aromatic content and biodegradability (Martini \& Schell, 1998).

\subsection{Biomass conversion processes}

There is a great amount of research involving new biomass fuel processing technologies to generate biofuels efficiently and economically (Pham, Holtzapple, \& ElHalwagi, 2010; Wils, Calmano, Dettmann, Kaltschmitt, \& Ecke, 2012). Biomass raw materials that can be used to produce biofuels are widely available from various forms; however there is no single energy conversion method which is suitable for all forms of biomass. Thermochemical conversion and biochemical conversion are the major ways to convert biomass to energy (Goyal, Seal, \& Saxena, 2008; McKendry, 2002a, 2002b). 


\subsubsection{Thermochemical conversion}

Thermal conversion is the oldest and the most common way to convert biomass into energy for heating, cooking, industrial processes and electricity. Thermal conversion of biomass in an enclosure is usually more efficient than simply burning it in an open environment (Ahuja, Joshi, Smith, \& Venkataraman, 1987). Raw biomass materials can be directly burned in a boiler at a power plant to produce high-pressure steam which can drive a turbine to generate electricity. Liquid biofuels can be used in the ground and aviation transportation vehicles, and in engines and turbines of electrical power generators. Solid and gaseous biofuels can be used to generate electrical power by driving turbines in power plants. The biomass thermochemical conversion typically included combustion, gasification, pyrolysis and other processes (Jahirul, Rasul, Chowdhury, \& Ashwath, 2012). These processes convert the waste biomass into high energy-content products. Choice of conversion process depends upon the type and quantity of biomass feedstock, the desired forms of the energy, end-use requirements, environmental standards, economic conditions and project specific factors. The products of thermal conversion of biomass abased on available technologies and feedstock are shown in Figure 1-2. The basic steps of thermochemical conversion process are provided in the following sections.

\subsubsection{Combustion}

Combustion is used over a wide range of outputs to convert the chemical energy stored in biomass into heat using various items of process equipment such as stoves, boilers, steam turbines and furnaces (McKendry, 2002b). Biomass combustion consists of series of chemical reactions in which carbon is oxidized to carbon dioxide, and hydrogen 


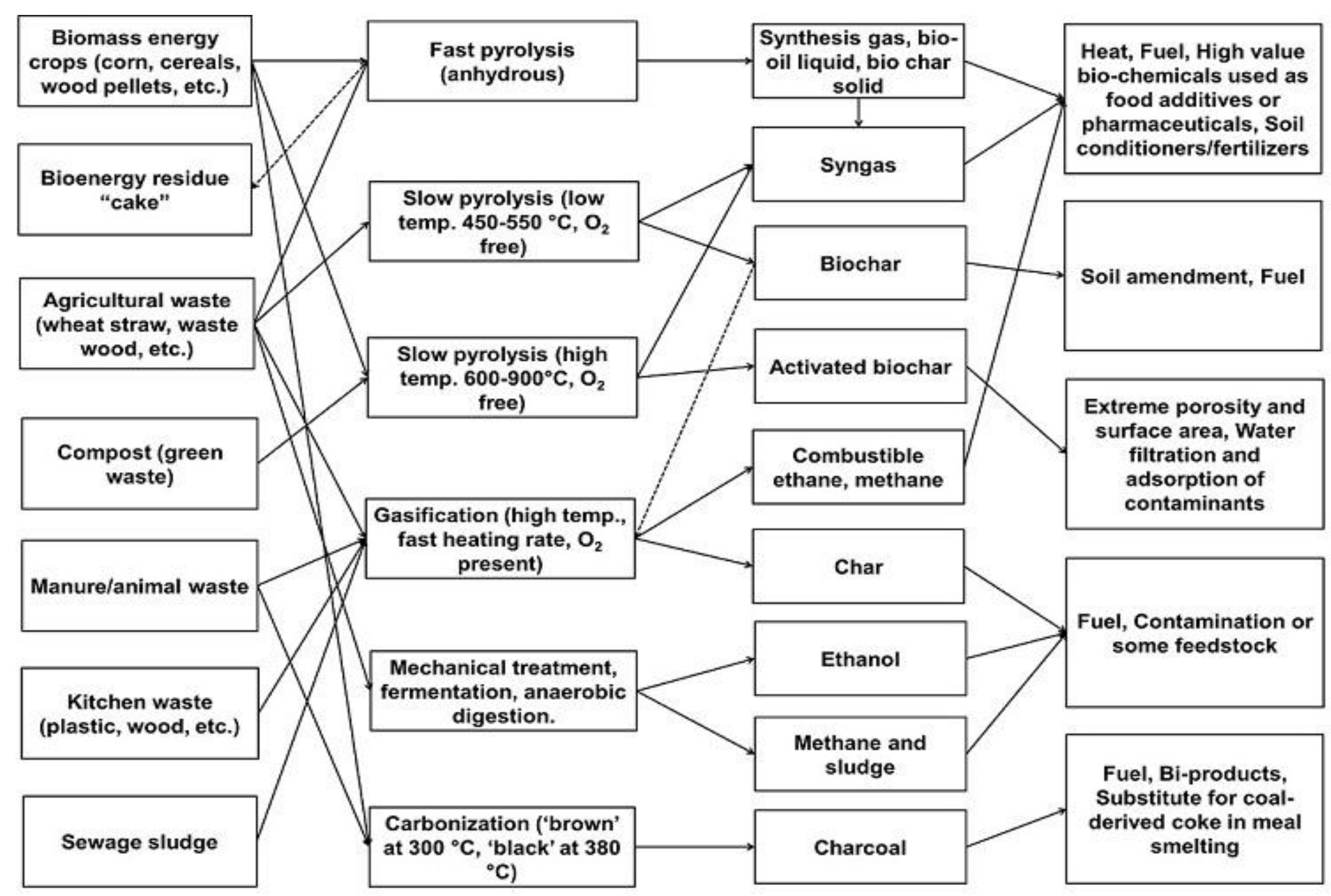

Figure 1-2. Products of thermal conversion of biomass according to available technologies and feedstock (Sohi, Krull, LopezCapel, \& Bol, 2010) 
is oxidized to water. Oxygen deficiency can lead to incomplete combustion and the formation of undesirable products, while excess air may cool the system and cause heat loss. Therefore, the air requirements and control is one of the important factors in combustion, and they are dependent on chemical and physical characteristics of the biofuels. In addition, the combustion of biomass relates to the fuel burn rate, the combustion products, the required excess air and the fire temperatures (Demirbas, 2005). The main processes of biomass combustion include drying, devolatilization, gasification, char combustion and gas-phase oxidation. Depending on the different biomass particle size and properties, the time used for each of these processes may vary (Nussbaumer, 2003).

\subsubsection{Gasification}

Gasification is the thermal breakdown conversion of biomass into a combustible gas and heat by the partial oxidation of biomass at an enclosed reactor with high temperature $\left(1200{ }^{\circ} \mathrm{C}-1400{ }^{\circ} \mathrm{C}\right)($ Roos, 2010). Gasification provides a competitive way to convert diverse, highly distributed and low-value lignocellulosic biomass to syngas for combined heat and power generation, synthesis of liquid fuels and production of hydrogen (L. Wang, Weller, Jones, \& Hanna, 2008). Gasification is an intermediate process between combustion and pyrolysis, and the distinction between pyrolysis and gasification is that pyrolysis is performed in an inert environment while gasification is conducted in the presence of an oxidizer such as water or air (Bridgwater, 1995). Gasification process consists of two major steps. First, the volatile components of the fuel are vaporized at

temperatures below $600{ }^{\circ} \mathrm{C}$ by a set of complex reactions with no oxygen needed. Hydrocarbon gases, hydrogen, carbon monoxide, carbon dioxide, tar and water vapor are 
included in the volatile vapors. Char and ash are the by-products of the process which are not vaporized. Second, char is gasified through the reactions with oxygen, steam and hydrogen, and some of the unburned char is combusted to release the heat needed for the endothermic gasification reactions (Sohi et al., 2010). The production of syngas from biomass allows the production of methanol and hydrogen which can be considered as fuels for future transportation.

\subsubsection{Pyrolysis}

Pyrolysis is the thermochemical decomposition of biomass to liquid, solid and gaseous fractions, by heating the biomass in the absence of air at elevated temperatures (Jahirul et al., 2012). In the pyrolysis process, long chains of carbon, hydrogen and oxygen compounds in biomass break down into smaller molecules in the form of gases, condensable vapors (tars and oils) and solid charcoal under pyrolysis conditions. Gaseous, liquid and solid pyrolysis products can be used as fuels as well, with or without prior upgrading, or they can be utilized as feedstock for chemical and material industries (Serio, Kroo, \& Wójtowicz, 2003). Biomass pyrolysis offers an attractive way of converting biomass into energy products which can be easily used for the production of heat, power and chemicals, and pyrolysis can also be carried out at relatively small scale and at remote locations which improve energy density of the biomass resource and reduce transportation and handling costs (Nussbaumer, 2001; Welling \& Shaw, 2004). Pyrolysis is still under active research and in current energy scenario, and pyrolysis has received special attention as it can convert biomass directly into solid, liquid and gaseous products by thermal decomposition of biomass (Goyal et al., 2008). 


\subsubsection{Biochemical conversion}

Biomass biochemical technologies mainly include anaerobic digestion and fermentation. Anaerobic digestion is a set of chemical reactions during which organic material is decomposed through the metabolic pathways of naturally occurring microorganisms in an oxygen depleted environment (Eliyan, 2007). Biochemical conversion of biomass involves use of bacteria, microorganisms and enzymes to breakdown biomass into gaseous or liquid fuels, such as biogas or bioethanol. When bacteria are used to decompose biomass, methane is usually produced, which can be obtained from landfills and sewage treatment plants to produce fuel for heat and power (Demirbas, 2008; Lin \& Tanaka, 2006). The schematic diagram of biomass biochemical conversion processes is shown in Figure 1-3.

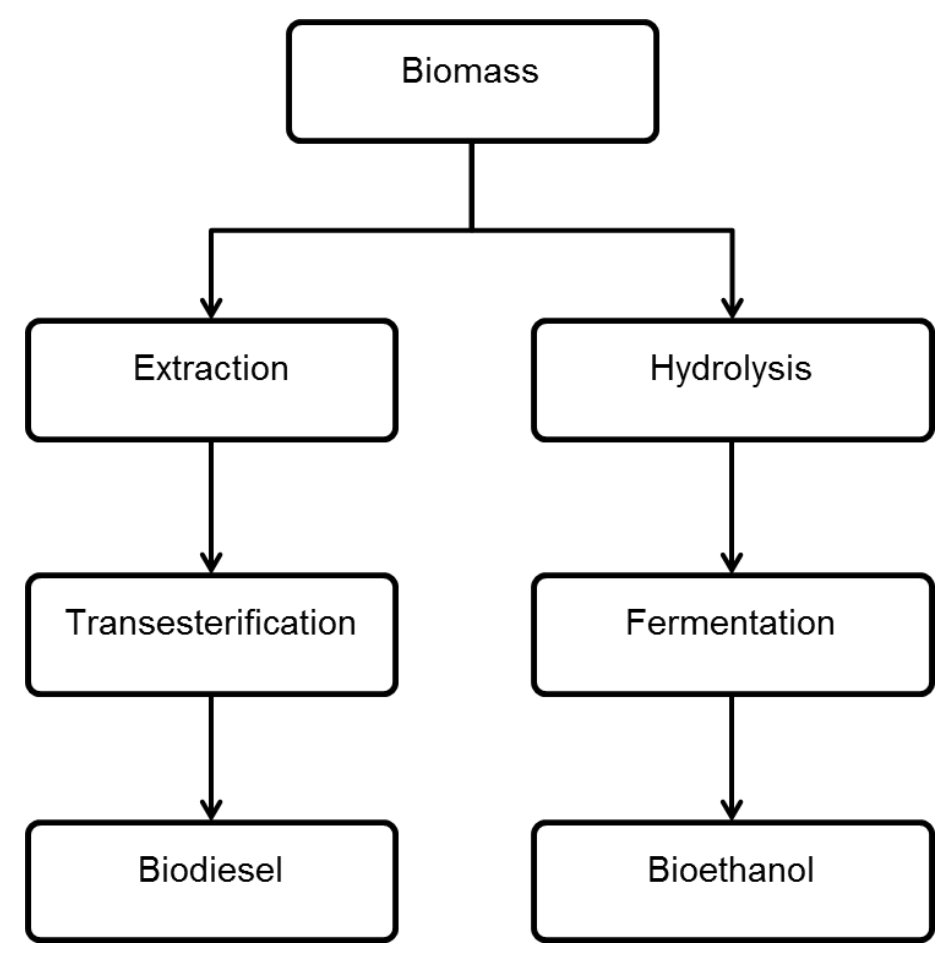

Figure 1-3. Schematic diagram of biomass biochemical conversion (Damartzis \& Zabaniotou, 2011). 


\subsubsection{Fermentation}

Biomass fermentation is an anaerobic process that decomposes the biomass within organic materials with the absence of air. The basic fermentation process involves the conversion of biomass into alcohol or acid. Yeast or bacteria are usually added to the biomass materials, which feed on the sugars to produce ethanol and carbon dioxide (Naik, Goud, Rout, \& Dalai, 2010). The produced ethanol is then distilled and dehydrated to obtain a higher concentration of alcohol to achieve the desired purity to be used as biofuels. The solid residue from the fermentation process can be used as animal feed. The most common forms of biomass that are used in the production of bio-ethanol are high in sugar, starchy materials or lignocellulosic materials such as the residues of corn, wheat, rice, agricultural wastes and woody materials. The decomposition of biomass material into fermentable sugars is complicated, but the fermentation, distillation and dehydration

processes are basically identical for bio-ethanol from agricultural crops or lignocellulosic biomass (Rutz \& Janssen, 2007; Sim \& Taylor, 2008).

\subsubsection{Anaerobic digestion}

Biomass anaerobic digestion is a natural process where biomass is broken down by micro-organisms in the absence of air (Franco, Mosquera-Corral, Campos, \& Roca, 2007). Anaerobic digestion typically includes multiple biological and chemical steps and it is beneficial in waste management and energy creation (Monnet, 2003). Anaerobic processes can be conducted naturally or in a controlled environment. Biomass and different kinds of bacteria are usually mixed in a digester so these processes could occur. In anaerobic digestion, certain microorganisms break down the biomass to produce $\mathrm{CH}_{4}$, a combustible gas with the absence of oxygen (Ciubota-Rosie, Gavrilescu, \& Macoveanu, 
2008). The first process of digestion process is bacterial hydrolysis of the input materials. Insoluble organic polymers, such as carbohydrates, are decomposed to soluble derivatives which will be available for other bacteria. Acidogenic bacteria then convert the sugars and amino acids into carbon dioxide, hydrogen, ammonia, and organic acids. Finally, methanogens convert these products to methane and carbon dioxide (Forgács, 2012; Gallert \& Winter, 2005).

\subsection{Biomass mechanical size reduction}

Raw biomass usually has very low energy density due to its physical form and moisture content (Jaya Shankar Tumuluru et al., 2011). Low energy density makes biomass inconvenient and inefficient for storage and transportation, and also unsuitable for use without certain pre-processing steps. Different kinds of biomass have different characteristics such as moisture content and size. These characteristics can be affected by transportation and storage as well. There are a range of processes available to convert raw biomass into more convenient forms. For ease of handling, transportation and storage, biomass may be cut into a number of physical forms, grinded and compressed to form pellets as best suit the requirements of the next handling or processing stage.

Mechanical pretreatment of biomass or biomass size reduction is a prerequisite step for further biomass thermochemical and biochemical processing in biomass fuel production (Balan, 2014; Foston \& Ragauskas, 2012). However, bioenergy crops are also hard-to-cut materials with wide variations (moisture content, biomass size, species, and etc.). Biomass harvesting, size reduction, compaction and transportation are energyintensive, and represent the significant cost factors in the production of energy crops (Mam, 2005; McKendry, 2002a). These existing issues brought up this research topic of 
biomass cutting performance investigation with different cutting methods, and the research goals in this dissertation are provided in the following section.

\subsection{The research goals}

This research is focused on lignocellulosic miscanthus and switchgrass numerical and mechanical pre-processing investigation, specifically biomass cutting. Biomass cutting during harvesting and pre-processing is an important challenge for sustainable biofuel production. Understanding the cutting and grinding mechanisms of biomass processing to enhance the biomass particle size reduction processes will have significant impact on biofuel production. Biomass size reduction can be an important step in densifying raw biomass in densification and handling an otherwise unwieldy crop.

In general, plant materials behave differently under tensile, compressive forces, and under static and dynamic loading (Ilker \& Szczesniak, 1990). Relatively limited number of studies have been published regarding biomass cutting dynamics, particle size reduction, grinding and harvest management (Clarke, Li, \& Li, 2011; Fike et al., 2006). Developing alternative methods or enhancing the conventional particle size reduction processes will have significant impact on biofuel production. However processing of biomass materials during harvesting and pre-processing is one of the challenges for sustainable biofuel production (B. Liu \& Koc, 2014; Miao, Grift, Hansen, \& Ting, 2013; Sambra, Sørensen, \& Kristensen, 2008).

Switchgrass and miscanthus are emerging as two of the most promising crops suitable for biomass production because of their high yield and low input requirements (McLaughlin, 1992). Switchgrass and miscanthus have been considered as good biofuels feedstock resources for years, but few studies have been published on their harvesting 
and size reduction. A critical analysis of literature survey indicated that cutting speed, blade profiles, shear angle (angle that the cut plane makes with the longitudinal axis of the biomass stem) and ultrasonic-assisted cutting can play critical roles in the fiber-rich material cutting process. In order to explore the biomass cutting dynamic properties and improve harvesting and size reduction processes, the objectives of this study are as follows:

- To determine the biomass (switchgrass and miscanthus) mechanical properties, such as Young's modulus, tensile strength and shearing strength for the numerical analysis of biomass cutting.

- To create an experimental biomass pre-processing system which can be used to conduct both conventional cutting and ultrasonic cutting on biomass materials.

- To develop an impact type numerical model for biomass mechanical pre-processing. Finite Element Analysis (FEA) with ABAQUS (Dassault Systèmes, Villacoublay Cedex, France) will be adopted to simulate the interactions between the cutting blades and materials to be cut.

- To investigate the effects of cutting speed, blade profile, shear angle and ultrasonication on biomass pre-processing.

\subsection{Scope of work}

The rest of this dissertation is organized as follows: Chapter 2 proposes the determination of mechanical properties of miscanthus and switchgrass, the experimental methods for these biomass types measured at two different moisture content levels. Chapter 3 presents a developed linear cutting and data acquisition system to investigate the biomass cutting performances using conventional cutting and ultrasonic-assisted 
cutting methods. Different cutting blade profiles are designed to explore the cutting performances. The data acquisition system is utilized to record the critical data such as cutting force, energy consumption by the ultrasonic generator. A computer user interface is built to record and display the data obtained from the data acquisition system, and to control the cutting system. Chapter 4 introduces the finite element analysis model developed to simulate the biomass cutting process. This modeling procedure is used to explore the aspects of biomass cutting ahead of actual experimental cutting tests. The simulation results can shed light on cutting parameters need to be chosen in cutting experiments as well as the cutting system design and improvement. Chapter 5 presents the experimental cutting tests of different biomass crops with and without ultrasonication. Experiments are carried out by using the demonstrated cutting system in Chapter 3 . Miscanthus and switchgrass samples with different moisture contents are prepared to conduct the cutting tests. The cutting performances are recorded and analyzed for exploring the optimized cutting parameters. In Chapter 6, conclusions of the research work are presented. Chapter 7 provides recommendations for the future work. 


\section{CHAPTER 2 MECHANICAL PROPERTIES DETERMINATION OF SWITCHGRASS AND MISCANTHUS}

\subsection{Introduction}

Biomass for renewable energy production includes a wide variety of materials such as woody biomass, energy crops, agricultural residues, industrial waste and co-products. As one of the important renewable energy forms, energy crops are specifically planted for use in a range of energy markets, such as dedicated biomass power stations, homes or businesses. Switchgrass and miscanthus are two types of important and promising energy crops that draw attention from both industry and academia, and this research is focused on these two crops.

Switchgrass or Panicum virgatum $L$. is a perennial bunchgrass native to the United States, Canada and Mexico (Sanderson, Adler, Boateng, Casler, \& Sarath, 2006). Switchgrass has been used primarily for soil conservation, forage production, and as bioenergy crop in the United States with the ability to produce moderate to high biomass yields on marginal lands. For bioenergy purpose, switchgrass has been used in several bioenergy conversion processes, such as cellulosic ethanol production, biogas, and direct combustion for thermal energy production (Center, 2011).

Miscanthus or Miscanthus $x$ giganteus is predominantly used for feedstock production for both energy and non-energy end uses, and it is another common perennial high yielding energy crop that can be harvested every year with benefits of no replanting, low maintenance, long lifespan, no pesticides and fertilizers (Scurlock, 1999). Because of the abovementioned attributes, miscanthus increasingly draws attention from people for biofuel production. 
Handling, transportation and storage of bioenergy crops to produce fuels, chemicals and bio-products are challenging, because of their wide spread distributions, uneven moisture contents and low bulk densities. Therefore, biomass mechanical pre-processing is one of the important steps in biomass energy production processes. In order to improve the biomass processing efficiency and enhance its economic utilization, the most widely used method is to preprocess the biomass materials and improve uniformity of the physical size, moisture content and bulk density. Research on pre-processing operations has potential to improve the capacity, energy efficiency, optimal material size, and reduce input energy and operational cost. In order to explore and reach these desirable aspects, composite engineering methods are needed to characterize mechanical properties of biomass materials.

Measurements of biomass mechanical properties can provide a knowledgebase for developing optimized harvesting, baling, and size reduction equipment for lower energy and less time input (Sharma, Jones, \& Khanchi, 2011; Yu, Womac, Igathinathane, Ayers, \& Buschermohle, 2006). The mechanical properties of biomass can also provide key information in numerical analysis of biomass pre-processing such as cutting, grinding and pelletizing. The numerical analysis results of biomass mechanical pre-processing helps biomass processing equipment design and optimization (González-Montellano, Gómez, Fuentes, Gallego, \& Ayuga, 2012).

\subsection{Literature review}

Increasing interests in profitable bioenergy production with lower grinding/chopping energy and less time require measurements of mechanical properties of biomass crops (Kronbergs, 2000; J. S. Tumuluru, Wright, Hess, \& Kenney, 2011). Biomass mechanical 
properties influence the accuracy of numerical simulation results of cutting and grinding; correspondingly impact the pre-processing equipment design. Prince (1968) conducted experiments to determine tensile, compressive, and shear strengths, and bending characteristics of corn stocks. The research results showed that mechanical properties of biomass materials like corn stock could not be measured as precisely as metals, because of existing and unavoidable varieties. Kitani (1989) provided the impact of biomass characteristics on processing and handling, and interaction among them. Shear and tensile strength properties were reported to have important influence on energy requirements determination of biomass pre-processing. Yu et al. (2006) measured switchgrass ultimate stresses over ranges in maturity and moisture content. They found that switchgrass Alamo had larger ultimate tensile stress and ultimate shear stress than switchgrass Kanlow, and concluded that grinders that apply opposed-sliding actions were more energy efficient than other methods. Sharma et al. (2011) measured the tensile strength and the shear strength of Kanlow switchgrass before and after frost at internodes 2 and 3. The experimental results showed that the tensile strength before frost was significantly greater than that after frost and the tensile strength was approximately three times the shear strength. Q. Liu, Mathanker, Zhang, and Hansen (2012) measured the cutting force at the first internode of miscanthus samples, and biomechanical properties, shearing strength, tensile strength, and bending strength were determined at internodes one through seven. Analysis of this study showed that the serrated blade had lower cutting energy and reduced cutting force than the flat one.

Literature review showed that limited research has been done to determine the anisotropic mechanical properties of switchgrass and miscanthus which currently are 
considered as the most promising energy crops in the United States. This chapter will include measurements of mechanical properties of switchgrass and miscanthus, experimental results of these biomass samples at two different moisture levels along and cross fiber directions.

\subsection{Materials and methods}

Determination of mechanical properties provides accurate parameters for numerical analysis of biomass pre-processing. It also helps build a database to design and develop optimized size reduction equipment for lower energy and less time inputs. However, determining the mechanical properties of biomass faces challenges in holding small and fragile biomass samples without breaking them, as experienced with wheat straw, rice straw, and corn stalk (Q. Liu et al., 2012). Special gripping and holding tools need to be designed for mechanical tests on biomass samples. In this study, swithgrass (Alamo) and miscanthus samples were collected from a research farm at the University of MissouriColumbia, Missouri. Healthy and mature switchgrass and miscanthus samples were manually cut close to the ground and shipped to a laboratory for experimental tests. Tensile test, compressive test and shearing test were conducted by using a universal testing system model TA-HDi (Texture Technologies Corp., Scarsdale, NY). With special fixtures, the biomass samples were applied enough force to make a failure, and the universal testing machine continuously recorded the applied force and displacement data on a PC for later data analysis purpose. This testing unit has the capability to measure forces up to $7500 \mathrm{~N}$. The accuracy of the load cell used to measure forces is within $0.5 \%$. The crosshead speed, on which the test fixtures were mounted, ranges from $0.01 \mathrm{~mm} / \mathrm{s}$ to $20 \mathrm{~mm} / \mathrm{s}$. A digital caliper with an accuracy of $\pm 0.01 \mathrm{~mm}$ was used to 
measure the dimensions of the test specimens. All specimens were prepared using an USW-334 ultrasonic cutter to create smooth cutting edges and avoid cracks. The setup of the experiments is shown in Figure 2-1.

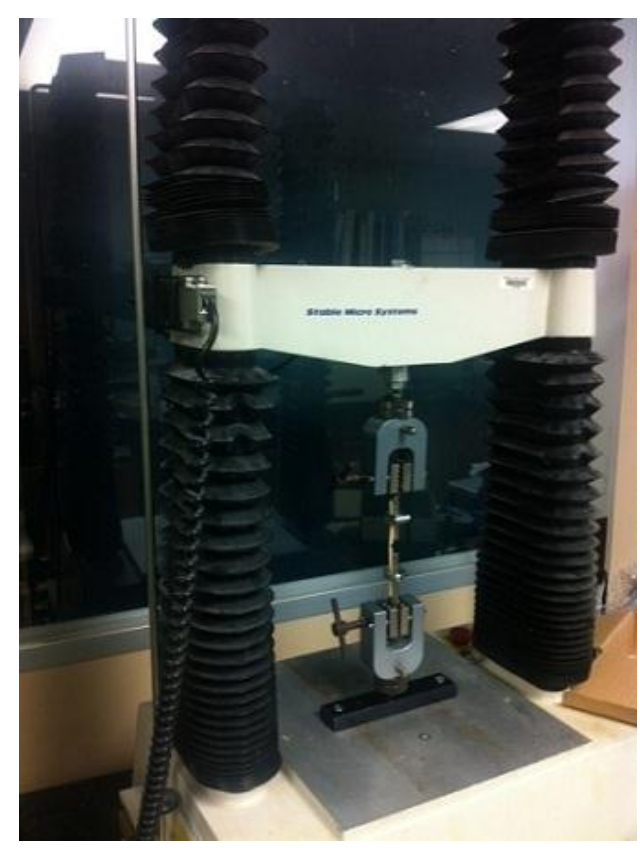

Figure 2-1. Experimental setup for biomas mechanical property determination.

The unconditioned moisture contents of switchgrass and miscanthus were $9.8 \%$ and $10.2 \%$ respectively. Another moisture content level was created for both switchgrass and miscanthus by spraying water on prepared samples and placing them in sealed plastic bags over 48 hours before tests. The conditioned moisture contents of switchgrass and miscanthus were measured at $14.6 \%$ and $15.1 \%$ respectively. All the moisture contents were determined by measuring the mass of the samples (greater than 30 grams) before and after keeping them in an oven for 24 hours at a constant temperature of $103{ }^{\circ} \mathrm{C}$ as specified in ASAE Standard S358.2 (ASAE, 2003). The soft pith parts in all the miscanthus and switchgrass samples were removed manually, because they were much softer and fragile compared to other outer stem parts. Sample stems at all internodes for 
each biomass type (switchgrass, miscanthus) were used in the tests, and nodes were not tested in this study.

\subsubsection{Tensile test}

In tensile tests, switchgrass and miscanthus specimens were subjected to tensile forces along or cross the fiber directions until failures occurred. Test clamps in the universal testing system had to be used carefully to ensure that gripping and holding biomass materials would not damage the sample ends and affect the measurement results. Therefore, specialized attachments and grips for biomass tensile tests were designed and manufactured to determine the biomass mechanical properties.

In tensile tests along the fiber direction, the specimens were cut in a "dog-bone" shape and grips of the testing apparatus held the specimen firmly at the wide ends (Figure 2-2). The "dog-bone" shape concentrated the stress in the test area and made the fractures and most of the strains occur at the test area. If a fracture occurred outside the narrowed area in which the strain was measured, the test results were neglected and not used. The metal grips might allow the biomass specimen to slip during the tests, so the wider sample ends (outside of the test section) were glued and/or clamped to the sample holder in all the tests (Figure 2-3). The edges of the test specimens were also smoothened to avoid concentrated stress before any testing. Biomass stems came with different stem diameters, hence the curvature might cause the specimens to crack when they were glued and clamped to the metal grips. Therefore different sizes of steel bars were manufactured and adopted for various specimens in the tests so as to minimize the cracks and sliding. 


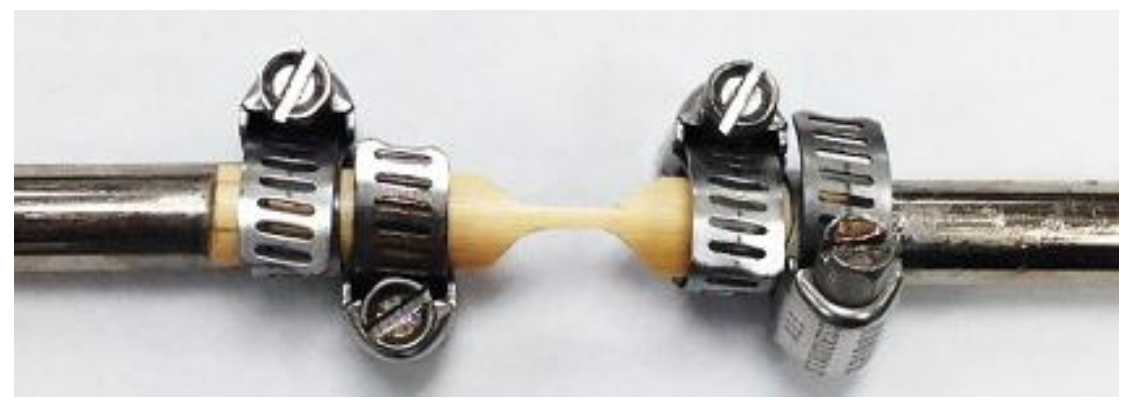

Figure 2-2 "Dog-bone" shape specimen.

In the tensile tests cross the fiber direction, the sliding and curvature issues were very challenging because of the small and fragile samples. To avoid these issues, two steel plates were manufactured and each of these plates had a small pump that could fit the curvatures of the specimens. Super glue was also used to bond the specimen and the metal plates. Two small notches were cut at the two ends to guide the cracks. The experimental setup is shown in Figure 2-4.

Tensile forces were longitudinally (along fiber direction) and transversely (cross fiber direction) applied to the specimens respectively to cause specimens to fail. The displacement and force data were recorded on a PC for latter calculation purposes. The crosshead speed was set at $1 \mathrm{~mm} / \mathrm{min}$ in the tests.

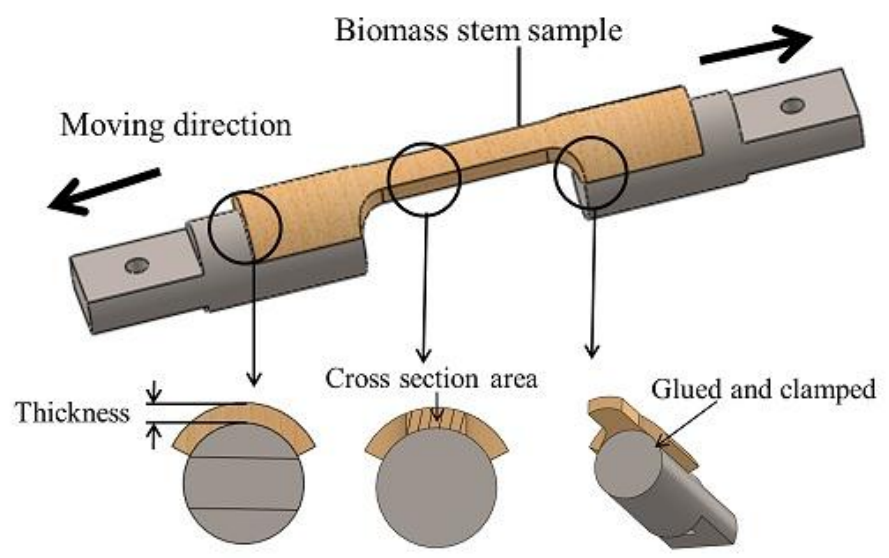

Figure 2-3. Specimen test preparation for tensile test on longitudinal direction (along fiber). 


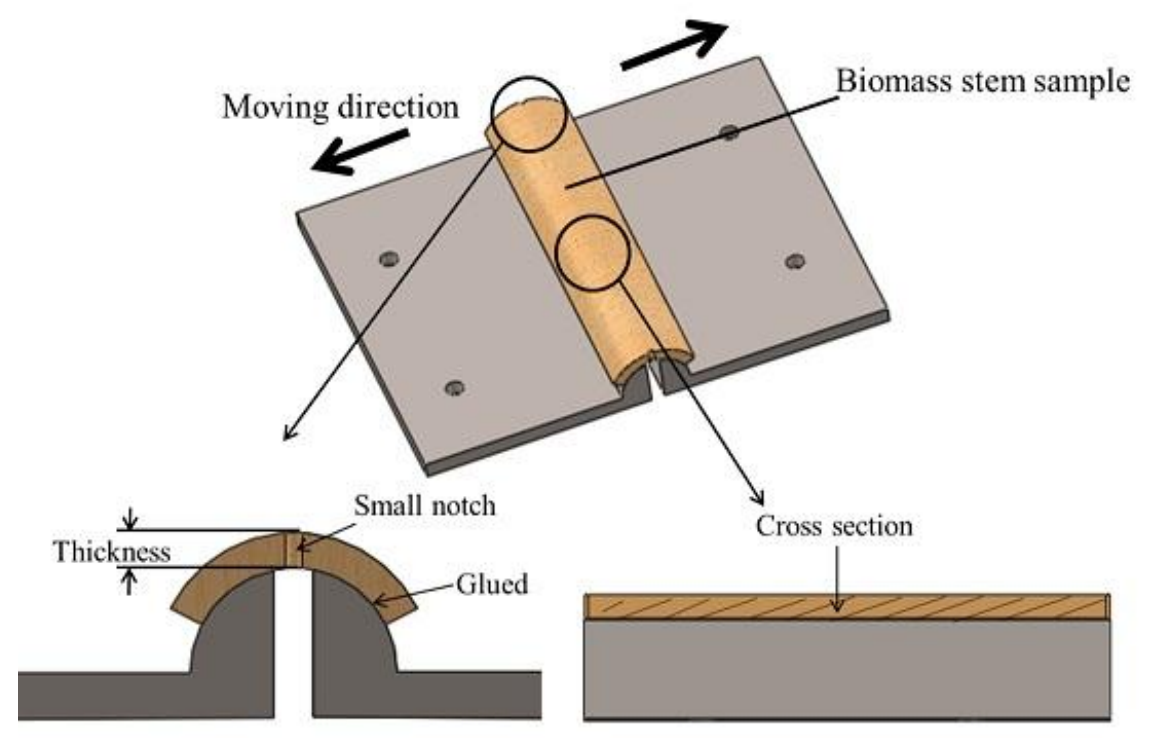

Figure 2-4. Specimen preparation for tensile tests on transverse direction (cross fiber).

The tensile strength of the samples were computed from the maximum load acting normally to the cross sectional area where the sample failure occurs. The dimensions of the stem area at notches were measured using a digital caliper. Tensile strength was calculated from the following expression:

$$
\delta_{t}=\frac{F_{t}}{A_{t}} \times 10^{-6}
$$

where, $\delta_{t}$ is the tensile strength at failure in $\mathrm{MPa}, F_{t}$ is the tensile force at failure, and $A_{t}$ is the failure area of sample at the notch in $\mathrm{m}^{2}$. Young's modulus or modulus of elasticity is to describe the elastic properties of linear objects which are stretched or compressed, and it is defined by the ratio of the stress to the strain. The strain is calculated by Equation 22, stress is defined in Equation 2-3, and the Young's modulus is given in Equation 2-4.

$$
\begin{gathered}
\varepsilon=\frac{\Delta L}{L} \\
\sigma=\frac{F}{A}
\end{gathered}
$$




$$
E=\frac{\sigma}{\varepsilon}=\frac{F}{A} \frac{L}{\Delta L}
$$

where, $L$ is the sample length, $\Delta L$ is the change of length, $F$ is force, $A$ is the area where the force is applied to, and $E$ is Young's modulus. The results of tensile strength and Young's modulus were obtained from the tests of switchgrass and miscanthus from different diameters at two different moisture content levels.

\subsubsection{Compressive test}

The apparatus used for the compressive experiments is the same as the one used for tensile tests. Compressive strength is usually obtained experimentally by means of a compressive test. However, in this test a compressive load is applied instead of a tensile load. Under a compression force, the length of the specimen will shorten. Equation 2-5 is used to determine the compressive strength:

$$
\delta_{c}=\frac{F_{c}}{A_{c}} \times 10^{-6}
$$

where, $\delta_{c}$ is the compressive strength at failure in $\mathrm{MPa}, F c$ is the compressive force at failure, and $A c$ is the failure area of a sample. Physical dimensions, compressive force and displacement curves for each biomass stem sample were recorded. The crosshead speed was set at $1 \mathrm{~mm} / \mathrm{min}$ in the tests.

In the longitudinal direction compression tests, two special metal blocks were manufactured for each type of biomass. Each block has nine holes in which the biomass stem ends are placed. The diameters of the holes were $2.2 \mathrm{~mm}, 2.3 \mathrm{~mm}, 2.6 \mathrm{~mm}, 2.9 \mathrm{~mm}$, $3.2 \mathrm{~mm}, 3.5 \mathrm{~mm}, 3.8 \mathrm{~mm}, 4.1 \mathrm{~mm}$, and $4.5 \mathrm{~mm}$ for switchgrass compressive tests. For the Miscanthus compressive tests, the diameters of the holes were $4.5 \mathrm{~mm}, 5.5 \mathrm{~mm}, 6.5 \mathrm{~mm}$. 
$7.5 \mathrm{~mm}, 8.5 \mathrm{~mm}, 9.5 \mathrm{~mm}, 10.5 \mathrm{~mm}, 11.5 \mathrm{~mm}$ and $12.5 \mathrm{~mm}$. The depth of all the holes was $5 \mathrm{~mm}$. The sample stems were put in the holes, which fitted the most, and the upper and lower blocks were aligned well in the compressive tests. In the transverse direction compressive test, metal blocks were built with different grove widths in them to fit the sample shell piece. In order to reduce the impact of the shell curvature on the test, the shell pieces were cut in small sizes to make them "flat" (shown in Figure 2-5). The experimental setup for the compressive tests along the longitudinal direction and transversal direction are shown in Figure 2-6 and Figure 2-7 respectively.

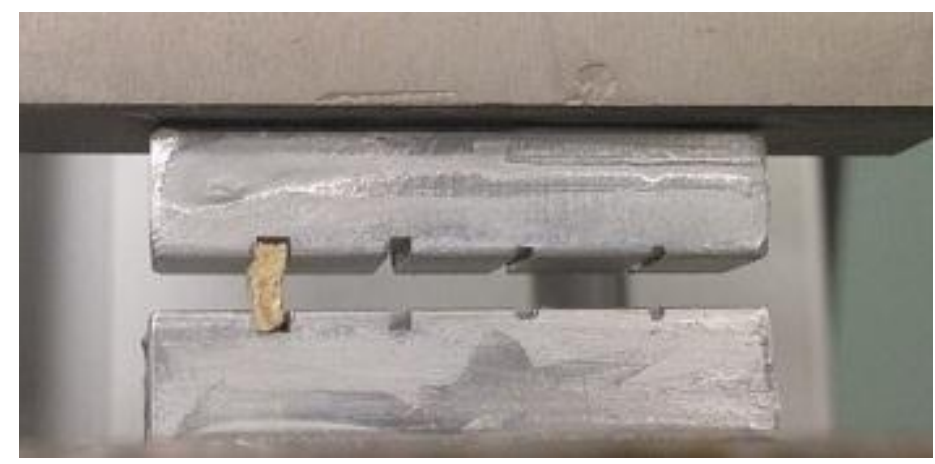

Figure 2-5 Specimen preparation for compressive test on transversal direction. Biomass stem sample

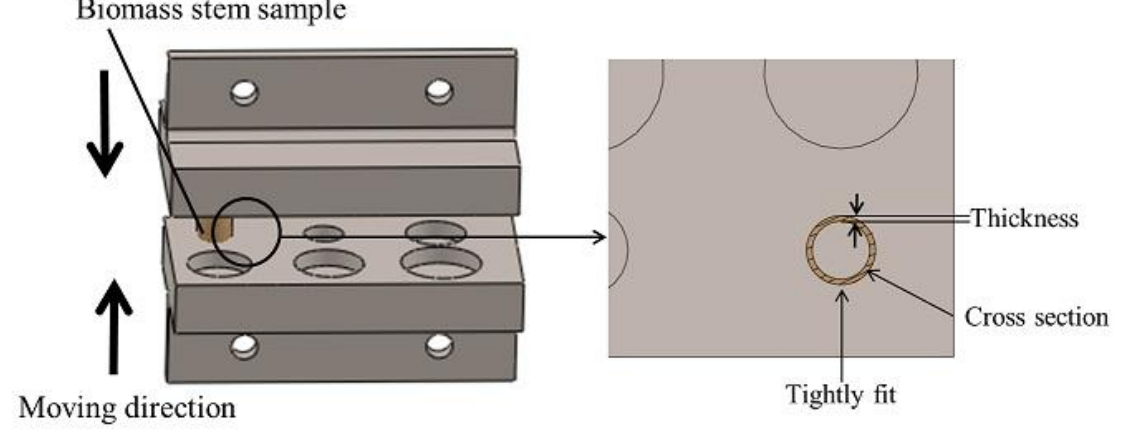

Figure 2-6. Specimen preparation for compressive test on longitudinal direction (along fiber). 


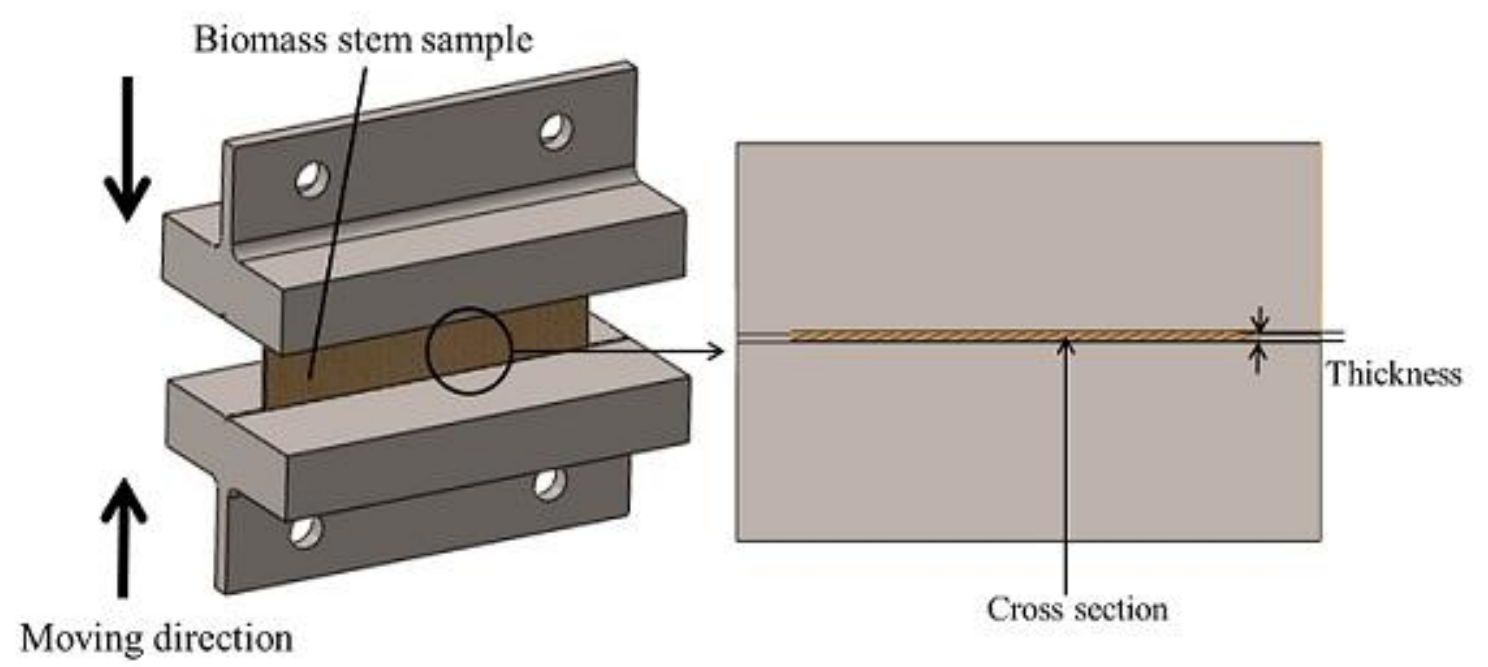

Figure 2-7. Specimen preparation for compressive tests on transversal direction (cross fiber).

\subsubsection{Shearing test}

Shear testing is performed to determine the shear strength of a material. It measures the maximum shear stress that may be sustained before a material ruptures. Shearing is typically reported as MPa based on the area of the sheared edge. The shearing experiments could provide information about the fundamental shear characteristics of the samples, although the shear rate was much lower than actual cutting and grinding equipment. Ultimate shear stress or shear strength was calculated using the following equation:

$$
\delta_{s}=\frac{F_{s}}{A_{s}} \times 10^{-6}
$$

where, $\delta_{s}$ is the shear stress at failure in $\mathrm{MPa}, F_{s}$ is the shear force at failure, and $A_{s}$ is the failure area of the sample. Shear stress measurements were carried out by applying force in the shearing direction to cause the sample to fail. Physical dimensions, shearing force and displacement curves for each biomass stem sample were determined during the tests. 
A fixed crosshead speed of $1 \mathrm{~mm} / \mathrm{min}$ was used in the test. Special sample holders were designed and manufactured to hold a whole stem vertically (Figure 2-8), and a metal cuboid was used to shear the stem along its fiber direction. For the shearing tests on transversal direction (Figure 2-9), only a small piece of stem (with neglectable curvature ) was used and clamped by four metal blocks, and a metal cuboid was used to shear the stem across its fiber direction.

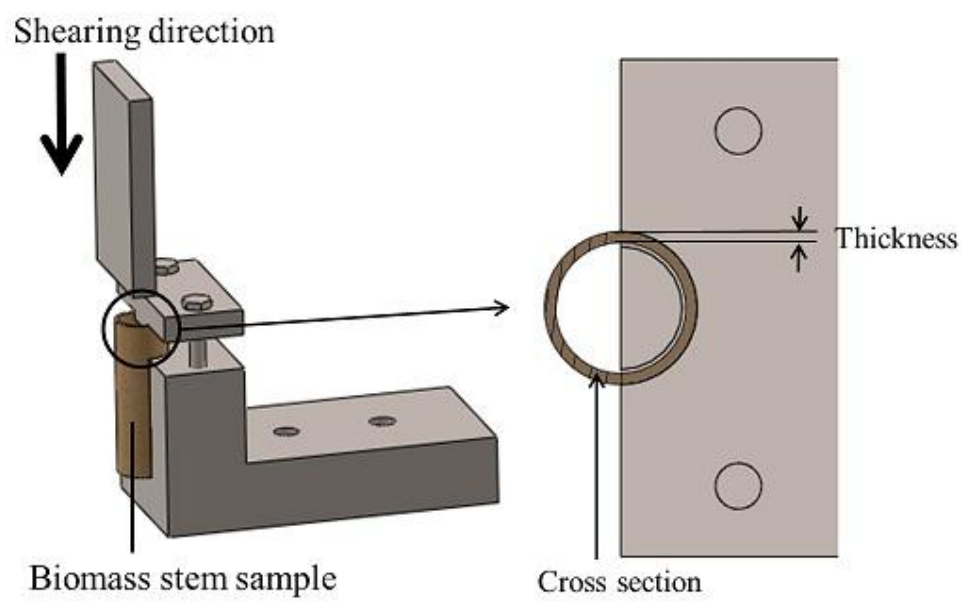

Figure 2-8. Specimen preparation for shearing test on longitudinal direction (along fiber).

\section{Shearing direction}
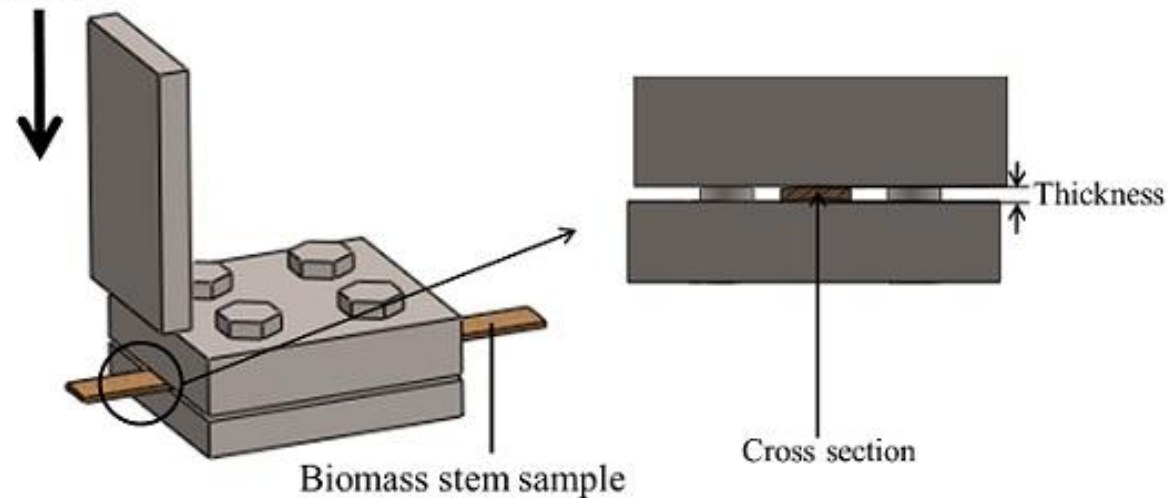

Figure 2-9. Specimen preparation for shearing test on transversal direction (cross fiber). 


\subsection{Experimental results}

Tensile tests, shearing tests and compressive tests were conducted on switchgrass and miscanthus samples by following the procedures and strategies described in Section 2.3. Since the bigger biomass stems (with larger diameter) tend to have higher mechanical property values, the calculated mechanical properties based on the experimental data are presented versus the sample stem diameters, and linear regressions involving the independent variable $X$ (stem diameter) and dependent variable $Y$ (mechanical properties) were carried to fit the experimental data points. The 95\% confidence limits on the mean response were calculated by using the following equation:

$$
C I= \pm t(a, d f) S_{y x} \sqrt{\frac{1}{n}+\frac{\left(x_{i}-\bar{x}\right)^{2}}{\sum_{i=1}^{n}\left(x_{i}-\bar{x}\right)^{2}}}
$$

Where, $t$ is the critical $\mathrm{t}$ statistic, $S_{y x}$ the standard error of the estimate, $x_{i}$ the given value of $x, \bar{x}$ is the average of the $x$ values and $n$ is the number of data points used in the regression analysis.

\subsubsection{Switchgrass properties}

Tensile tests, compressive tests and shearing tests were conducted on switchgrass specimens at two different moisture content levels (9.8\% and 14.6\%) and along different directions (longitudinal and transversal). The mechanical properties were calculated based on the methods in Section 2.2, and the results provided in the following sections. Linear regression with a 95\% mean confidence interval was chosen, the confidence interval consists of the space between the inner two curves (dotted lines), and the $95 \%$ prediction limits are the outer dotted lines. 


\subsubsection{Mechanical properties of switchgrass at moisture content 9.8\% (w.b.\%)}

For the switchgrass samples with $9.8 \%$ (wet based) moisture content at the longitudinal direction (along the fiber), the tensile strength, Young's modulus, compressive strength, shearing strength and the shearing modulus results are shown in Figures 2-10 to 2-14. The outer dotted lines are 95\% prediction limits, and the inner dotted lines are $95 \%$ confident limits.

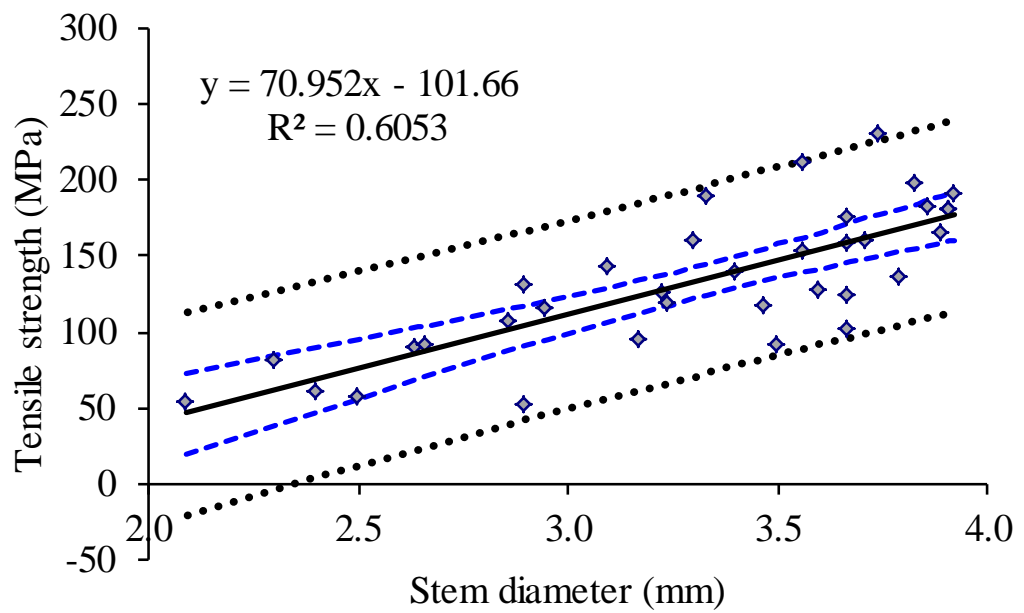

Figure 2-10. Tensile strength of switchgrass (9.8\% w.b.) longitudinal direction.

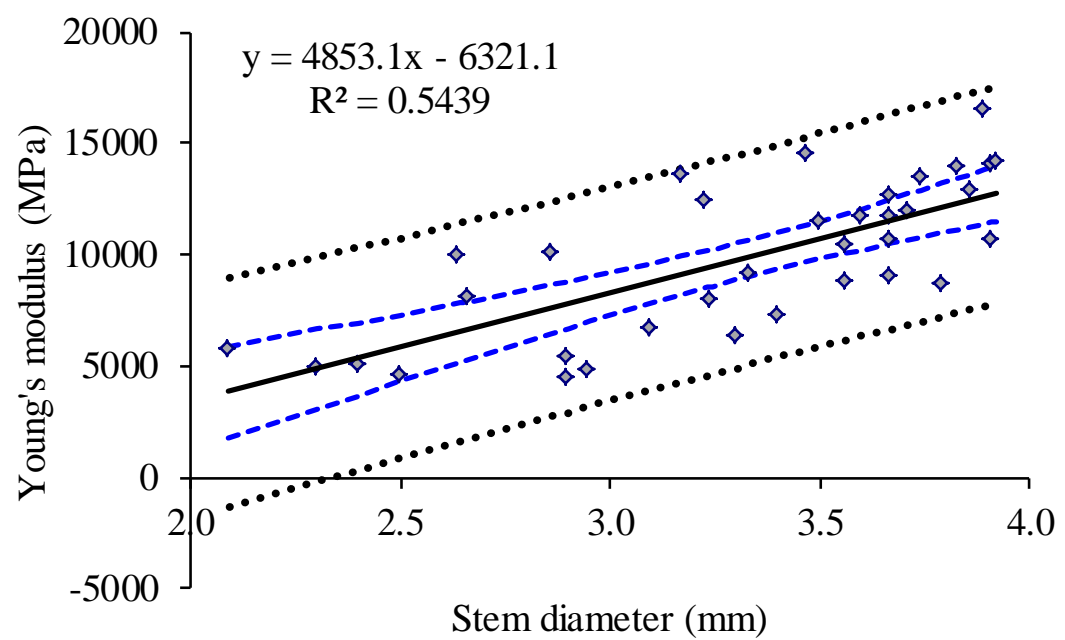

Figure 2-11. Young's modulus of switchgrass (9.8\% w.b.) longitudinal direction. 


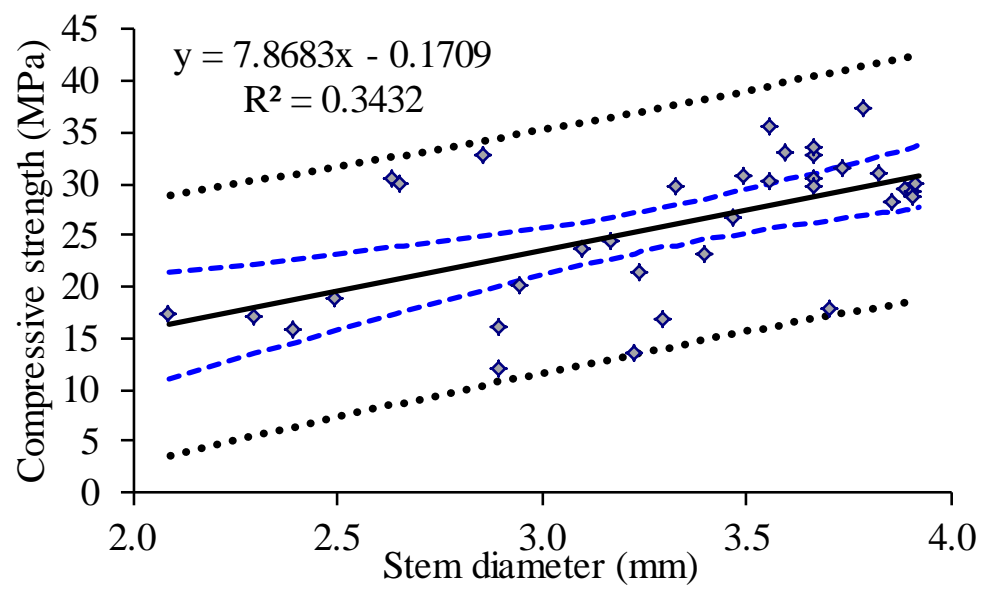

Figure 2-12. Compressive strength of switchgrass (9.8\% w.b.) longitudinal direction.

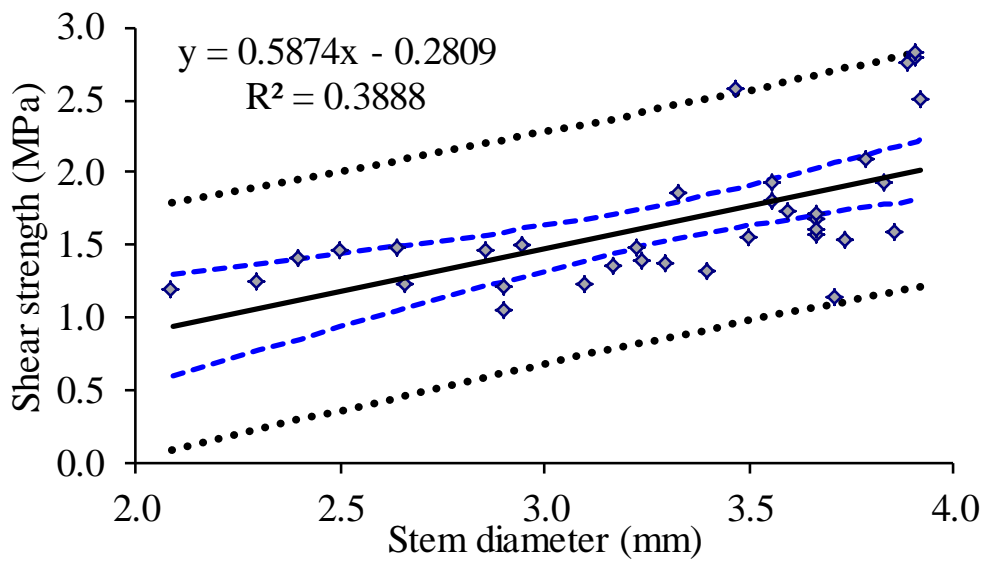

Figure 2-13. Shearing strength of switchgrass $(9.8 \%$ w.b.) longitudinal direction .

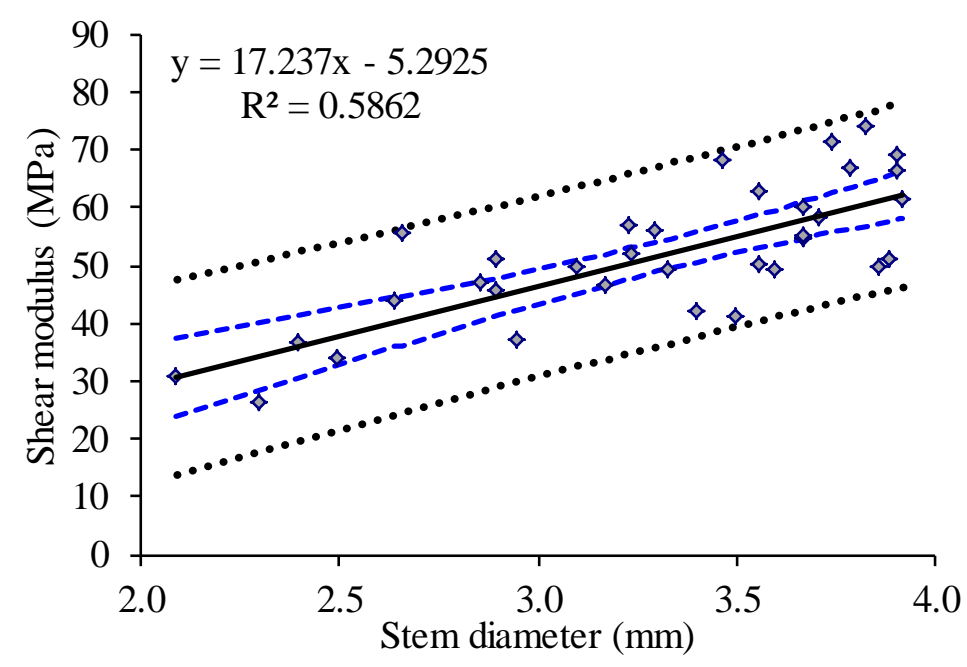

Figure 2-14. Shear modulus of switchgrass (9.8\% w.b.) longitudinal direction . For the switchgrass samples with $9.8 \%$ (wet based) moisture content at the transversal direction (cross the fiber), the tensile strength, Young's modulus, compressive 
strength, shearing strength and the shearing modulus results are shown in Figures 2-15 to 2-19. The outer dotted lines are $95 \%$ prediction limits, and the inner dotted lines are $95 \%$ confident limits.

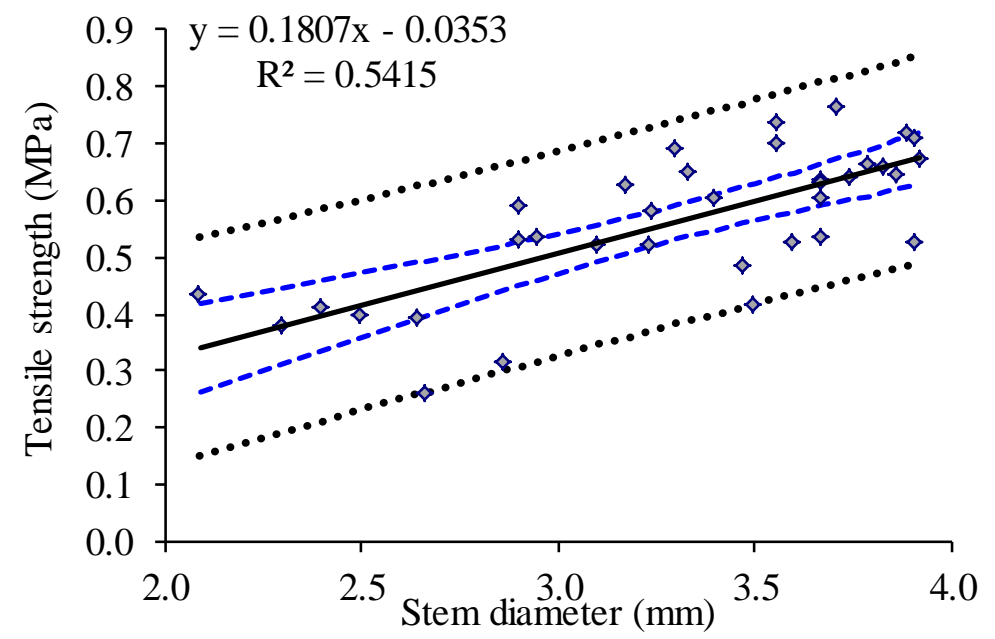

Figure 2-15. Tensile strength of switchgrass (9.8\% w.b.) transversal direction.

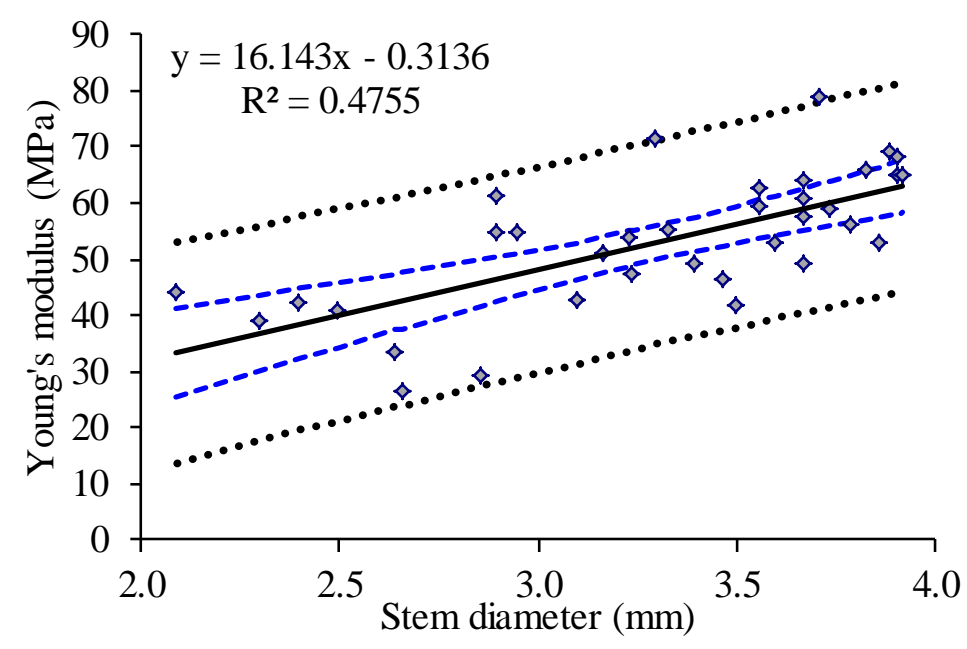

Figure 2-16. Young's modulus of switchgrass (9.8\% w.b.) transversal direction. 


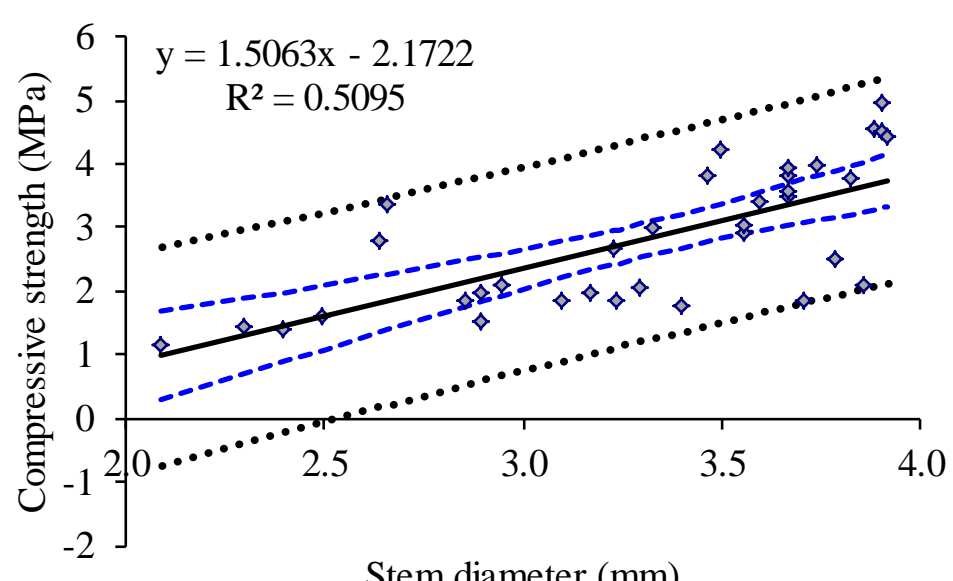

Stem diameter $(\mathrm{mm})$

Figure 2-17. Compressive strength of switchgrass (9.8\% w.b.) transversal direction.

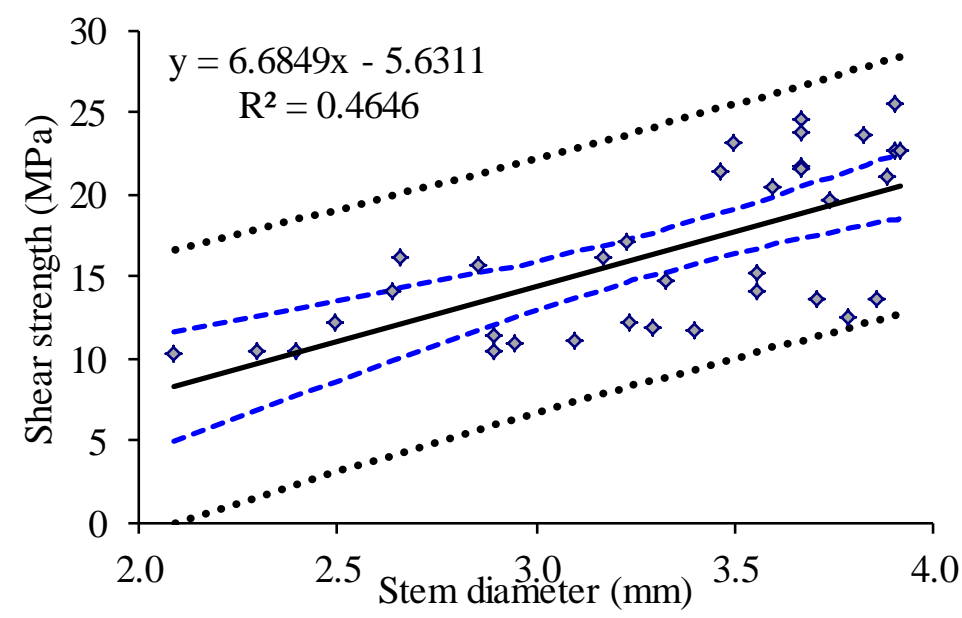

Figure 2-18. Shearing strength of switchgrass (9.8\% w.b.) transversal direction.

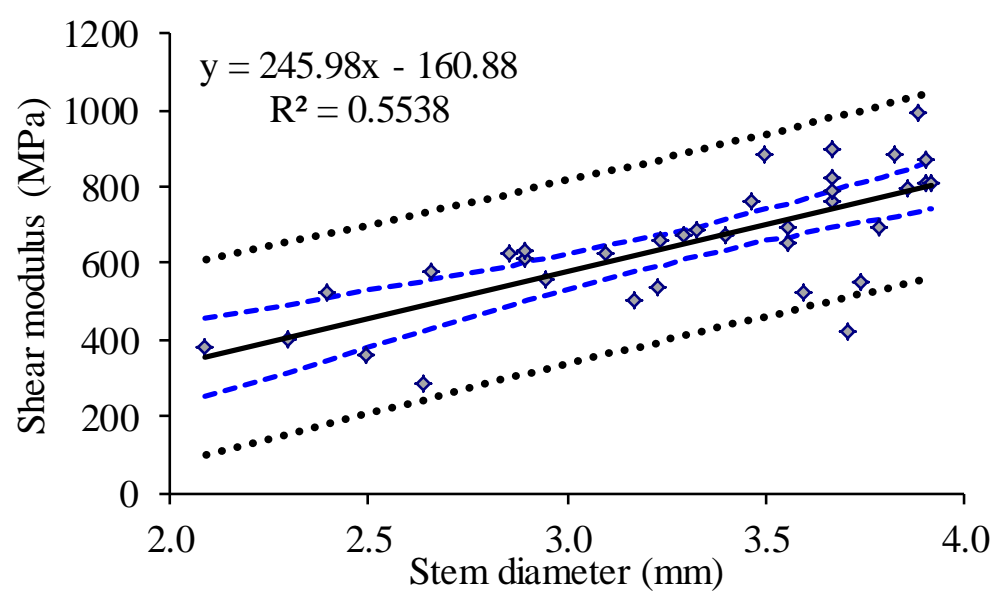

Figure 2-19. Shear modulus of switchgrass $(9.8 \%$ w.b.) transversal direction 


\subsubsection{Mechanical properties of switchgrass at moisture content 14.6\% (w.b.)}

For switchgrass with $14.6 \%$ (wet based) moisture content at the longitudinal direction (along the fiber), the tensile strength, Young's modulus, compressive strength, shearing strength and the shearing modulus results are shown in Figures 2-20 to 2-24. The outer dotted lines are 95\% prediction limits, and the inner dotted lines are 95\% confident limits.

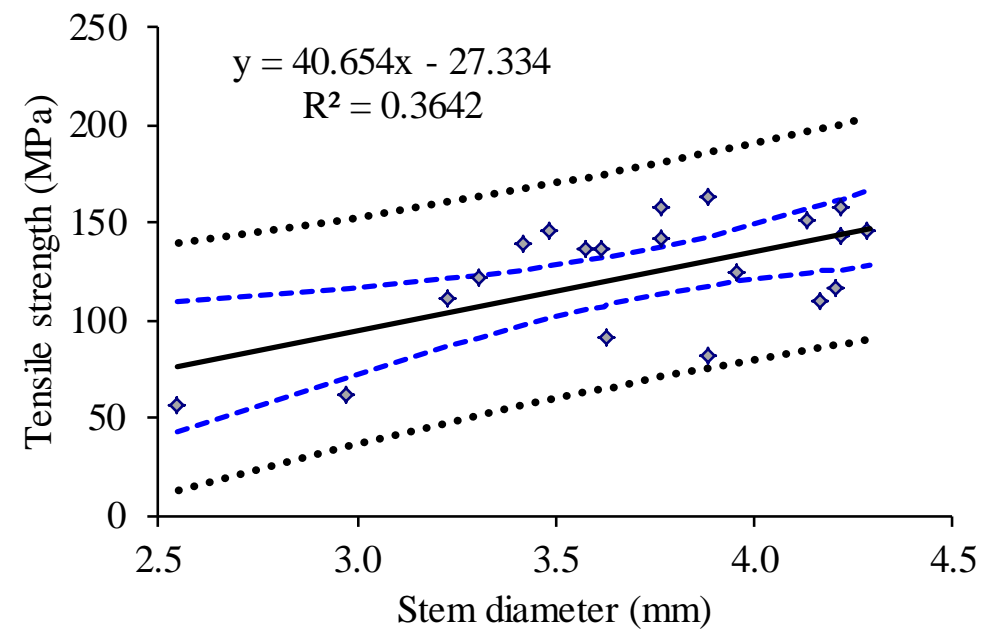

Figure 2-20. Tensile strength of switchgrass (14.6\% w.b.) longitudinal direction.

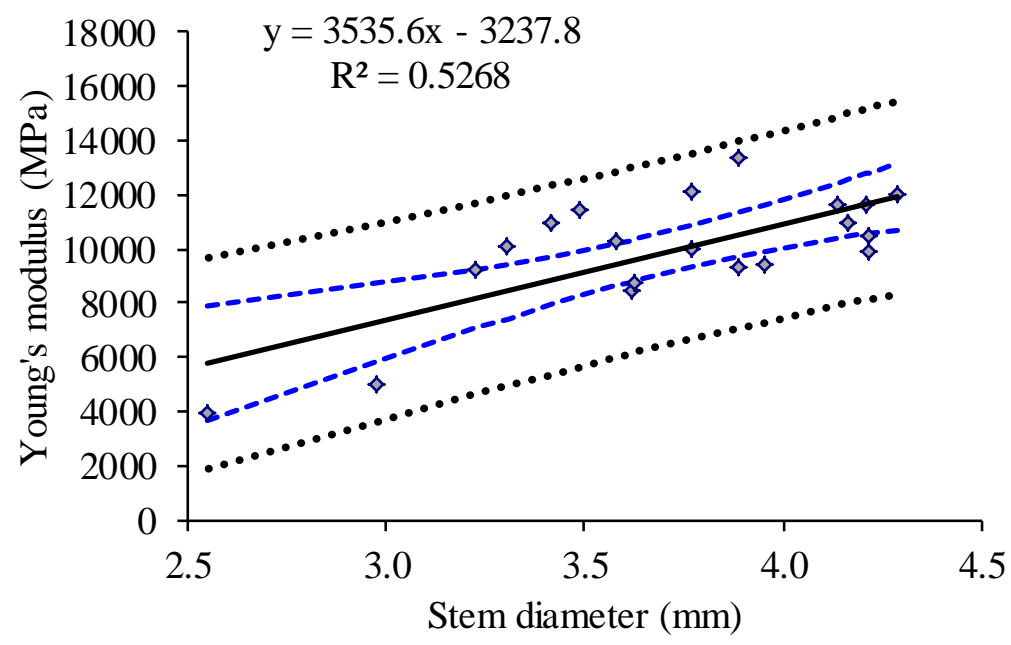

Figure 2-21. Young's modulus of switchgrass (14.6\% w.b.) longitudinal direction. 


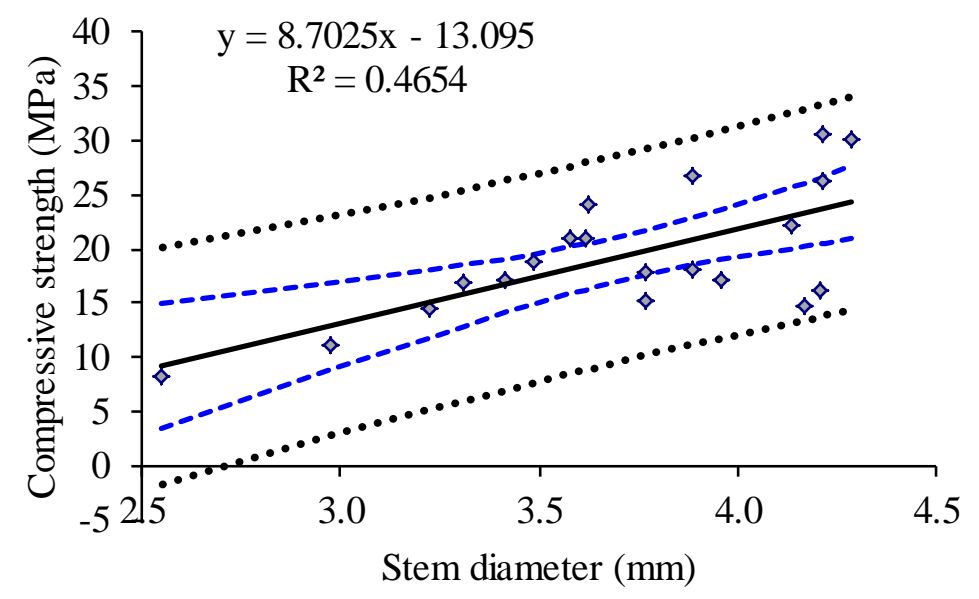

Figure 2-22. Compressive strength of switchgrass (14.6\% w.b.) longitudinal direction.

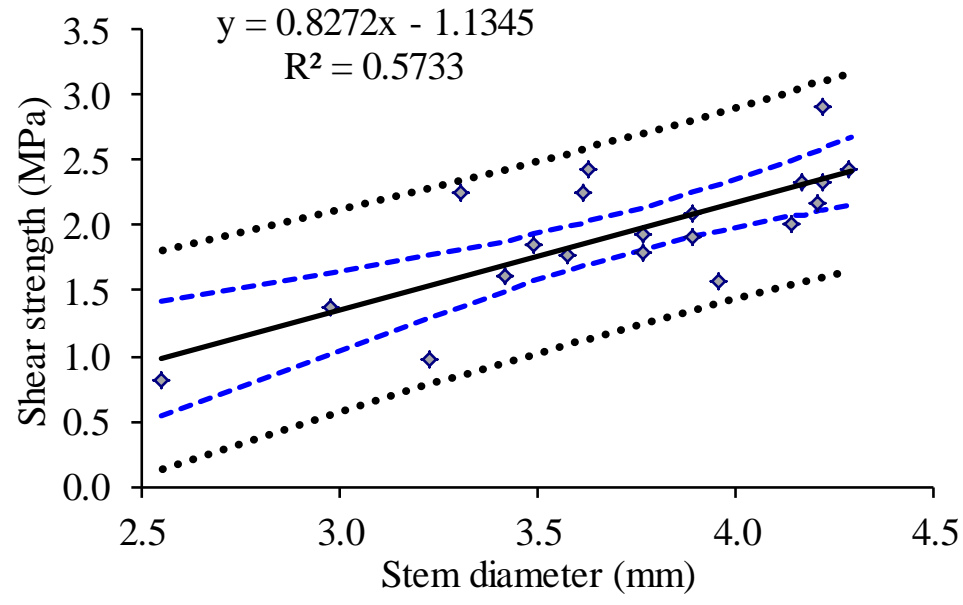

Figure 2-23. Shearing strength of switchgrass (14.6\% w.b.) longitudinal direction .

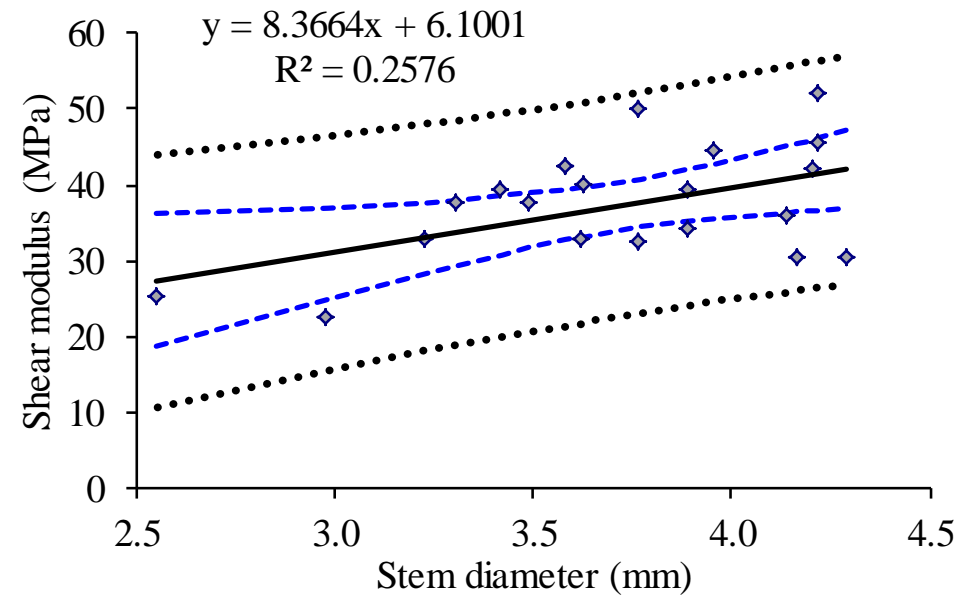

Figure 2-24. Shear modulus of switchgrass (14.6\% w.b.) longitudinal direction. 
For the switchgrass sample with $14.6 \%$ (wet based) moisture content at the transversal direction (cross the fiber), the tensile strength, Young's modulus, compressive strength, shearing strength and the shearing modulus results are shown in Figure 2-25 to 2-29. The outer dotted lines are $95 \%$ prediction limits, and the inner dotted lines are $95 \%$ confident limits.

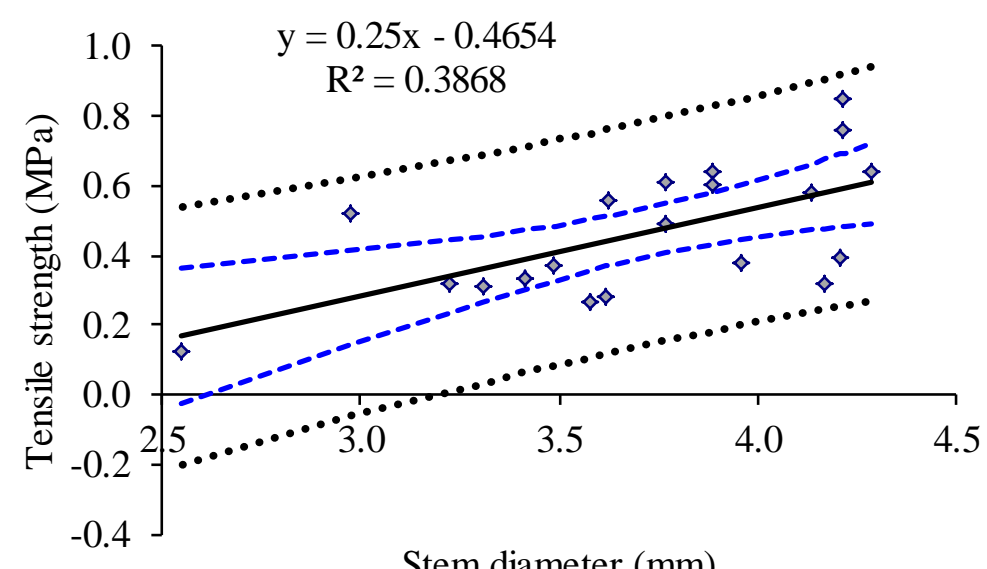

Stem diameter $(\mathrm{mm})$

Figure 2-25. Tensile strength of switchgrass (14.6\% w.b.) transversal direction.

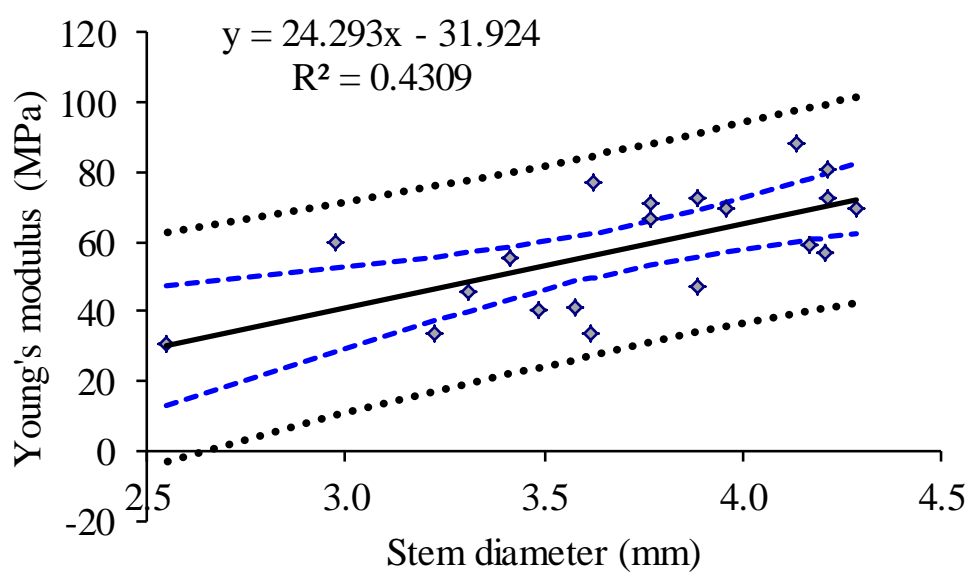

Figure 2-26. Young's modulus of switchgrass (14.6\% w.b.) transversal direction. 


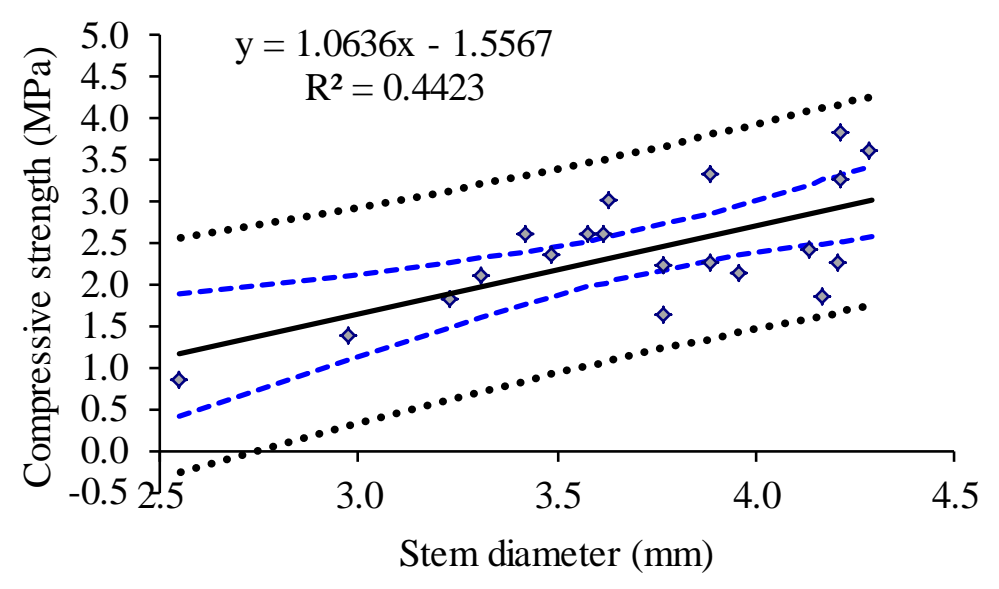

Figure 2-27. Compressive strength of switchgrass (14.6\% w.b.) transversal direction.

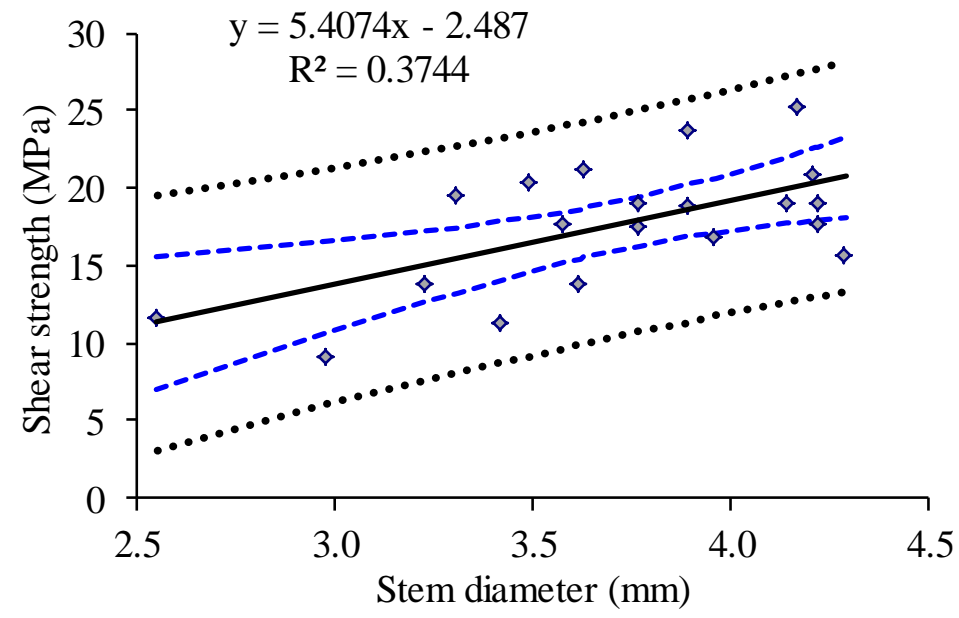

Figure 2-28. Shearing strength of switchgrass (14.6\% w.b.) transversal direction.

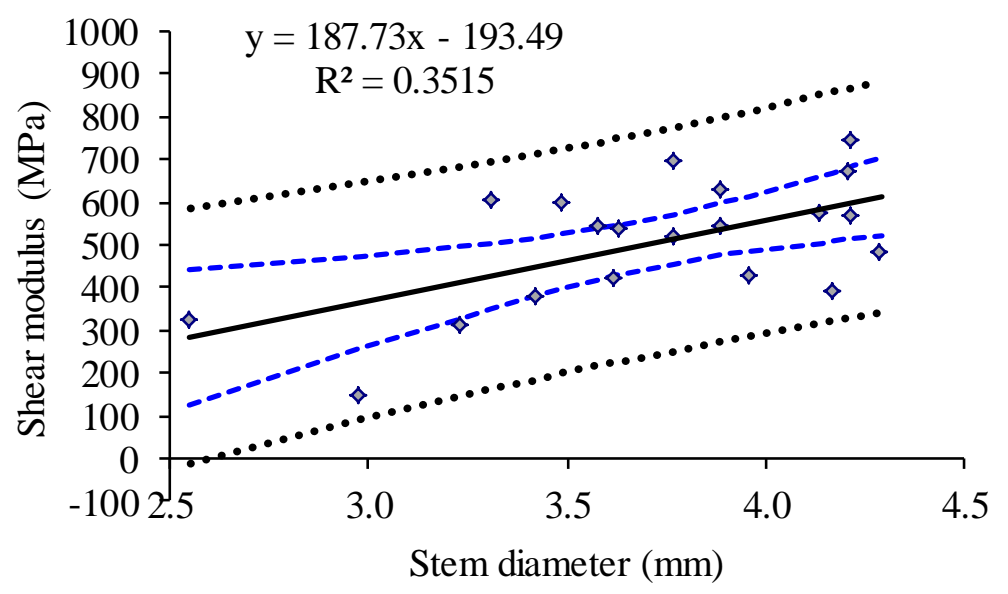

Figure 2-29. Shear modulus of switchgrass ( $14.6 \%$ w.b.) transversal direction. 


\subsubsection{Miscanthus properties}

Tensile tests, compressive tests and shearing tests were conducted on miscanthus specimens at two different moisture content levels (10.2\% and 15.1\%) and along different directions (longitudinal and transversal). The mechanical properties were calculated based on the methods provided in Section 2.2, and the results provided in the following sections.

\subsubsection{Mechanical properties of miscanthus at moisture content $10.2 \%$ (w.b.)}

For the miscanthus with $10.2 \%$ (wet based) moisture content at the longitudinal direction (along the fiber), the tensile strength, Young's modulus, compressive strength, shearing strength and the shearing modulus results are shown in Figure 2-30 to 2-34.

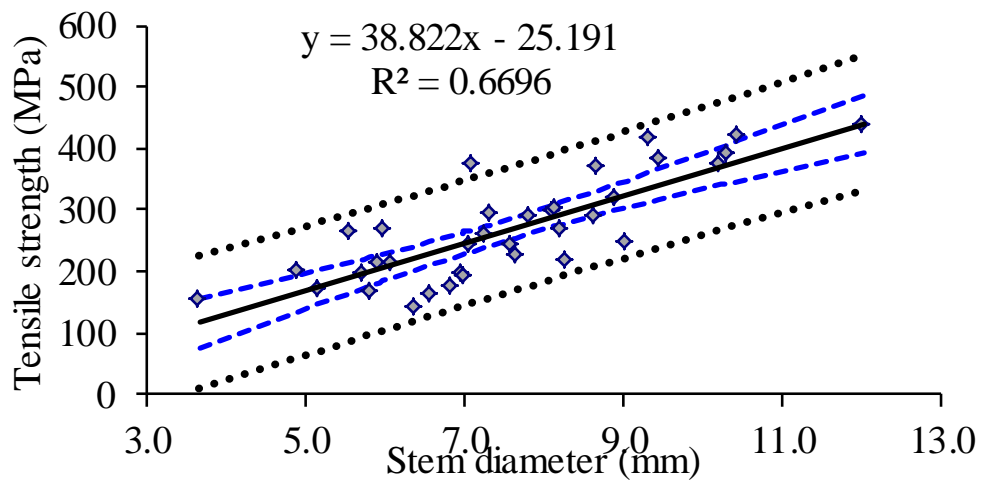

Figure 2-30. Tensile strength of miscanthus (10.2\% w.b.) longitudinal direction.

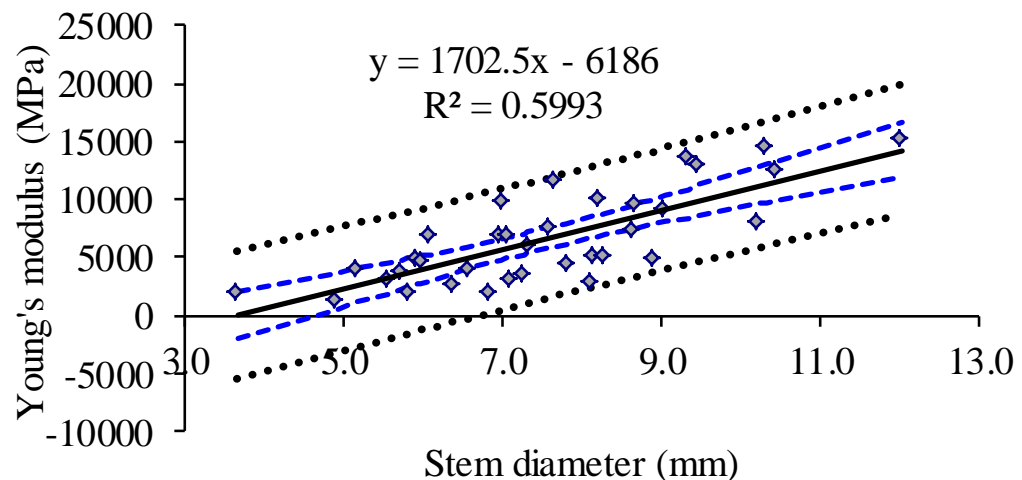

Figure 2-31. Young's modulus of miscanthus (10.2\% w.b.) longitudinal direction. 


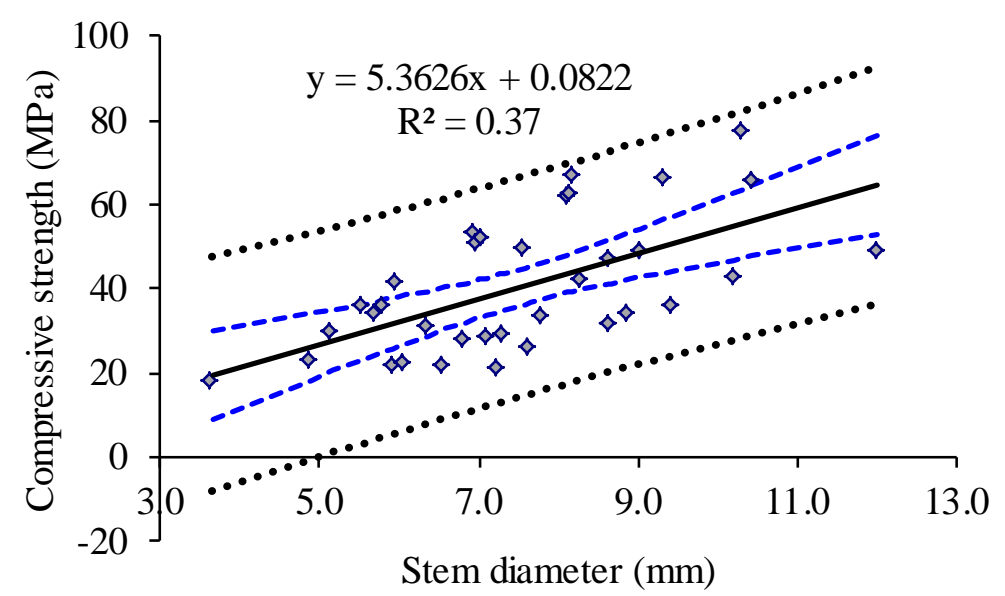

Figure 2-32. Compressive strength of miscanthus (10.2\% w.b.) longitudinal direction.

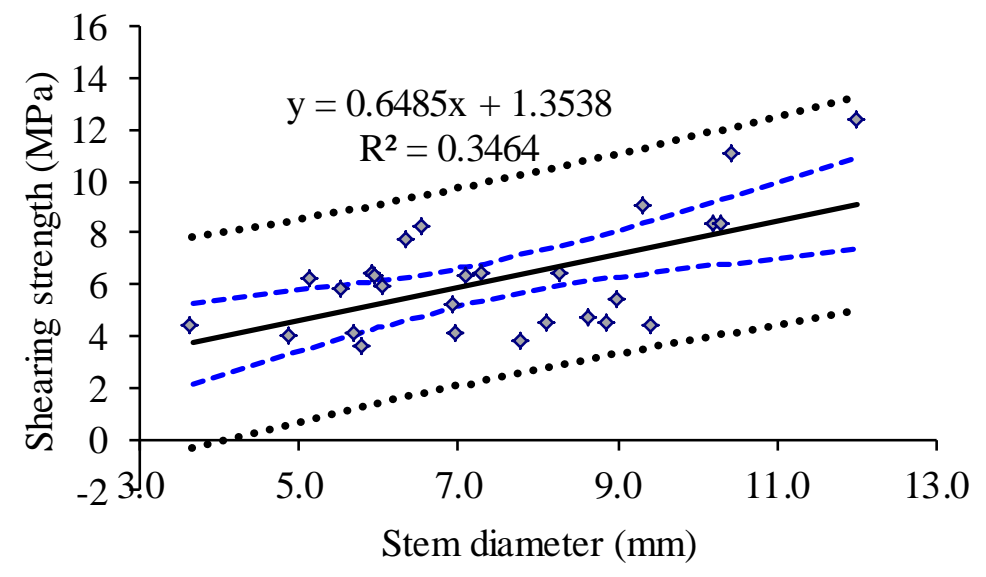

Figure 2-33. Shearing strength of miscanthus (10.2\% w.b.) longitudinal direction.

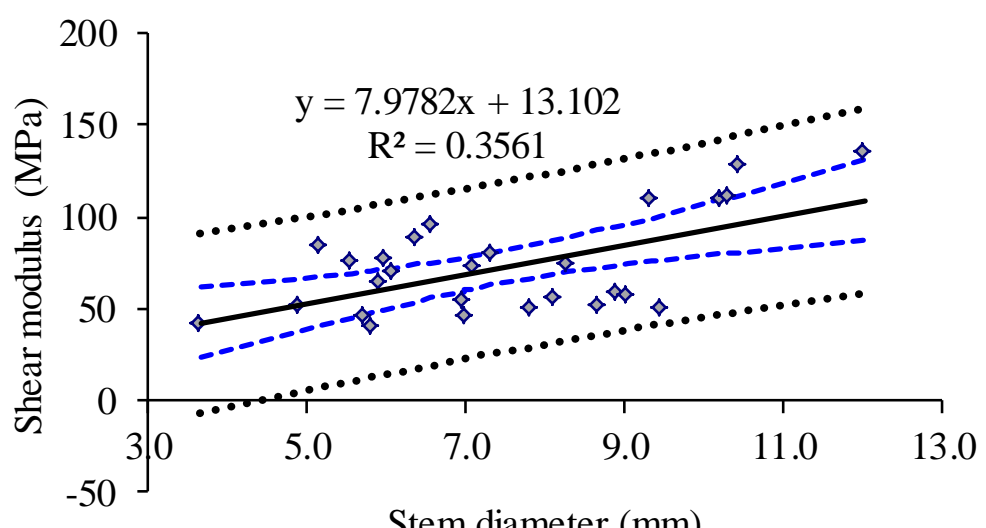

Stem diameter $(\mathrm{mm})$

Figure 2-34. Shear modulus of miscanthus (10.2\% w.b.) longitudinal direction.

For the miscanthus sample with $10.2 \%$ (wet based) moisture content at the transversal direction (cross the fiber), the tensile strength, Young's modulus, compressive 
strength, shearing strength and the shearing modulus results are shown in Figure 2-35 to 2-39. The outer dotted lines are $95 \%$ prediction limits, and the inner dotted lines are $95 \%$ confident limits.

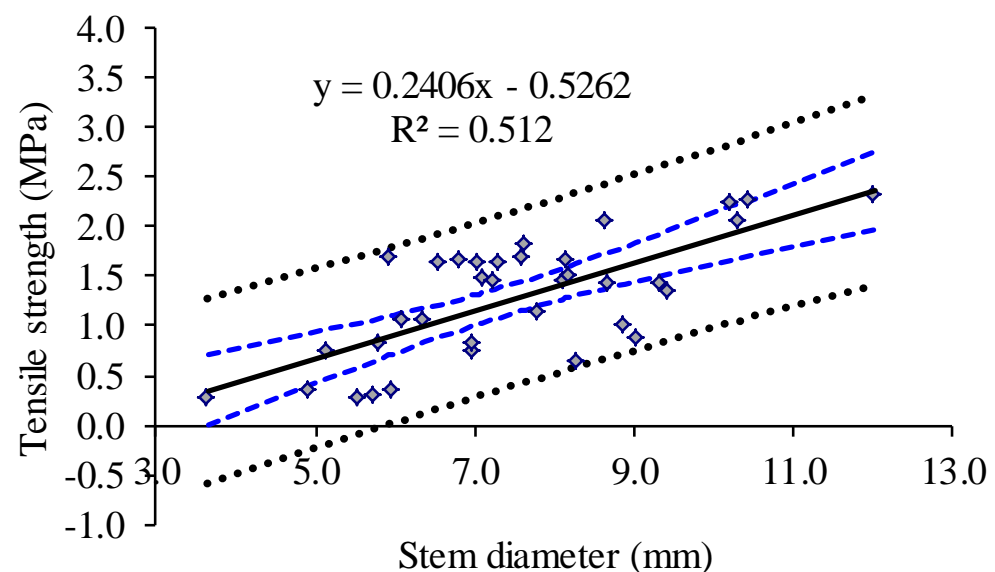

Figure 2-35. Tensile strength of miscanthus (10.2\% w.b.) transversal direction.

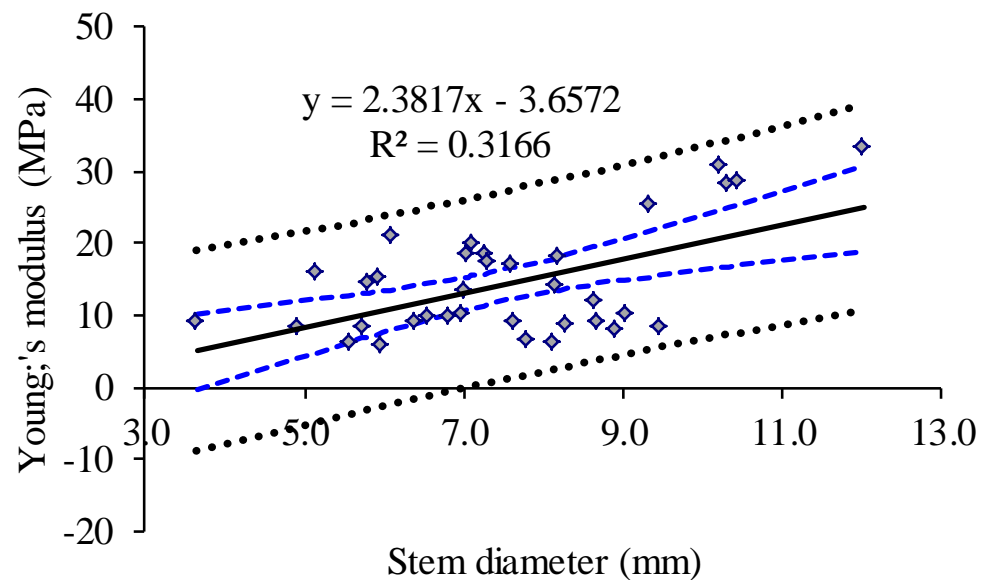

Figure 2-36. Young's modulus of miscanthus (10.2\% w.b.) transversal direction. 


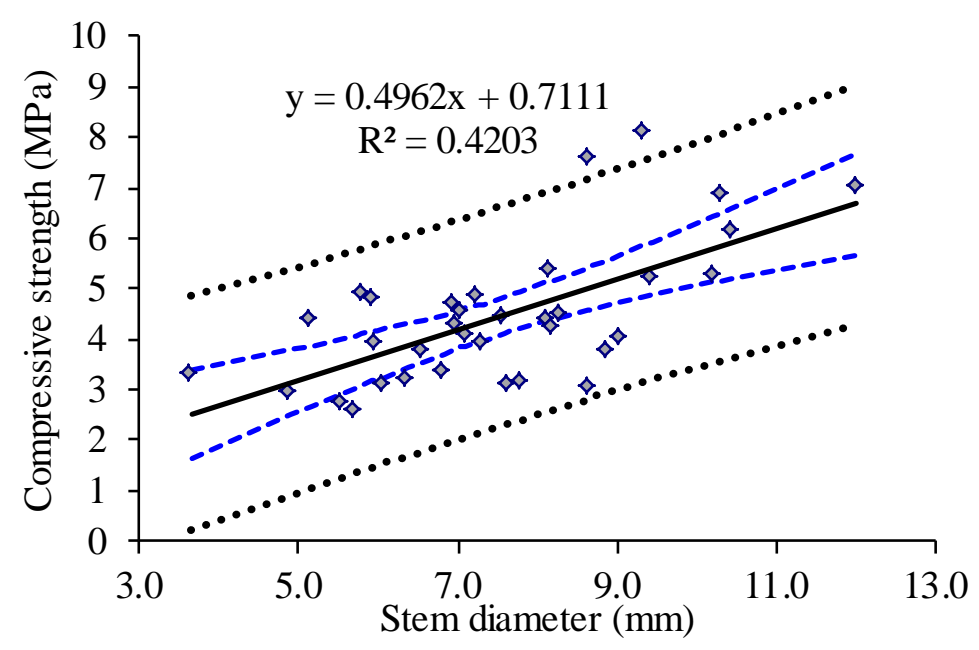

Figure 2-37. Compressive strength of miscanthus (10.2\% w.b.) transversal direction.

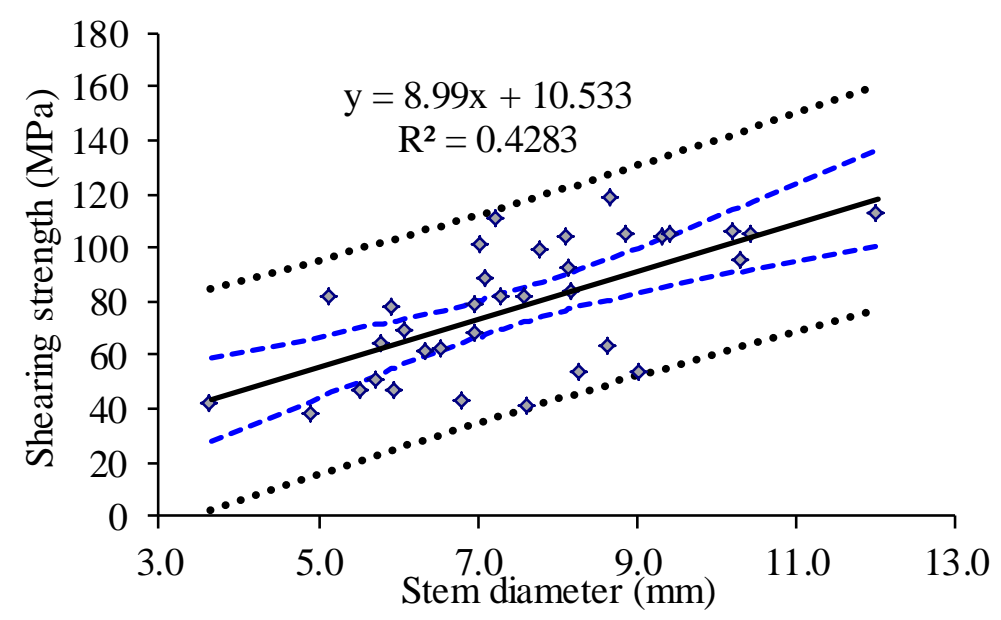

Figure 2-38. Shearing strength of miscanthus (10.2\% w.b.) transversal direction.

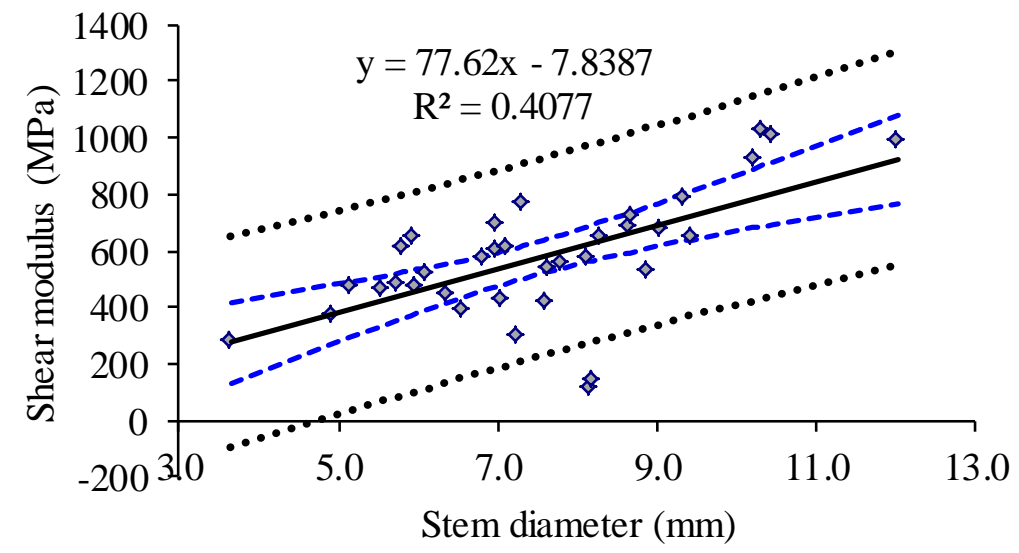

Figure 2-39. Shear modulus of miscanthus (10.2\% w.b.) transversal direction. 


\subsubsection{Mechanical properties of miscanthus at moisture content of $15.1 \%$ (w.b.)}

For the miscanthus sample with $15.1 \%$ (wet based) moisture content at the longitudinal direction (along the fiber), the tensile strength, Young's modulus, compressive strength, shearing strength and the shearing modulus results are shown in Figure 2-40 to 2-44. The outer dotted lines are $95 \%$ prediction limits, and the inner dotted lines are $95 \%$ confident limits.

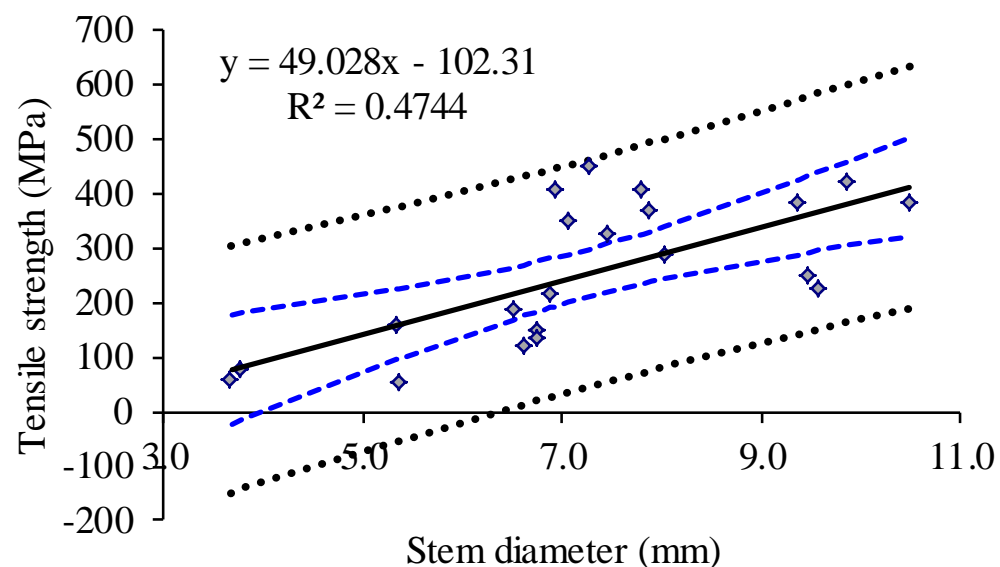

Figure 2-40. Tensile strength of miscanthus ( $15.1 \%$ w.b.) longitudinal direction.

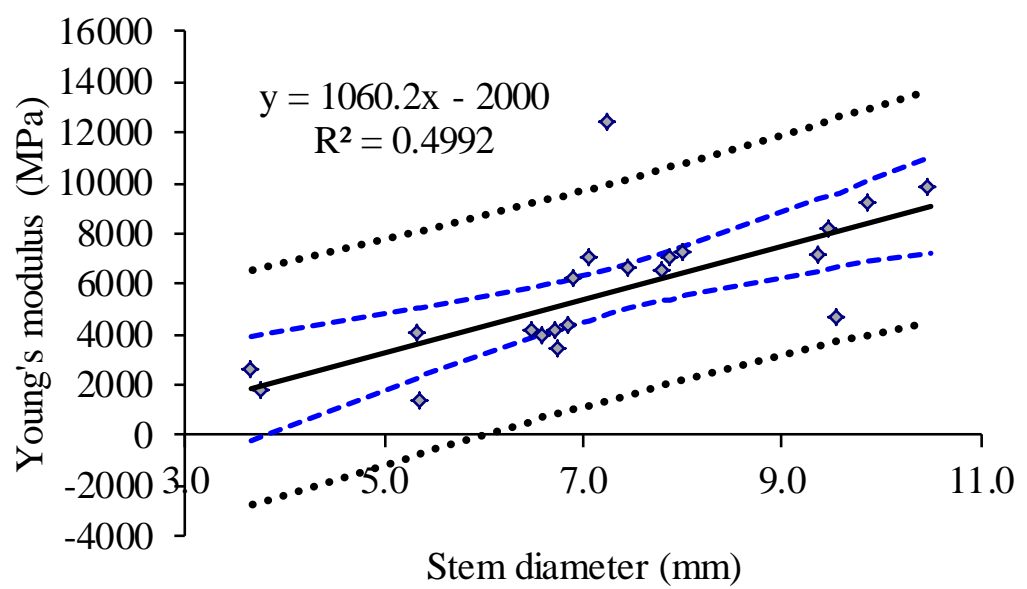

Figure 2-41. Young's modulus of miscanthus ( $15.1 \%$ w.b.) longitudinal direction. 


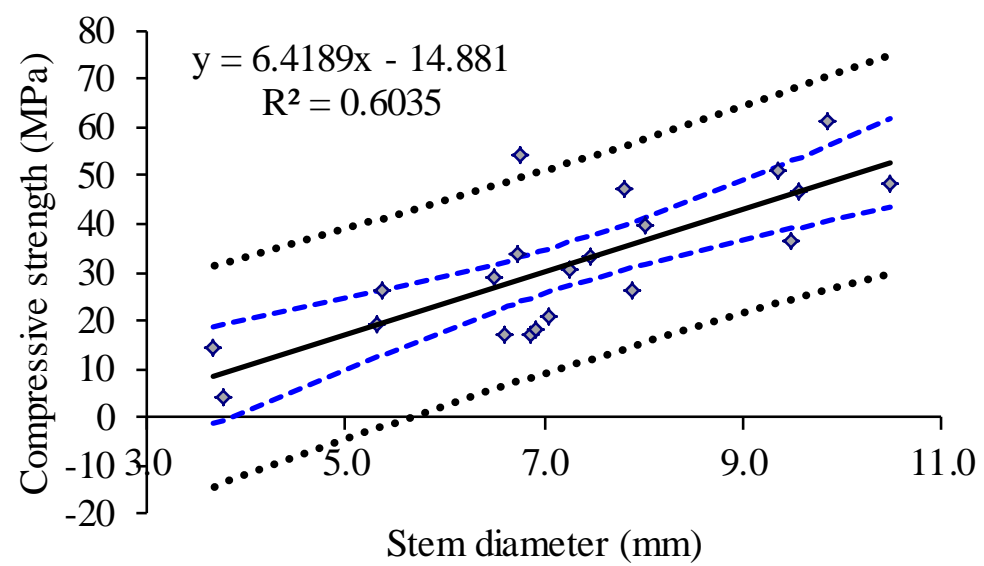

Figure 2-42. Compressive strength of miscanthus (15.1\% w.b.) longitudinal direction.

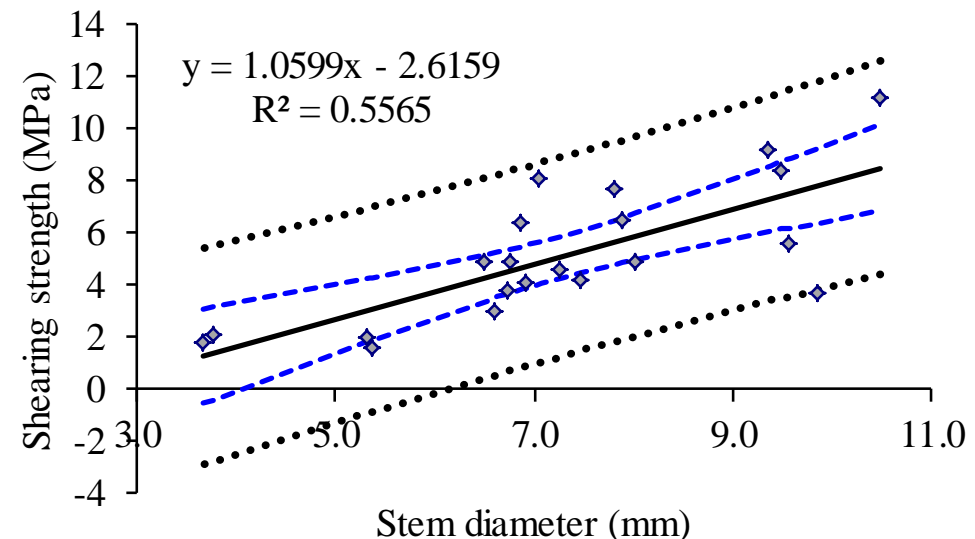

Figure 2-43. Shearing strength of miscanthus (15.1\% w.b.) longitudinal direction.

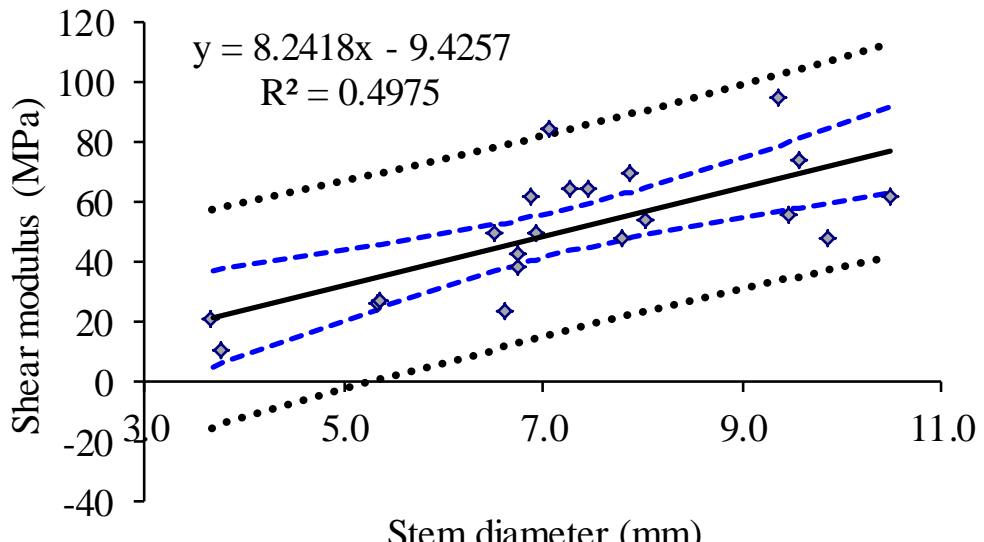

Figure 2-44. Shear modulus of miscanthus (15.1\% w.b.) longitudinal direction. 
For the miscanthus sample with $15.1 \%$ (wet based) moisture content at the transversal direction (cross the fiber), the tensile strength, Young's modulus, compressive strength, shearing strength and the shearing modulus results are shown in Figure 2-45 to 2-49. The outer dotted lines are $95 \%$ prediction limits, and the inner dotted lines are $95 \%$ confident limits.

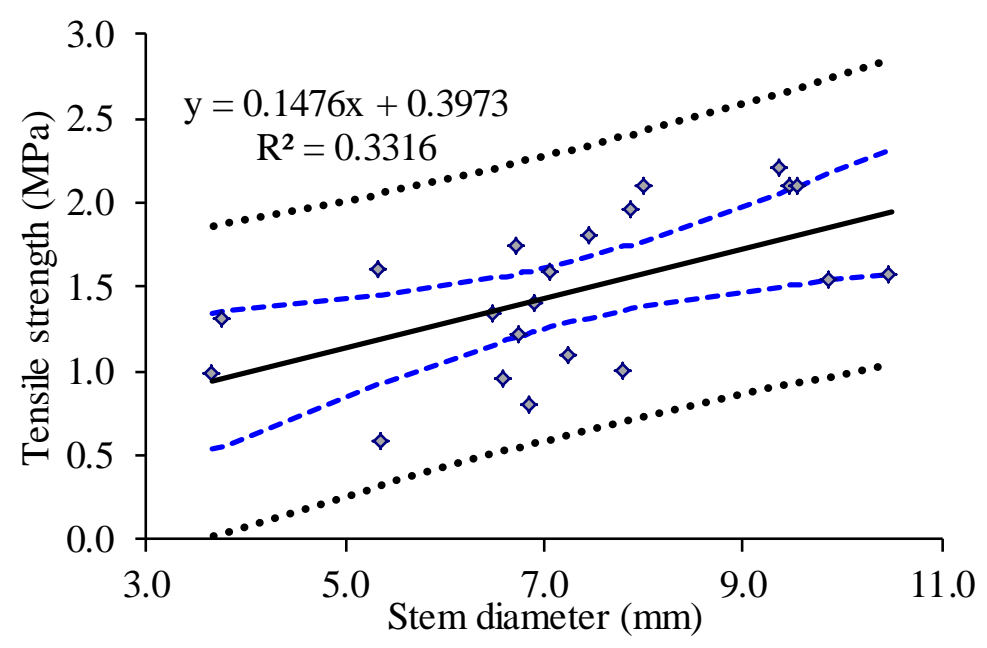

Figure $2-45$. Tensile strength of miscanthus (15.1\% w.b.) transversal direction.

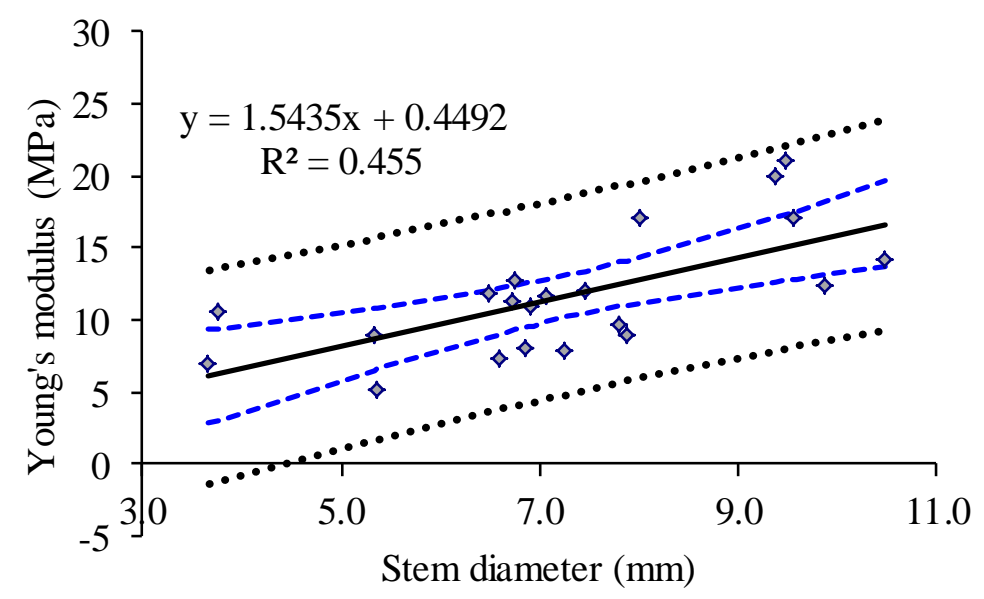

Figure 2-46. Young's modulus of Miscanthus (15.1\% w.b.) transversal direction. 


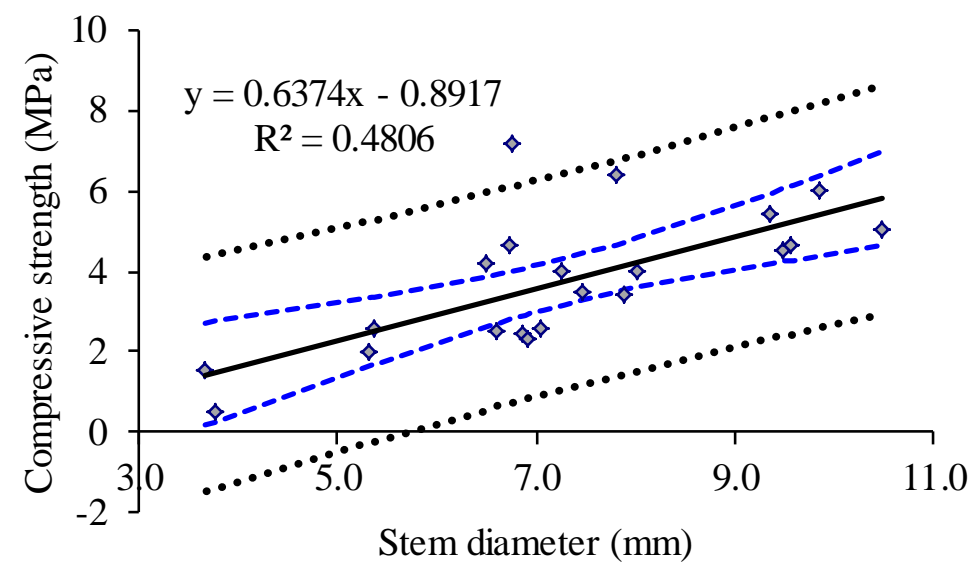

Figure 2-47. Compressive strength of miscanthus (15.1\% w.b.) transversal direction.

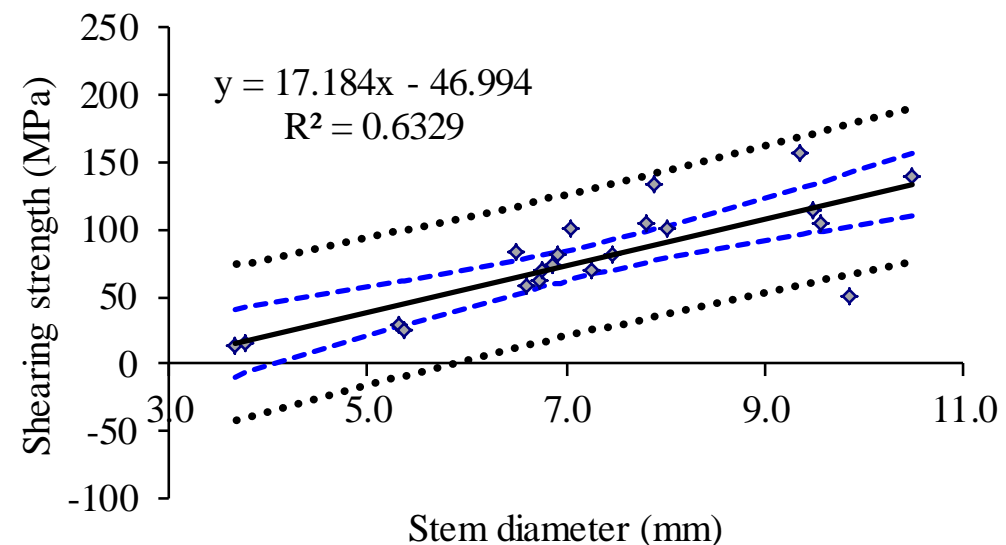

Figure 2-48. Shearing strength of miscanthus (15.1\% w.b.) transversal direction.

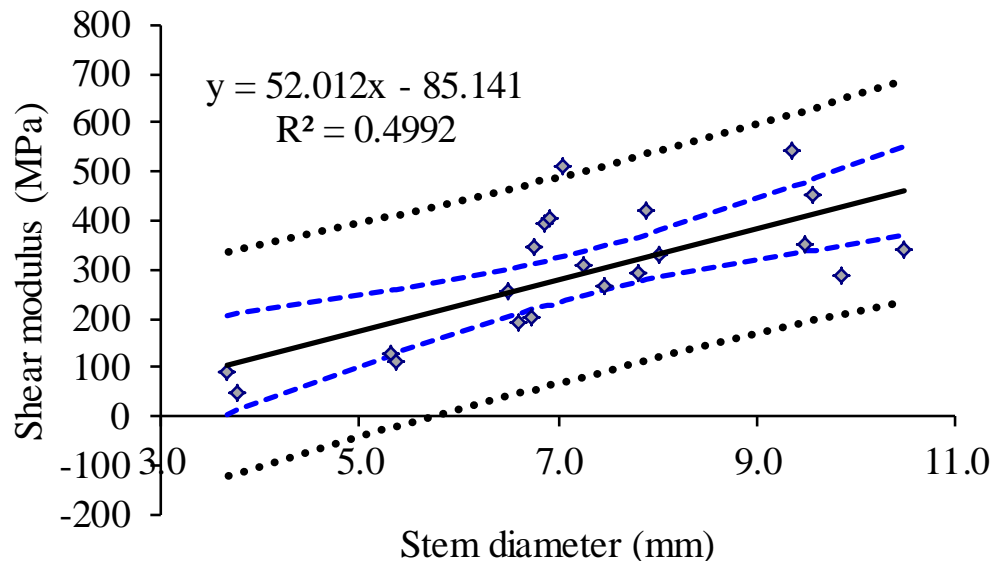

Figure 2-49. Shear modulus of miscanthus (15.1\% w.b.) transversal direction. 
Biomechanical properties of switchgrass and miscanthus stems were determined via tensile, shearing and compressive tests in this research at two different moisture levels at different directions (longitudinal and transversal). The mechanical properties with larger stem diameters (internodes that are closer to the ground in most cases) have higher values than the ones with smaller diameters for both switchgrass and miscanthus stems. The possible reasons might be the stems with larger diameters have more matured fibers and packed cells. In addition, the experimental results indicated that mechanical properties of biomass materials could not be measured as accurately as man-made, uniform materials, such as metals and plastics.

Tensile test results on switchgrass and miscanthus stems showed the tensile strength and Young's modulus at longitudinal direction had much higher values than the ones at the transversal direction. Tensile strength and Young's modulus values on the longitudinal direction had significantly higher values than the transversal direction. One of the possible reasons is the fibers are grown in longitudinal direction, which makes it hard to fail under tensile forces.

The compressive test results showed that the stem samples with higher moisture content had less compressive strength than the lower moisture content samples, because stems with higher moisture contents are tended to be "softer". Specimens with lower moisture contents were brittle and tended to break easier, therefore the shearing strength values were smaller for the biomass stems with low moisture content.

The linear regression analysis of the mechanical properties of switchgrass and miscanthus are summarized in Table 2-2 and 2-3. 
Table 2-1. Linear regression analys is of mechanical properties of switchgrass.

\begin{tabular}{|c|c|c|c|c|c|}
\hline & \multirow[b]{2}{*}{ Mechanical property } & \multicolumn{2}{|c|}{$9.8 \%$ moisture content } & \multicolumn{2}{|c|}{$14.6 \%$ moisture content } \\
\hline & & Linear regression & $\mathrm{R}^{2}$ & Linear regression & $\mathrm{R}^{2}$ \\
\hline \multirow{5}{*}{ Longitudinal } & Tensile strength & $y=70.95 x-101.66$ & 0.61 & $y=40.65 x-27.33$ & 0.36 \\
\hline & Young's modulus & $y=4853.1 x-6321.1$ & 0.54 & $y=3535.6 x-3237.8$ & 0.53 \\
\hline & Compressive strength & $y=7.8683 x-0.1709$ & 0.34 & $y=8.7025 x-13.095$ & 0.47 \\
\hline & Shearing strength & $y=0.5874 x-0.281$ & 0.39 & $y=0.8272 x-1.1345$ & 0.57 \\
\hline & Shear modulus & $y=17.237 x-5.292$ & 0.59 & $y=8.37 x+6.10$ & 0.26 \\
\hline \multirow{5}{*}{ Transversal } & Tensile strength & $y=0.1807 x-0.035$ & 0.54 & $y=0.25 x-0.4654$ & 0.39 \\
\hline & Young's modulus & $y=16.143 x-0.314$ & 0.48 & $y=24.293 x-31.924$ & 0.43 \\
\hline & Compressive strength & $y=1.5063 x-2.1722$ & 0.51 & $y=1.0636 x-1.5567$ & 0.44 \\
\hline & Shearing strength & $y=6.6849 x-5.6311$ & 0.46 & $y=5.4074 x-2.487$ & 0.37 \\
\hline & Shear modulus & $y=245.98 x-160.88$ & 0.55 & $y=187.73 x-193.49$ & 0.35 \\
\hline
\end{tabular}

Table 2-2. Linear regression analys is of mechanical properties of miscanthus.

\begin{tabular}{|c|c|c|c|c|c|}
\hline & \multirow[b]{2}{*}{ Mechanical property } & \multicolumn{2}{|l|}{$10.2 \%$ moisture content } & \multicolumn{2}{|c|}{$15.1 \%$ moisture content } \\
\hline & & Linear regression & $\mathrm{R}^{2}$ & Linear regression & $\mathrm{R}^{2}$ \\
\hline \multirow{5}{*}{ Longitudinal } & Tensile strength & $y=38.822 x-25.191$ & 0.67 & $y=49.028 x-102.31$ & 0.47 \\
\hline & Young's modulus & $y=1702.5 x-6186$ & 0.60 & $y=1060.2 x-2000$ & 0.50 \\
\hline & Compressive strength & $y=5.36 x+0.08$ & 0.37 & $y=6.42 x-14.88$ & 0.60 \\
\hline & Shearing strength & $y=0.65 x+1.35$ & 0.35 & $y=1.0599 x-2.6159$ & 0.56 \\
\hline & Shear modulus & $y=7.9782 x+13.102$ & 0.36 & $y=8.2418 x-9.4257$ & 0.50 \\
\hline \multirow{5}{*}{ Transversal } & Tensile strength & $y=0.2406 x-0.5262$ & 0.51 & $y=0.1476 x+0.3973$ & 0.33 \\
\hline & Young's modulus & $y=2.3817 x-3.6572$ & 0.32 & $y=1.5435 x+0.4492$ & 0.46 \\
\hline & Compressive strength & $y=0.4962 x+0.7111$ & 0.42 & $y=0.6374 x-0.8917$ & 0.48 \\
\hline & Shearing strength & $y=8.99 x+10.533$ & 0.43 & $y=17.184 x-46.994$ & 0.63 \\
\hline & Shear modulus & $y=77.62 x-7.8387$ & 0.41 & $y=52.012 x-85.141$ & 0.50 \\
\hline
\end{tabular}




\subsection{Summary}

Biomass mechanical properties were measured with two different controlled moisture contents for both switchgrass and miscanthus internodes, and the experimental results of the mechanical property tests were measured based on biomass stem diameters. The mechanical properties of biomass materials, specifically, miscanthus and switchgrass were determined by conducting tensile tests, compressive tests, shearing tests. Properties of the biomass stem nodes will differ from internode areas, and stem nodes have more complicated properties and non-uniform shapes. In this study, only the mechanical properties of biomass stem internodes were investigated. Compared to man-made isotropic materials such as plastics and glass, biomass materials do not have uniform physical and mechanical properties and smooth shapes. These non-uniformity and anisotropic properties of biomass introduced difficulties in determining the mechanical properties. The experimental results also showed that failures caused by tension in longitudinal direction required the highest energy compared to the other failure tests for both biomass materials at different moisture contents. Therefore, biomass size reduction or harvesting blade designs should minimize or avoid longitudinal tension failures. 


\section{CHAPTER 3 BIOMASS EXPERIMENTAL PRE- PROCESSING SYSTEM DEVELOPMENT}

\subsection{Introduction}

The biomass pre-processing options usually include size reduction (cutting, chipping and grinding), densification (baling and pelletizing), drying, thermochemical conversion, biochemical conversion and fiber expansion. The basic purpose of biomass preprocessing is to conduct size reduction or transform biomass into a form that is suitable for material handling, storage and transportation prior to conversion to biofuels and other bio-products (Wright, Pryfogle, Stevens, Hess, \& Radtke, 2006). Biomass mechanical pre-processing is one of the most important operations in the feedstock supply chain and it is carried out to make the overall system to be effective and to increase the biomass added values.

Compared to fossil fuels, one of the barriers of using biomass energy is overcoming the operational and logistical limitations by successfully pre-processing biomass. Handling, transportation and storage of bioenergy crops to produce fuels, chemicals and bio-products are challenging tasks due to various spread distribution, uneven moisture content and low bulk density of these biomass materials (Sokhansanj, Cushman, \& Wright, 2003). Though most plant biomass is relatively similar in chemical composition, the variations can significantly affect energy production, the thermochemical conversion process and equipment, biomass property variations can also cause problems like inefficient physical ability to feed material into an energy production platform, undesirable conversion rate and temperature for chemistry reactions. Therefore, mechanical pre-processing (mainly size reduction and densification) is necessary to 
change biomass materials into uniform size, shape, and high bulk density prior to pretreatment for conversion to biofuels for efficient, ease of handling and conveying throughout the biorefinery processes (Hamelinck, Suurs, \& Faaij, 2005).

In this chapter, an experimental pre-processing system was designed to explore the impact of processing parameters on cutting performances, such as energy consumptions used to process biomass, cutting force required to carry out the processing. Besides conventional processing methods, the ultrasonic-assisted cutting method was introduced and applied to the designed cutting system to investigate its effects on biomass mechanical cutting performances. The detailed mechanical design, electrical system design and the control system development of the experimental pre-processing system were also provided.

\subsection{Literature review}

In general, plants are viscoelastic materials and their deformations are the functions of time and the modulus of elasticity. Understanding the cutting/grinding mechanisms of biomass to enhance the biomass particle size reduction processes will have significant impact on biofuel production. However, limited numbers of studies have been published on biomass cutting dynamics, particle size reduction, grinding and harvest management (Clarke et al., 2011; Fike et al., 2006). O'Dogherty and Gale (1991) reported that the critical cutting speed for grass stems ranged from 15 to $35 \mathrm{~m} / \mathrm{s}$, and cutting speeds lower than the critical speed could result in large stem deflections and high stubble heights. Ghahraei (2011) reported an optimum design of knife edge angle, knife shear angle, knife approach angle, and knife rake angle as $25^{\circ}, 40^{\circ}, 40^{\circ}$ and $40^{\circ}$ respectively for kenaf stems. In addition to harvesting, particle size reduction plays an important role in biomass 
feedstock logistics. Yu et al. (2006) concluded that switchgrass size reduction by using shear failure rather than tensile failure was expected to be more energy efficient.

Moisture content is an important parameter affecting the cutting resistance of biomass. Researchers observed that increasing moisture content reduced the ultimate shear force (Yu et al., 2006). In addition to moisture content, there is a unique correlation between the geometric design of cutting edge and the cutting force requirement (Woldt, Schubert, \& Jäckel, 2004). Straw and stalks of grasses and cereal crops have long stems and they should be precut to smaller pieces before grinding. Igathinathane, Womac, Sokhansanj, and Narayan (2008) investigated the performance of a pressure plate with linear grit knife and reduced the energy requirement for grinding switchgrass and corn stover. Long pieces of straw and stalk of biomass feedstocks prevented uniform feeding of biomass into the subsequent fine processing in discs or hammer mill grinders (Schell \& Harwood, 1994).

Ultrasound-assisted blades are attractive in different applications because of their effects on cutting performances and cutting power (X. Wang, Zhou, Gan, \& Ngoi, 2002). Zahn, Schneider, and Rohm (2006) reported that ultrasonic excitation could reduce the friction resistance of product which reduces the cutting force. Since energy for cutting is directly proportional to the friction resistance of biomass crops (Chattopadhyay \& Pandey, 1999), ultrasonic-assisted cutting has potential to reduce cutting energy. Several researchers observed the effect of ultrasound during cutting on product quality parameters such as surface fineness and product shape (Y. Schneider, Zahn, \& Linke, 2002). Recent studies examined the ultrasound-assisted conventional cutting to reduce power requirement for shearing food products (Arnold, Leiteritz, Zahn, \& Rohm, 2009; 
Yvonne Schneider, Zahn, \& Rohm, 2008; Yvonne Schneider, Zahn, Schindler, \& Rohm, 2009). The researchers placed ultrasonic transducers at the bottom of the sample holder of a universal testing machine and reported that ultrasound excitation of food products reduced the amount of power requirement for cutting.

\subsection{Development of a biomass experimental pre-processing system}

\subsubsection{Design of a linear cutting platform}

A biomass experimental cutting system was designed to investigate the influences of cutting parameters (cutting speed, cutting angle, blade profile, with and without ultrasonication) on biomass cutting performances. The experimental results can provide information about the potential designs and methods that can be used to develop a biomass cutting system. A linear sliding platform was designed to move a biomass sample towards the blade at varying speeds. The sliding platform speed was controlled by a computer program and the cutting force was recorded during the tests. The schematic diagram of the designed cutting system is shown in Figure 3-1, and the actual experiment setup is shown in Figure 3-2.

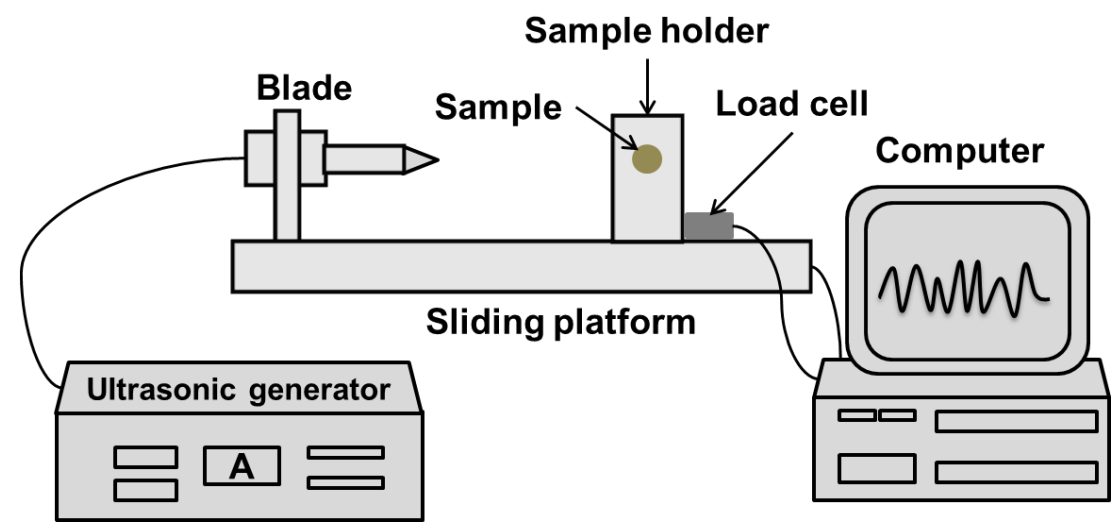

Figure 3-1. Schematic diagram of the experimental cutting system. 


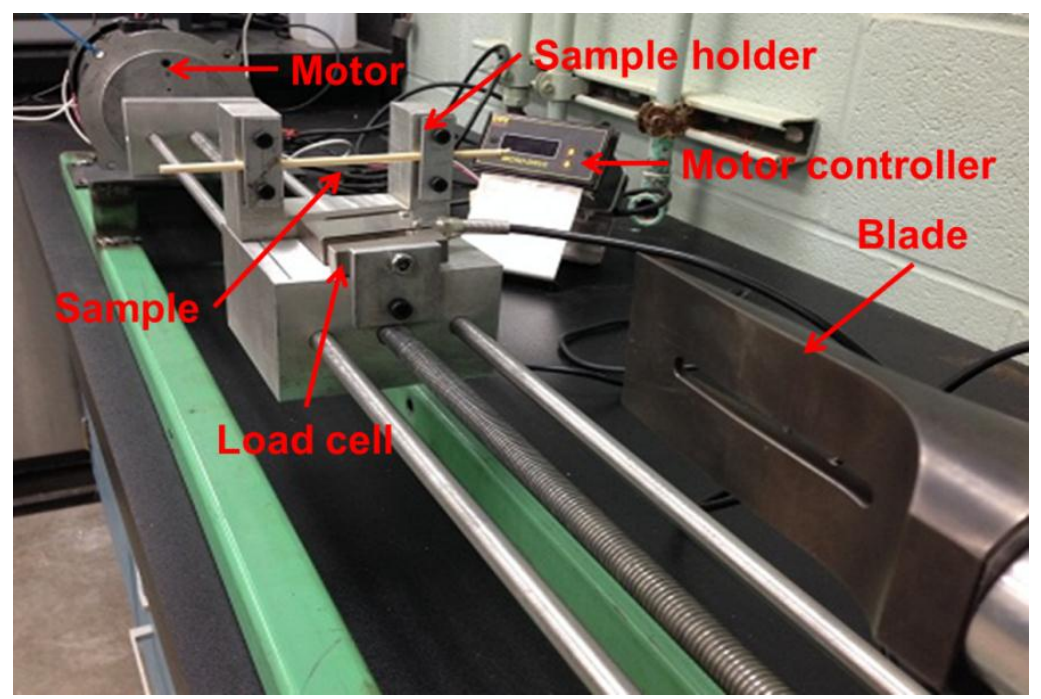

Figure 3-2. Designed experimental linear cutting system.

\subsubsection{Development of a data acquisition and control system}

As shown in the above section, the developed experimental cutting system moves a biomass specimen to the blade with a constant speed. When the biomass specimen is interacting with the blade, the load cell attached to the sample holder can record the cutting force data. The motor speed and direction were controlled by a motor controller. In order to analyze the energy input of ultrasonic-assisted cutting compared to the conventional cutting method, a Kill-A-Watt (P3 International Corp., New York, NY) was modified to transit electricity energy consumption information wirelessly to the PC in real time. The schematic diagram of the control and data acquisition system development is illustrated in Figure 3-3.

Three analog signal pins (voltage pin, high current pin and low current pin) were connected from the Kill-A-Watt to an ATtiny 85 microcontroller (Atmel, San Jose, CA). When the current was lower than 1.5 A, the low current information was used, when the current was higher than $1.5 \mathrm{~A}$, the high current information was used in power calculation. A 5V power supply was added to power the microcontroller and the RF link 
transmitter. The microcontroller reads the voltage and current signals, calculates the power usage of the ultrasonic generator using Equation 3-1, and transmits the power information via the transmitter wirelessly to the receiver connected to the PC. The details of the electronic diagram of the wireless power monitoring circuit is shown in Appendix I.

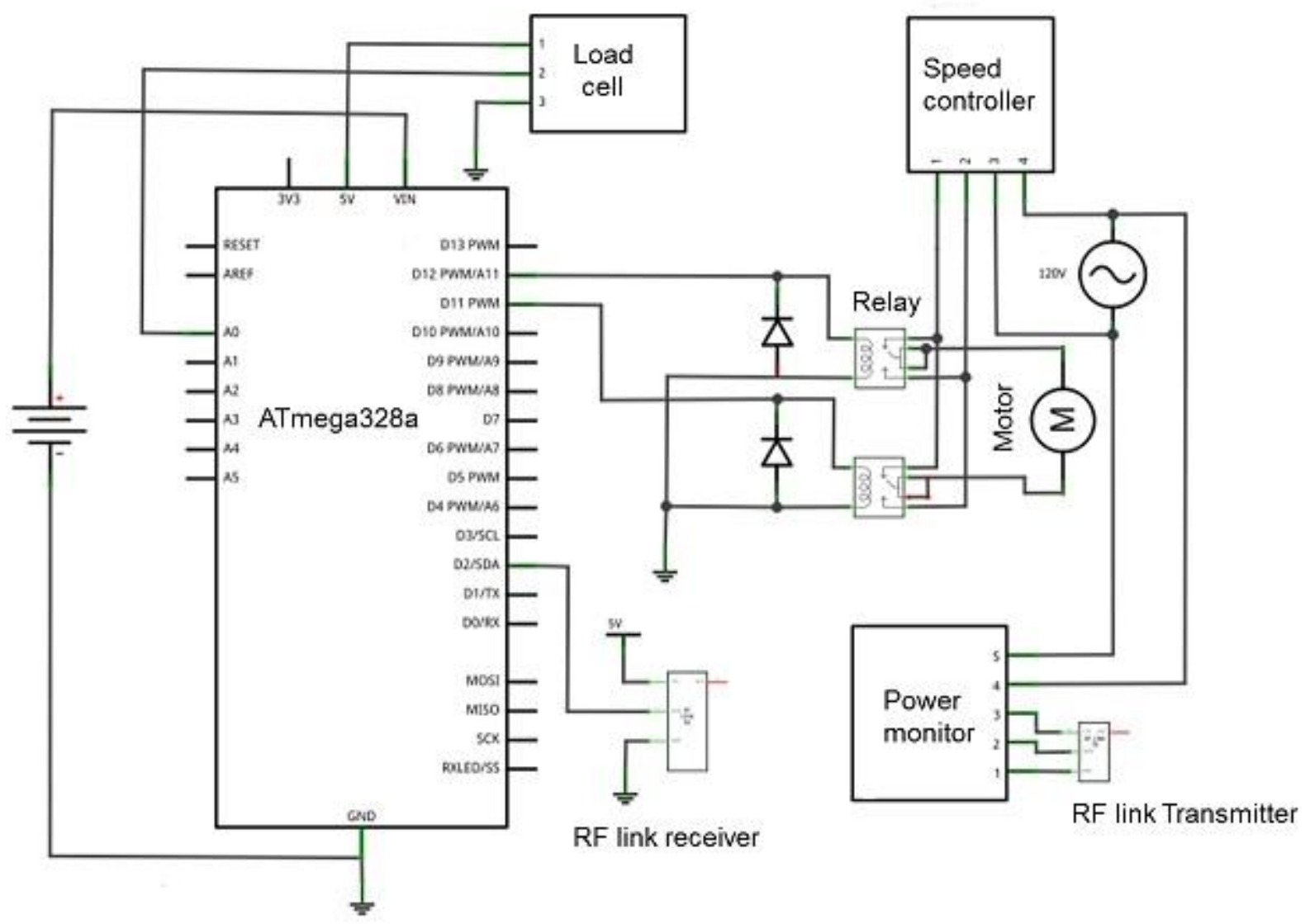

Figure 3-3. Schematic diagram of the control and data acquisition system development.

$$
P=V_{r m s} I_{r m s} \cos (\phi)
$$

where $V_{r m s}$ and $I_{r m s}$ are root mean squared values of voltage and current values, and $\cos (\phi)$ is power factor. The power usage was calculated by the microcontroller and the results were transmitted via a wireless RF transmitter to the PC for further analysis. 
When the ultrasonic generator was deactivated (conventional cutting), the voltage and current signals are shown in Figure 3-4; when the ultrasonication was activated (ultrasonic-assisted cutting), the voltage and current signals are shown in Figure 3-5.

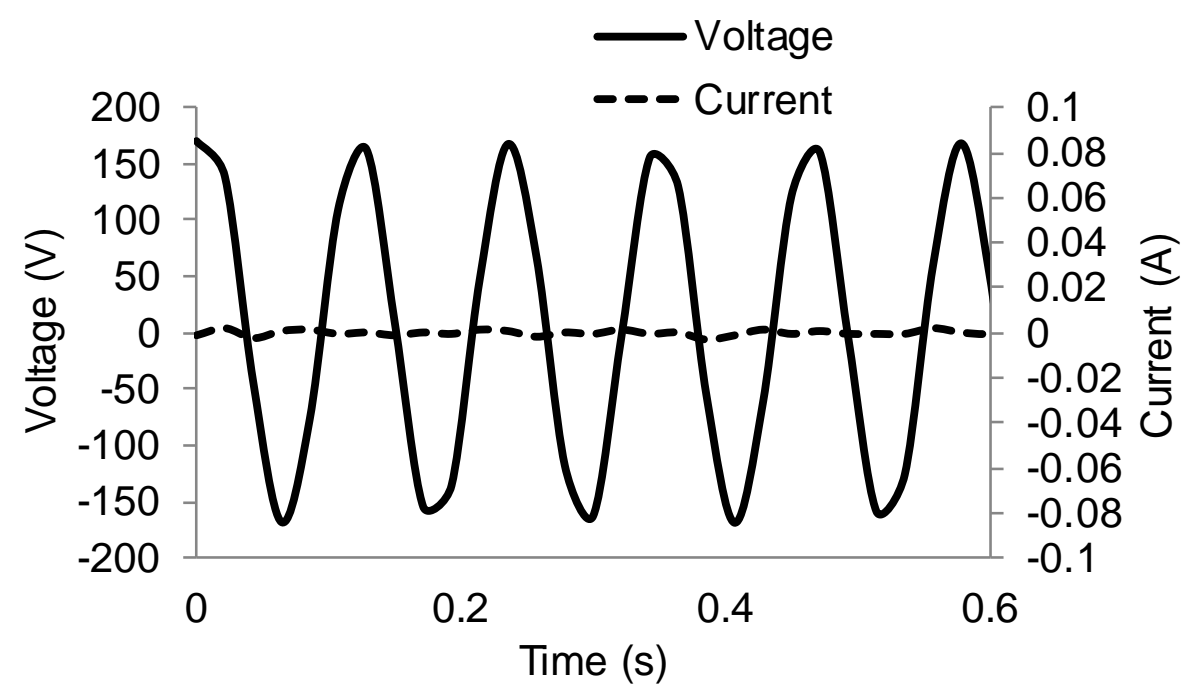

Figure 3-4. Recorded voltage and current information (ultrasonic generator deactivated).

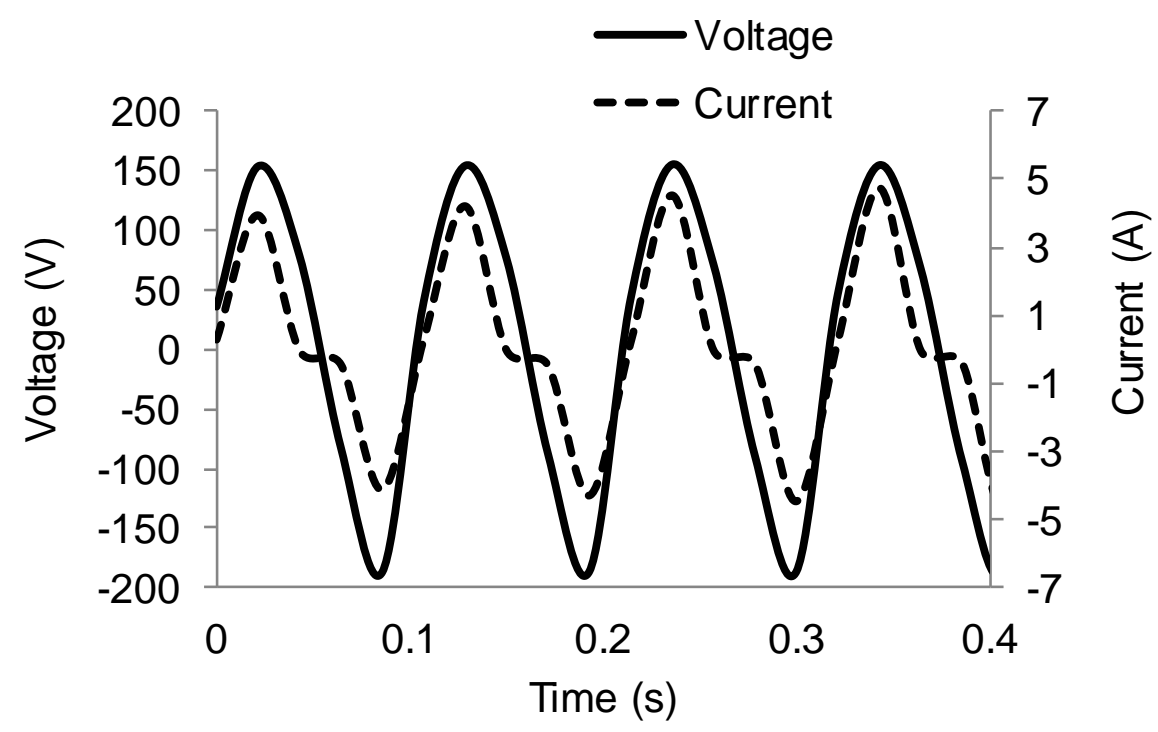

Figure 3-5. Recorded voltage and current information (ultrasonic generator activated). 


\subsubsection{Design of a control system software}

To control the cutting speed and to record the cutting force and cutting energy data, a C\# windows presentation foundation (WPF) user interface was created. This program was installed on the PC and could communicate with an ATmega328p microcontroller (Atmel, San Jose, CA) via serial ports to implement the motor control and data acquisition. The recorded data can be saved as text files locally. The user interface is shown in Figure 3-6.

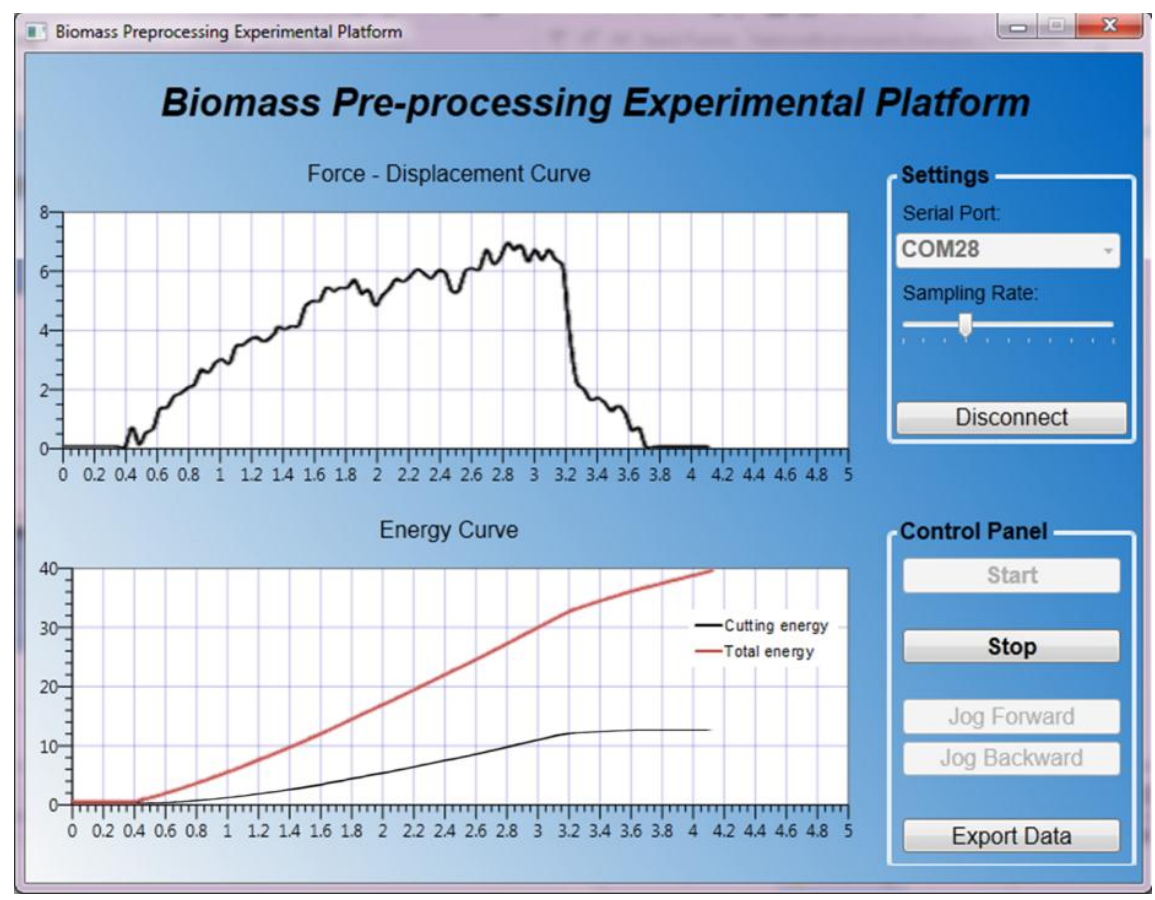

Figure 3-6. Biomass pre-processing user interface

\subsection{Ultrasonic assisted cutting system integration}

Ultrasonic assisted cutting method was conducted under different cutting parameters, and the cutting performances were compared to the results from the conventional cutting method. Ultrasonic cutting method utilizes the propagated energy to change the form, framework and function of the objects to be cut with a series of ultrasonic effects such as mechanical, thermal, acoustic and chemical effects (Gallego-Juarez, 2010). In order to 
investigate the effects of ultrasonic-assisted cutting on biomass pre-processing, an ultrasonic cutting system has been designed and integrated into the existing cutting platform. When the ultrasonication was activated on the blade, the system served as ultrasonic cutting system, and when the ultrasonication was deactivated, the system worked as a conventional cutting system. In this section, the ultrasonic cutting theory will be explained and the design process of the ultrasonic assisted cutting system development will be explained.

\subsubsection{Theory of ultrasonic cutting}

During an ultrasonic cutting process, the blade tip oscillates at the ultrasonic frequency and propagates the energy to the specimen to be cut. Being activated by ultrasonic waves, the part of the specimen near the oscillating blade tip vibrates at the same ultrasonic frequency first. As the energy propagates further, inner parts in the specimen start to vibrate as well, behaving like being alternately pushed and pulled at a high frequency. This phenomenon is the mechanical effect, and it is the leading cause of locus disfigurements in the ultrasonic cutting process. For the material to be cut, the locus of the material contacting with the vibrating blade tip has the same movement, the displacement of an element contacting the blade tip can be described in Equation 3-2 (Kim \& Lee, 1996; Ma, Shamoto, Moriwaki, \& Wang, 2004; Zahn et al., 2006).

$$
u_{m}(t)=A_{m} \sin (\omega t-\theta)
$$

Where $u_{m}$ is displacement, $A_{m}$ is the vibration amplitude, $\omega$ is the angular velocity, $t$ is time and $\theta$ is the phase. If the derivative of Equation 3-2 is taken, the velocity can be described in Equation 3-3, and the acceleration can also be derived by taking the derivative of velocity (shown in Equation 3-4). 


$$
\begin{gathered}
v_{m}(t)=A_{m} \omega \cos (\omega t-\theta) \\
a_{m}(t)=-A_{m} \omega^{2} \sin (\omega t-\theta)
\end{gathered}
$$

Without the effects of gravity, the total force acting on the element with mass $m$ in the materials becomes:

$$
F_{m}(t)=m a_{m}(t)=-A_{m} \omega^{2} m \sin (\omega t-\theta)
$$

From Equations 3-2 to $3-5$, it is obvious that when the frequency is high, the ultrasonic mechanical effect generates tremendous force and instantaneous acceleration on the contacting part of the specimen. Many micro-disfigurements will happen under the large concentrated and alternating pressure, when the acceleration and force are beyond thresholds.

For the vibrating ultrasonic blade tip, the displacement is calculated by Equation 3-6.

$$
u_{b}(t)=v_{b} t+A_{b} \sin (\omega t-\theta)
$$

Where, $v_{b}$ is the blade cutting velocity and $A_{b}$ is vibration amplitude. The relative velocity during ultrasonic cutting process is calculated by Equation 3-7.

$$
v_{r e l}(t)=v_{b}-A_{b} \omega \cos (\omega t-\theta)
$$

Where, $v_{r e l}$ is the relative velocity. The modified Coulomb friction model can be presented by Equation 3-8 (Littmann, Storck, \& Wallaschek, 2001).

$$
F_{R}=F_{C}\left(\frac{2}{\pi} \sin ^{-1}\left(\frac{v_{b}}{A_{b} \omega}\right)\right)
$$

Where, $F_{R}$ is the average friction force, and $F_{C}$ is Coulomb friction force. It is shown that friction reduction in the presence of ultrasonic assisted vibration depends on the ratio of the moving velocity to the vibration velocity. Due to this type of non-continuous 
interaction between the blade and the material to be cut, the pulsating cutting force is reduced drastically and the net cutting time is shortened as well, which saves tool life, improves cutting stability and reduces cutting energy (Ikawa et al., 1991; Ma et al., 2004; Nath, Rahman, \& Neo, 2009).

\subsubsection{Ultrasonic cutting system components}

Ultrasound is a cyclic sound pressure with a frequency higher than the upper limit of human hearing (around $20 \mathrm{kHz}$ ). In low-intensity ultrasound applications, ultrasound is used to convey the information about or through a system, such as non-destructive testing; while in high-intensity ultrasound applications, the intent is to permanently change the physical properties of a system (B. Liu \& Koc, 2012).

The ultrasonic blade vibrates its blade with microscopic amplitude in the longitudinal direction with high frequency. As a result of this type of movement, the ultrasonic cutter can be used to cut difficult-to-cut materials. The schematic diagram of an ultrasonic cutting system is shown in Figure 3-7.

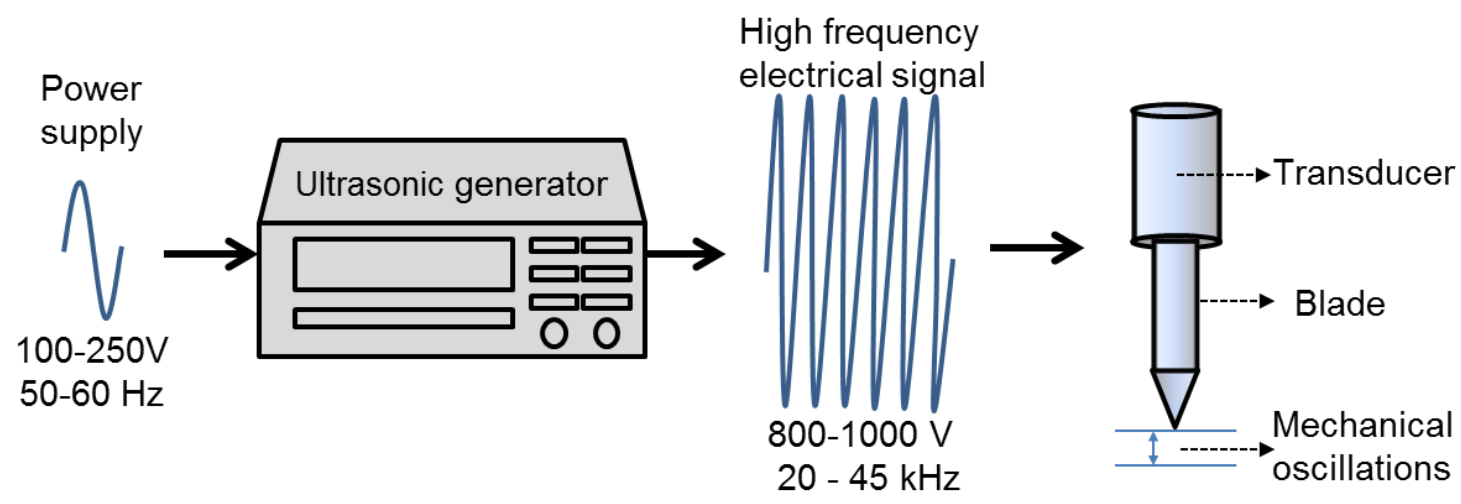

Figure 3-7. Schematic diagram of an ultrasonic cutting system. 
An ultrasonic cutter is typically composed of a power supply, an ultrasonic generator, a transducer, a booster and a specially designed blade. The ultrasonic generator converts the power supply (typically 100-250V, 50-60 Hz) into an 800-1000 V, $20 \mathrm{kHz}$ or above electrical signal. This signal is applied to a converter or transducer that converts the electrical signal into high frequency mechanical oscillations. The active elements in the transducer are usually piezoelectric ceramics. A back-block mass (reflector) might be added behind the ceramics discs to balance motions of the transducer. Electrodes or electrical contacts are used on both sides of a ceramic disk and cause it to expand and contract when voltage is applied. An optional booster connected to the transducer serves as an amplitude transformer to magnify the amplitude by its geometrical shape. The last and important part is the ultrasonic blade which contacts with the materials to be cut. Ultrasonic blades are specially designed to vibrate at their natural frequency or resonance frequency and form a defined mode shape. A typical ultrasonic blade composition diagram is shown in Figure 3-8, and the following section will illustrate how to design ultrasonic blades.

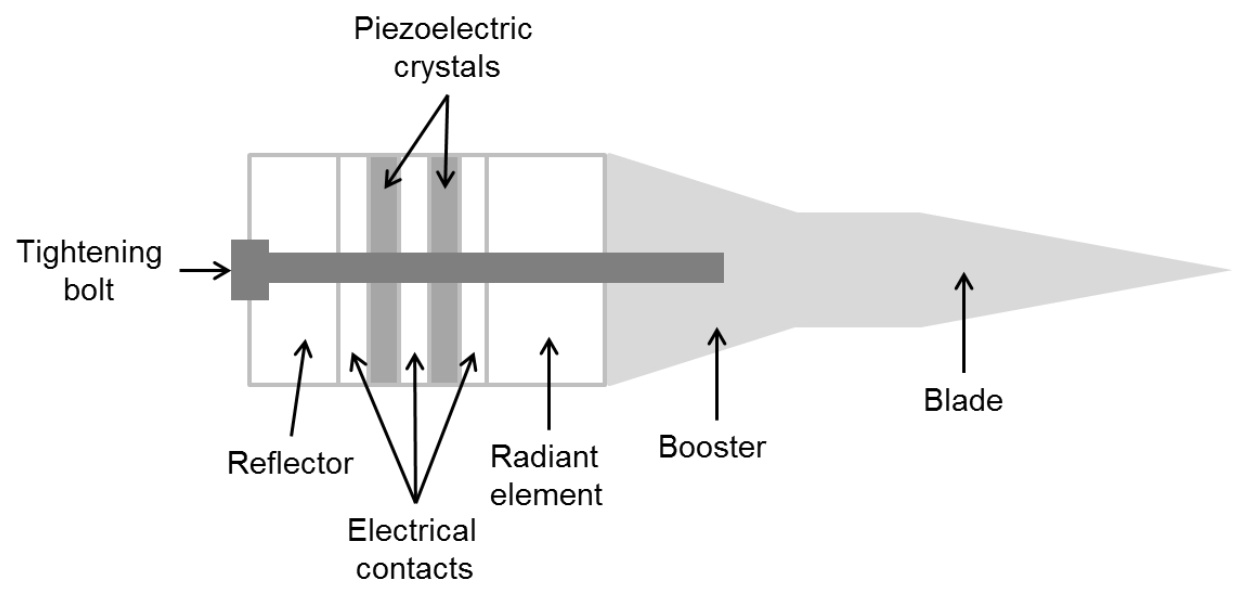

Figure 3-8. A typical ultrasonic blade composition. 


\subsubsection{Ultrasonic blade design}

The design process of three prototype ultrasonic cutting blades is presented in this section. The blades were designed as cutting tools for experimental biomass preprocessing, and they were tuned in the first longitudinal mode at a frequency of $20 \mathrm{kHz}$.

Every structure has the tendency to vibrate at a certain frequency, which is called natural or resonant frequency. Each natural frequency is associated with a geometrical shape, which is known as mode shape. When an object is excited by a dynamic load at its natural frequencies, the body undergoes large displacements and stresses, this phenomenon is known as resonance (Humar, 2012). The goal of modal analysis in ultrasonic blade design is to determine the natural mode shapes and frequencies and make sure the designed blades vibrate at their first longitudinal mode shape with the frequency of $20 \mathrm{kHz}$. In this study, finite element analysis was used to perform modal analysis and investigate the design parameters and performances.

\subsubsection{Theoretical background to blade design}

An important aspect of ultrasonic blade design is the calculation of the resonant length, which should usually be in multiples of half the wavelength of the system. The higher the frequency is, the shorter the acoustic wavelength, consequently a smaller blade will be manufactured. The traditional methods of designing an ultrasonic horn/blade are based on the equilibrium of an infinitesimal element under elastic action, inertia forces, and integration over the horn/blade length to attain resonance (Amin, Ahmed, \& Youssef, 1995). The resonance frequency of the first longitudinal vibration mode is usually selected to achieve the highest vibration amplitude. Merkulov (1957) and Nad' (2010) provided method to calculate the resonant length for several common horn profiles. 
For an ultrasonic horn with a cylindrical bar shape, the wavelength is defined as:

$$
\begin{gathered}
L=\frac{c}{2 f} \\
c=\sqrt{\frac{E}{\rho}}
\end{gathered}
$$

For an ultrasonic horn with an exponential shape, the wavelength is defined as:

$$
L=\frac{C}{f} \sqrt{1+\left(\ln \frac{N}{2 \pi}\right)^{2}}
$$

For an ultrasonic horn with a stepped shape, the wavelength is defined as:

$$
L=K_{1} \frac{c}{4 f}+K_{2} \frac{c}{4 f}
$$

where $c$ is the acoustic speed, $E$ is Young's modulus, $f$ is the desired natural frequency, $\rho$ horn material density, $\mathrm{N}$ is the diameter radio, $K_{1}, K_{2}$ can be assumed to be unity. In general, the half wavelength blades/horns are commonly used in ultrasonic applications. Half wavelength blades were adopted and designed in this research.

\subsubsection{Theoretical background to blade modal analysis}

Finite element analysis programs are usually used to design and identify the longitudinal mode and the resonant frequency. The modal analysis can be used to calculate the undamped natural modes of the designed ultrasonic blades. The generalized equation of motion for the blades can be described by the following equation (Clough, W., \& Penzien, 1993) :

$$
[M]\{\ddot{u}\}+[C]\{\dot{u}\}+[K]\{u\}=\{F(t)\}
$$

where $[M]$ is the mass matrix, $\ddot{u}$ is the 2nd time derivative of the displacement $u, \dot{u}$ is the velocity, $[C]$ is a damping matrix, $[K]$ is the stiffness matrix, and $[F]$ is the force 
vector. The general problem, with nonzero damping is a quadratic eigenvalue problem. For vibrational modal analysis, the damping is generally ignored and the general equation becomes:

$$
[M]\{\ddot{u}\}+[K]\{u\}=\{0\}
$$

This is the general form of the eigensystem encountered in structural engineering using the finite element analysis. To represent the free-vibration solutions of the structure' harmonic motion is assumed, so that $\dot{u}$ is taken to equal $\lambda[U]$, where $\lambda$ is an eigenvalue, and the equation reduces to:

$$
\left([K]-\omega^{2}[M]\right)\{\phi\}=\{0\}
$$

where $\{\phi\}$ is the eigenvector (mode shapes) and $\omega$ is the circular frequency. Solving eigen value problem for different blade designs can give the natural frequencies and the mode shapes (eigenvector). In order to achieve the desired blade design with longitudinal mode shape at $20 \mathrm{kHz}$ natural frequency, adjusting the shape of the blade (the mass and stiffness) and performing model analysis using resubmitting the finite element analysis. The longitudinal mode was identified to investigate whether if it was vibrating at the driving ultrasonic frequency or not until the longitudinal mode of vibration occurred at the desired driving frequency.

\subsubsection{Finite element modal analysis}

Designing an ultrasonic blade is one of the most important tasks in an ultrasonic cutting system development. The ultrasonic blade acts as an acoustic waveguide or transformer to amplify and focus the ultrasonic vibrations to the samples. The ultrasonic blade can transfer the ultrasonic mechanical vibrational energy from the transducer to the 
work pieces through direct physical contacts. It can also amplify the vibrational amplitude to provide the desired tip amplitude for the cutting process requirements. The gain (amplitude magnification ratio) of the ultrasonic blade is determined by its profile. Ultrasonic blades are generally made of metals like titanium, tool steel, stainless steel, aluminum and other metals that have high fatigue strengths and low acoustic losses. Tool steel DC53 was used to manufacture the ultrasonic blades in this study, because of its low cost, availability and decent acoustic characteristics. The mechanical properties of tool steel DC53 are shown in Table 3-1.

Another important parameter needs to be considered in the ultrasonic blade design is the amplitude uniformity. Reliable performance of the blades is normally affected by the uniformity of vibration amplitude at the contacting areas, where blade and materials tobe-cut interact. The formula to calculate the uniformity is shown in Equation 3-16.

$$
\text { Uniformity }=\left(\frac{u_{\min }}{u_{\max }}\right) \times 100
$$

Table 3-1. Tool steel DC53 material properties.

\begin{tabular}{ll}
\hline Parameters & Value \\
\hline Poisson's Ratio & 0.28 \\
Shear Modulus & $83.2 \mathrm{Gpa}$ \\
Mass Density & $7870 \mathrm{~kg} / \mathrm{m}^{3}$ \\
Tensile Strength & $2.75 \mathrm{GPa}$ \\
Young's Modulus & $2.13 \mathrm{GPa}$ \\
\hline
\end{tabular}

High amplitude uniformity is preferred because it produces uniform vibration amplitude, which prevent damage to the blades and allows the cutting system to proceed 
with a uniform rate. Because of the complexity of the ultrasonic cutting blade shape and the acceptable analysis results, it is desirable to use finite element method to perform the modal analysis. The vibration amplitude analysis of the initial blade design was obtained by performing a modal analysis, and the blade amplitude result is shown in Figure 3-9. The figure shows that the vibration amplitude on the blade tip is not uniform, and the uniformity of the blade design (5 $\mathrm{cm}$ blade with) is $74.3 \%$, and uniformity dropped quickly when the blade width reached a certain value (around $9 \mathrm{~cm}$ ). Therefore, it is obvious that uniformity becomes very low for wide blade designs, and such low uniformities are undesirable for blade life and uniform cutting rate.

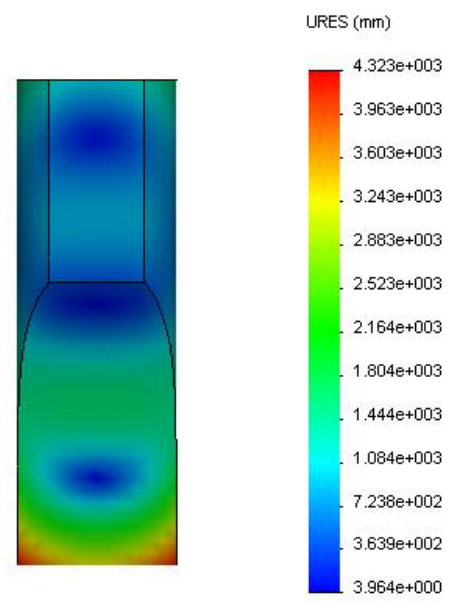

Figure 3-9. Modal analys is displacement distribution.

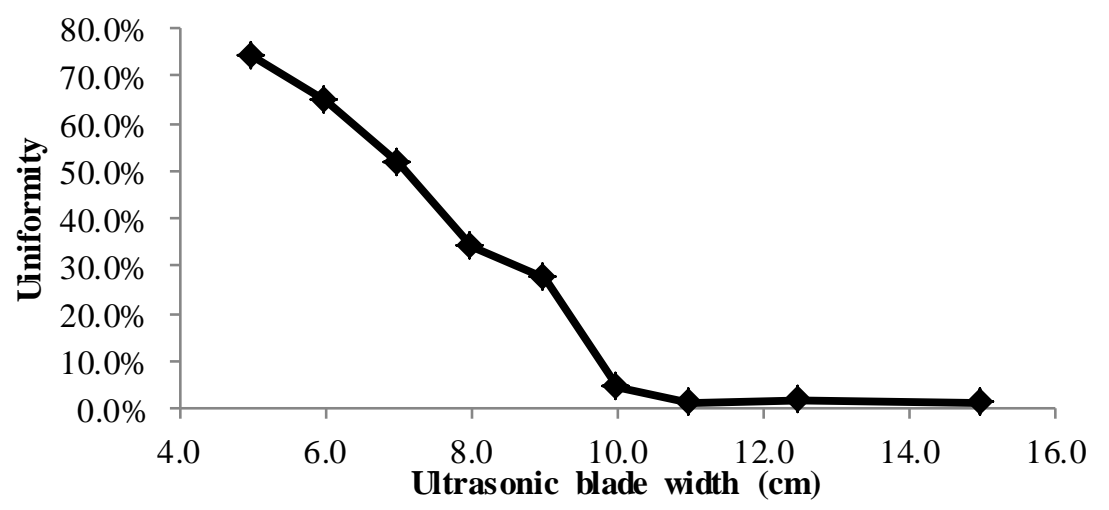

Figure 3-10. Uniformity versus blade width. 
A common method used to increase the amplitude uniformity is implementing grooves and slots (Figure 3-11) in ultrasonic blade designs (Koike, Kurosawa, Ueha, \& Adachi, 1991). In order to maximize the vibration amplitude uniformity and minimize the computational and experimental time, different slot and groove sizes were designed and analyzed systematically by finite element modal analysis. The uniformity results were analyzed by ANOVA (Analysis of variance) and the blade width of $5 \mathrm{~cm}$ was chosen.
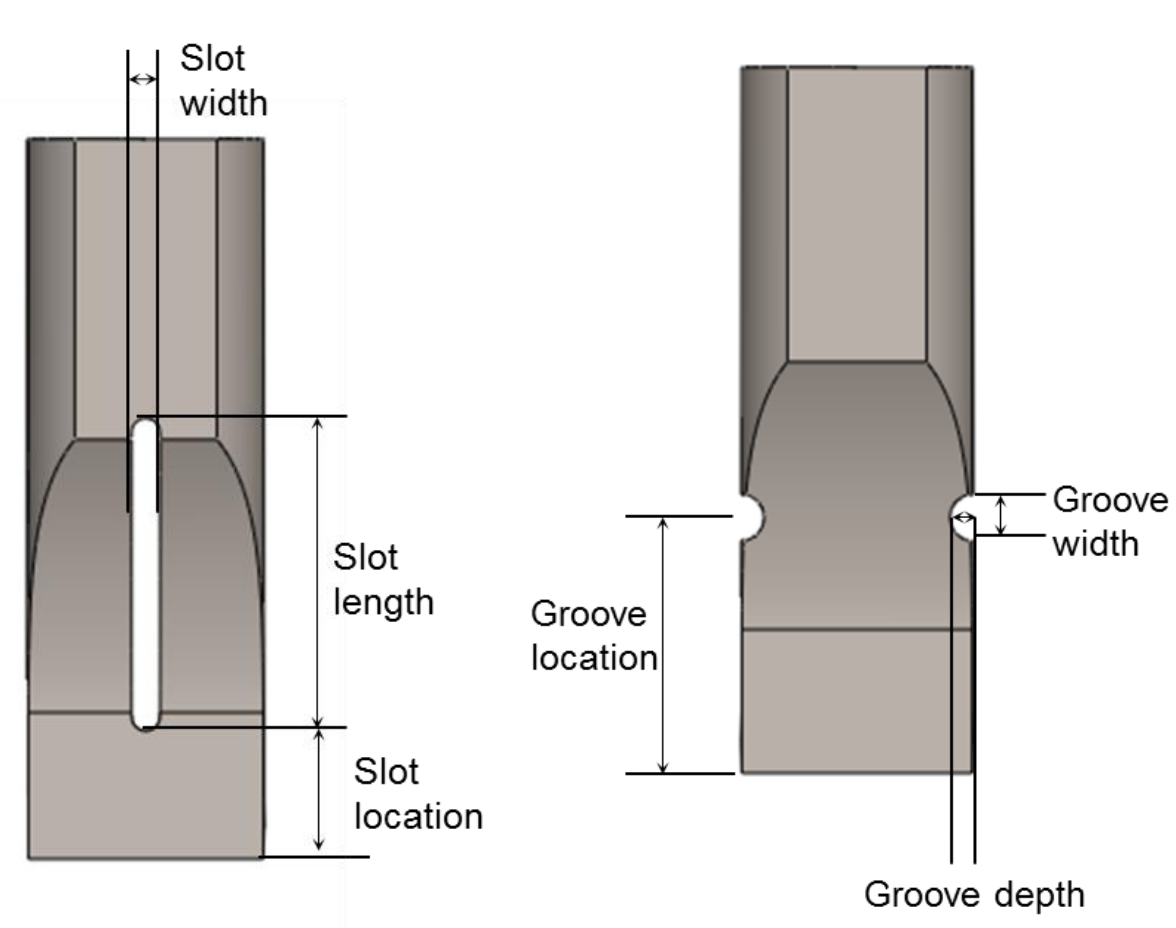

Table 3-11. Tip vibration amplitude control using a slot or groove.

The slot dimensions (length, width and location) and the groove dimensions (width, depth and location) were designed in 3 levels shown in Table 3-2 and 3-3 by using Orthogonal Array Testing Strategy (OATS) (Kacker, Lagergren, \& Filliben, 1991). The ultrasonic blade designs with different slot or groove dimensions were analyzed using the OATS. OATS is a systematic and statistical way of a black box testing technique. It is used when the number of inputs to the application under test is small but too complicated 
for an exhaustive testing (Lazic \& Mastorakis, 2008). The experimental parameter orthogonal arrays and uniformity results with slot and groove are shown in Table 3-4 and Table 3-5.

In order to investigate the most significant dimension parameters that influence the blade vibration uniformity, MINITAB was used to do ANOVA analysis. Figure 3-12 illustrates the main effects plot for means, and delta values can be calculated by subtracting the lowest mean value from the highest one. A higher delta value for a parameter indicates that it affects the results more significantly than the other parameters. The calculated delta values of the slot parameters are Slength $=0.37$, $\delta$ width $=0.26$ and $\delta l o c=0.55$. The result implies that the slot location has the most significant effect on uniformity, followed by the slot length and the slot width. Figure 3-13 shows the main effects of the means of groove parameters. The calculated delta values of the groove parameters are $\delta$ width $=0.11$, depth $=0.21, \delta l o c=0.67$, therefore, groove location has the most significant influence on amplitude uniformity, followed by groove depth and width.

Table 3-2. Slot control parameters.

\begin{tabular}{lccc}
\hline & Level 1 & Level 2 & Level 3 \\
\hline Slot Length & $0.01 \mathrm{~m}$ & $0.02 \mathrm{~m}$ & $0.03 \mathrm{~m}$ \\
Slot Width & $0.003 \mathrm{~m}$ & $0.006 \mathrm{~m}$ & $0.01 \mathrm{~m}$ \\
Slot Location (from tip) & $0.07 \mathrm{~m}$ & $0.05 \mathrm{~m}$ & $0.02 \mathrm{~m}$ \\
\hline
\end{tabular}


Table 3-3. Groove control parameters.

\begin{tabular}{lccc}
\hline Design parameters & Level 1 & Level 2 & Level 3 \\
\hline Groove Width & $0.005 \mathrm{~m}$ & $0.01 \mathrm{~m}$ & $0.015 \mathrm{~m}$ \\
Groove Depth & $0.01 \mathrm{~m}$ & $0.03 \mathrm{~m}$ & $0.06 \mathrm{~m}$ \\
Groove Location (from tip) & $0.07 \mathrm{~m}$ & $0.05 \mathrm{~m}$ & $0.02 \mathrm{~m}$ \\
\hline
\end{tabular}

Table 3-4. Orthogonal array slot design matrix

\begin{tabular}{ccccc}
\hline Experiment No. & Slot Length & Slot Width & Slot Location & Uniformity \\
\hline 1 & Level 1 & Level 1 & Level 1 & $94.1 \%$ \\
2 & Level 1 & Level 2 & Level 2 & $94.3 \%$ \\
3 & Level 1 & Level 3 & Level 3 & $61.8 \%$ \\
4 & Level 2 & Level 1 & Level 2 & $93.9 \%$ \\
5 & Level 2 & Level 2 & Level 3 & $9.0 \%$ \\
7 & Level 2 & Level 3 & Level 1 & $86.6 \%$ \\
7 & Level 3 & Level 1 & Level 3 & $40.8 \%$ \\
9 & Level 3 & Level 2 & Level 1 & $94.8 \%$ \\
& Level 3 & Level 3 & Level 2 & $3.0 \%$ \\
\hline
\end{tabular}


Table 3-5. Orthogonal array groove design matrix.

\begin{tabular}{ccccc}
\hline Experiment No. & Groove Width & Groove Depth & Groove Location & Uniformity \\
\hline 1 & Level 1 & Level 1 & Level 1 & $74.1 \%$ \\
2 & Level 1 & Level 2 & Level 2 & $43.3 \%$ \\
3 & Level 1 & Level 3 & Level 3 & $55.3 \%$ \\
4 & Level 2 & Level 1 & Level 2 & $92.7 \%$ \\
5 & Level 2 & Level 2 & Level 3 & $7.1 \%$ \\
7 & Level 2 & Level 3 & Level 1 & $95.2 \%$ \\
8 & Level 3 & Level 1 & Level 3 & $3.8 \%$ \\
9 & Level 3 & Level 2 & Level 1 & $96.7 \%$ \\
& Level 3 & Level 3 & Level 2 & $61.2 \%$ \\
\hline
\end{tabular}

Figures 3-14 and 3-15 show the interaction plots for parameters such as slot length, width, and location. An interactions plot is a plot of means for each level of a factor with the level of a second factor held constant. Interaction is present when the response at a factor level depends upon the levels of other factors. Parallel lines in an interactions plot indicate no interaction. The greater the departure of the lines from the parallel state, the higher the degree of interaction. This plot shows apparent interaction because the lines are not parallel, implying that optimal levels of each parameter can be obtained. Because the uniformity is influenced most significantly by the slot location and groove location, it appears that the uniformity can be optimized by adjusting the slot location or the groove location. 
Mean Effects Plot for Uniformity

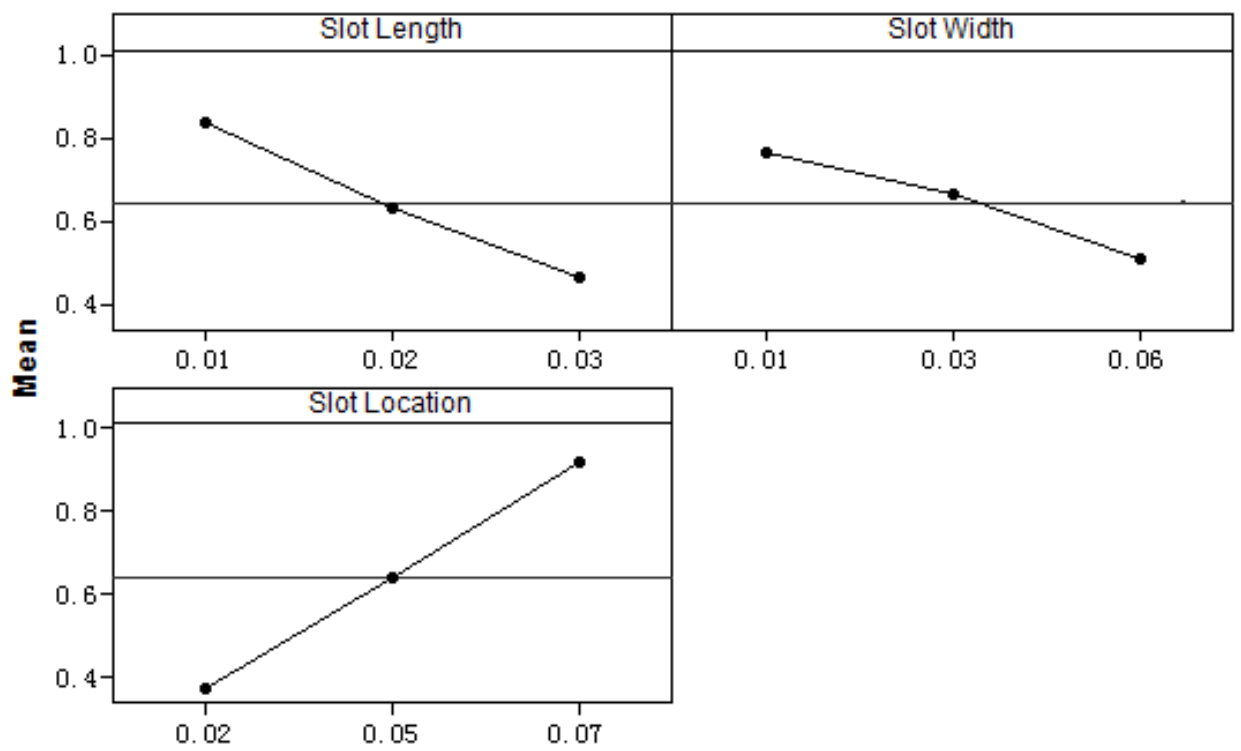

Figure 3-12. Main effect plots for means of slot parameters.

Main Effects Plot for Uniformity

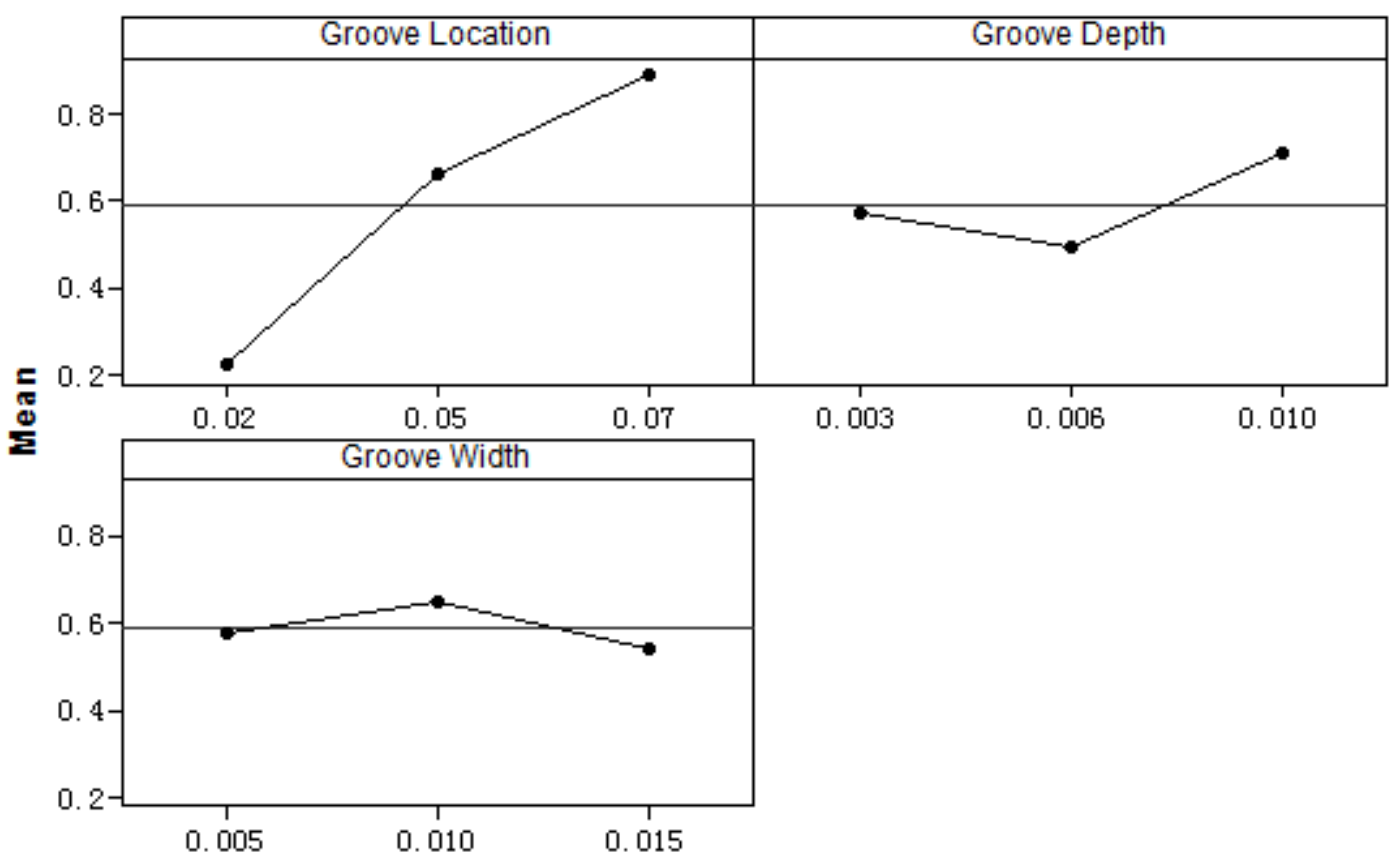

Figure 3-13. Main effect plots for means of groove parameters. 


\section{Interaction Plot for Uniformity}

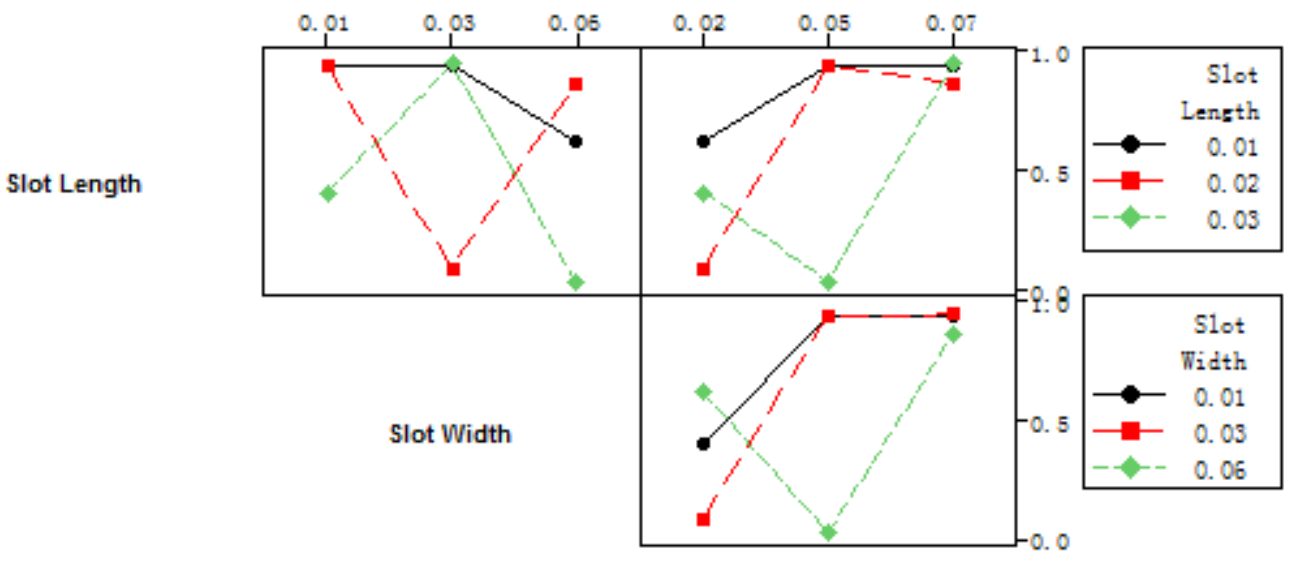

Slot Location

Figure 3-14. Interaction plots for means of slot parameters.

\section{Interaction Plot for Uniformity}

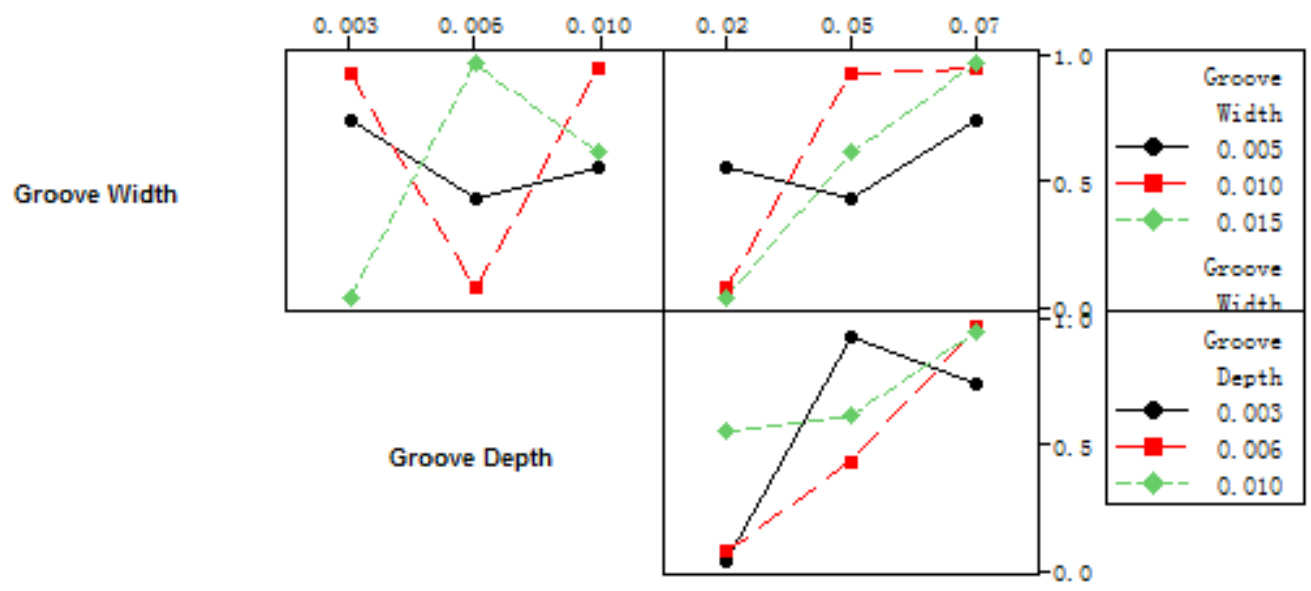

Groove Location

Figure 3-15. Interaction plots for means of groove parameters.

\subsubsection{Blade design and manufacturing}

As simulation results showed in the previous section, the amplitude uniformity of the ultrasonic blade can be decreased by increasing the blade width, and adding slots or groves in the blade design can improve the uniformity. In the design process of the 
ultrasonic blade, adopting slots into blade designs were used. The first designed blade is shown in Figure 3-16. The longitudinal mode shape was mode 7, the natural frequency was $19738 \mathrm{~Hz}$, and the uniformity was $99.4 \%$.
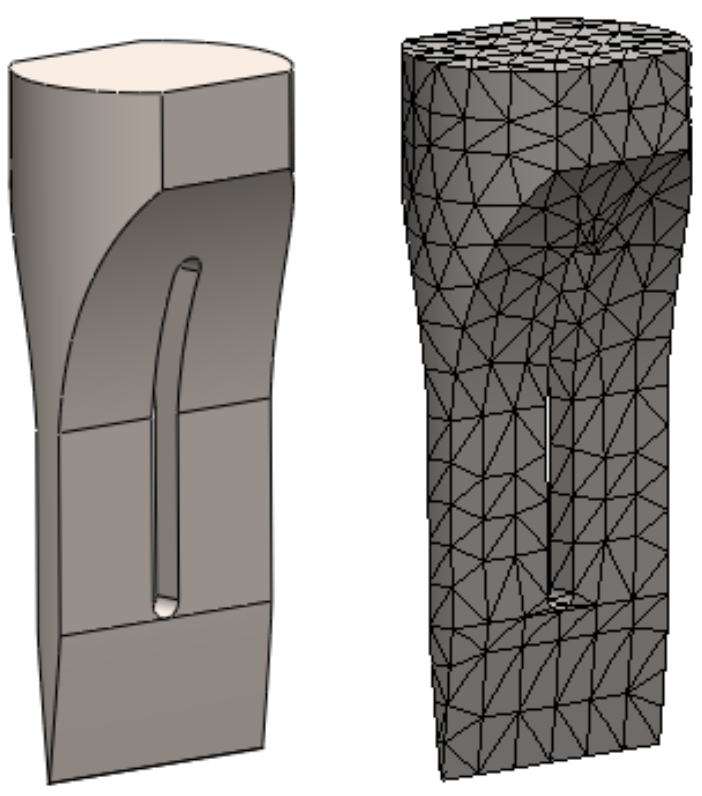

Figure 3-16. First ultrasonic blade design: (a) blade design and (b) finite element mesh.

Table 3-6. Model shapes and natural frequencies of the first design.

\begin{tabular}{|c|c|c|c|}
\hline Mode shape 1 & Mode shape 2 & \\
$13130 \mathrm{~Hz}$ & & $13782 \mathrm{~Hz}$ & \\
\hline Mode shape 3 & & Mode shape 4 & \\
\hline $15144 \mathrm{~Hz}$ & & $15555 \mathrm{~Hz}$ & \\
\hline
\end{tabular}




\begin{tabular}{|c|c|c|c|}
\hline Mode shape 5 & & Mode shape 6 \\
\hline $16865 \mathrm{~Hz}$ & & & \\
\hline Mode shape 7 & & & \\
\hline $19738 \mathrm{~Hz}$ & & $22170 \mathrm{~Hz}$ & \\
\hline Mode shape 9 & & & \\
\hline
\end{tabular}

The second designed blade is shown in Figure 3-17. The designed longitudinal mode shape was made 7, and the natural frequency was $20125 \mathrm{~Hz}$, and the uniformity was $99.2 \%$. 

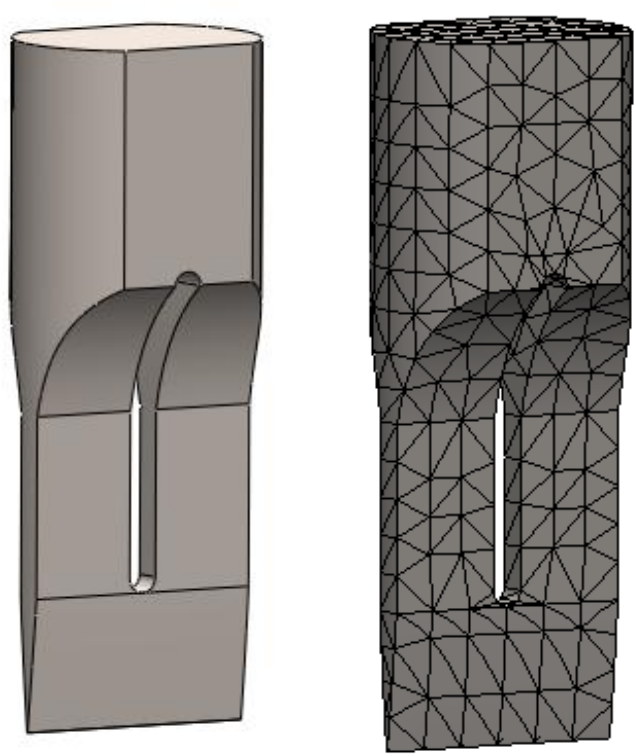

Figure 3-17. Second ultrasonic blade design: (a) blade design and (b) finite element mesh.

Table 3-7. Model shapes and natural frequencies of the second design.

\begin{tabular}{|l|l|l|l|}
\hline Mode shape 1 & Mode shape 2 \\
\hline $13525 \mathrm{~Hz}$ & & & \\
\hline Mode shape 3 & & Mode shape 4 & \\
\hline
\end{tabular}




\begin{tabular}{|l|l|l|l|}
\hline Mode shape 5 & & & Mode shape 6 \\
\hline $18050 \mathrm{~Hz}$ & & $19065 \mathrm{~Hz}$ & \\
\hline Mode shape 7 & & Mode shape 8 & \\
\hline $20125 \mathrm{~Hz}$ & & $23195 \mathrm{~Hz}$ & \\
\hline Mode shape 9 & & & \\
\hline
\end{tabular}

The second designed blade is shown in Figure 3-18. The designed longitudinal mode shape is mode 7, the natural frequency was $19951 \mathrm{~Hz}$, and the uniformity was $99.7 \%$. 

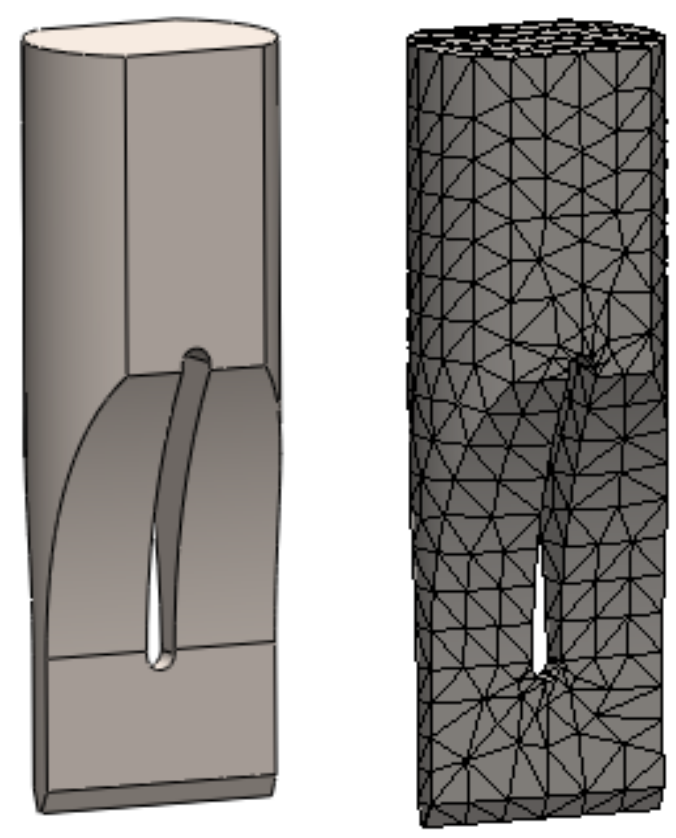

Figure 3-18. Third ultrasonic blade design: (a) blade design and (b) finite element mesh.

Table 3-8. Model shapes and natural frequencies of the third design

\begin{tabular}{|l|l|l|l|}
\hline Mode shape 1 & & Mode shape 2 \\
\hline $11716 \mathrm{~Hz}$ & & $13757 \mathrm{~Hz}$ & \\
\hline Mode shape 3 & & Mode shape 4 & \\
\hline
\end{tabular}




\begin{tabular}{|l|l|l|l|}
\hline Mode shape 5 & Mode shape 6 \\
\hline $17560 \mathrm{~Hz}$ & $19862 \mathrm{~Hz}$ & \\
\hline Mode shape 7 & & & \\
\hline $19951 \mathrm{~Hz}$ & & & \\
\hline Mode shape 9 & & & \\
\hline
\end{tabular}

The third designed blade is shown in Figure 3-18. The designed longitudinal mode shape was made 7, and the natural frequency was $19951 \mathrm{~Hz}$, and the uniformity was $99.3 \%$.

\subsubsection{Experimental modal analysis of blade}

After the modal analysis of blades, it is necessary to test them and verify its natural frequencies and mode shapes. This process is called an experimental modal analysis. Laser scanning vibrometer is typically used for verifying the ultrasonic blade designs and troubleshooting the designed blades, because this method provides an unambiguous 
phase reference, precise measurement data without mass interference problems and a high spatial resolution for finite element method correlations. The results of the experimental modal analysis were used to calibrate the built blades.

The experimental model analysis equipment used in this study consists of an ultrasonic generator that produces a sinusoidal excitation signal, a transducer that converts the amplified electrical signal to mechanical vibration through the piezoelectric effect, a tuned ultrasonic cutting blade excited by vibration supplied from the transducer, a non-contact Polytec PSV-200 scanning laser vibrometer system to measure the response of the system and a data acquisition system and modal analysis software to capture the measured data and interpret the experimental data using Fast Fourier Transform (FFT) analysis respectively.

The non-contact laser vibrometer can detect the instantaneous velocity of the blade surface. The measurement is deduced by shining a direct laser beam at a target on the structure and measuring the Doppler shifted wavelength of the reflected beam by using an interferometer. A reflective surface on the target is usually needed to accurately measurement the reflection signals. The wavelength of the reflected light is different from the wavelength of the incident beam, when the ultrasonic blades vibrate, and this phenomenon is called Doppler shift. If the wavelength of the incident light is known, then the velocity of the object can be determined from the change in wavelength of the reflected light. When the measurement signals are gathered at various target locations on the blades by the response measuring devices, the data is processed using a spectrum analyzer to extract the natural frequencies and mode shapes of the system. Fourier transforms convert response signals from the measurement devices in the time domain to 
spectral properties in the frequency domain using digital Fourier transform (DFT) analysis. A schematic diagram of the experimental testing configuration is shown in Figure 3-19.

Three different ultrasonic blades were designed and the blade tip velocity and frequency of the designed blades were measured to verify the FEA design. The three designed ultrasonic cutting blades were manufactured accurately by using precision engineering equipment and further tuned based on the experimental modal analysis results. The manufactured blades were shown in Figure 3-20. The measurement was captured in the time domain and then converted to the frequency domain using FFT algorithm. The data processing software interface is shown in Figure 3-21. In the analysis, the bandwidth was $50 \mathrm{kHz}$, FFT lines were 6400 and the frequency resolution was $7.812 \mathrm{~Hz}$. The vibration speed amplitude of these three blades was round $0.3 \mathrm{~m} / \mathrm{s}$, vibration amplitude was $2.8 \mu \mathrm{m}$. The measured and calculated natural frequencies are listed in Table 3-9. The results showed that the designed blades were working at the desired frequency.

Table 3-9. Natural frequencies of experimental and simulation modal analysis results.

\begin{tabular}{llll}
\hline & Blade profile 1 & Blade profile 2 & Blade profile 3 \\
\hline FEA modal analysis & $19738 \mathrm{~Hz}$ & $20125 \mathrm{~Hz}$ & $19951 \mathrm{~Hz}$ \\
Experimental modal analysis & Mean :19551 Hz & Mean: $19912 \mathrm{~Hz}$ & Mean: $20201 \mathrm{~Hz}$ \\
(3 experiments for each blade) & Std.: $34.5 \mathrm{~Hz}$ & Std.: $47.5 \mathrm{~Hz}$ & Std.: $42.1 \mathrm{~Hz}$ \\
\hline
\end{tabular}




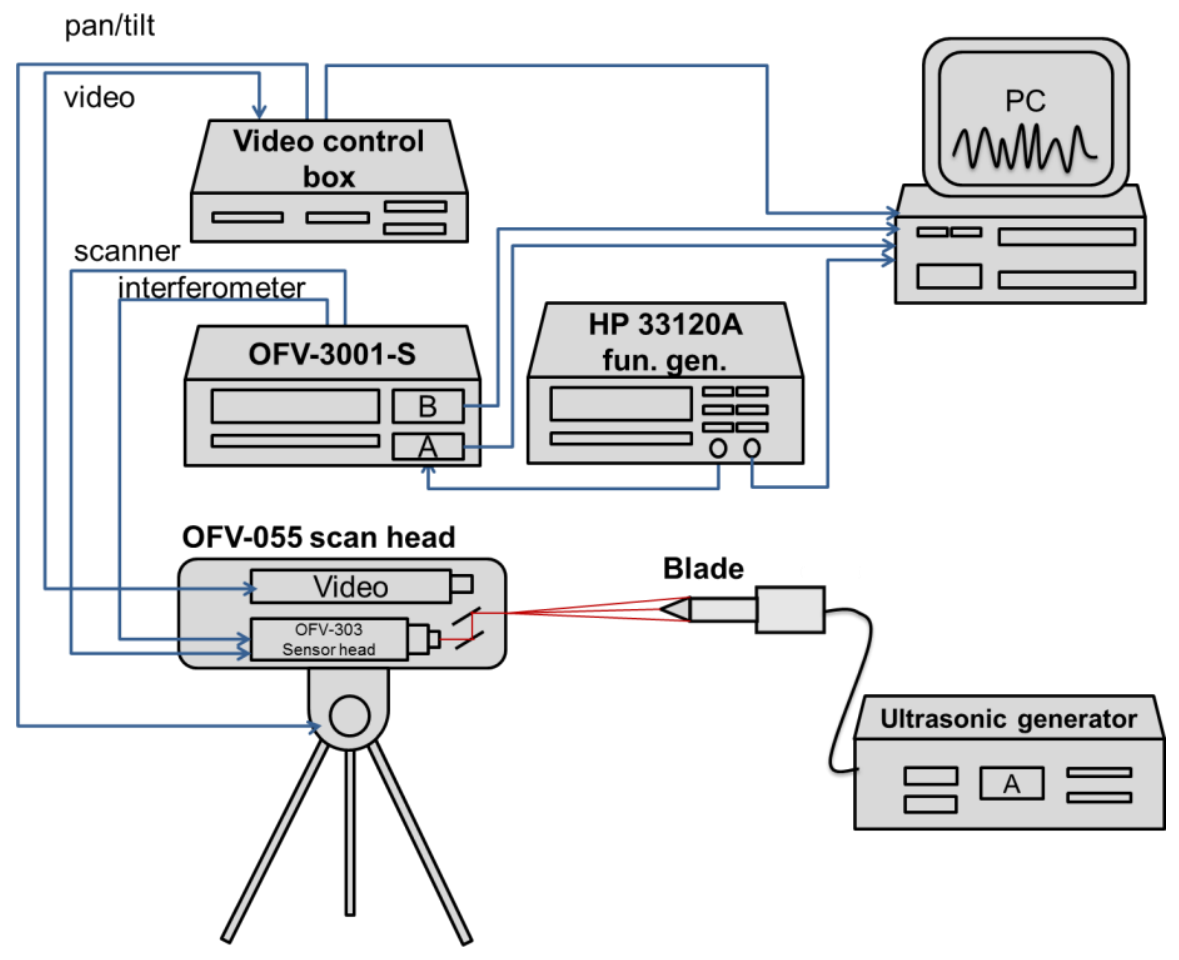

Figure 3-19. Polytec PSV-200 scanning laser vibrometer.

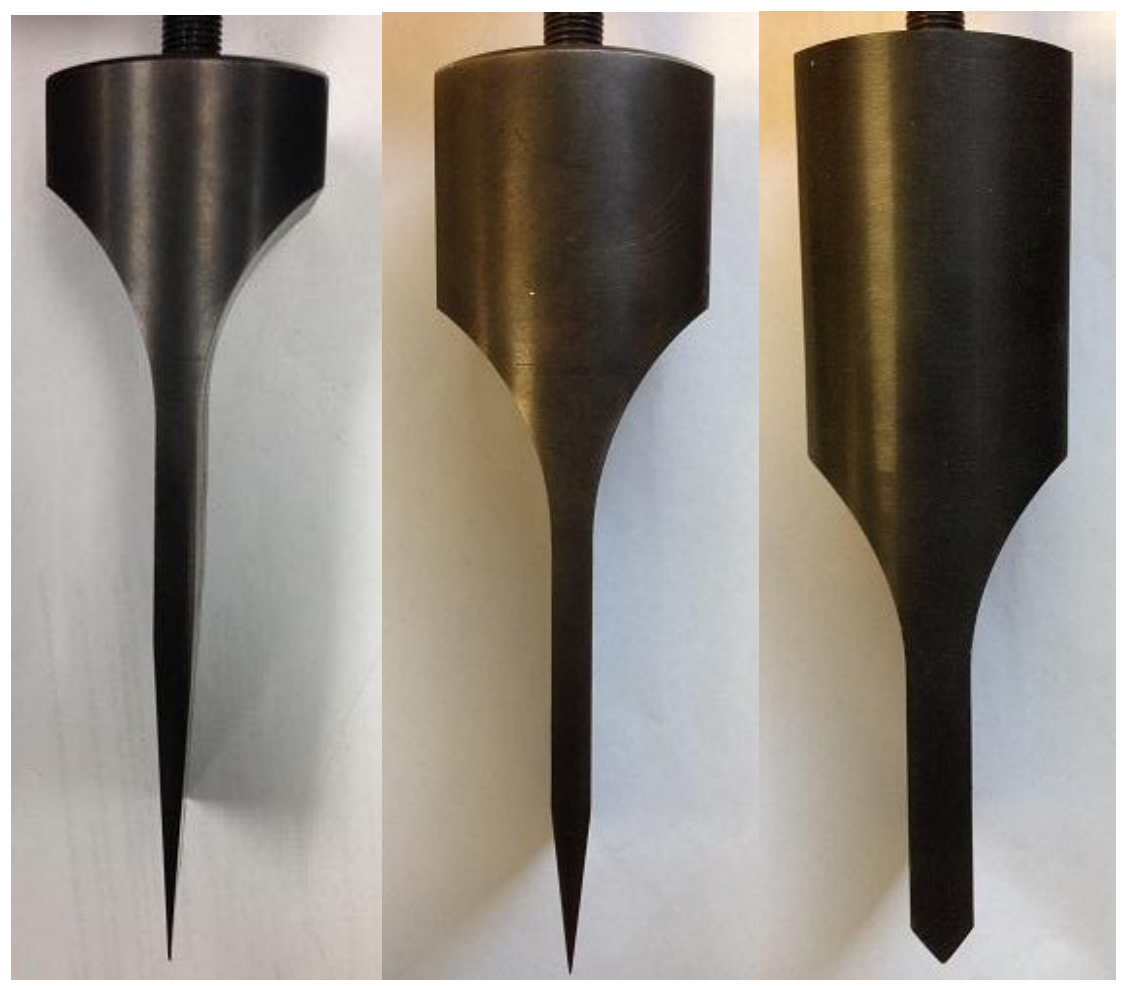

Figure 3-20. Manufactured blades: (a) first design (b) second design and (c) third design. 


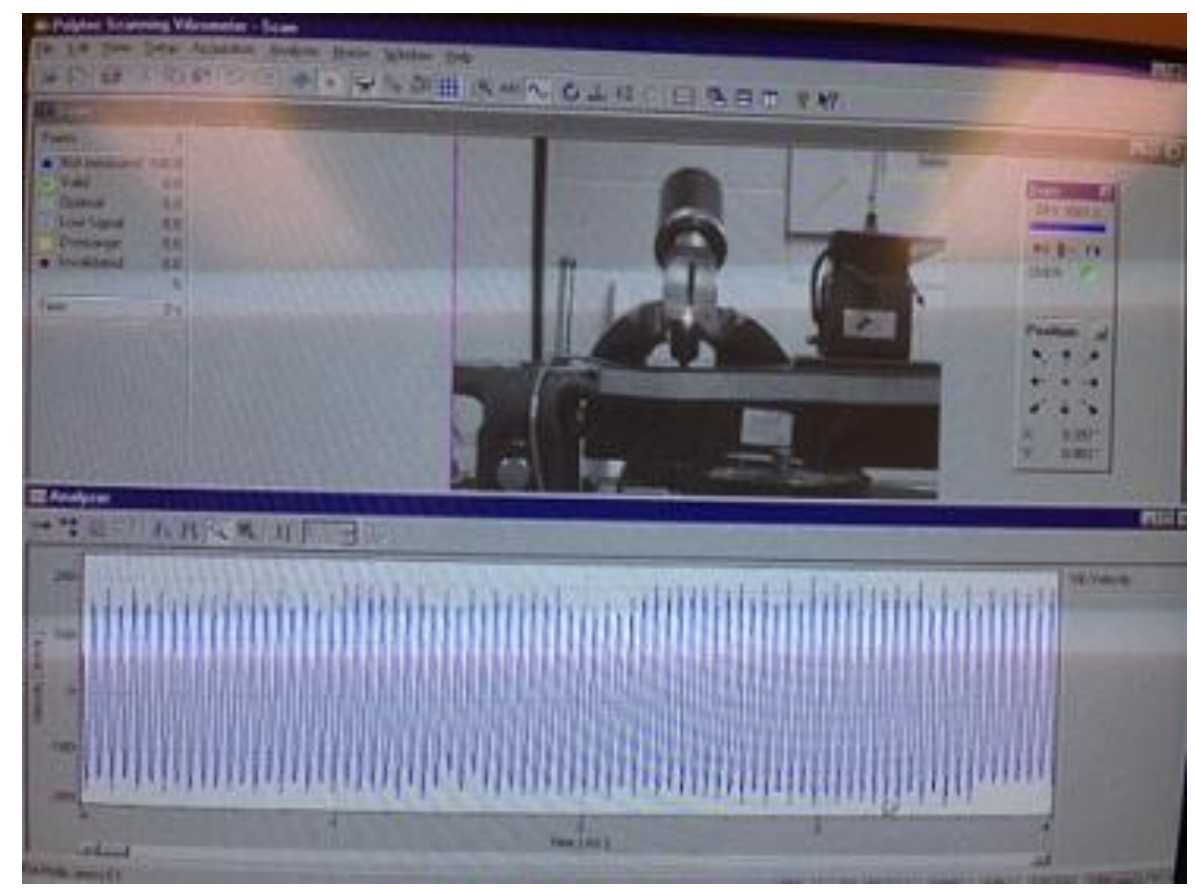

3-21. Polytec PSV-200 scanning laser vibrometer software.

\subsection{Summary}

The finite element analysis was conducted to investigate the blade dynamic parameters and its structural behaviors. Three prototypes were manufactured and experimentally tested by experimental modal analysis. The experimental modal analysis can provide the actual modal behaviors of the designed blades and cutting experiments can be conducted to investigate the overall performances.

An important aspect of blade design is the calculation of the correct resonant length, which should usually be in multiples of half the wavelength of the system. The higher the frequency is, the shorter the acoustic wavelength gets, and consequently a smaller horn is obtained. The gain of the ultrasonic horn is determined by its profile. The amplitude at the ultrasonic blades must be sufficiently uniform to avoid damaging the cutting system and prevent heating. Grooves and slots were utilized for the blade design to achieve high uniformity. The uniformity was found to be influenced significantly by the groove depth 
and slot width. The analysis and experimental work conducted have demonstrated that the blade was operating efficiently at the desired frequency. 


\section{CHAPTER 4 FINITE ELEMENT ANALYSIS OF BIOMASS MECHANICAL PRE-PROCESSING}

\subsection{Introduction}

Ultrasonic assisted cutting has been an established technology to process many difficult-to-cut materials, such as metals, bones and woods. The design of ultrasonic cutting tools is based on the tuning of a single blade or multiple blade system to a desired ultrasonic frequency, followed by trials and adaptations of the design to achieve the acceptable performances. Finite element analysis has been extensively used to simulate conventional cutting/grinding processes; however simulations of ultrasonic-assisted cutting processes are very limited. Finite element analysis is used to design ultrasonic tools and simulate the biomass cutting processes, because it can eliminate the manufacturing of repeated and modified tools, predict optimum cutting parameters, allow novel blade designs to be proposed and help researchers to further understand blade and material interactions during the cutting processes. Numerical simulation models of ultrasonic cutting are demonstrated in this chapter. A description of the ultrasonic and conventional cutting model with cutting tool and product interaction at the cut site is simulated. In addition, detailed simulation methods and techniques are provided. The simulation models offered an opportunity to conduct a parametric study of the effects of blade profile, ultrasonic amplitude, cutting angle and cutting speed as an integral part of the cutting tool design process.

\subsection{Literature review}

Reduction of cutting forces and uniform size distribution are important goals for wood and biomass cutting processes. However, few studies have been done in this area. 
K. Kato (1971) studied the application of ultrasonic vibrations with cutting tools in two vibration directions: longitudinal vibration and lateral vibration. The research results showed that ultrasonic cutting led to lower cutting forces and improved the quality of the machined surfaces compared to the conventional cutting method, and chips formed during cutting were affected by ultrasonic vibrations. Sinn, Zettl, Mayer, and StanzlTschegg (2005) investigated ultrasonic-assisted cutting experiments on two wood species, spruce and beech in dry and wet states. Conclusions were made that compared to conventional cutting, reduction of cutting forces in the order of $50 \%$ is achieved at relatively small vibration amplitudes of $8 \mu \mathrm{m}$, and reduced friction forces was caused by ultrasonic vibration of the cutting knife. Zhang et al. (2011) experimentally investigated the ultrasonic vibration-assisted pelleting of cellulosic feedstocks, and explored the effects of ultrasonic vibration, moisture content, and particle size on pellet density, stability, durability, pelleting force, and yield of biofuel conversion in ultrasonic-assisted pelleting. The research showed that ultrasonic vibration-assisted pelleting increased the density of cellulosic feedstocks and the yield of biofuel conversion.

Ultrasonic assisted cutting technique has been applied in many areas, such food processing, biological materials cutting and metal machine. Lucas, MacBeath, McCulloch, and Cardoni (2006) created finite element models for ultrasonic cutting of single layer and multi-layer material. The models were proposed to represent ultrasonic cutting of three different materials using specimens of cheese, polyurethane foam and epoxy resin, and enabled ultrasonic cutting systems to be designed for applications both in the field of food processing and surgical procedures. The study incorporated an estimation of the friction condition between the cutting blade and the material to be cut 
and allowed adjustment of the frequency, cutting amplitude and cutting speed. The experimental and simulation results showed that the finite element models were able to adjust the cutting parameters, such as frequency and blade tip amplitude, to predict the excitation force or cutting speed required to cut effectively through different material layers. Yvonne Schneider et al. (2009) conducted model experiments to analyze friction between flanks of a cutting tool and the food material to be cut, and ultrasonic amplitude and the texture of the contacting food surface on friction force were investigated. The research showed that ultrasonic vibration significantly reduced the sliding friction force; the amplitude showed no influence within the tested range; the texture of the contact surface of the food affected the intensity of ultrasonic transportation effects. Muhammad, Ahmed, Roy, and Silberschmidt (2012) developed three-dimensional finite element models for both conventional and ultrasonically assisted turning techniques in MSC Marc/Mentat to investigate the effect of vibration on cutting forces in a cutting region for various cutting conditions. The simulation and the experimental results demonstrated that the finite element analysis was able to predict the ultrasonic cutting processes.

\subsection{Finite element analysis}

Finite element analysis is a method to analyze an object and calculate how the applied stresses will affect the object or design. The finite element analysis is done by generating a mesh of points in the shape of the object that contains information about the material or the object at each point for analysis (Mobley, Carroll, \& Canann, 1998). Because of the complicated nature of biomass cutting processes, a complete finite element simulation procedure for biomass cutting simulation involves many components. The purpose of this section is to discuss the modeling method in the commercial code 
ABAQUS to simulate the biomass ultrasonic and conventional cutting processes. The finite element model uses the explicit solver and the element deletion option, and the model represents the biomass cutting process (shown in Figure 4-1).

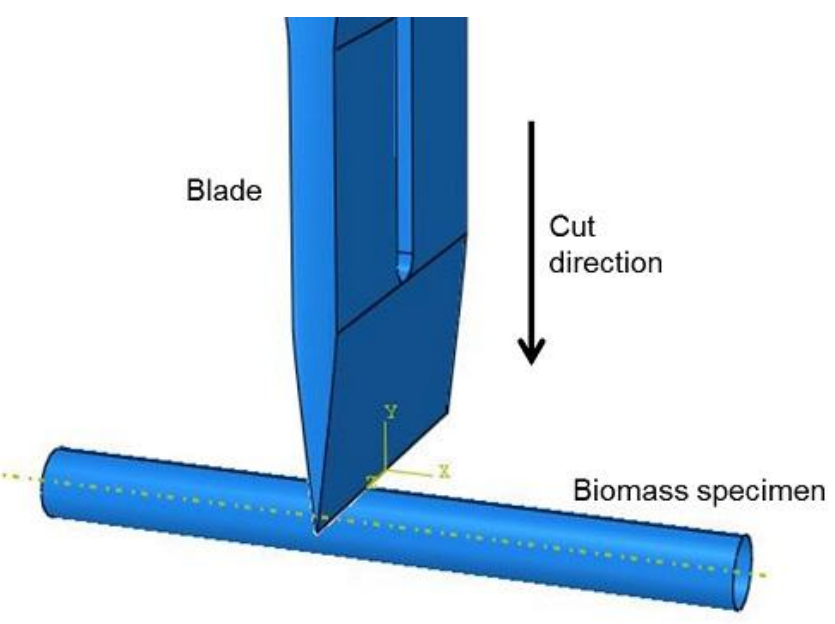

Figure 4-1. Guillotine cutting configuration of biomass .

\subsubsection{Material properties}

The properties of biomass materials used in the finite element analysis simulations in this section can be found in Chapter 2. The ultrasonic vibrations of the cutting blade tips are represented in simulations using the predefined blade tip amplitude with a periodic sinusoidal waveform and the cutting speed was applied to the biomass specimens. The analysis incorporates a contact definition at the interface between the biomass specimens and the blade using a Coulomb friction model.

The biomass materials, switchgrass and miscanthus, have very complicated structures and very different properties at the same time. A cross-section area diagram of biomass stems is shown in Figure 4-2. In order to simplify the biomass stem structure, while presenting the biomass structure as close to the real biomass structure as possible in the simulations, biomass stems were treated as a composite mixture of two basic 
materials. One of them is the material (matrix) in which all other are embedded, and the other material (reinforcement) is unidirectional fiber. The mechanical properties were assumed to be orthotropic, and the soft parenchyma materials were not considered in the simulation because they were much softer and lighter compared to the epidermis rind part and the fibers.

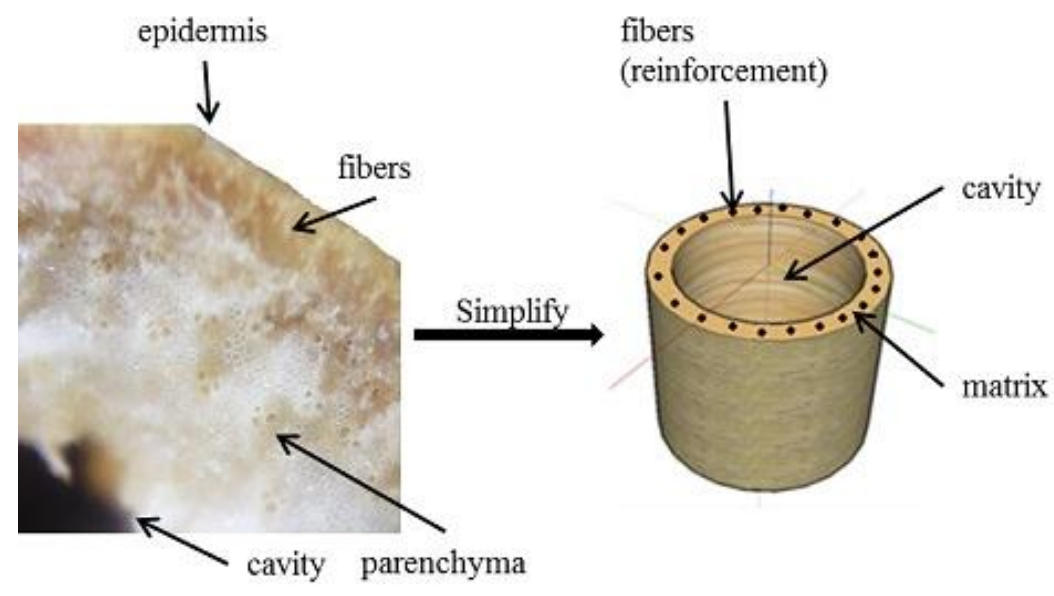

Figure 4-2. Simplified biomas s stem structure.

For the blades, tool steel DC53 was chosen as the material of the cutting blade because of its decent acoustic properties, availability and low price. The DC53 tool steel properties are provided in Table 3-1. Values for these parameters for the biomass materials can be found in Chapter 2 of this thesis. The mechanical properties of biomass allow the finite element models of ultrasonic cutting to be validated and to provide confidence in the modeling technique for conventional and ultrasonic cutting of biomass.

To develop a simulation that provides accurate response from the biomass materials, the contact characteristics for the entire assembly must be carefully defined, including all surfaces and interactions. Friction coefficients between biomass materials and blades are important parameters need to be determined for numerical analysis cutting dynamics of biomass. This section provides the process of how to determine these friction coefficients 
with different experimental settings. Specimens of switchgrass and miscanthus were moved at a constant velocity across the metal blade under an applied load and a Coulomb friction method was used to calculate the coefficients of static and dynamic frictions, $\mu_{s}$ and $\mu_{d}$. Tests were conducted with and without ultrasonic excitation of the blade.

Flat specimens cut from the samples were glues to a block of metal which was connected to the force transducer of the testing machine by a cotton fiber. Specimens were moved along the horizontal sliding surface by moving the crosshead of the universal testing machine with an upward velocity of $0.3 \mathrm{~m} / \mathrm{min}$ over a distance of $200 \mathrm{~mm}$. The normal force $F_{N}$ for each test was calculated by adding the mass of the holder and the additional load to specimen mass, and multiplying the load with the acceleration of gravity. The experimental setup diagram is shown in Figure 4-3. The tensile draw-off strength along the sliding direction represents the friction force $F_{F}$, which was used to calculate the dynamic friction coefficient $\mu_{d}$ :

$$
\mu_{d}=\frac{F_{F}}{F_{N}}
$$

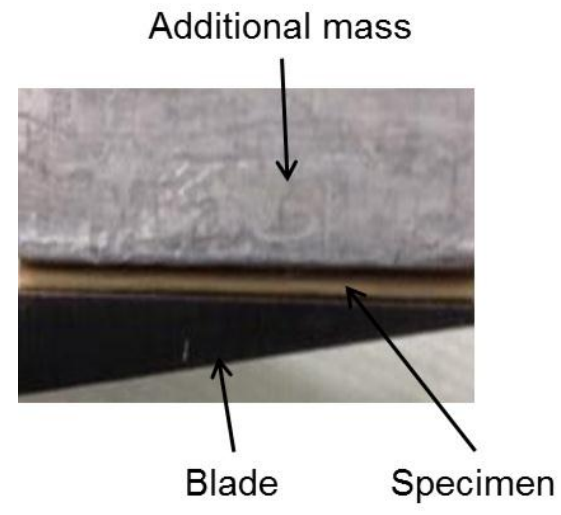

(a)

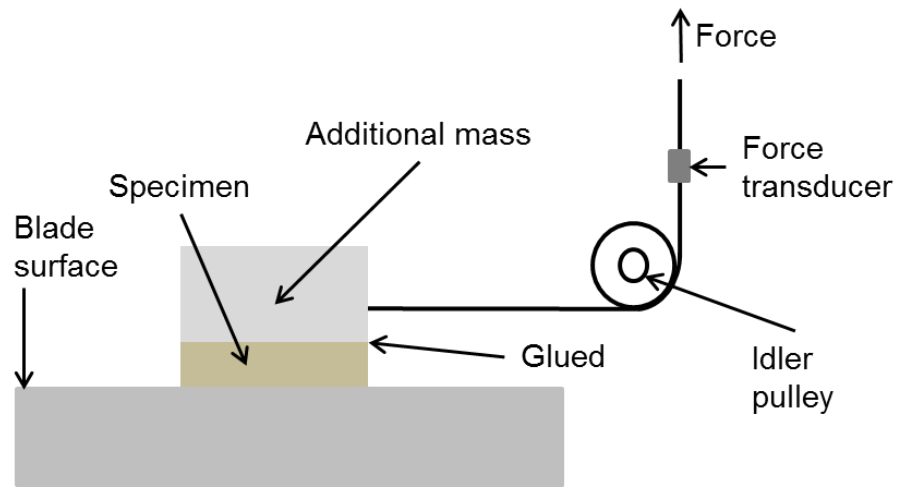

(b)

Figure 4-3. Sliding friction experiments: (a) Experiment setup and (b) Schematic diagram. 
For the calculation of $\mu_{d}$, the force data was averaged along a sliding distance of 60 mm. For each type of biomass materials, 10 individual experiments were performed with and without ultrasonic excitation. As shown in Table 4-1, the coefficients of friction were significantly affected by ultrasonic excitation for both biomass materials at two different moisture levels. The coefficients of dynamic friction with and without ultrasonic excitation of the test surface were used in the finite element model of the biomass cutting process to provide the interface boundary condition.

Table 4-1. Biomass friction coefficient with blade (DC53 steel).

\begin{tabular}{lcccc}
\hline & \multicolumn{3}{c}{ Switchgrass } & \multicolumn{2}{c}{ Miscanthus } \\
\hline Friction coefficient & $9.8 \%$ & $14.6 \%$ & $10.2 \%$ & $15.1 \%$ \\
& w.b. & w.b. & w.b. & w.b. \\
\hline$\mu_{s}$ & 0.322 & 0.353 & 0.331 & 0.349 \\
$\mu_{d}$ (without ultrasound) & 0.241 & 0.274 & 0.252 & 0.279 \\
$\mu_{d}$ (with ultrasound) & 0.025 & 0.026 & 0.023 & 0.022 \\
\hline
\end{tabular}

\subsubsection{Model creation}

Material failure means the complete loss of load carrying capacity which caused by progressive degradation of the material stiffness. Stiffness degradation is usually modeled by using damage mechanics. The biomass materials were assumed to be transversely isotropic with respect to the fiber direction (shown in Figure 4-4). Axis 1 is the axis of symmetry (fiber direction), and axes 2 and 3 which form the plane of two dimensional isotropy. 


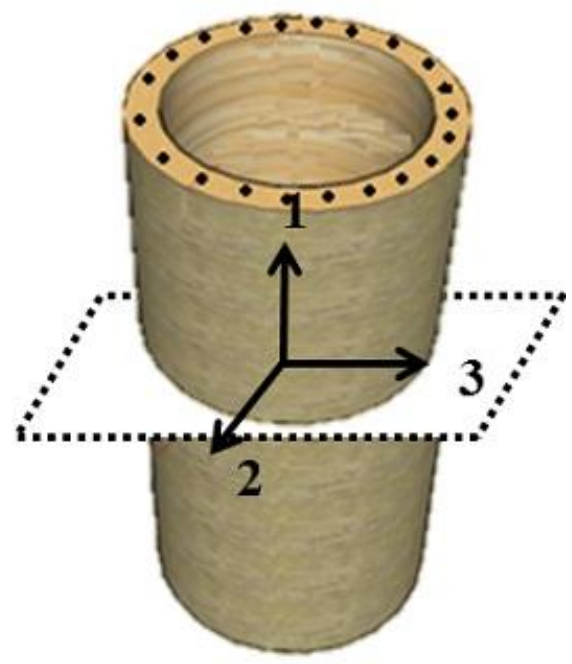

Figure 4-4. Biomass stem structure.

Given the tensile test results of switchgrass and miscanthus in Chapter 2, it is obvious that biomass stems are elastic-brittle materials at the tested moisture levels. The stress-strain response illustrated in Figure 4-5 showed distinct phases between elastic brittle materials and elastic-plastic materials.

For elastic-plastic materials (for instance, metals), the material response is initially linear elastic (A-B) followed by plastic yielding with strain hardening (B-C). When the stress is beyond point $\mathrm{C}$, a remarkable reduction of load-carrying capacity will happen until rupture $(\mathrm{C}-\mathrm{D})$. Point $\mathrm{C}$ identifies the material state at the onset of damage, and it is referred to as the damage initiation criterion. Beyond point $\mathrm{C}$, the stress-strain response $\mathrm{C}-\mathrm{D}$ is governed by the evolution of the degradation of the stiffness in the region of strain localization.

For elastic-brittle materials (for instance, glass), the material response is initially linear elastic (A'-B') followed by a remarkable reduction of load-carrying capacity until 
the rupture $\left(\mathrm{B}^{\prime}-\mathrm{C}^{\prime}\right)$, the stress-strain response $\mathrm{B}^{\prime}-\mathrm{C}^{\prime}$ is governed by the evolution of the degradation of the stiffness in the region of strain localization.

From Figure 4-6, we can see that miscanthus stems are elastic-brittle materials at the tested moisture levels. In this study, all the biomass materials being cut were represented as an elastic-brittle material model using the mechanical properties derived from experimental test data in Chapter 2. The cutting process of switchgrass and miscanthus were simulated to observe the cutting parameters and obtain guidelines for the design of the blades.

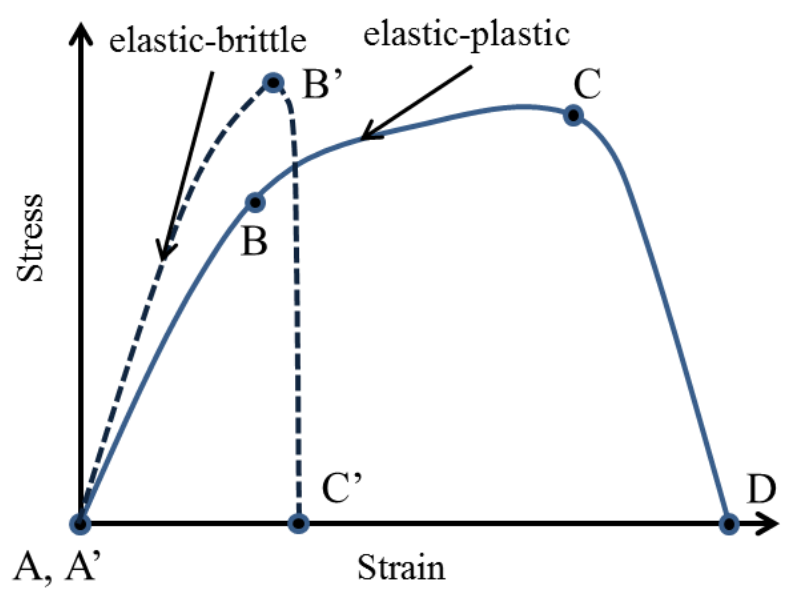

Figure 4-5. Typical uniaxial stress-strain response of brittle and ductile material.

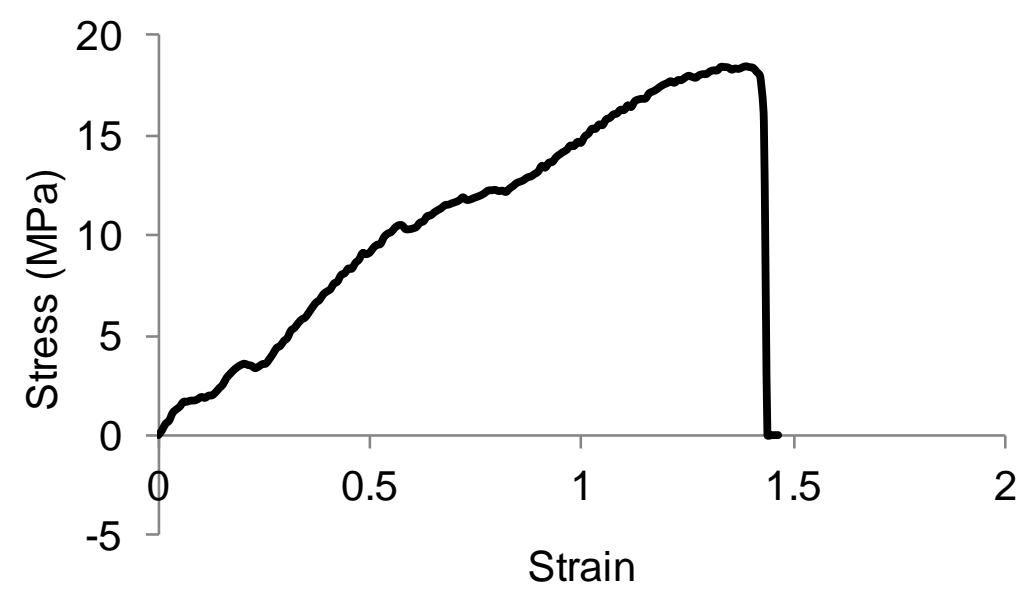

Figure 4-6. A typical tensile test of miscanthus specimen. 
In this study, Hashin's failure criteria method (Hashin, 1980) was used to simulate the failure process of biomass during shearing by the blade. The Hashin damage model predicts anisotropic damage in elastic-brittle materials. The response of the undamaged material is assumed to be linearly elastic, and the model is intended to predict the behavior of fiber-reinforced materials. The damage evolution law is based on the energy dissipated during the damage process and linear material softening. These are interacting failure criteria where more than one stress components have been used to evaluate the different failure modes. These criteria were originally developed for unidirectional polymeric composites, and applications to other types of laminates and non-polymeric composites have significant approximations.

Usually, Hashin criteria are implemented within two-dimensional classical lamination approach for point stress calculations with ply discounting as the material degradation model. Failure indices for Hashin criteria are related to the fiber and matrix failures and involve four failure modes. The criteria are extended to three dimensional problems where the maximum stress criteria are used for transverse normal stress component. Elements with a plane stress formulation (plane stress, shell, continuum shell, and membrane elements) were used for modeling. Four different modes of failure were considered: fiber rupture in tension; fiber buckling and kinking in compression; matrix cracking under transverse tension and shearing; and matrix crushing under transverse compression and shearing. Hashin failure criterion is quadratic in nature due to curve fitting but not physical reasoning of material behavior. The Hashin criterion is given by: 
Tensile fiber failure for $\sigma_{11} \geq 0$ :

$$
\left(\frac{\sigma_{11}}{X_{T}}\right)^{2}+\frac{\sigma_{12}^{2}+\sigma_{13}^{2}}{S_{12}^{2}}= \begin{cases}\geq 1 & \text { failure } \\ <1 & \text { no failure }\end{cases}
$$

Compressive fiber failure for $\sigma_{11}<0$ :

$$
\left(\frac{\sigma_{11}}{X_{C}}\right)^{2}= \begin{cases}\geq 1 & \text { failure } \\ <1 & \text { no failure }\end{cases}
$$

Tensile matrix failure for $\sigma_{22}+\sigma_{33}>0$ :

$$
\frac{\left(\sigma_{22}+\sigma_{33}\right)^{2}}{Y_{T}^{2}}+\frac{\sigma_{23}^{2}-\sigma_{22} \sigma_{33}}{S_{23}^{2}}+\frac{\sigma_{12}^{2}+\sigma_{13}^{2}}{S_{12}^{2}}= \begin{cases}\geq 1 & \text { failure } \\ <1 & \text { no failure }\end{cases}
$$

Compressive matrix failure for $\sigma_{22}+\sigma_{33}<0$ :

$$
\left[\left(\frac{Y_{C}}{2 S_{23}}\right)^{2}-1\right]\left(\frac{\sigma_{22}+\sigma_{33}}{Y_{C}}\right)+\frac{\left(\sigma_{22}+\sigma_{33}\right)^{2}}{4 S_{23}^{2}}+\frac{\sigma_{23}^{2}-\sigma_{22} \sigma_{33}}{S_{23}^{2}}+\frac{\sigma_{12}^{2}+\sigma_{13}^{2}}{S_{12}^{2}}= \begin{cases}\geq 1 & \text { failure } \\ <1 & \text { no failure }\end{cases}
$$

Interlaminar tensile failure for $\sigma_{33}>0$ :

$$
\left(\frac{\sigma_{33}}{Z_{T}}\right)^{2}= \begin{cases}\geq 1 & \text { failure } \\ <1 & \text { no failure }\end{cases}
$$

Interlaminar compression failure for $\sigma_{33}<0$ :

$$
\left(\frac{\sigma_{33}}{Z_{T}}\right)^{2}= \begin{cases}\geq 1 & \text { failure } \\ <1 & \text { no failure }\end{cases}
$$

where, $\sigma_{i j}$ denotes the stress components on $i$ surface in $j$ direction, and the tensile and compressive allowable strengths for lamina are denoted by subscripts $T$ and $C$, respectively. $X_{T}, Y_{T}$, and $Z_{T}$ denote the allowable tensile strengths in three respective material directions. Similarly, $X_{C}, Y_{C}$, and $Z_{C}$ denote the allowable compressive strengths in three respective material directions. Further, $S_{12}, S_{13}$ and $S_{23}$ denote allowable shear strengths in the respective principal material directions. 
By default, an element is removed or deleted once damage variables for all failure modes at all material points reach failure criterion, the element status will be set from 1 to 0 , and the material point stresses are reduced to zero, therefore it will not contribute to the model stiffness. When all material points of an element have been reduced to zero, the element is removed from the model mesh (Figure 4-7).

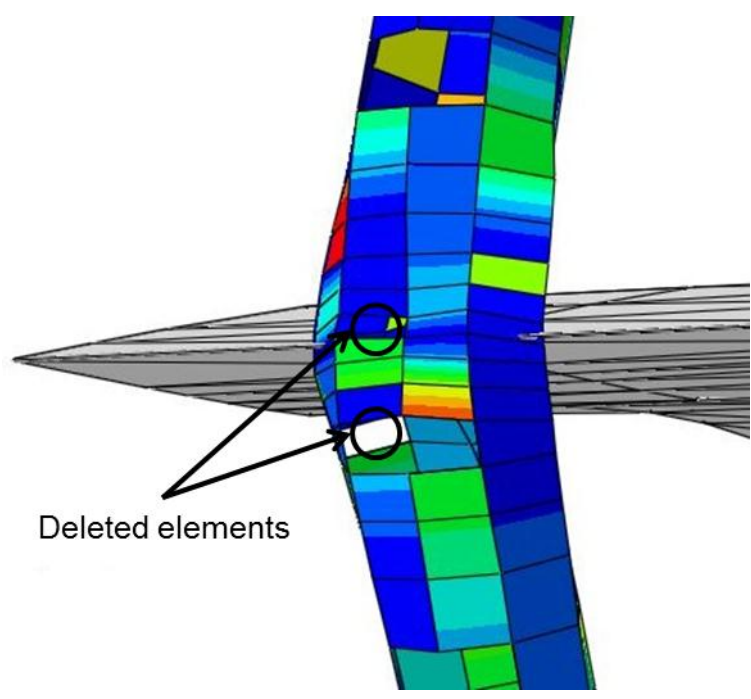

Figure 4-7. Element deletion in the model.

The simulation assembly of the cutting system is shown in Figure 4-8. The blade was modeled with C3D8R elements, and the biomass stems were assumed as a hollow cylinder and modeled using S4R elements. The ultrasonic vibration in the model was applied in the direction of blade travel, and the amplitude $u$ is defined in the form of Equation 4-8:

$$
u=A_{0}+\sum_{n-1}^{N}\left[A_{n} \cos n \omega\left(t-t_{0}\right)+B_{n} \sin n \omega\left(t-t_{0}\right)\right]
$$

where, the frequency of the vibration was set to $20 \mathrm{kHz}, A_{0}, t_{0}, N, A_{n}, B_{n}, n=1,2, \ldots N$ were user defined constants. 


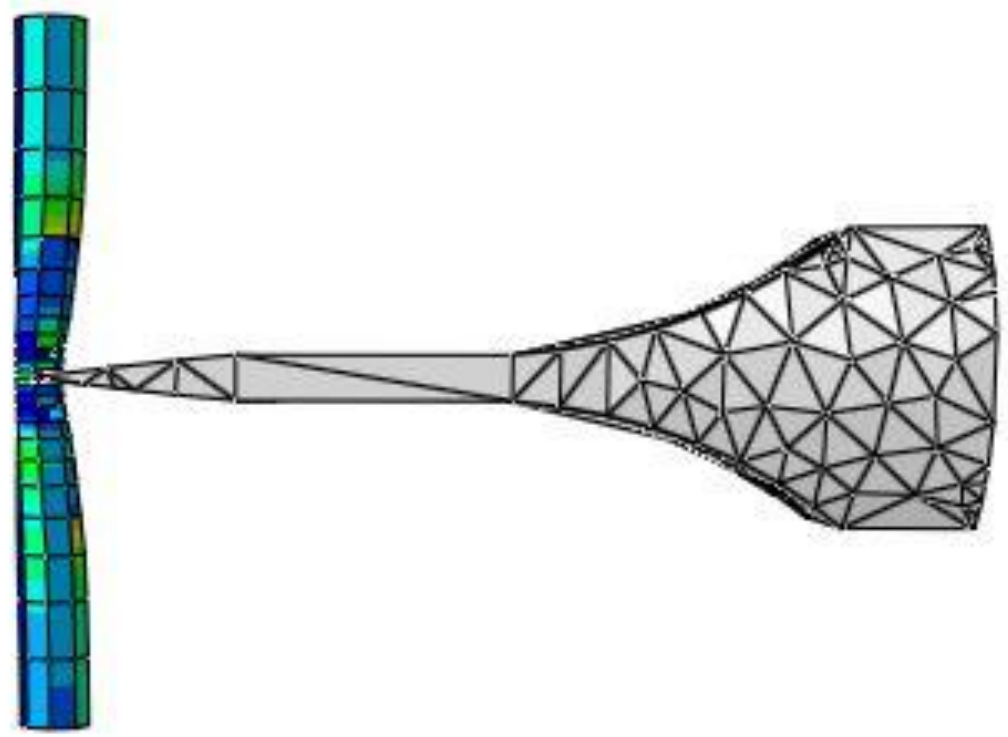

Figure 4-8. Finite element analys is model of biomass cutting.

\subsection{Summary}

Finite element analysis simulation models were demonstrated in this chapter, the theory and simulation background of the ultrasonic and conventional cutting models with cutting tool and product interactions were provided. The mechanical properties used in the models were based on the data in Chapter 2. The simulation models offered an opportunity to conduct a parametric study of the effects of blade profile, ultrasonic amplitude, shear angle and cutting speed as an integral part of the cutting tool design process. The simulations can guide the cutting system design and help modify the design before any manufacturing takes place. Numerical simulations can save design time and reduce experimental costs.

The oscillatory movement of the blade was included in the model by applying a sinusoidal oscillation at $20 \mathrm{kHz}$ at $2.4 \mu \mathrm{m}$ blade tip amplitude. The cutting speed was 
simulated in the model by applying a velocity to the biomass specimen and moving it into the oscillating blade. Frictional contact is specified between the resonant blade and the material to be cut using a Coulomb friction model. The static and dynamic coefficients of friction were experimentally determined from Coulomb friction experiments between the biomass material and the cutting blades. These parameters were determined with and without ultrasonic excitation of the block horn for incorporation into the finite element models. The work described in this chapter provides a foundation for further refinement of the modeling techniques to continue. The cutting simulation results will be provided and compared to the results of the experimental cutting experiments in the next chapter. 


\section{CHAPTER 5 EXPERIMENTAL AND FINITE ELEMENT ANALYSIS OF BIOMASS CUTTING}

\subsection{Introduction}

FEA models were developed to conduct simulations of cutting tool and biomass material interactions. The simulations allowed the cutting parameters to be derived numerically to enhance the cutting blade design and the cutting system development. The FEA models incorporated experimentally derived mechanical properties of switchgrass and miscanthus. Estimations of accurate mechanical properties of biomass for inclusion in the FEA models were determined experimentally using the materials testing techniques explained in Chapter 2. The ultrasonic cutting blades were designed using finite element analysis, and experimentally tuned and verified by using experimental modal analysis method. The experimental cutting investigations were performed on a linear cutting rig demonstrated in Chapter 3 to validate the FEA models. In order to investigate the influences of cutting parameters (cutting speed, shear angle, blade profile and ultrasonication) on cutting performances (cutting force and total cutting energy), and cutting parameters were systematically configured based on orthogonal array testing methods. After identifying the most significant cutting parameters on cutting performances, the energy consumption of the different cutting parameter configurations were analyzed in this chapter as well.

In order to investigate the cutting parameters' influences on cutting force and cutting energy, orthogonal array test method was used. The cutting control parameters are shown in Table 5.1. Blade profile, cutting speed and cutting angle had three levels and cutting method had two levels. The three prototype blades stand for the level 1 to level 3 of the 
blade profiles. Three speed levels $3 \mathrm{~mm} / \mathrm{s}, 30 \mathrm{~mm} / \mathrm{s}$ and $300 \mathrm{~mm} / \mathrm{s}$ were chosen for cutting speed. Three cutting angles included $90^{\circ}, 60^{\circ}$ and $45^{\circ}$, and the shear angle (cutting angle) was defined as the angle between the cut plane and the longitudinal axis of the biomass stem shown in Figure 5-1. The cutting performances monitored were illustrated in Figure 5-2. For the cutting method, CC stands for conventional cutting method without ultrasonic vibration, and UC stands for ultrasonic cutting method with ultrasonic vibration. The table of the cutting control parameters and their levels are shown in Table 5-1, and the designed orthogonal array cutting matrix is shown in Table $5-2$.

Table 5-1. Cutting control parameters

\begin{tabular}{llll}
\hline Parameters & Level 1 & Level 2 & Level 3 \\
\hline Blade profile & Profile 1 & Profile 2 & Profile 3 \\
Cutting speed & $3 \mathrm{~mm} / \mathrm{s}$ & $30 \mathrm{~mm} / \mathrm{s}$ & $300 \mathrm{~mm} / \mathrm{s}$ \\
Cutting angle & $90^{\circ}$ & $60^{\circ}$ & $45^{\circ}$ \\
Cutting method & CC & UC & - \\
\hline
\end{tabular}

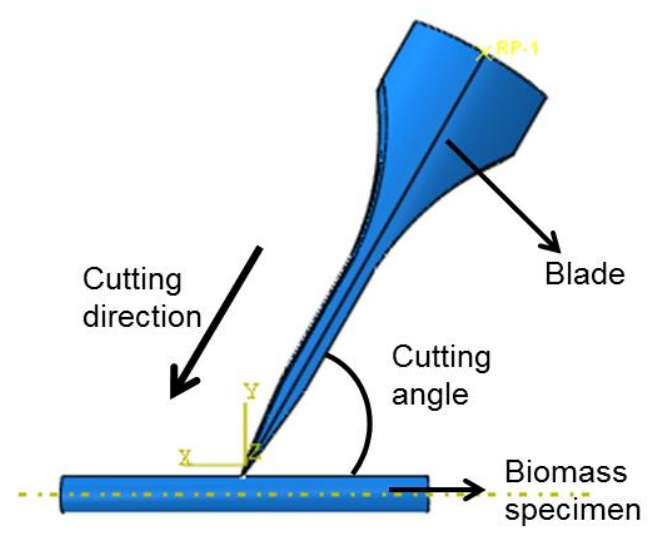

Figure 5-1. Biomass cutting parameters configuration. 


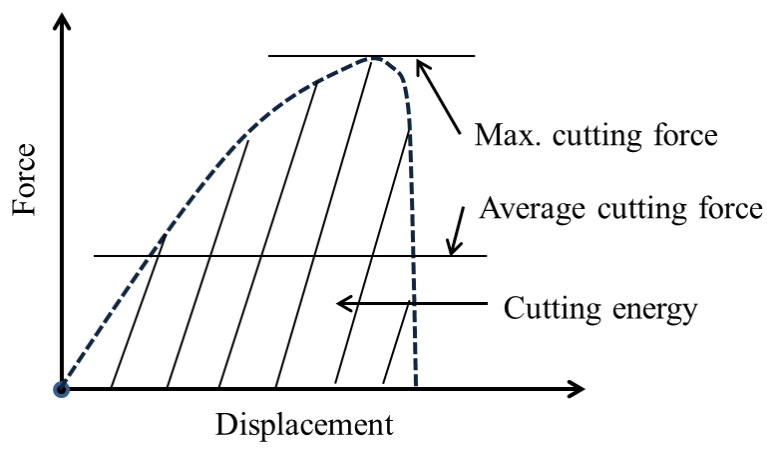

Figure 5-2. Monitored biomass cutting performances.

Table 5-2. Orthogonal array cutting matrix.

\begin{tabular}{ccccc}
\hline Experiment No. & Blade profile & Cutting speed & Cutting angle & Cutting method \\
\hline 1 & Level 1 & Level 1 & Level 1 & Level 1 \\
2 & Level 1 & Level 2 & Level 2 & Level 2 \\
3 & Level 1 & Level 3 & Level 3 & Level 1 \\
4 & Level 2 & Level 1 & Level 2 & Level 2 \\
5 & Level 2 & Level 2 & Level 3 & Level 1 \\
6 & Level 2 & Level 3 & Level 1 & Level 2 \\
7 & Level 3 & Level 1 & Level 3 & Level 1 \\
8 & Level 3 & Level 2 & Level 1 & Level 2 \\
9 & Level 3 & Level 3 & Level 2 & Level 1 \\
\hline
\end{tabular}

Switchgrass stems (9.8\% moisture content) with a typical diameter of $3.5 \mathrm{~mm}$ and shell thickness of $0.5 \mathrm{~mm}$; miscanthus (10.2\% moisture content) stems with a typical diameter of $7.7 \mathrm{~mm}$ and shell thickness of $1.01 \mathrm{~mm}$ were selected. All the biomass specimens with the same diameter and thickness (the same cross section area) were assumed to have the same mechanical properties. Cutting experiments were carried out 
on both miscanthus and switchgrass samples based on the cutting parameters configuration shown in Table 5-3.

Table 5-3. Orthogonal array cutting experiment.

\begin{tabular}{ccccc}
\hline Experiment No. & Blade profile & Cutting speed & Cutting angle & Cutting method \\
\hline 1 & Profile 1 & $3 \mathrm{~mm} / \mathrm{s}$ & $90^{\circ}$ & $\mathrm{CC}$ \\
3 & Profile 1 & $30 \mathrm{~mm} / \mathrm{s}$ & $60^{\circ}$ & $\mathrm{UC}$ \\
4 & Profile 1 & $300 \mathrm{~mm} / \mathrm{s}$ & $45^{\circ}$ & $\mathrm{CC}$ \\
5 & Profile 2 & $3 \mathrm{~mm} / \mathrm{s}$ & $60^{\circ}$ & $\mathrm{UC}$ \\
6 & Profile 2 & $30 \mathrm{~mm} / \mathrm{s}$ & $45^{\circ}$ & $\mathrm{CC}$ \\
7 & Profile 2 & $300 \mathrm{~mm} / \mathrm{s}$ & $90^{\circ}$ & $\mathrm{UC}$ \\
8 & Profile 3 & $3 \mathrm{~mm} / \mathrm{s}$ & $45^{\circ}$ & $\mathrm{CC}$ \\
9 & Profile 3 & $30 \mathrm{~mm} / \mathrm{s}$ & $90^{\circ}$ & $\mathrm{UC}$ \\
\hline
\end{tabular}

\subsection{Switchgrass mechanical pre-processing}

The cutting force and displacement relation data and cutting energy data were recorded and displayed.

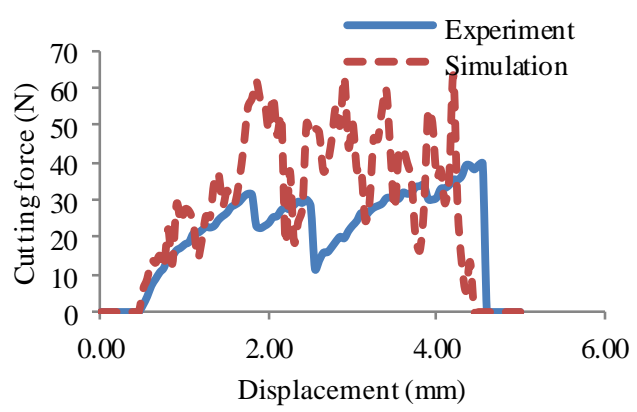

(a)

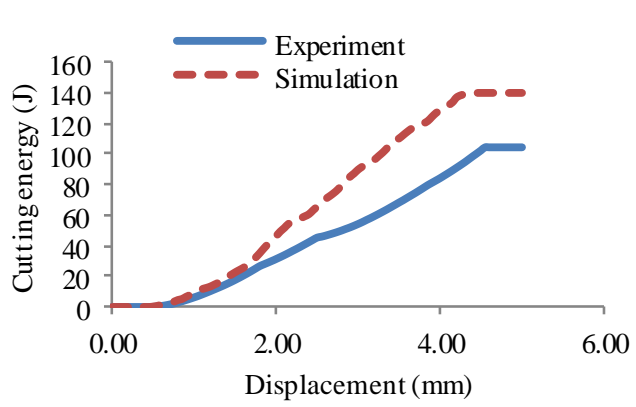

(b)

Figure 5-3. Switchgrass cutting blade profile 1 at $3 \mathrm{~mm} / \mathrm{s}$ cutting speed, $90^{\circ}$ cutting angle and with conventional cutting method: (a) force vs. displacement, and (b) cutting energy vs. displacement. 


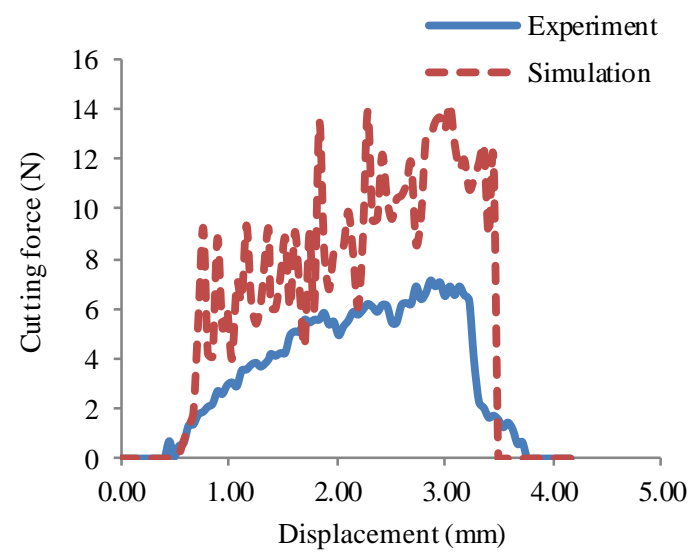

(a)

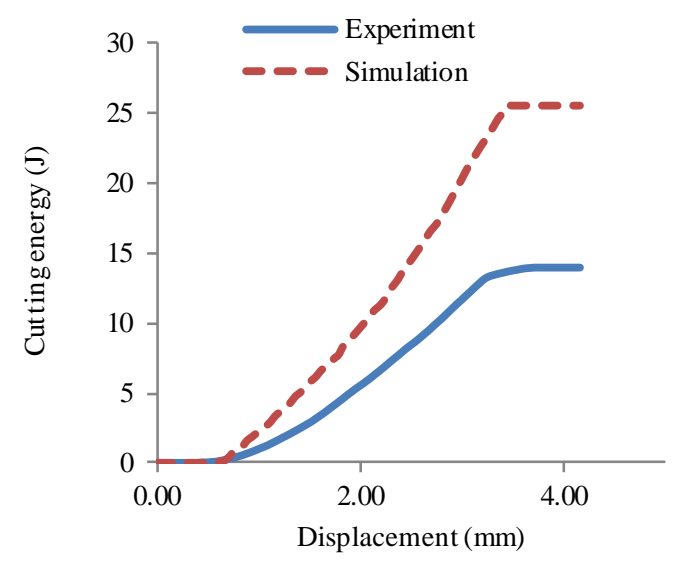

(b)

Figure 5-4. Switchgrass cutting blade profile 1 at $30 \mathrm{~mm} / \mathrm{s}$ cutting speed, $60^{\circ}$ cutting angle and with ultrasonic cutting method: (a) force vs. displacement, (b) cutting energy vs. displacement.

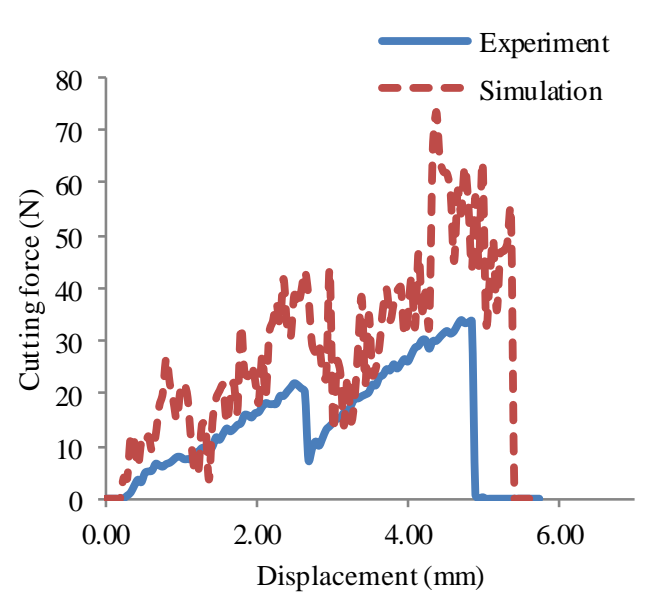

(a)

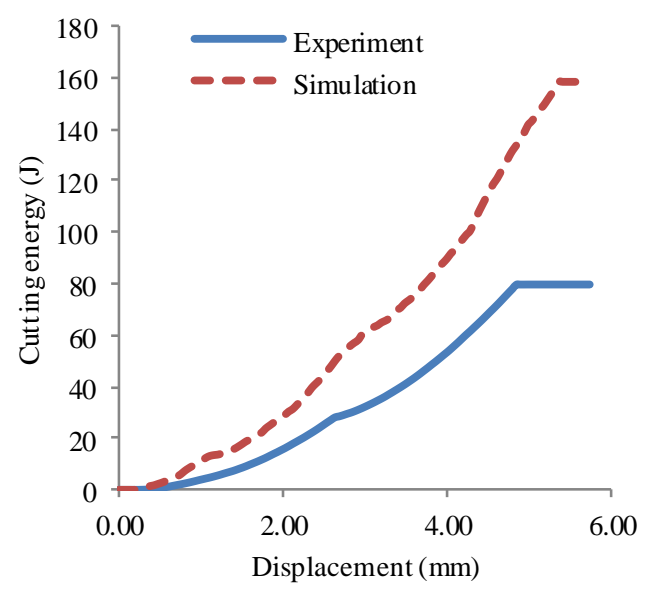

(b)

Figure 5-5. Switchgrass cutting with blade profile 1 at $300 \mathrm{~mm} / \mathrm{s}$ cutting speed, $45^{\circ}$ cutting angle and with conventional cutting method: (a) force vs. displacement and (b) cutting energy vs. displacement. 


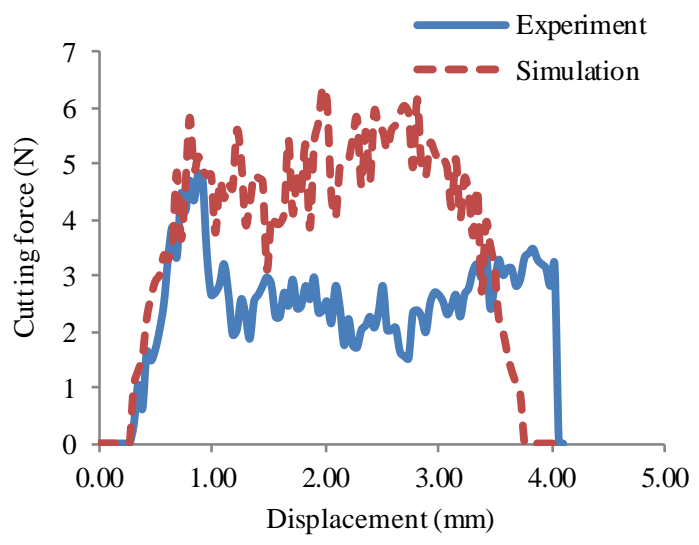

(a)

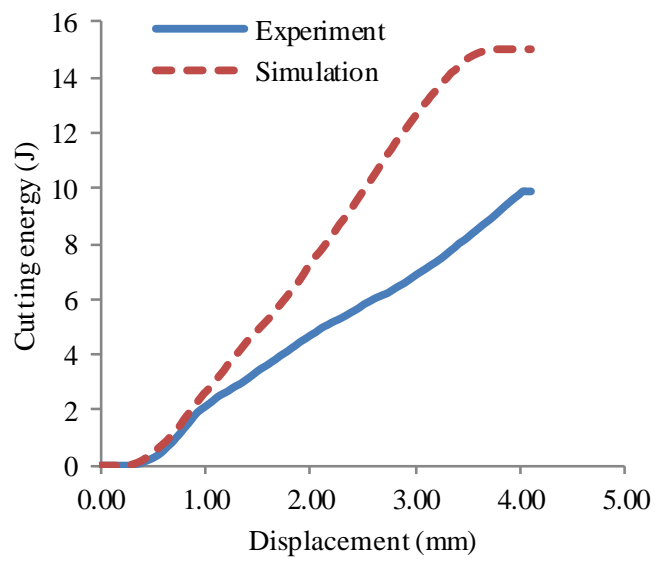

(b)

Figure 5-6. Switchgrass cutting with blade profile 2 at $3 \mathrm{~mm} / \mathrm{s}$ cutting speed, $60^{\circ}$ cutting angle and with ultrasonic cutting method: (a) force vs. displacement and (b) cutting energy vs. displacement.

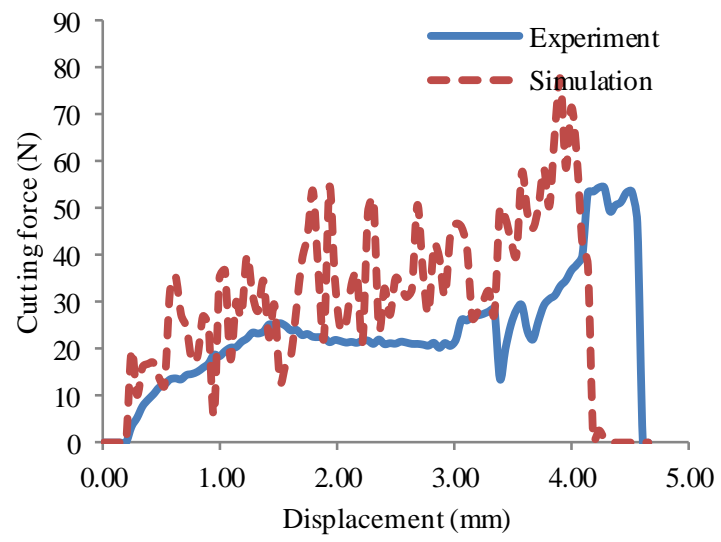

(a)

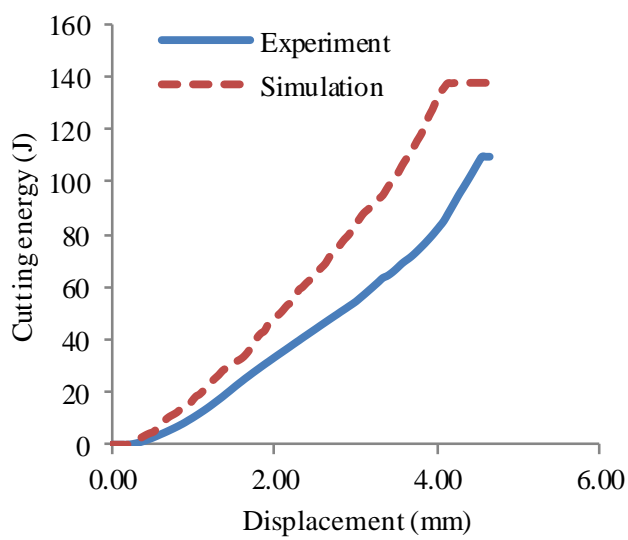

(b)

Figure 5-7. Switchgrass cutting with blade profile 2 at $30 \mathrm{~mm} / \mathrm{s}$ cutting speed, $45^{\circ}$ cutting angle and with conventional cutting method: (a) force vs. displacement and (b) cutting energy vs. displacement. 


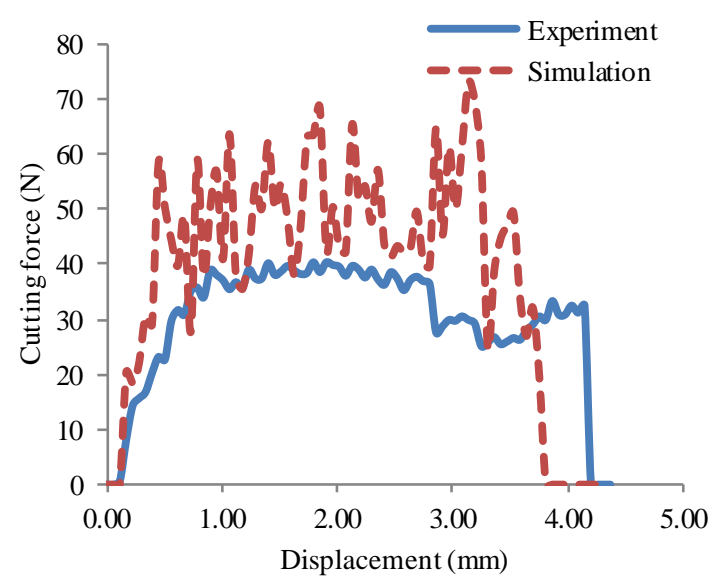

(a)

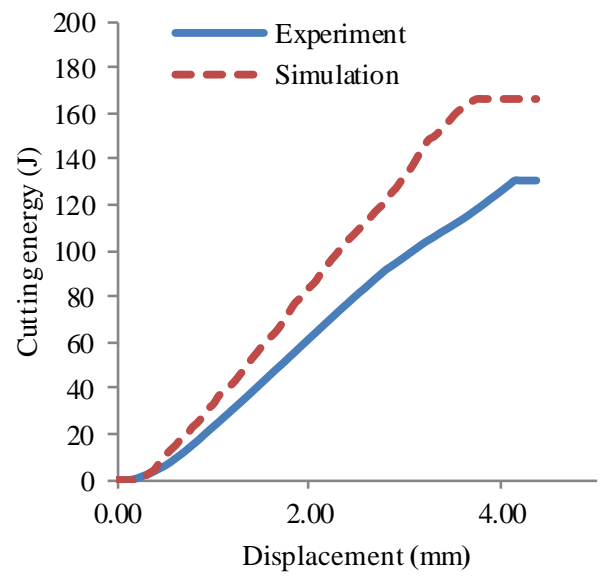

(b)

Figure 5-8. Switchgrass cutting with blade profile 2 at $300 \mathrm{~mm} / \mathrm{s}$ cutting speed, $90^{\circ}$ cutting angle and with ultrasonic cutting method: (a) force vs. displacement and (b) cutting energy vs. displacement.

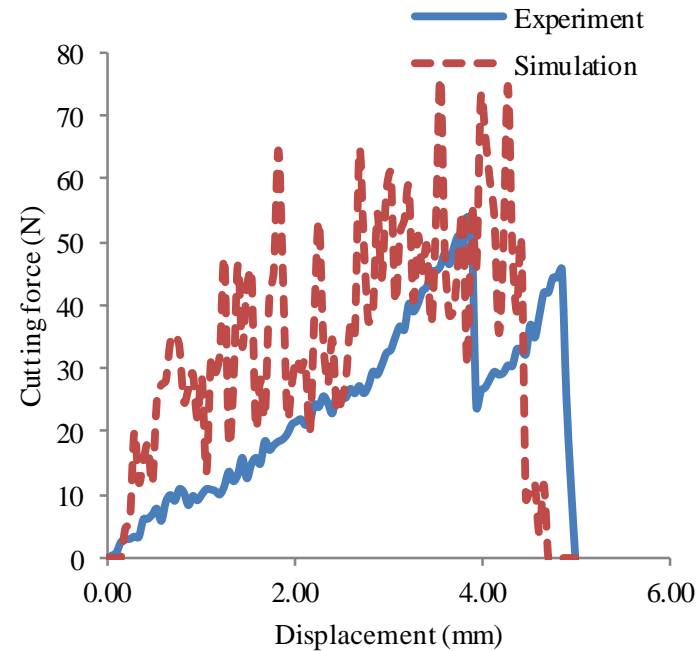

(a)

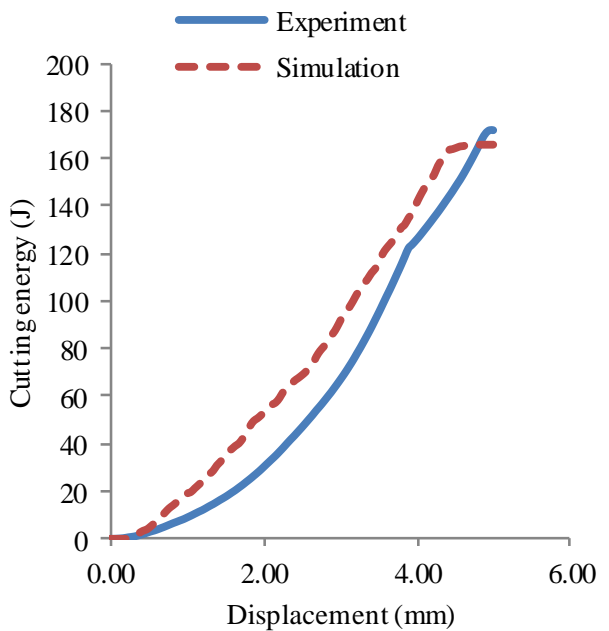

(b)

Figure 5-9. Switchgras sutting with blade profile 3 at $3 \mathrm{~mm} / \mathrm{s}$ cutting speed, $45^{\circ}$ cutting angle and with conventional cutting method: (a) force vs. displacement and (b) cutting energy vs. displacement. 


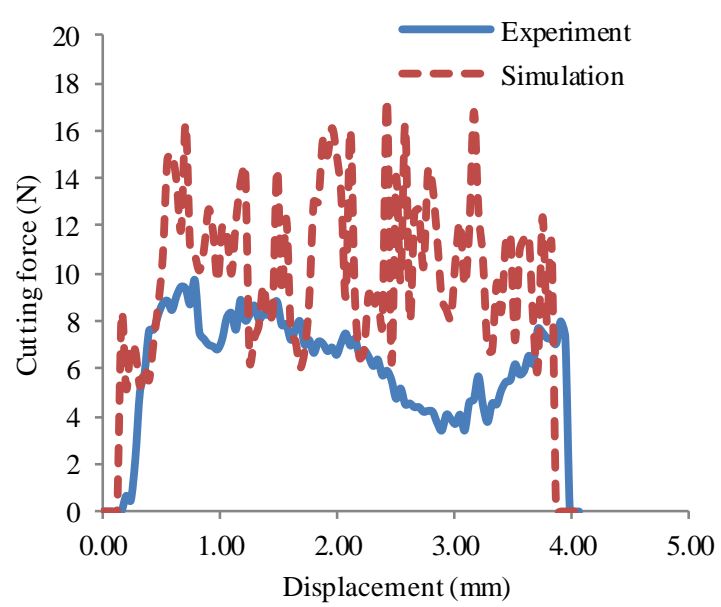

(a)

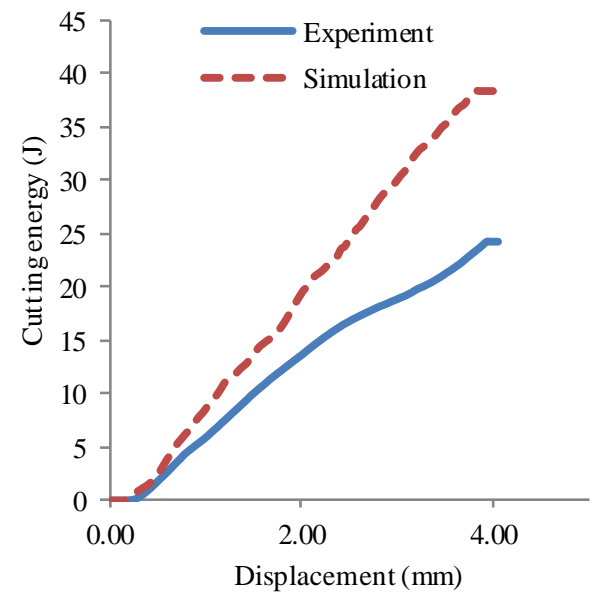

(b)

Figure 5-10. Switchgrass cutting with blade profile 3 at $30 \mathrm{~mm} / \mathrm{s}$ cutting speed, $90^{\circ}$ cutting angle and with ultrasonic cutting method: (a) force vs. displacement and (b) cutting energy vs. displacement.

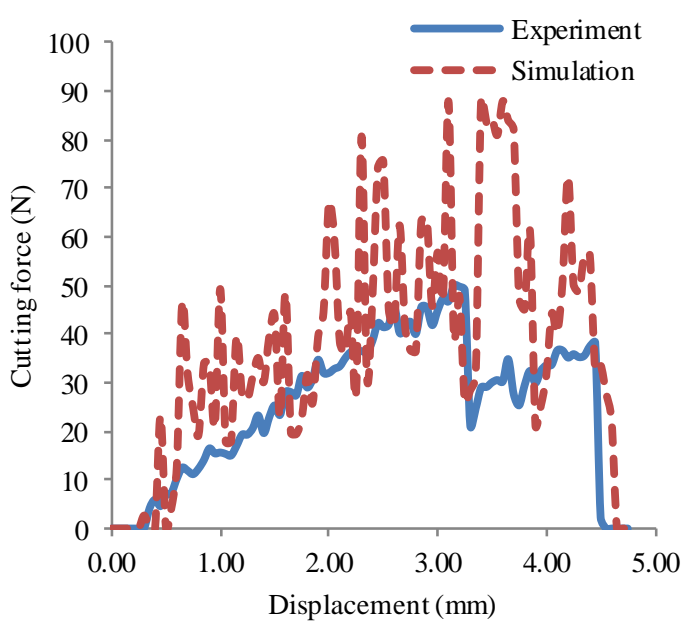

(a)

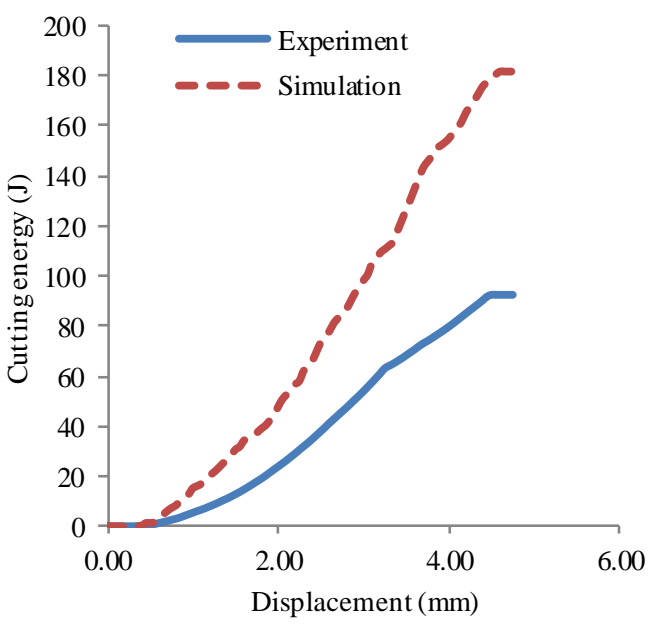

(b)

Figure 5-11. Switchgrass cutting with blade profile 3 at $300 \mathrm{~mm} / \mathrm{s}$ cutting speed, $60^{\circ}$ cutting angle and with conventional cutting method: (a) force vs. displacement and (b) cutting energy vs. displacement. 


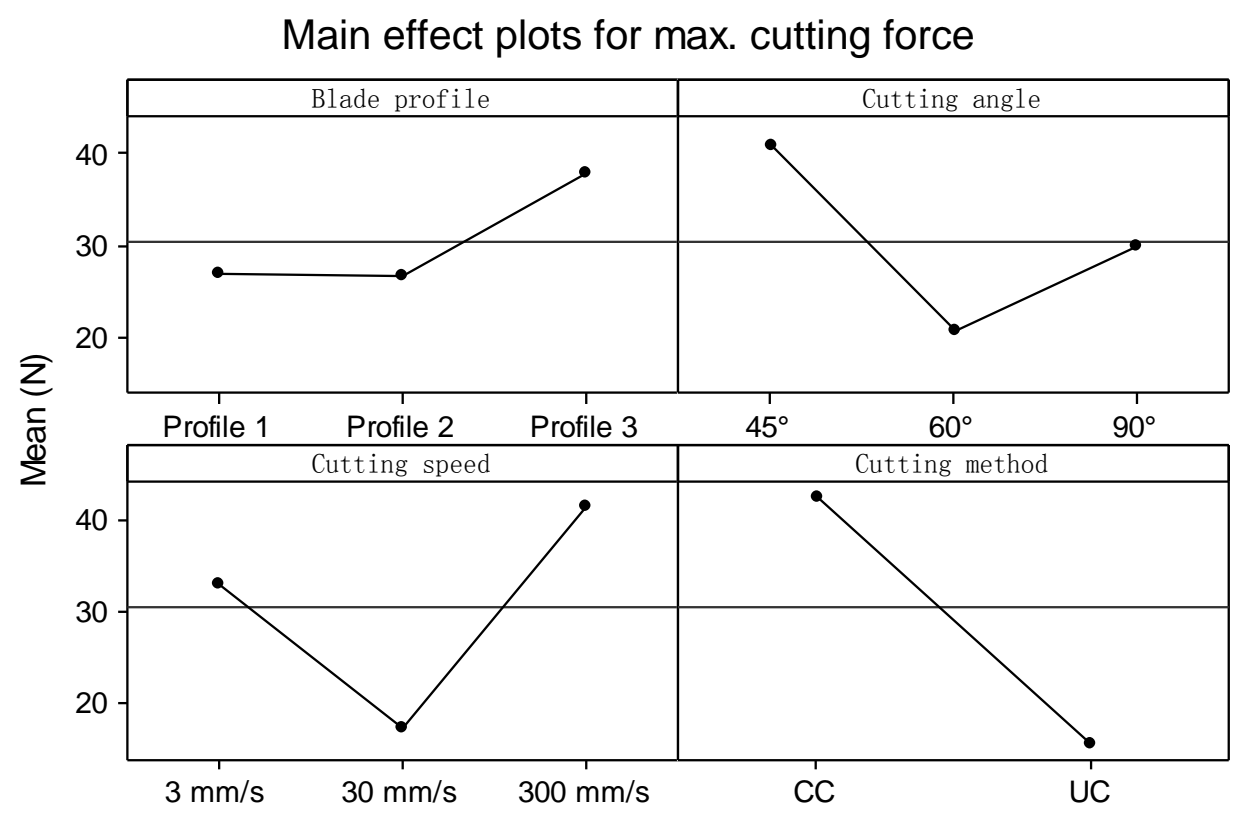

Figure 5-12. Switchgrass main effect plots for experimental max. cutting force.

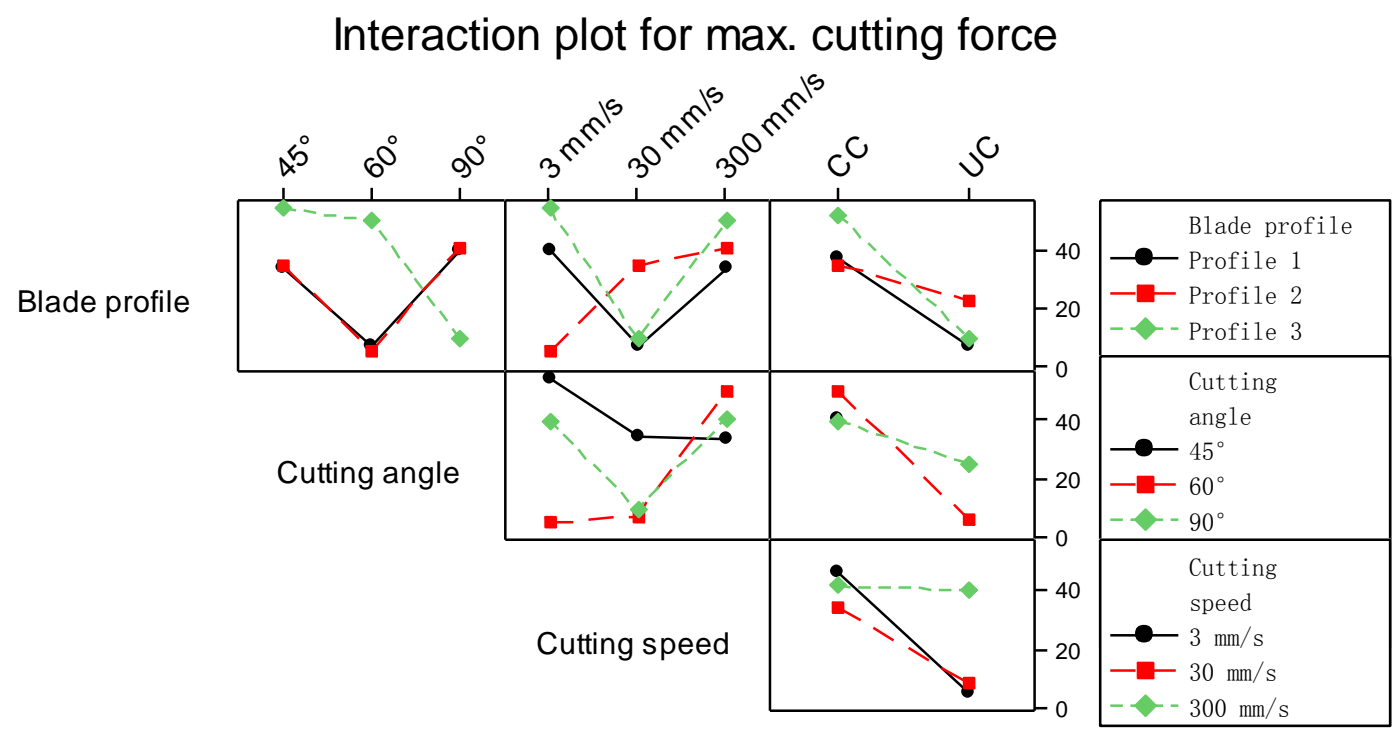

Cutting method

Figure 5-13. Switchgrass interaction plot for experimental max. cutting force.

The cutting performances with systematically designed cutting parameters are summarized in Table 5-4. In order to find the parameters that have most impact on 
cutting parameters, ANOVA was adopted to analyze the results for both experiments and simulations. The analysis results are shown in Figure 5-12 to Figure 5-23.

Table 5-4. Switchgrass cutting performances with different cutting parameters .

\begin{tabular}{cccc|ccc}
\hline \multirow{3}{*}{ Trial } & \multicolumn{3}{c|}{ Experiment } & \multicolumn{3}{c}{ Simulation } \\
\cline { 2 - 7 } No. & $\begin{array}{c}\text { Max. } \\
\text { cutting } \\
\text { force }(\mathrm{N})\end{array}$ & $\begin{array}{c}\text { Average } \\
\text { cutting } \\
\text { force }(\mathrm{N})\end{array}$ & $\begin{array}{c}\text { Cutting } \\
\text { Energy } \\
(\mathrm{J})\end{array}$ & $\begin{array}{c}\text { Max. } \\
\text { cutting } \\
\text { force }(\mathrm{N})\end{array}$ & $\begin{array}{c}\text { Average } \\
\text { cutting } \\
\text { force }(\mathrm{N})\end{array}$ & $\begin{array}{c}\text { Cutting } \\
\text { Energy } \\
(\mathrm{J})\end{array}$ \\
\hline 1 & 39.77 & 25.42 & 104.20 & 63.35 & 35.37 & 139.71 \\
2 & 7.13 & 3.71 & 13.95 & 14.18 & 8.35 & 25.52 \\
3 & 33.92 & 16.93 & 79.59 & 73.46 & 30.59 & 158.17 \\
4 & 4.83 & 2.63 & 9.88 & 6.36 & 4.34 & 15.01 \\
5 & 34.58 & 22.64 & 98.96 & 77.56 & 33.30 & 137.72 \\
6 & 40.32 & 31.16 & 130.67 & 73.00 & 39.83 & 166.24 \\
7 & 53.98 & 24.48 & 101.89 & 107.79 & 49.46 & 235.43 \\
8 & 9.72 & 6.35 & 24.27 & 17.32 & 10.45 & 38.39 \\
9 & 49.97 & 28.85 & 108.31 & 66.40 & 32.23 & 136.51 \\
\hline
\end{tabular}

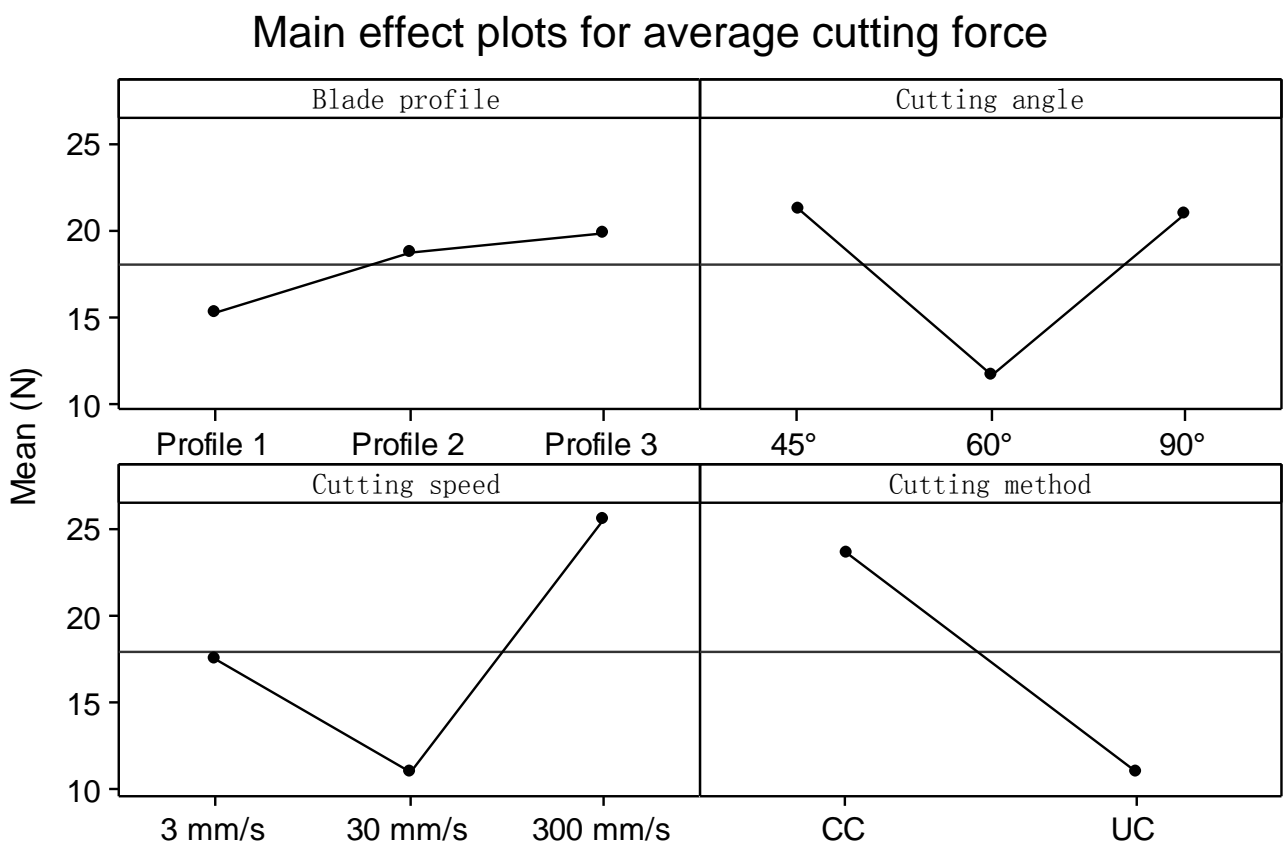

Figure 5-14. Switchgrass main effect plots for experimental average cutting force. 
Interaction plot for average force

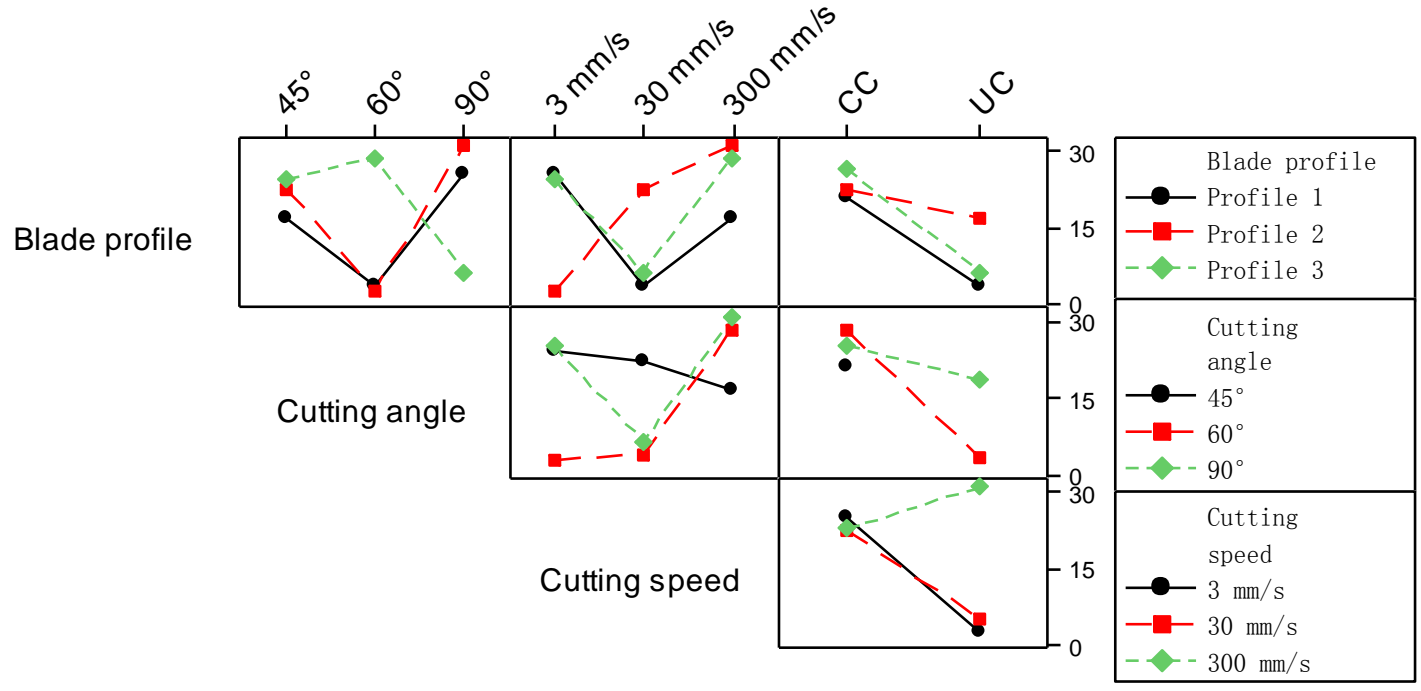

Cutting method

Figure 5-15. Switchgrass interaction plot for experimental average cutting force.

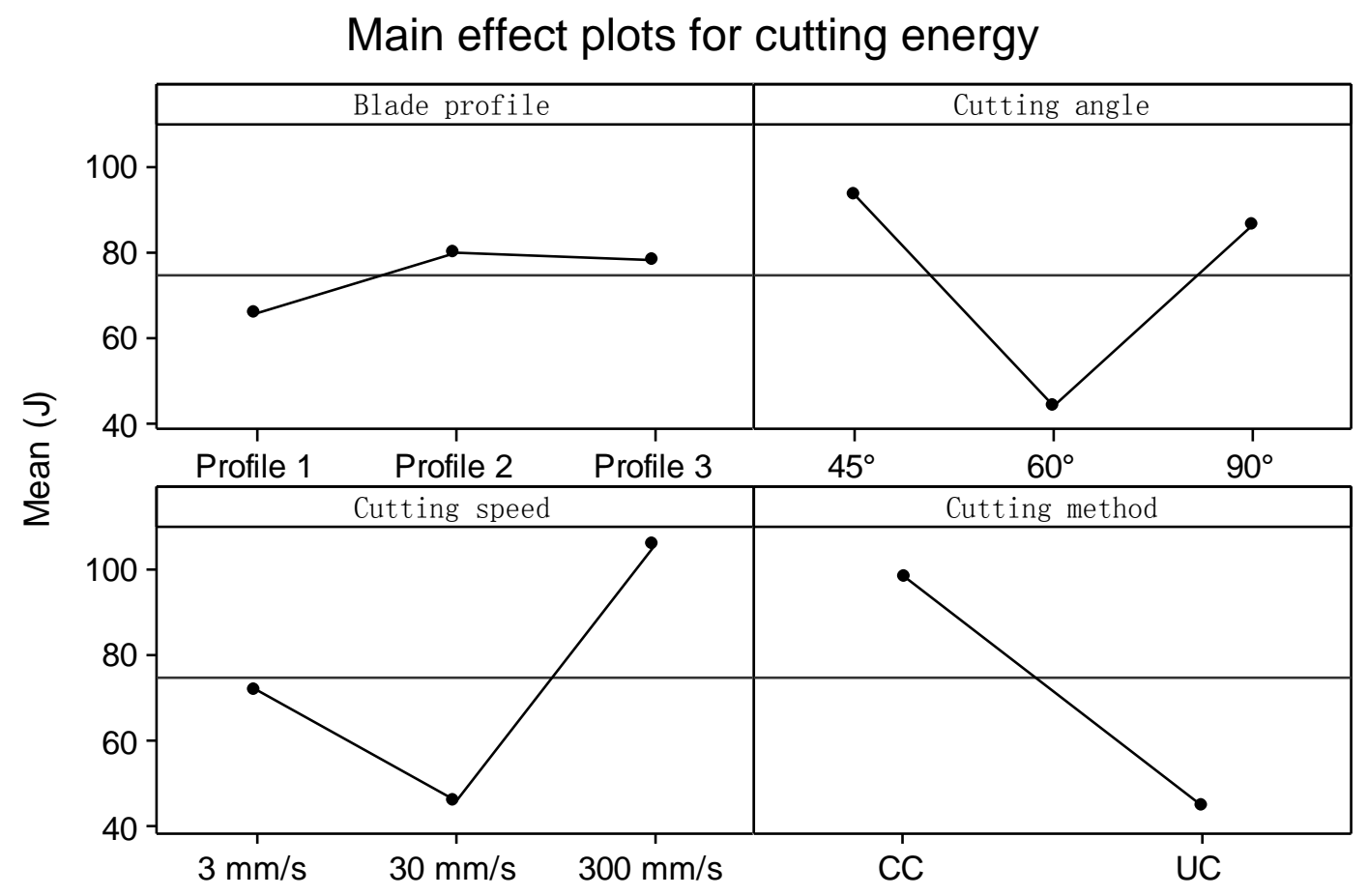

Figure 5-16. Switchgrass main effect plots for experimental cutting energy. 
Interaction plot for cutting energy

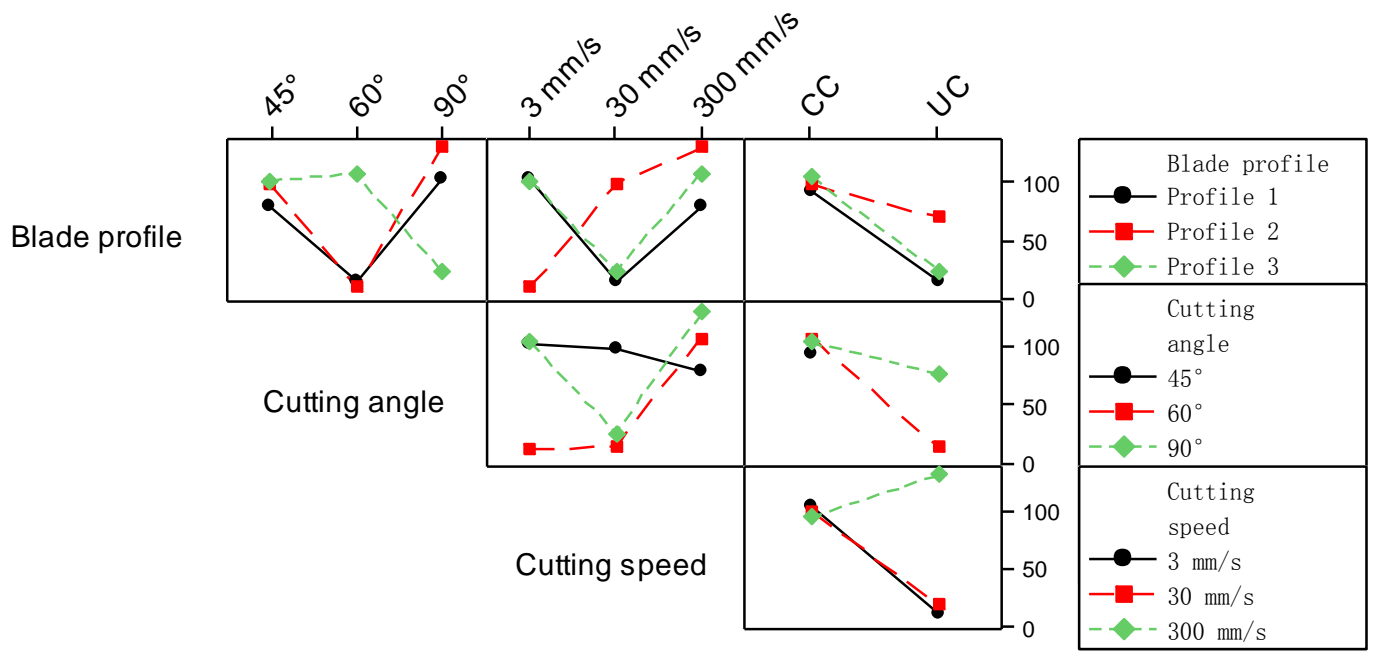

Cutting method

Figure 5-17. Switchgrass interaction plot for experimental average cutting force.

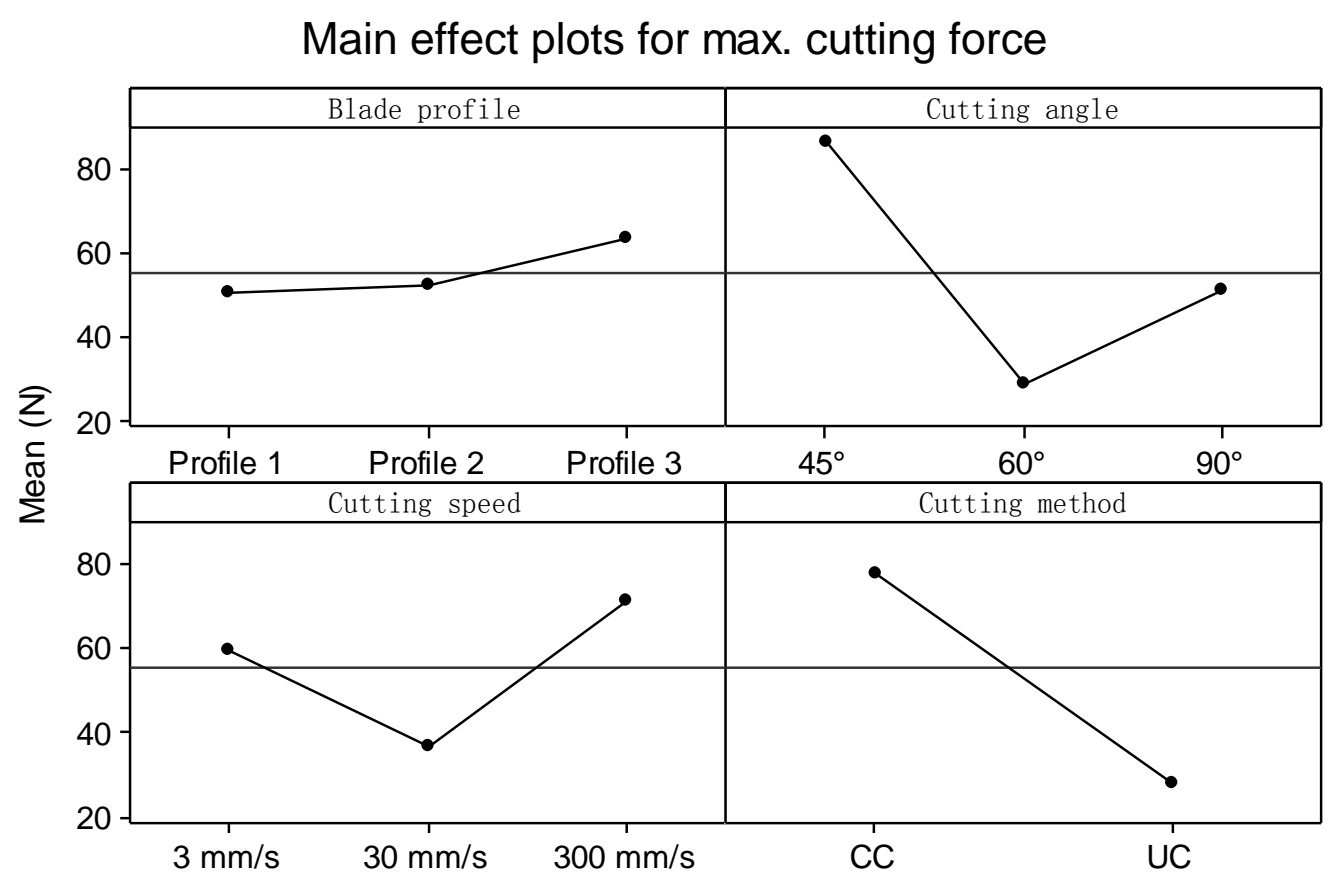

Figure 5-18. Switchgrass main effect plot for simulated max. cutting force. 


\section{Interaction plot for max. cutting force}

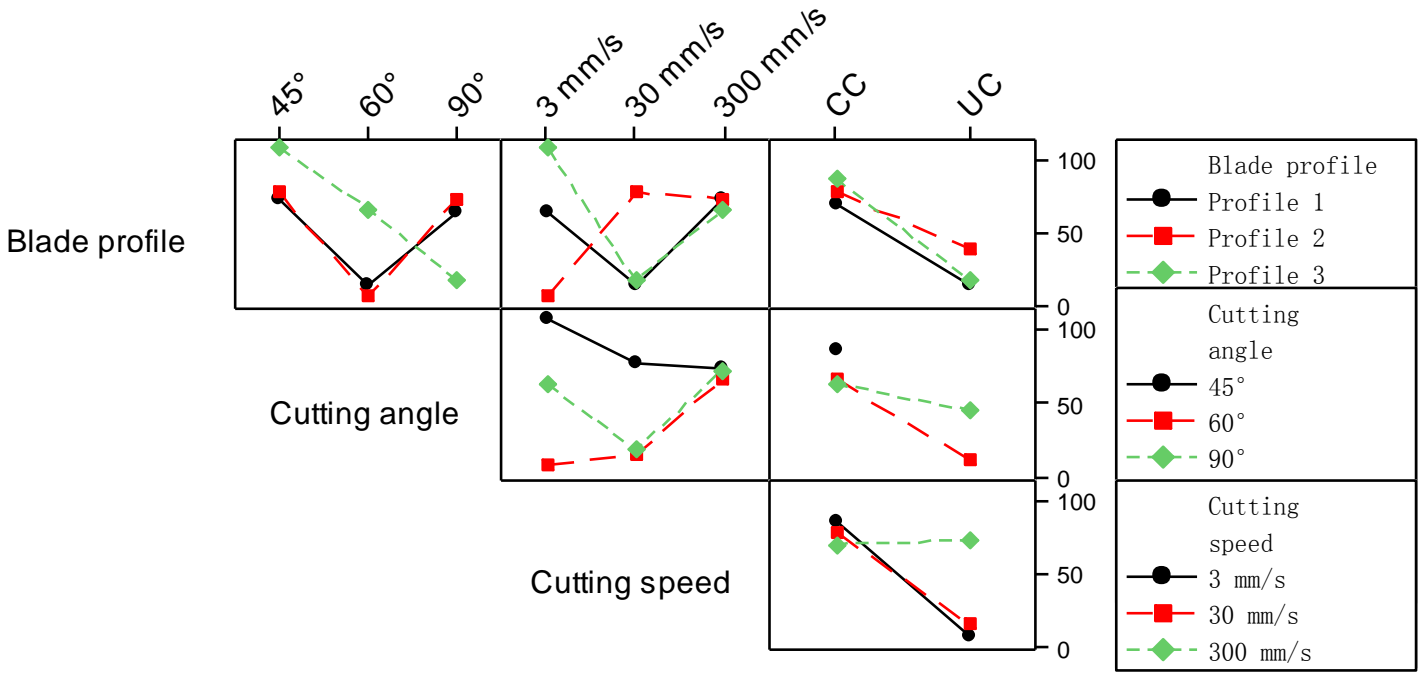

Cutting method

Figure 5-19. Switchgrass interaction plot for simulated max. cutting force.

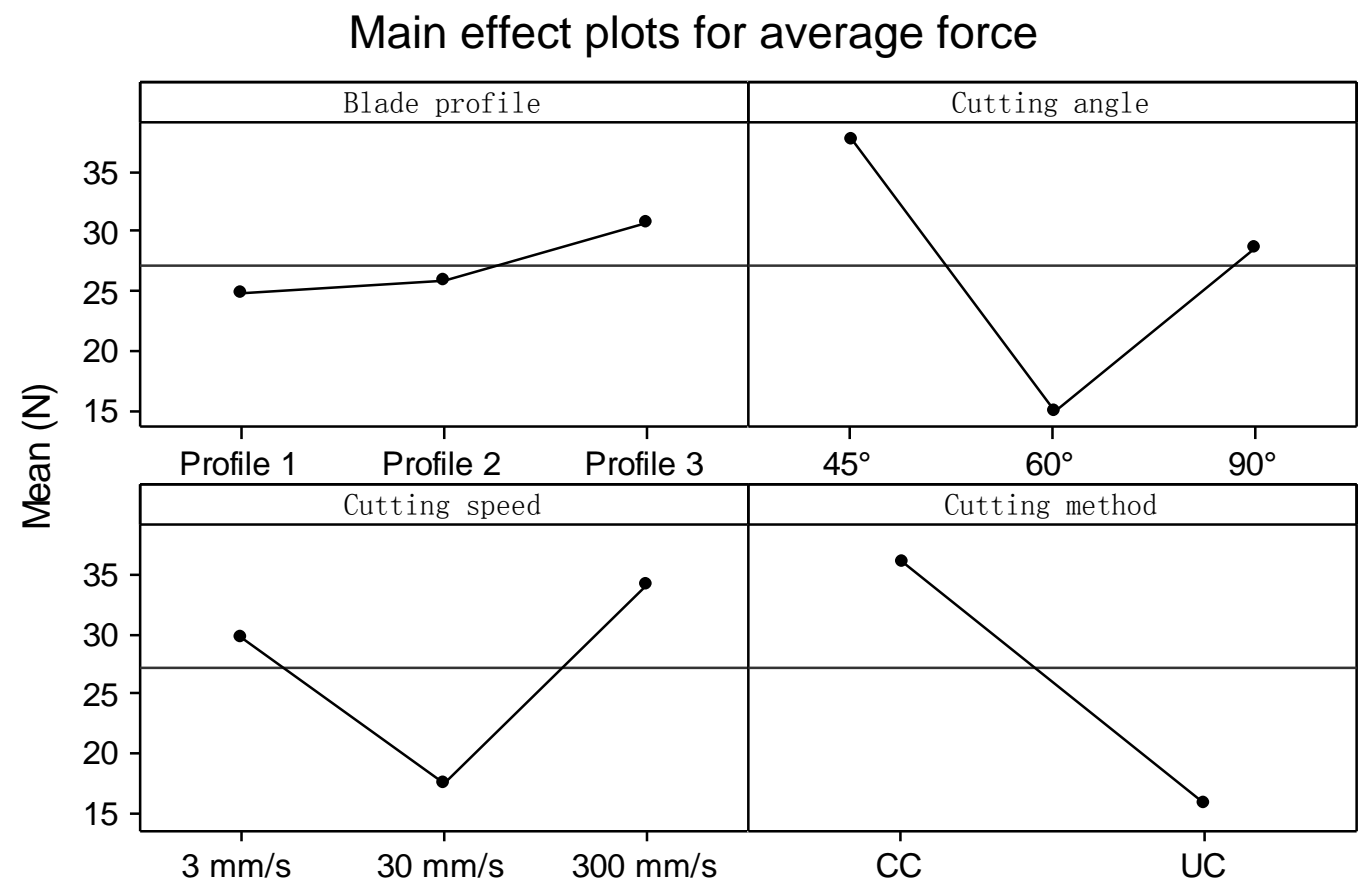

Figure 5-20. Switchgrass main effect for simulated average cutting force. 


\section{Interaction plot for average cutting force}

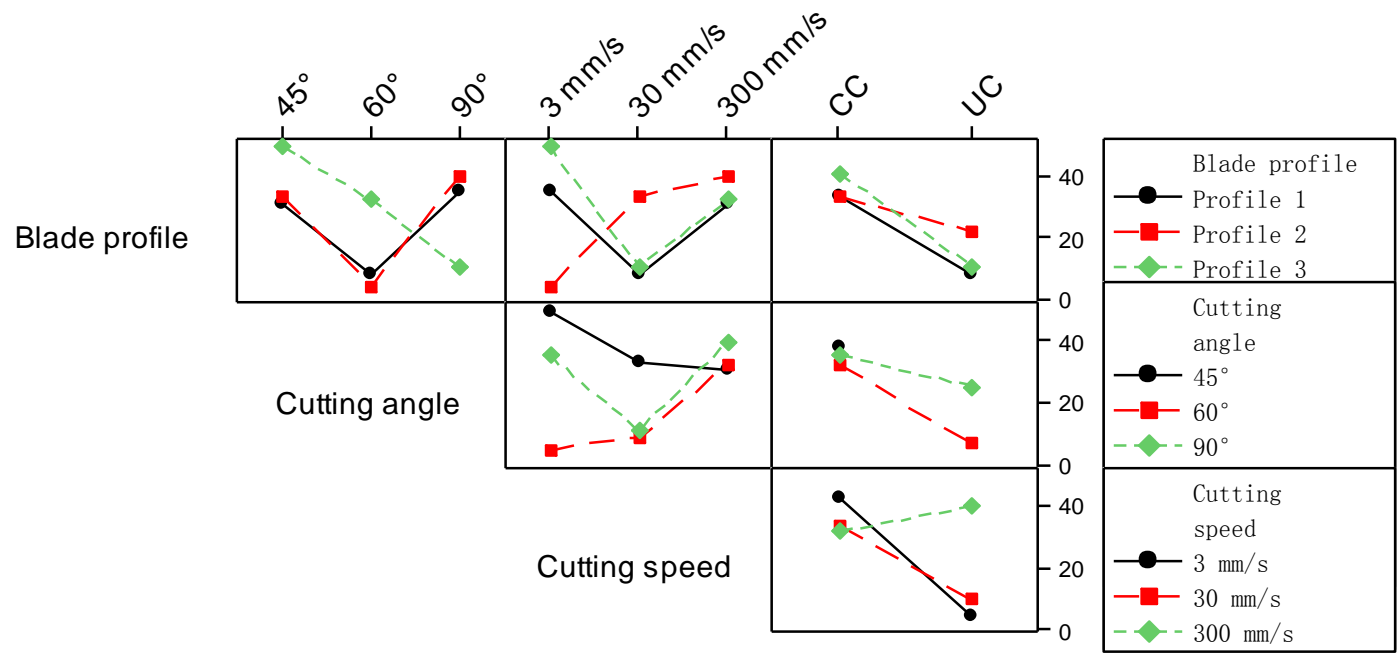

Cutting method

Figure 5-21. Switchgrass interaction plot for simulated average cutting force.

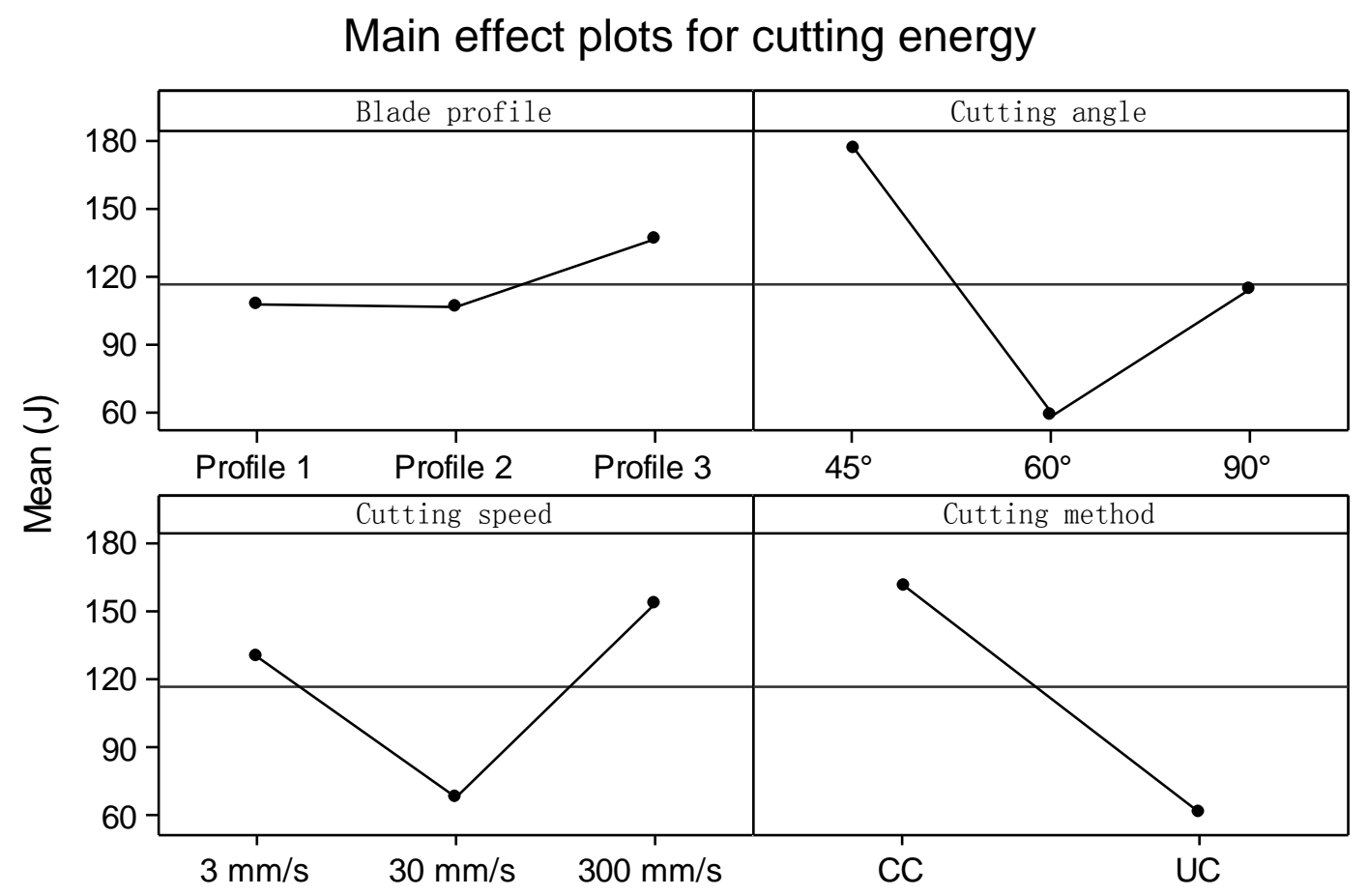

Figure 5-22. Switchgrass main effect plots for simulated cutting energy. 


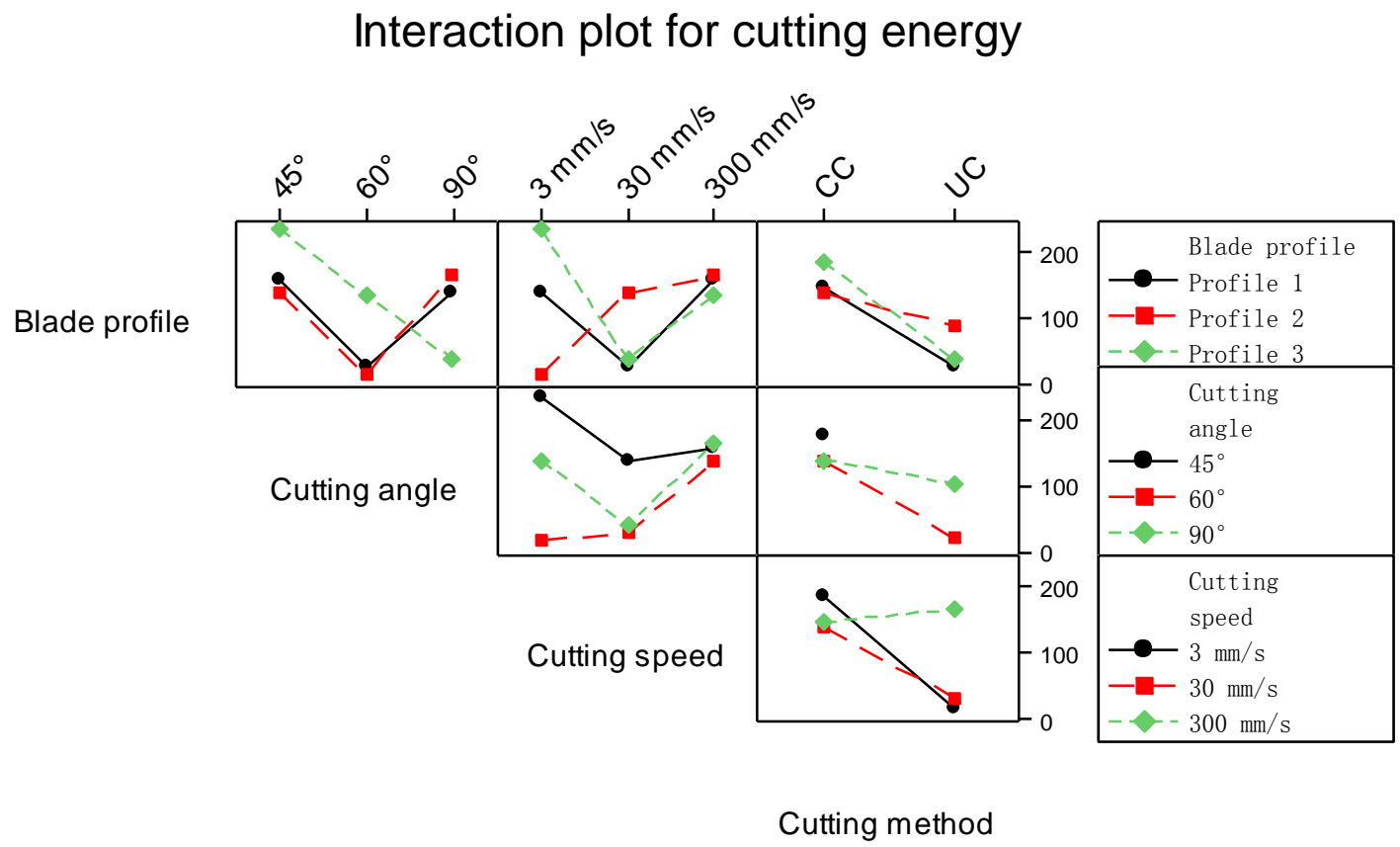

Figure 5-23. Switchgrass interaction plot for simulated cutting energy.

The ANOVA analysis of switchgrass cutting performance results are summarized in Table 5-5. Table 5-5 shows the main effects plot for means, and delta values were calculated by subtracting the lowest mean value from the highest one. A higher delta value for a parameter indicates that it affects the results more significantly than the other parameters. The delta values and their rankings (significance) are shown below (the ranking values are in parenthesis). The results show that cutting method, cutting speed and cutting angle are the most significant cutting parameters on cutting performances compared to blade profile. The interaction plots for maximum cutting force, average cutting force and cutting energy show that cutting parameters have interaction with each other, which indicates that the best cutting performances can be achieved by adjusting these cutting control parameters. 
Table 5-5. ANOVA table for switchgrass cutting performance delta values.

\begin{tabular}{|c|c|c|c|c|c|}
\hline & & $\begin{array}{l}\text { Blade } \\
\text { profile }\end{array}$ & $\begin{array}{l}\text { Cutting } \\
\text { angle } \\
\text { (Degree) }\end{array}$ & $\begin{array}{l}\text { Cutting } \\
\text { speed } \\
(\mathrm{mm} / \mathrm{s})\end{array}$ & $\begin{array}{l}\text { Cutting } \\
\text { method }\end{array}$ \\
\hline \multirow{3}{*}{ Experiment } & Max. cutting force $(\mathrm{N})$ & $10.98(4)$ & $20.2(3)$ & $24.3(2)$ & $26.9(1)$ \\
\hline & Average cutting force $(\mathrm{N})$ & $4.5(4)$ & $9.6(3)$ & $14.7(1)$ & $11.8(2)$ \\
\hline & Cutting energy $(\mathrm{J})$ & $12.15(4)$ & $49.5(3)$ & $60.5(1)$ & $53.9(2)$ \\
\hline \multirow{3}{*}{ Simulation } & Max. cutting force $(\mathrm{N})$ & $13.5(4)$ & $57.3(1)$ & $43.6(3)$ & $50(2)$ \\
\hline & Average cutting force $(\mathrm{N})$ & $10(4)$ & $20.8(2)$ & $19.73(3)$ & $22.5(1)$ \\
\hline & Cutting energy $(\mathrm{J})$ & $29(4)$ & $118.1(1)$ & $86.4(3)$ & $99.6(2)$ \\
\hline
\end{tabular}

\subsection{Miscanthus mechanical pre-processing}

The cutting force and displacement relationship data and cutting energy data of miscanthus cutting study were recorded and displayed as follows:

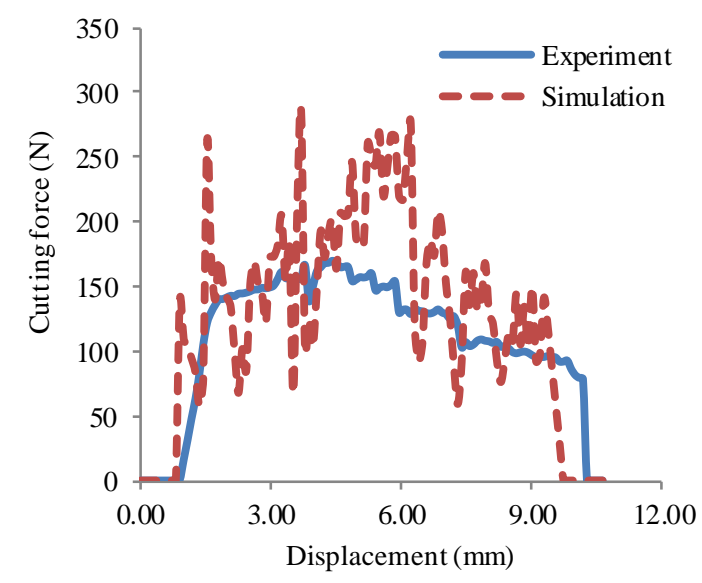

(a)

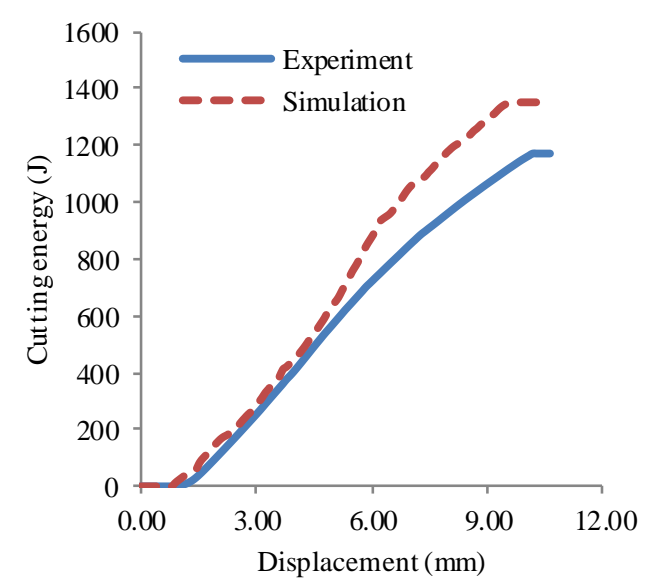

(b)

Figure 5-24. Miscanthus cutting with blade profile 1 at $3 \mathrm{~mm} / \mathrm{s}$ cutting speed, $90^{\circ}$ cutting angle and with conventional cutting method: (a) force vs. displacement and (b) cutting energy vs. displacement. 


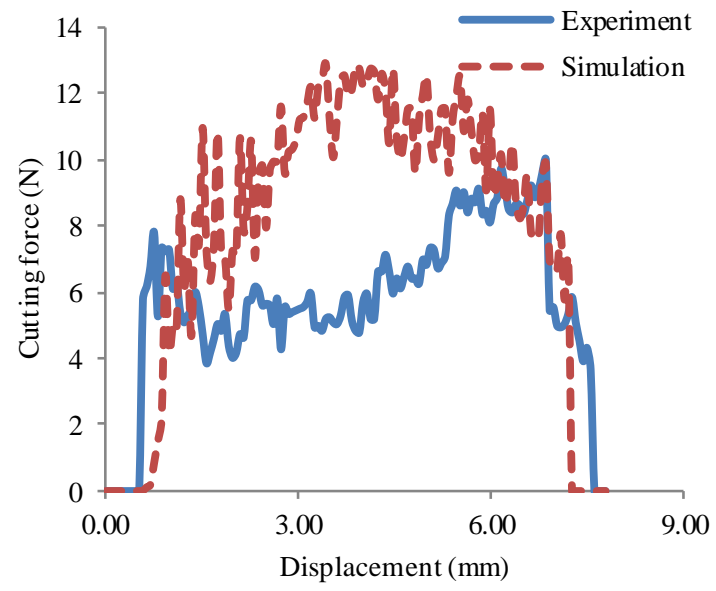

(a)

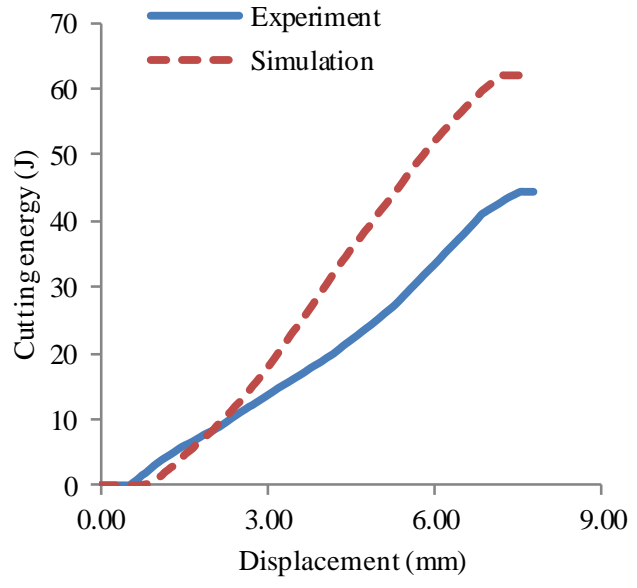

(b)

Figure 5-25. Miscanthus cutting with blade profile 1 at $30 \mathrm{~mm} / \mathrm{s}$ cutting speed, $60^{\circ}$ cutting angle and with ultrasonic cutting method: (a) force vs. displacement and (b) cutting energy vs. displacement.

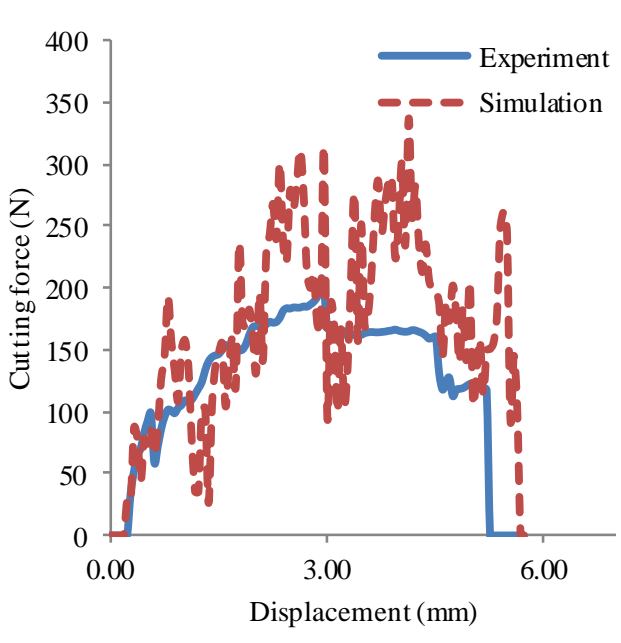

(a)

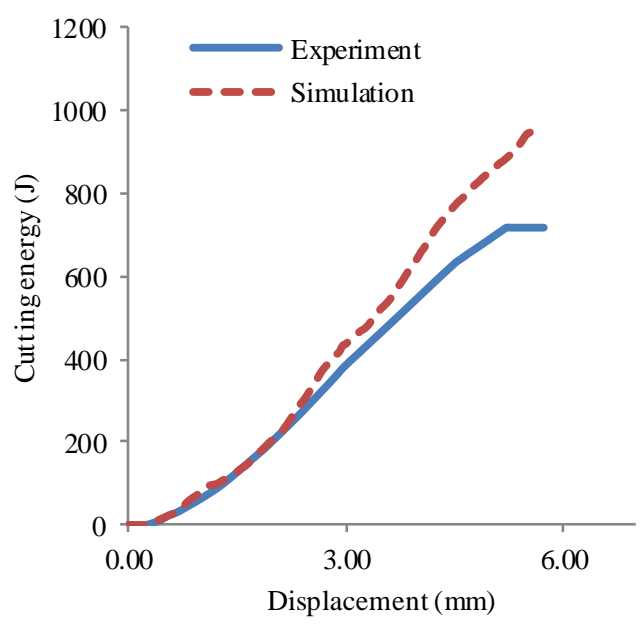

(b)

Figure 5-26. Miscanthus cutting with blade profile 1 at $300 \mathrm{~mm} / \mathrm{s}$ cutting speed, $45^{\circ}$ cutting angle and with conventional cutting method: (a) force vs. displacement and (b) cutting energy vs. displacement. 


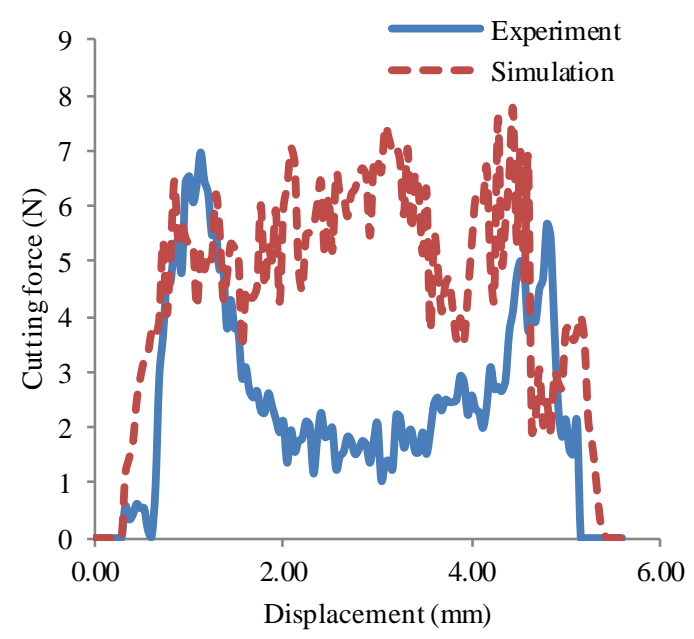

(a)

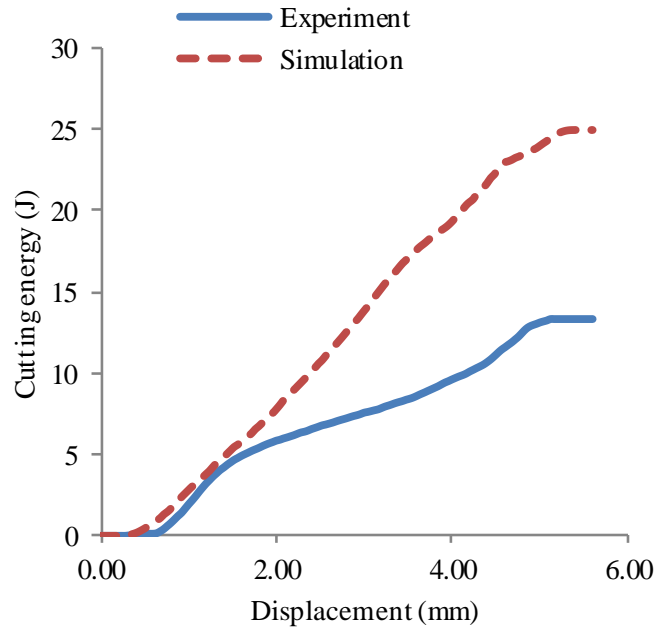

(b)

Figure 5-27. Miscanthus cutting with blade profile 2 at $3 \mathrm{~mm} / \mathrm{s}$ cutting speed, $60^{\circ}$ cutting angle and with ultrasonic cutting method: (a) force vs. displacement and (b) cutting energy vs. displacement.

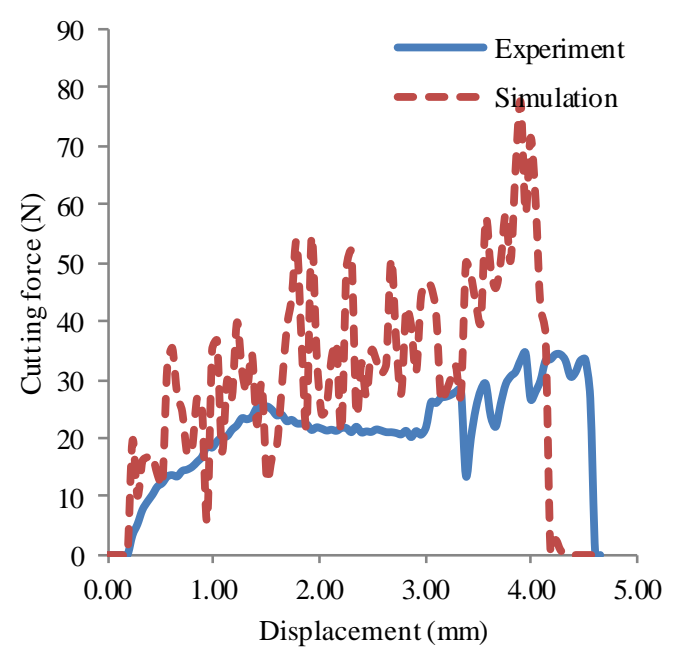

(a)

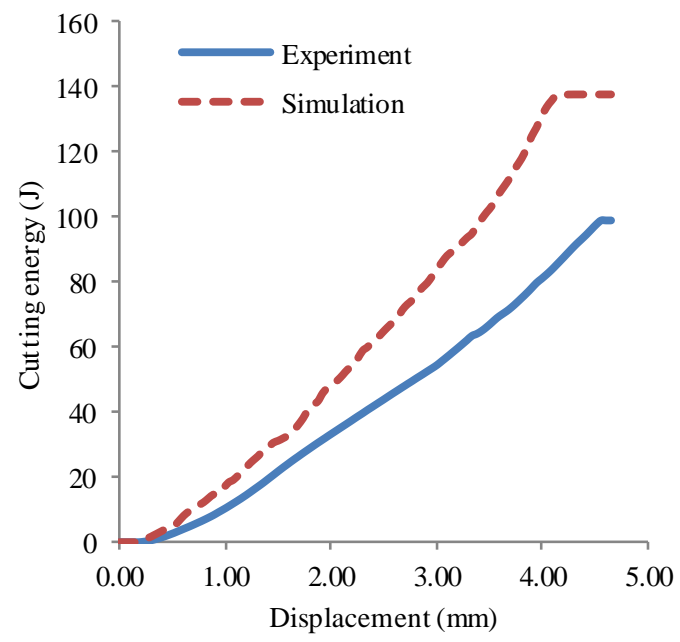

(b)

Figure 5-28. Miscanthus cutting with blade profile 2 at $30 \mathrm{~mm} / \mathrm{s}$ cutting speed, $45^{\circ}$ cutting angle and with conventional cutting method: (a) force vs. displacement and (b) cutting energy vs. displacement. 


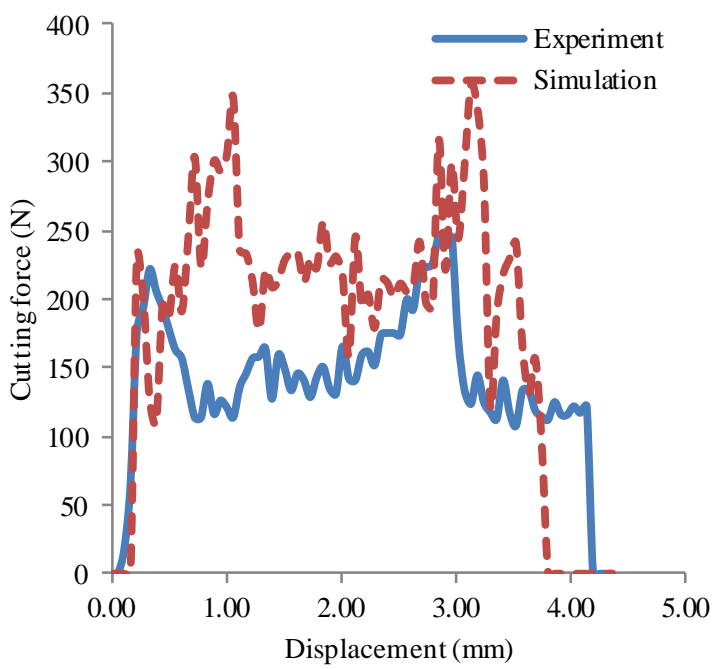

(a)

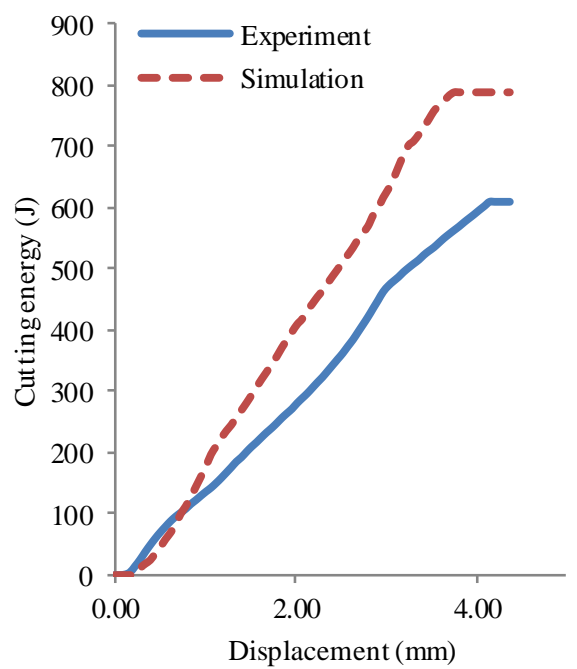

(b)

Figure 5-29. Miscanthus cutting with blade profile 2 at $300 \mathrm{~mm} / \mathrm{s}$ cutting speed, $90^{\circ}$ cutting angle and with ultrasonic cutting method: (a) force vs. displacement and (b) cutting energy vs. displacement.

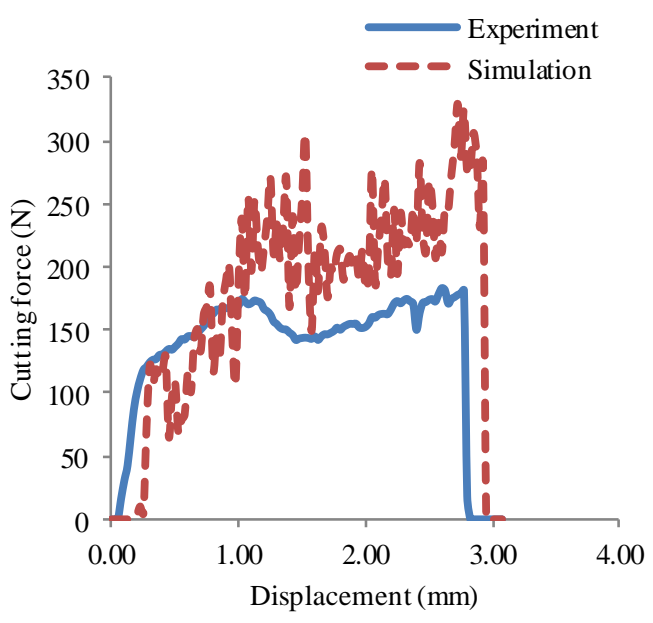

(a)

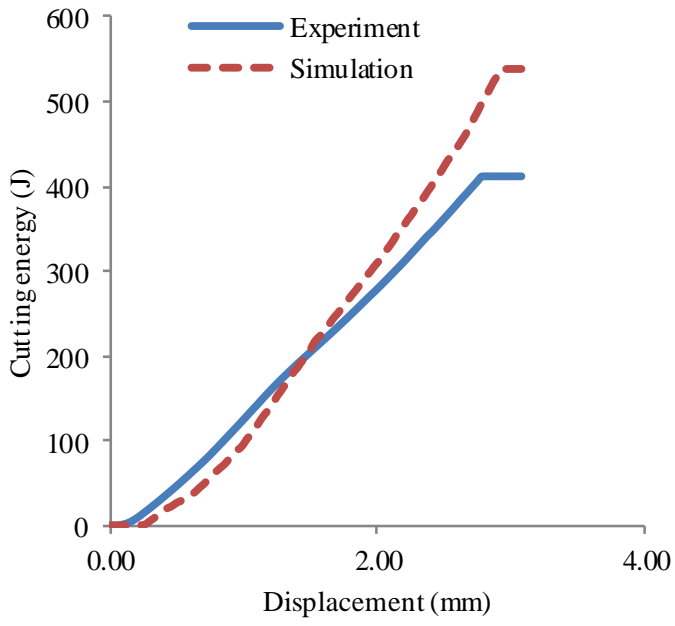

(b)

Figure 5-30. Miscanthus cutting with blade profile 3 at $3 \mathrm{~mm} / \mathrm{s}$ cutting speed, $45^{\circ}$ cutting angle and with conventional cutting method: (a) force vs. displacement and (b) cutting energy vs. displacement. 


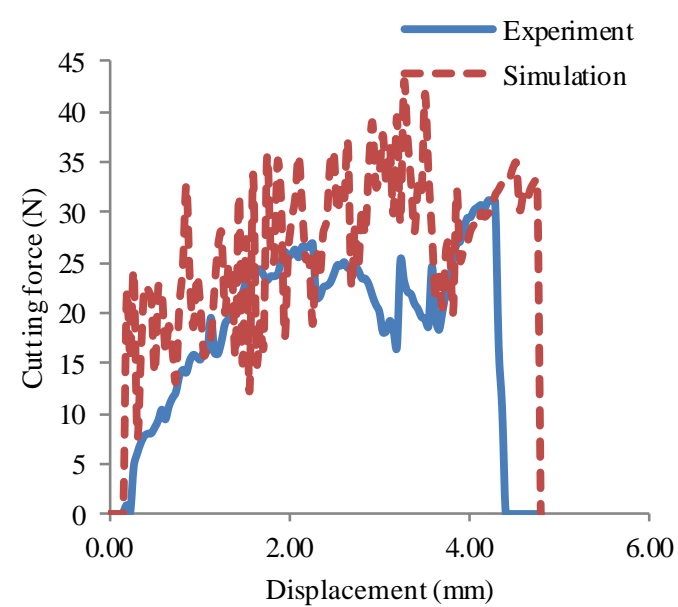

(a)

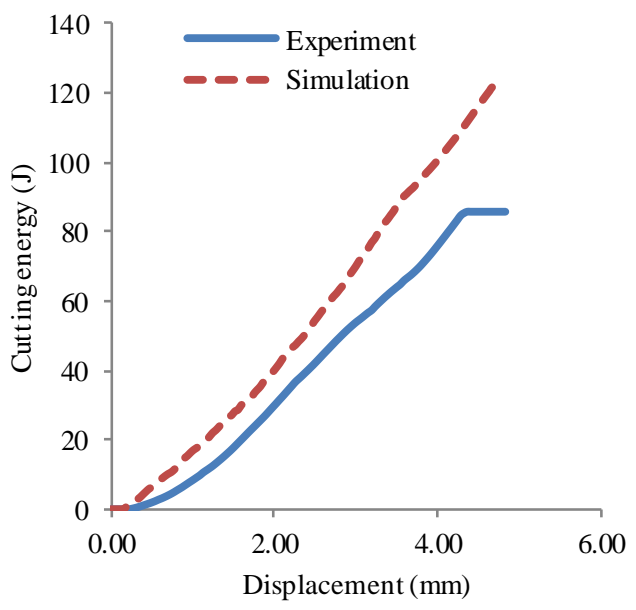

(b)

Figure 5-31. Miscanthus cutting with blade profile 2 at $300 \mathrm{~mm} / \mathrm{s}$ cutting speed, $90^{\circ}$ cutting angle and with ultrasonic cutting method: (a) force vs. displacement and (b) cutting energy vs. displacement.

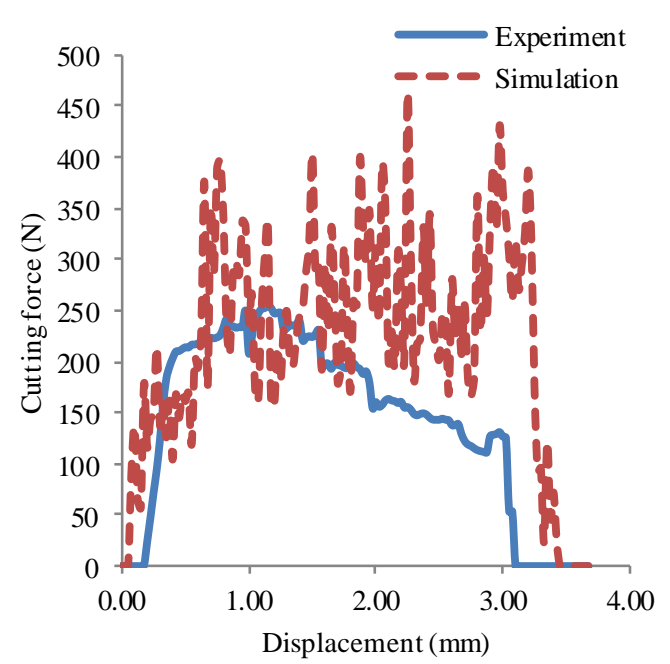

(a)

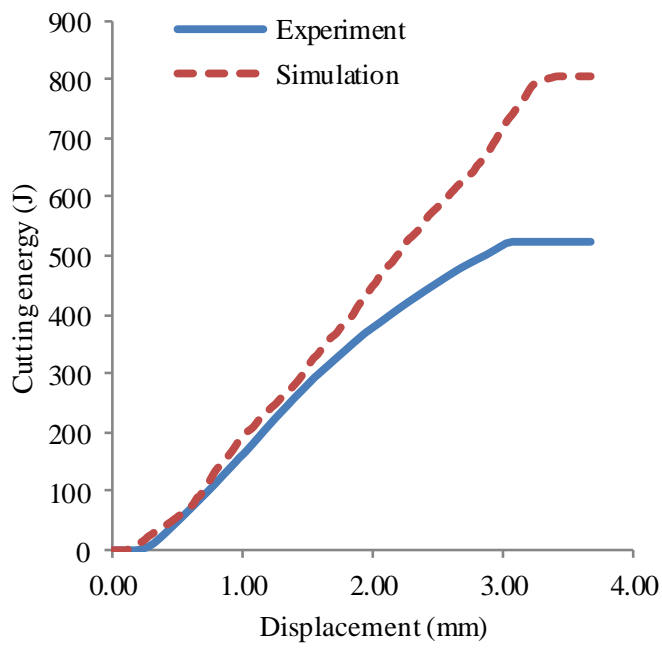

(b)

Figure 5-32. Miscanthus cutting with blade profile 3 at $300 \mathrm{~mm} / \mathrm{s}$ cutting speed, $60^{\circ}$ cutting angle and with conventional cutting method: (a) force vs. displacement and (b) cutting energy vs. displacement.

The cutting performances with systematically designed cutting parameters are summarized in Table 5-6. In order to find the parameters that have the most impact on 
cutting parameters, ANOVA was adopted to analyze the result for both the experiments and simulations. The analysis results are shown in Figure 5-33 to Figure 5-44.

Table 5-6. Miscanthus cutting performances with different cutting parameters .

\begin{tabular}{cccc|ccc}
\hline & \multicolumn{3}{c|}{ Experiment } & \multicolumn{3}{c}{ Simulation } \\
\cline { 2 - 7 } Trial & Max. & $\begin{array}{c}\text { Average } \\
\text { cutting } \\
\text { cutting } \\
\text { force }(\mathrm{N})\end{array}$ & $\begin{array}{c}\text { Cutting } \\
\text { Energy } \\
(\mathrm{N})\end{array}$ & $\begin{array}{c}\text { Max. } \\
\text { cutting } \\
\text { force }(\mathrm{N})\end{array}$ & $\begin{array}{c}\text { Average } \\
\text { cutting } \\
\text { force }(\mathrm{N})\end{array}$ & $\begin{array}{c}\text { Cutting } \\
\text { Energy } \\
(\mathrm{J})\end{array}$ \\
\hline 1 & 169.84 & 133.38 & 1171.20 & 285.72 & 153.22 & 1351.42 \\
2 & 9.98 & 5.79 & 44.41 & 12.87 & 9.30 & 62.01 \\
3 & 199.09 & 144.21 & 717.43 & 336.62 & 175.91 & 959.08 \\
4 & 6.97 & 2.58 & 13.33 & 7.75 & 4.98 & 24.96 \\
5 & 183.57 & 117.52 & 707.11 & 280.05 & 169.10 & 977.59 \\
6 & 246.36 & 144.17 & 610.07 & 356.45 & 223.78 & 789.08 \\
7 & 183.15 & 134.98 & 411.68 & 329.09 & 194.00 & 538.35 \\
8 & 31.17 & 19.37 & 85.79 & 42.84 & 26.70 & 121.83 \\
9 & 254.76 & 152.36 & 661.69 & 461.69 & 240.21 & 805.03 \\
\hline
\end{tabular}

Main effect plots for max. cutting force

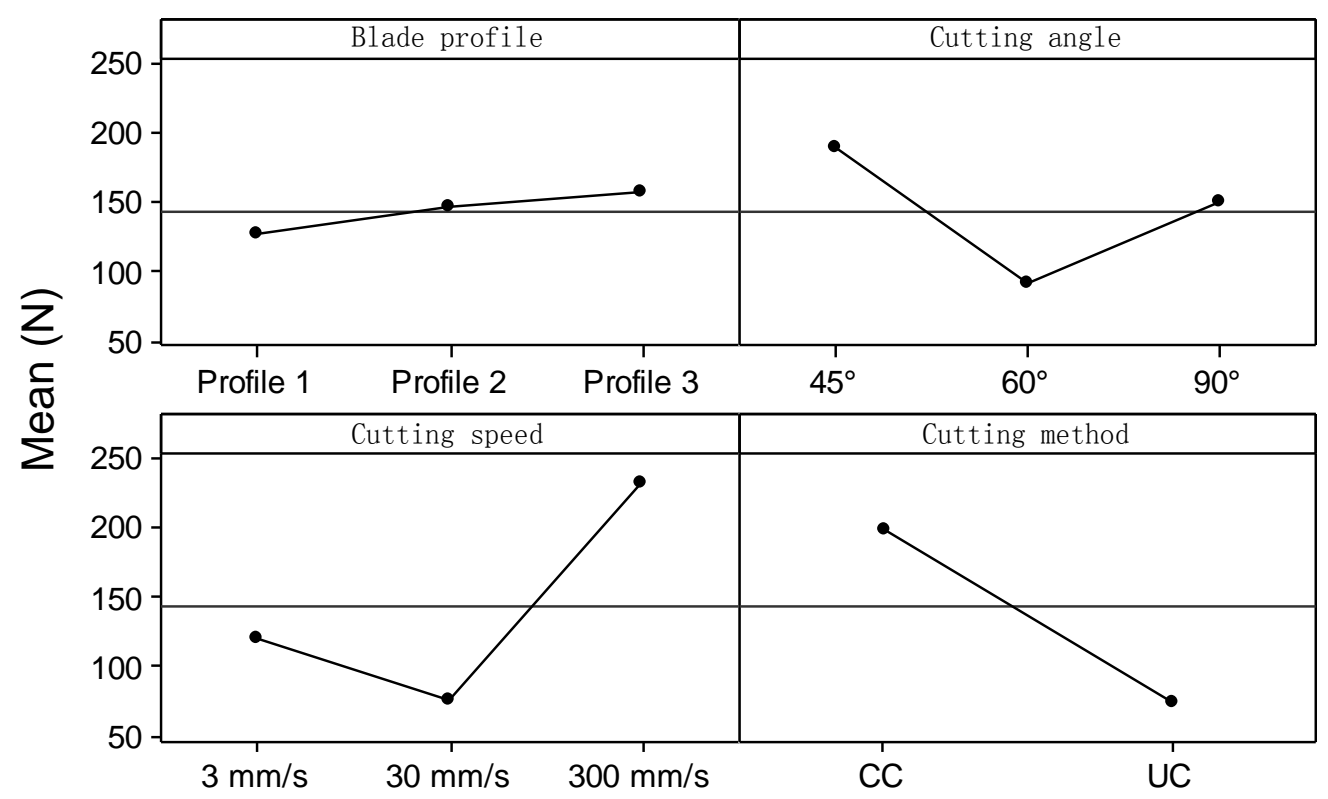

Figure 5-33. Miscanthus main effect plots for experimental max. cutting force. 


\section{Interaction plot for max. cutting force}

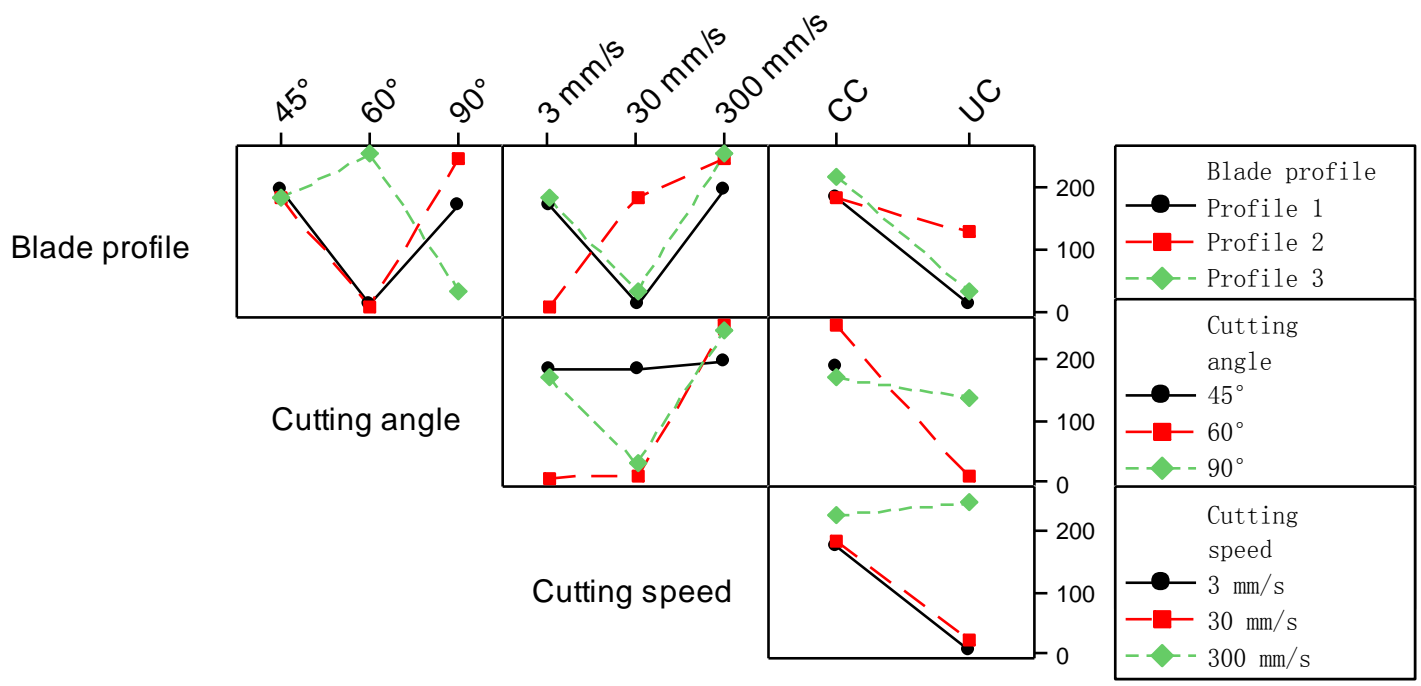

Cutting method

Figure 5-34. Miscanthus interaction plot for experimental max. cutting force.

\section{Main effect plots for average cutting force}

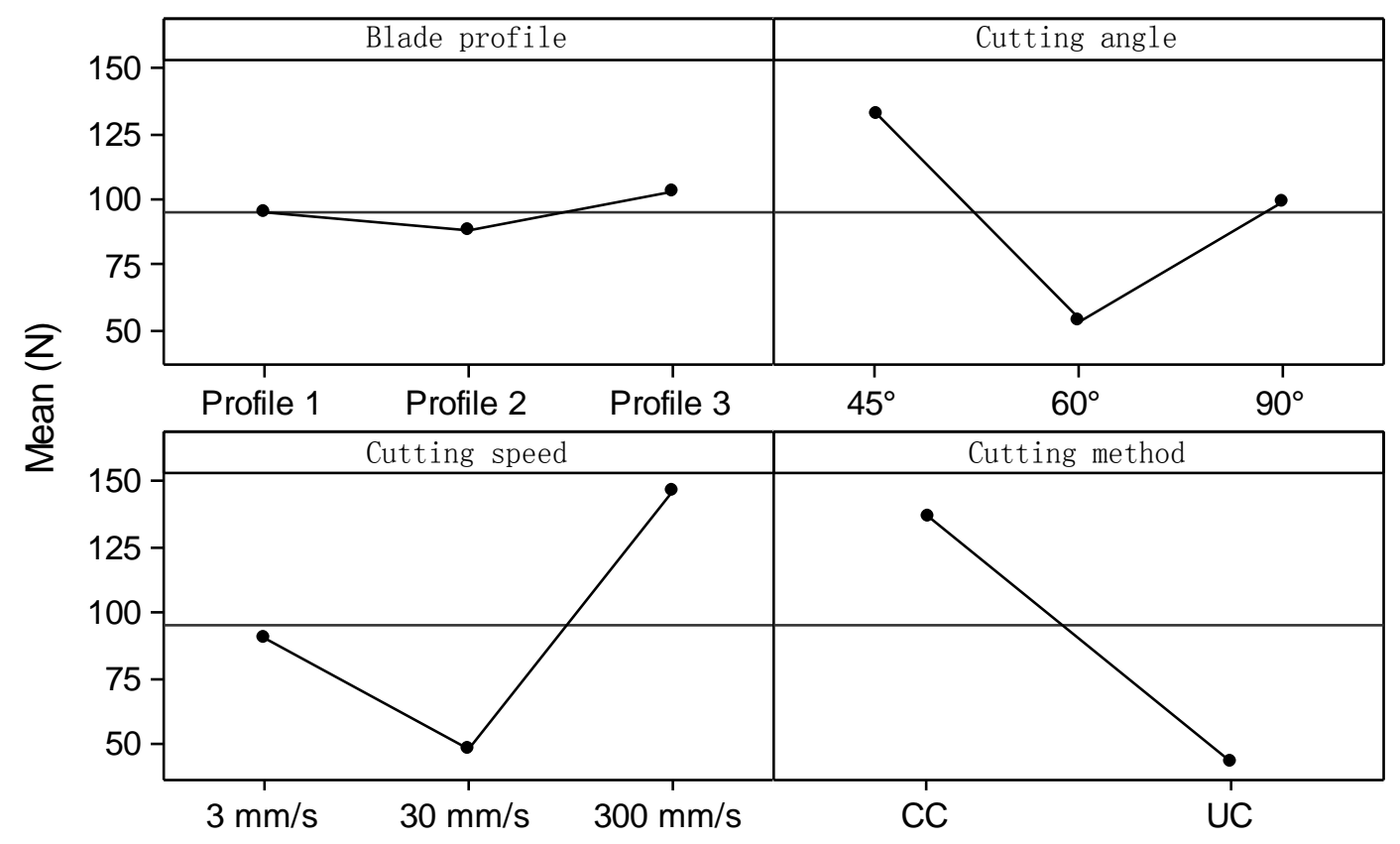

Figure 5-35. Miscanthus main effect plots for experimental average cutting force. 
Interaction plot for average force

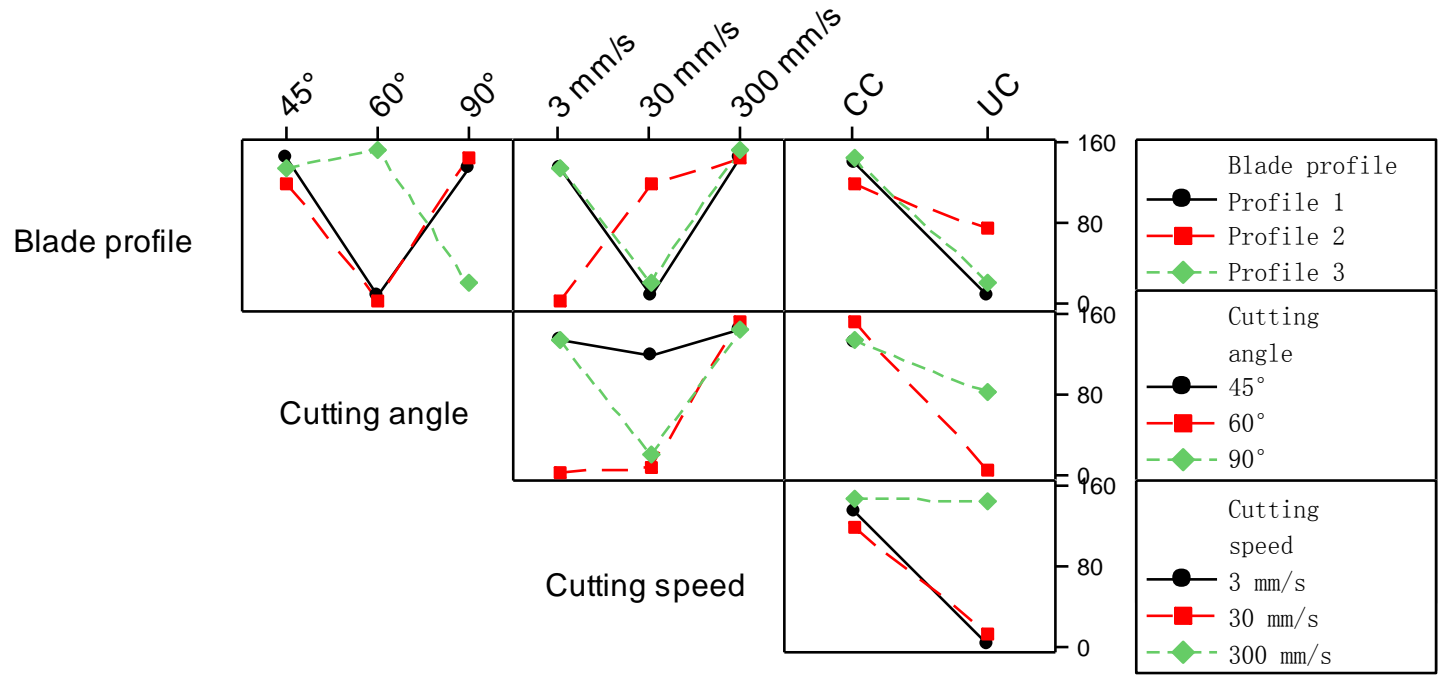

Cutting method

Figure 5-36. Miscanthus interaction plot for experimental average force.

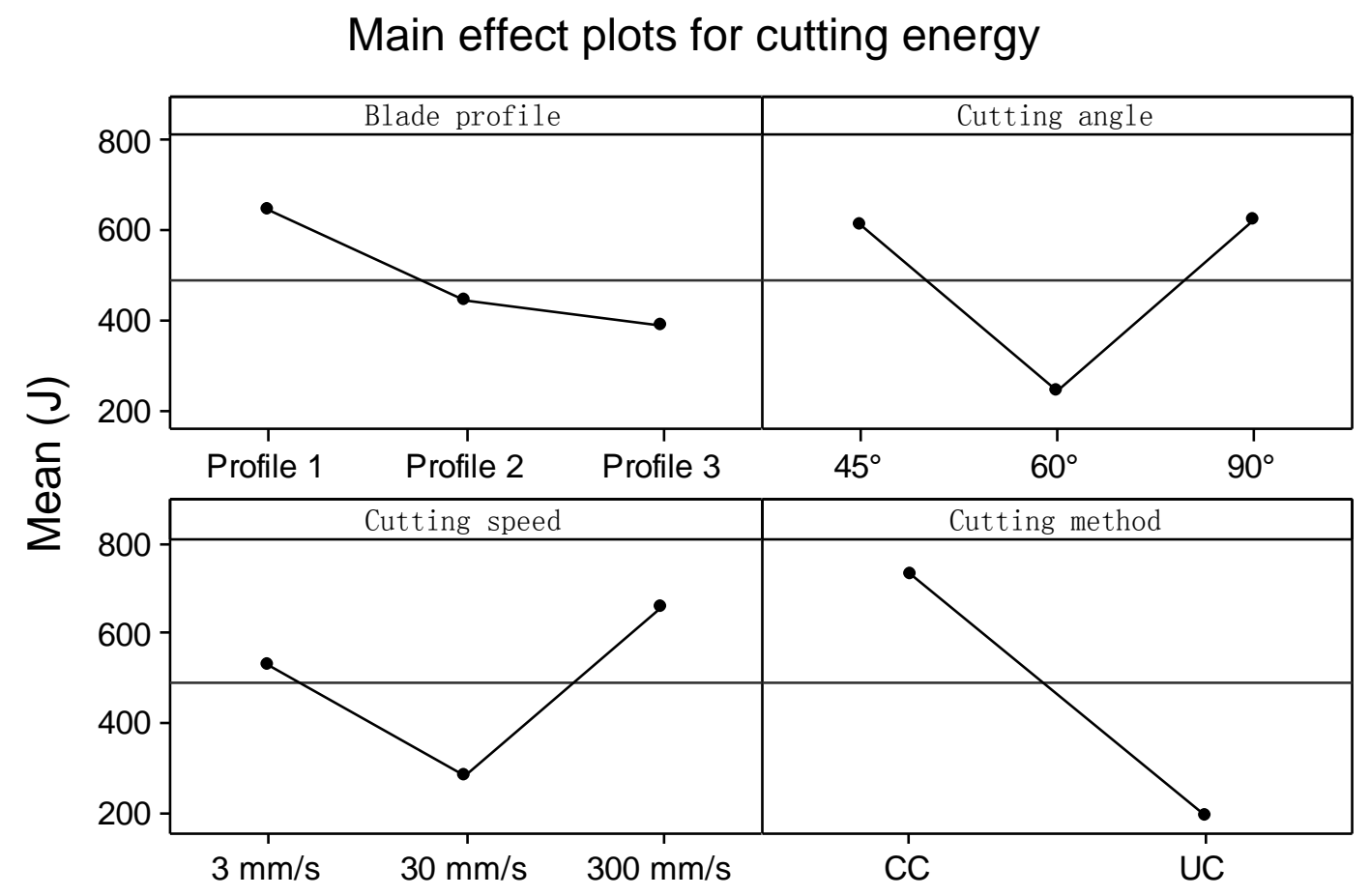

Figure 5-37. Miscanthus main effect plots for experimental cutting energy. 


\section{Interaction plot for cutting energy}

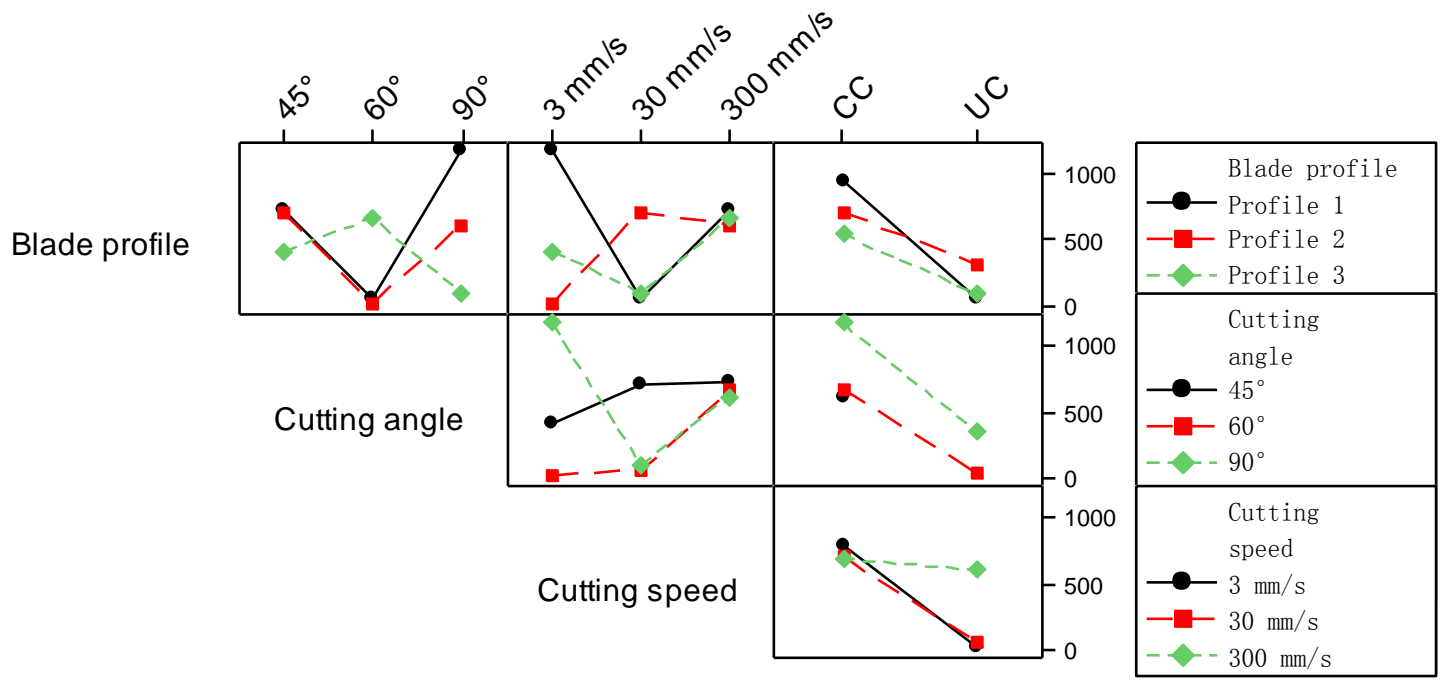

Cutting method

Figure 5-38. Miscanthus interaction plot for experimental cutting energy.

\section{Main effect plots for max. cutting force}

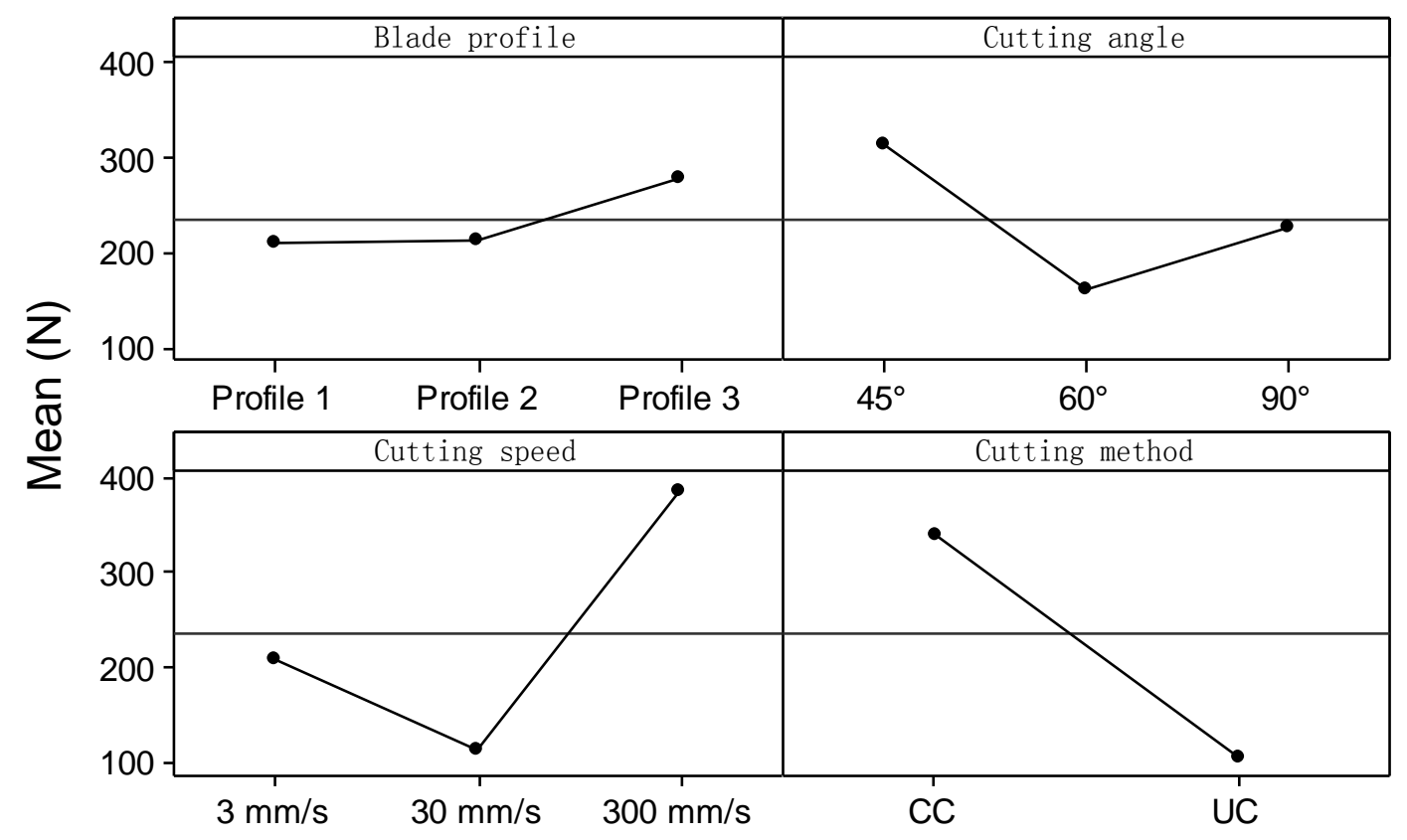

Figure 5-39. Miscanthus main effect plots for simulated max. cutting force. 


\section{Interaction plot for max. cutting force}

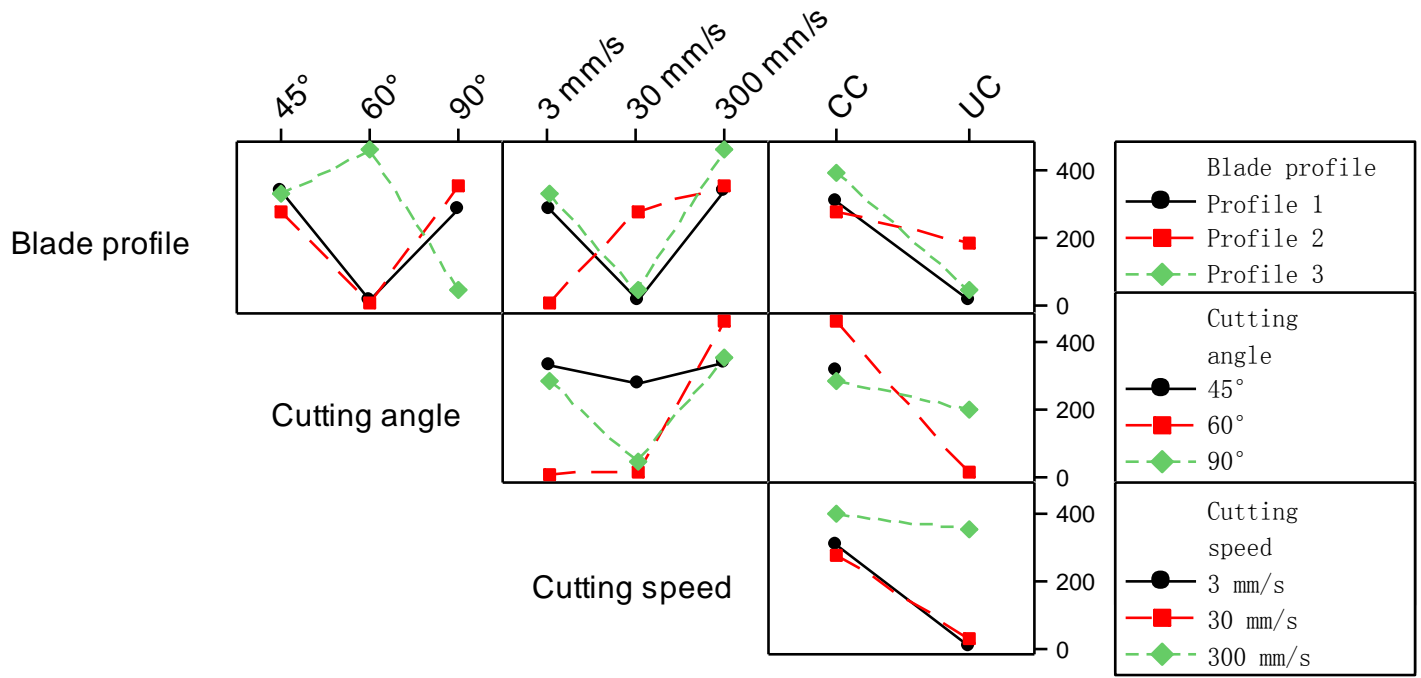

Cutting method

Figure 5-40. Miscanthus interaction plot for simulated max. cutting force.

\section{Main effect plots for average cutting force}

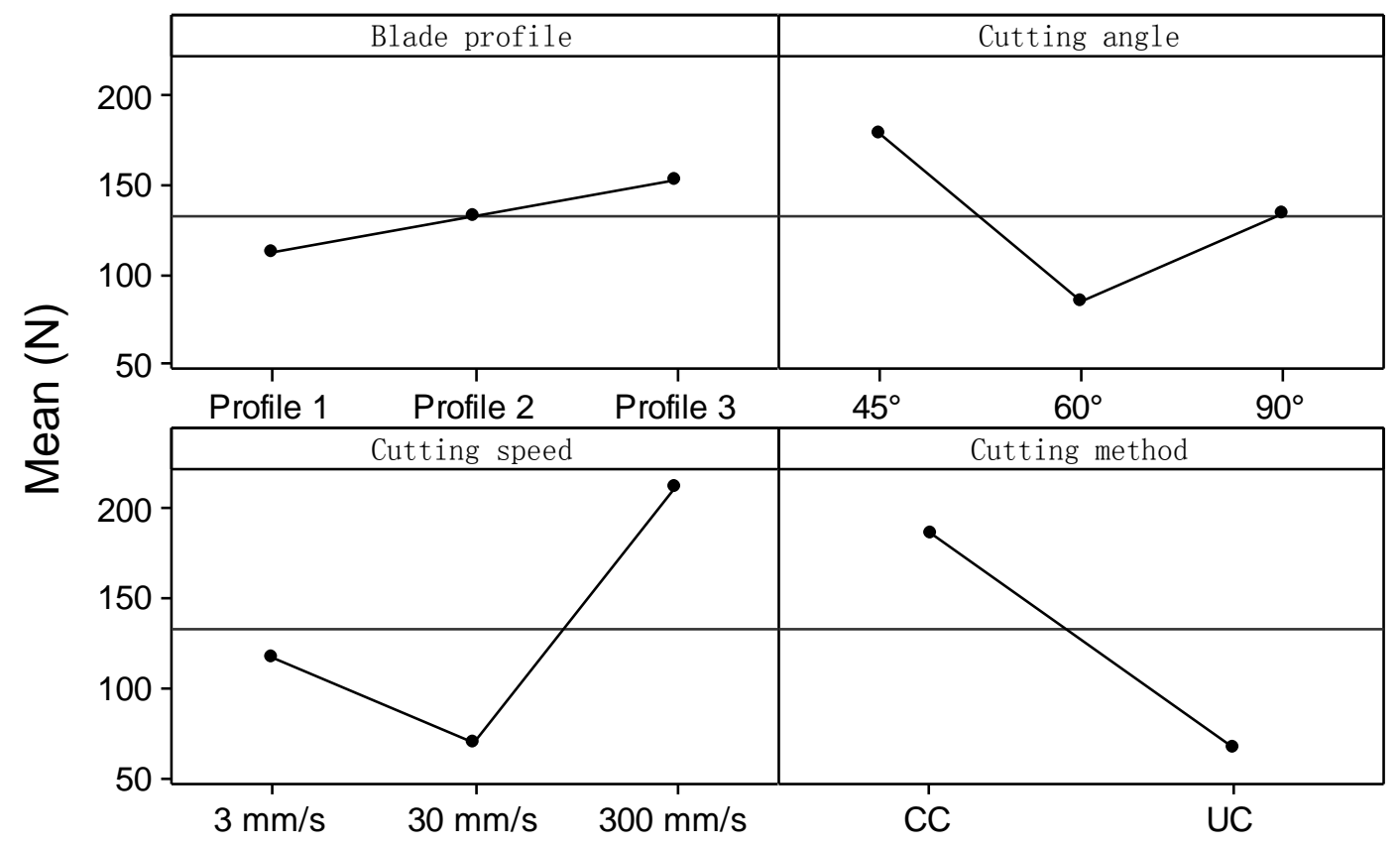

Figure 5-41. Miscanthus main effect plots for simulated average cutting force. 


\section{Interaction plot for average cutting force}

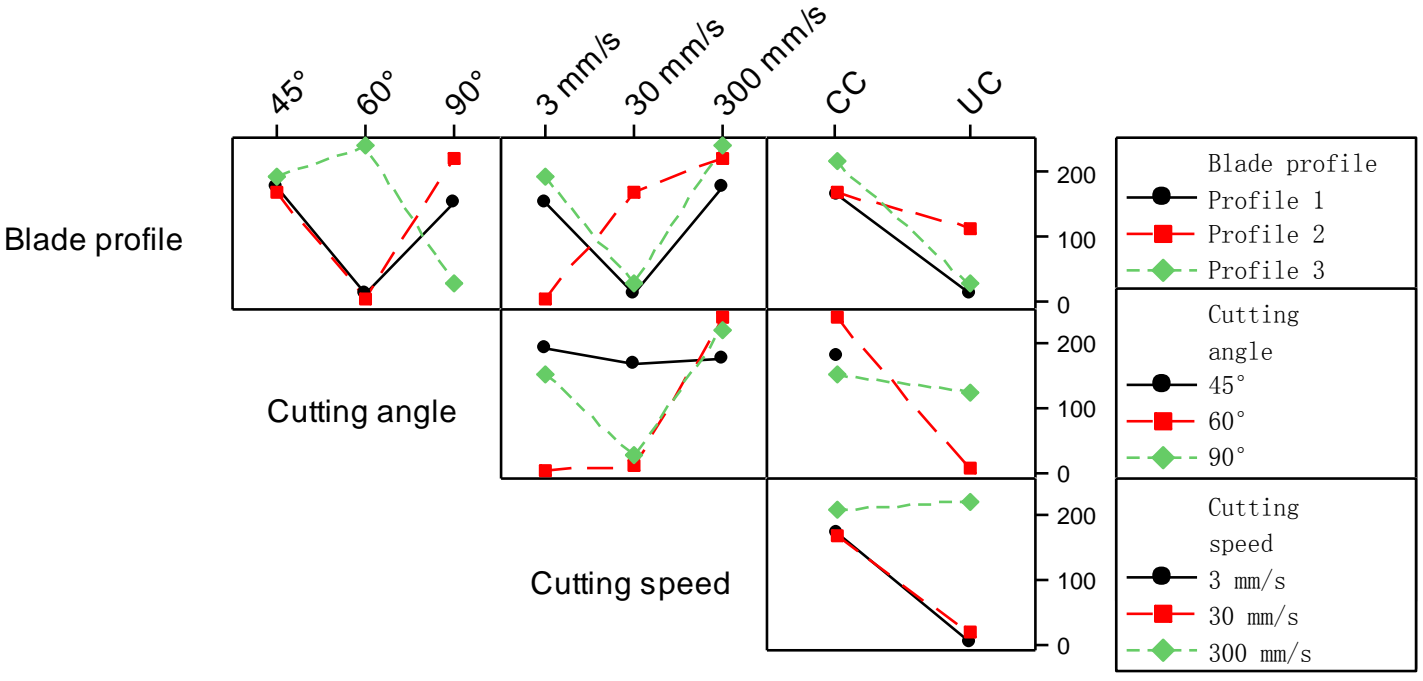

Cutting method

Figure 5-42. Miscanthus interaction plot for simulated average cutting force.

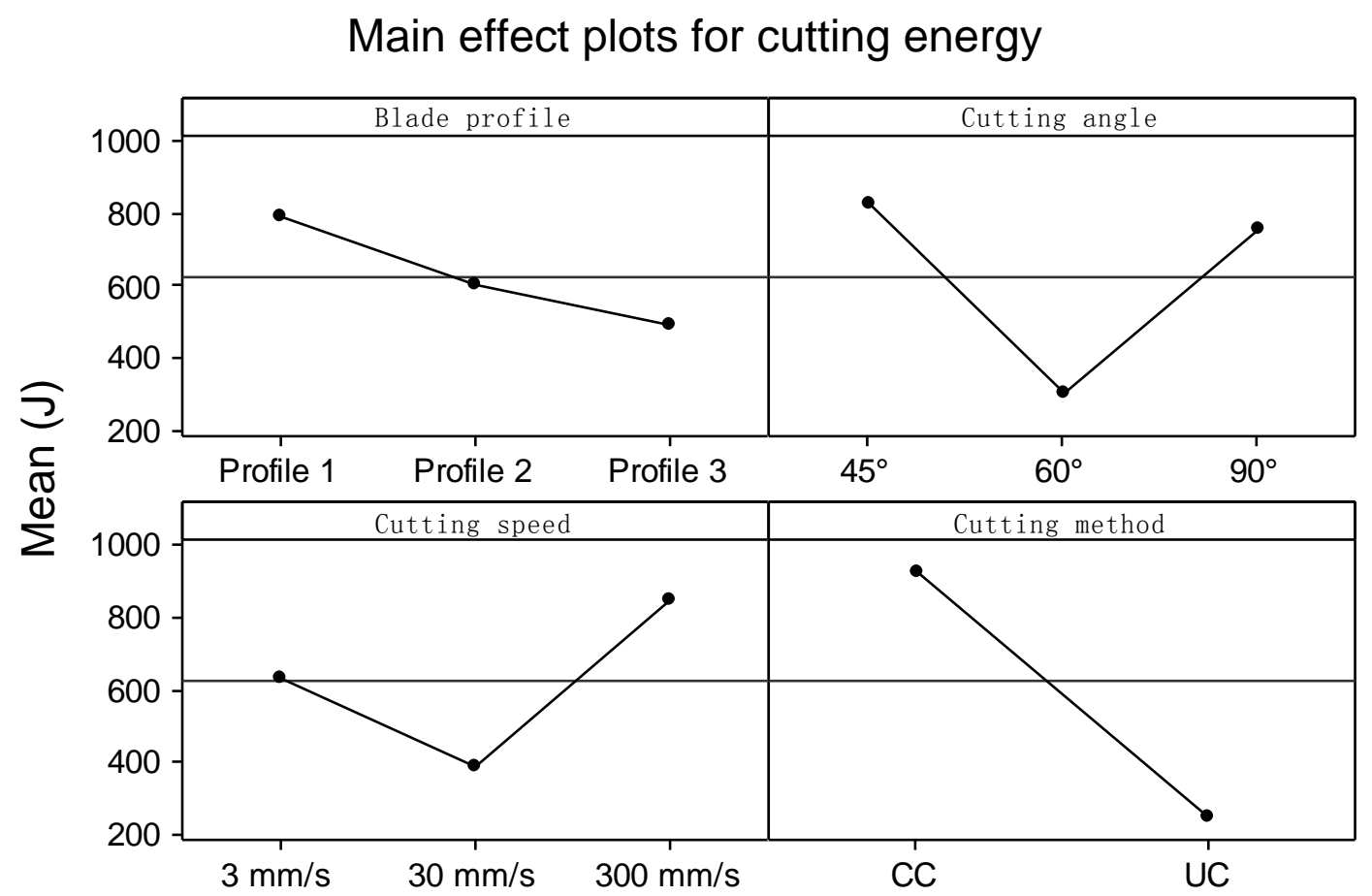

Figure 5-43. Miscanthus main effect plots for simulated cutting energy. 


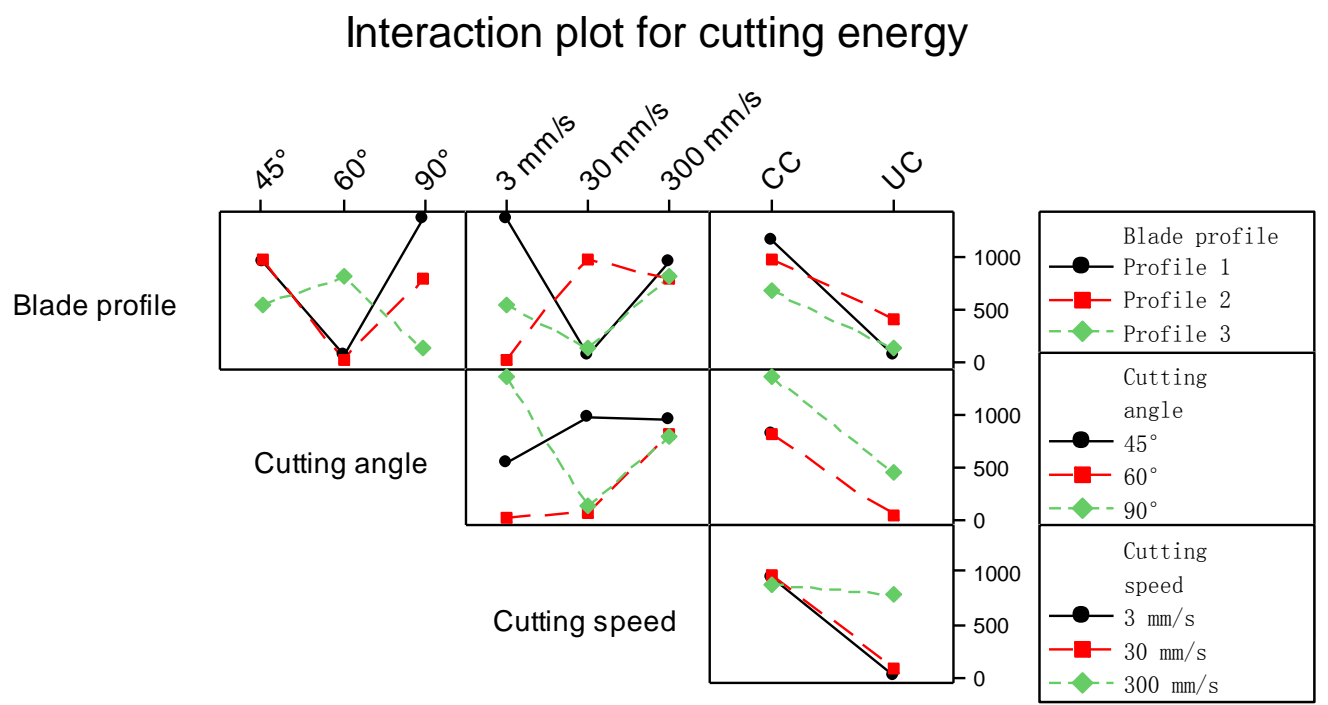

Cutting method

Figure 5-44. Miscanthus interaction plot for simulated cutting energy.

The ANOVA analysis of miscanthus cutting performance results are summarized in Table 5-7. The results show that cutting method, cutting speed and cutting angle are the most significant cutting parameters on cutting performances compared to blade profile. The interaction plots for maximum cutting force, average cutting force and cutting energy show that cutting parameters have interactions with each other, which indicates that the best cutting performance can be achieved by adjusting these cutting control parameters.

Table 5-7. ANOVA table for miscanthus cutting performance delta values.

\begin{tabular}{|c|c|c|c|c|c|}
\hline & & $\begin{array}{c}\text { Blade } \\
\text { profile }\end{array}$ & $\begin{array}{c}\text { Cutting } \\
\text { angle } \\
\text { (degree) }\end{array}$ & $\begin{array}{l}\text { Cutting } \\
\text { speed } \\
(\mathrm{mm} / \mathrm{s})\end{array}$ & $\begin{array}{l}\text { Cutting } \\
\text { method }\end{array}$ \\
\hline \multirow{3}{*}{ Experiment } & Max. cutting force $(\mathrm{N})$ & $30(4)$ & $98(3)$ & $158.5(1)$ & $124.5(2)$ \\
\hline & Average cutting force $(\mathrm{N})$ & $14.1(4)$ & $78.6(3)$ & $99.3(1)$ & $93.6(2)$ \\
\hline & Cutting energy $(\mathrm{J})$ & $257.9(4)$ & $372.3(3)$ & $384(2)$ & $545.4(1)$ \\
\hline \multirow{3}{*}{ Simulation } & Max. cutting force $(\mathrm{N})$ & $66.1(4)$ & $154.5(3)$ & $273(1)$ & $233.6(2)$ \\
\hline & Average cutting force $(\mathrm{N})$ & $40.8(4)$ & 94.9 (3) & $144.9(1)$ & $120.3(2)$ \\
\hline & Cutting energy $(\mathrm{J})$ & $302.4(4)$ & $531.7(2)$ & $464(3)$ & $676.8(1)$ \\
\hline
\end{tabular}




\subsection{Energy consumption of biomass cutting}

As discussed in the previous section, control parameters such as cutting method, cutting speed and shear angle can influence the cutting performances for both switchgrass and miscanthus. Interactions exist among the control parameters, which indicate that optimized cutting performances can be achieved by adjusting the major control parameters. In order to optimize the cutting performance, especially the energy consumption of biomass cutting, the most significant control parameters, cutting speed, cutting method and shear angle, were adjusted systematically to conduct cutting experiments. Since the blade profiles designed in this study had less impacts compared to other cutting parameters, only the blade profile 1 was used in the biomass energy consumption tests. Total energy for conventional cutting is the energy equals to the mechanical cutting energy. For ultrasonic cutting, total energy equals to mechanical cutting energy plus energy consumed by the ultrasonic generator. For both switchgrass and miscanthus, average-sized samples were collected $(3.5 \mathrm{~mm}$ diameter with switchgrass and $7.7 \mathrm{~mm}$ diameter with miscanthus). All the samples with the same cross section areas were assumed to have the same physical and mechanical properties.

For each cutting angle $\left(90^{\circ}, 60^{\circ}\right.$ and $\left.45^{\circ}\right)$, ultrasonic cutting method and conventional cutting method were used to cut biomass samples at speeds changing from 3 $\mathrm{mm} / \mathrm{s}$ to $350 \mathrm{~mm} / \mathrm{s}$. Average cutting force and total energy were monitored, the experimental results are shown in Figure 5-45 to Figure 5-56. 


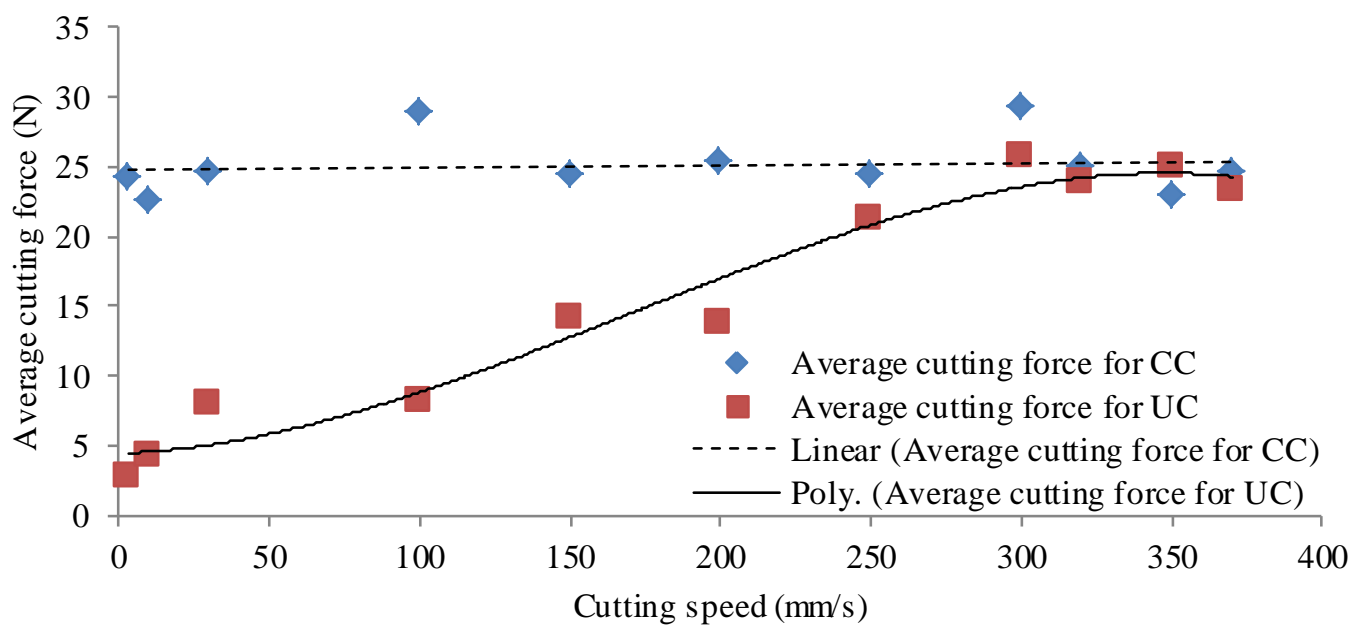

Figure 5-45. Average cutting force of switchgrass cutting with $90^{\circ}$ cutting angle.

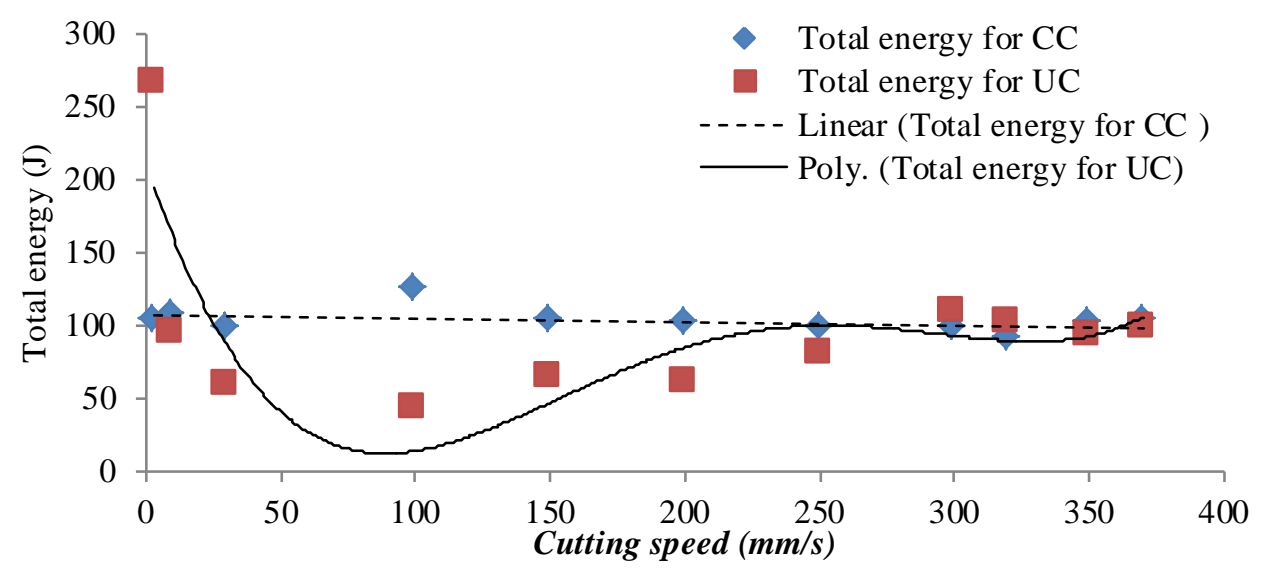

Figure 5-46. Total energy consumption of switchgrass cutting with $90^{\circ}$ cutting angle.

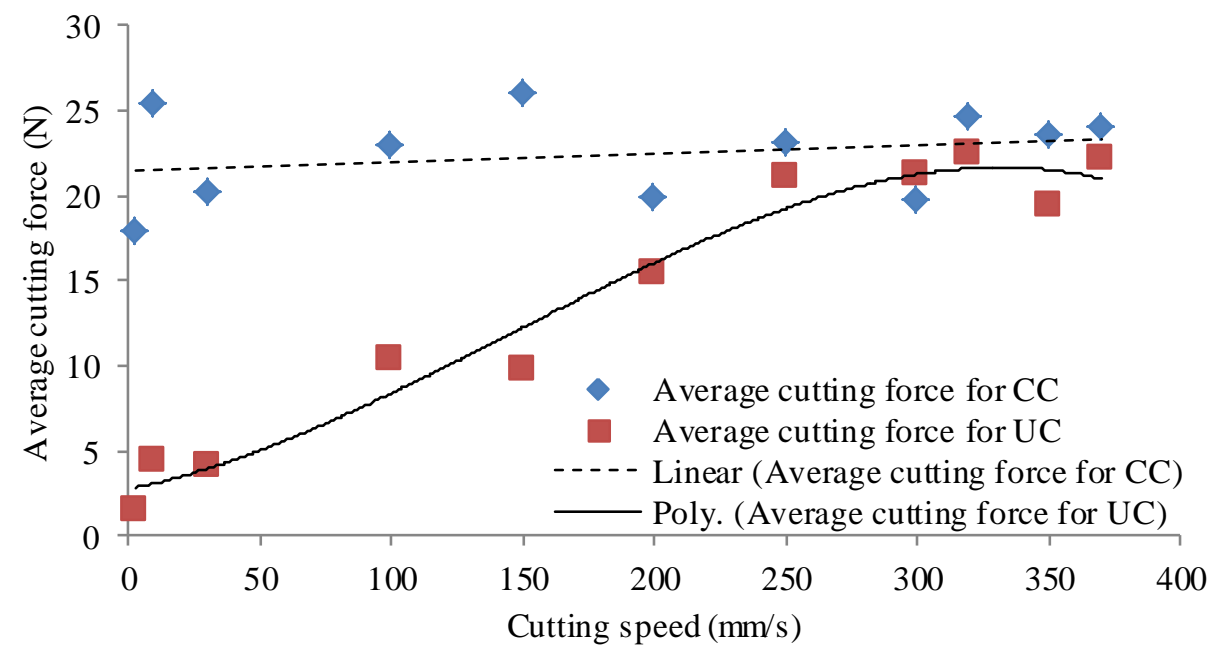

Figure 5-47. Average cutting force of switchgrass cutting with $60^{\circ}$ cutting angle. 


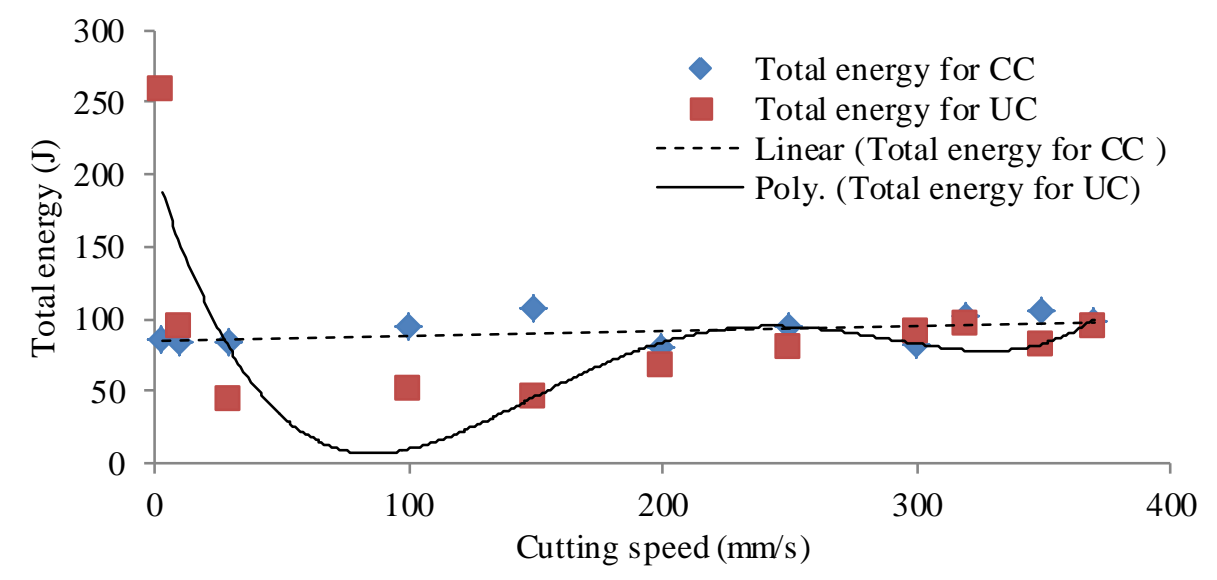

Figure 5-48. Total energy consumption of switchgrass cutting with $60^{\circ}$ cutting angle.

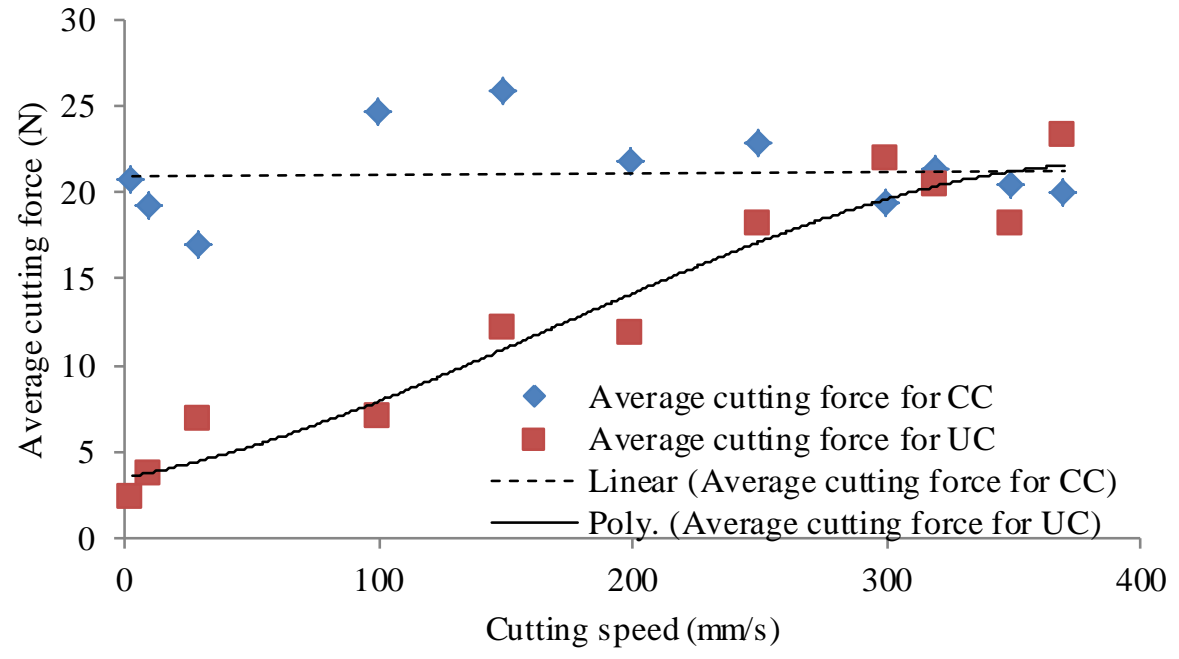

Figure 5-49. Average cutting force of switchgrass cutting with $45^{\circ}$ cutting angle.

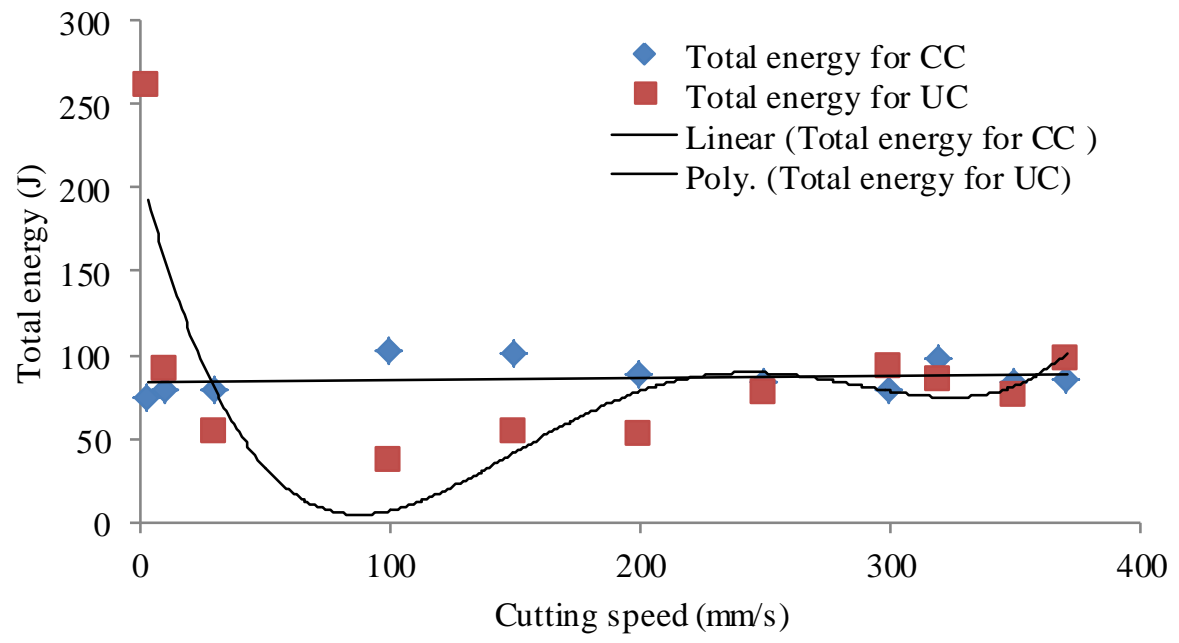

Figure 5-50. Total energy consumption of switchgrass cutting with $45^{\circ}$ cutting angle. 


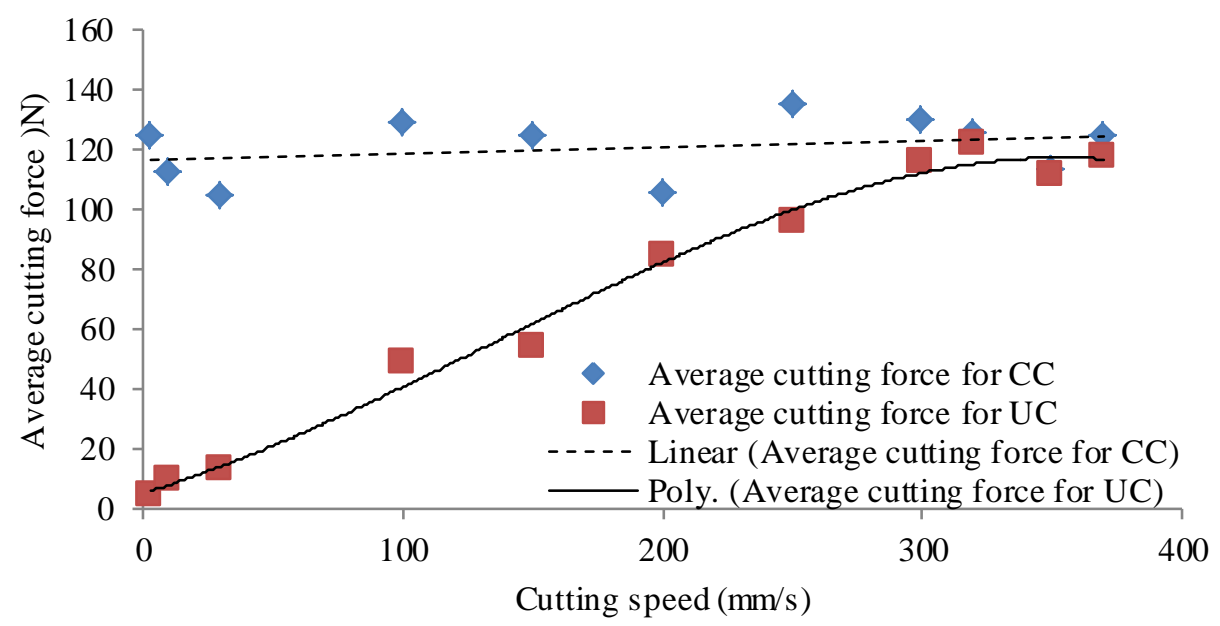

Figure 5-51. Average cutting force of miscanthus cutting with $90^{\circ}$ cutting angle.

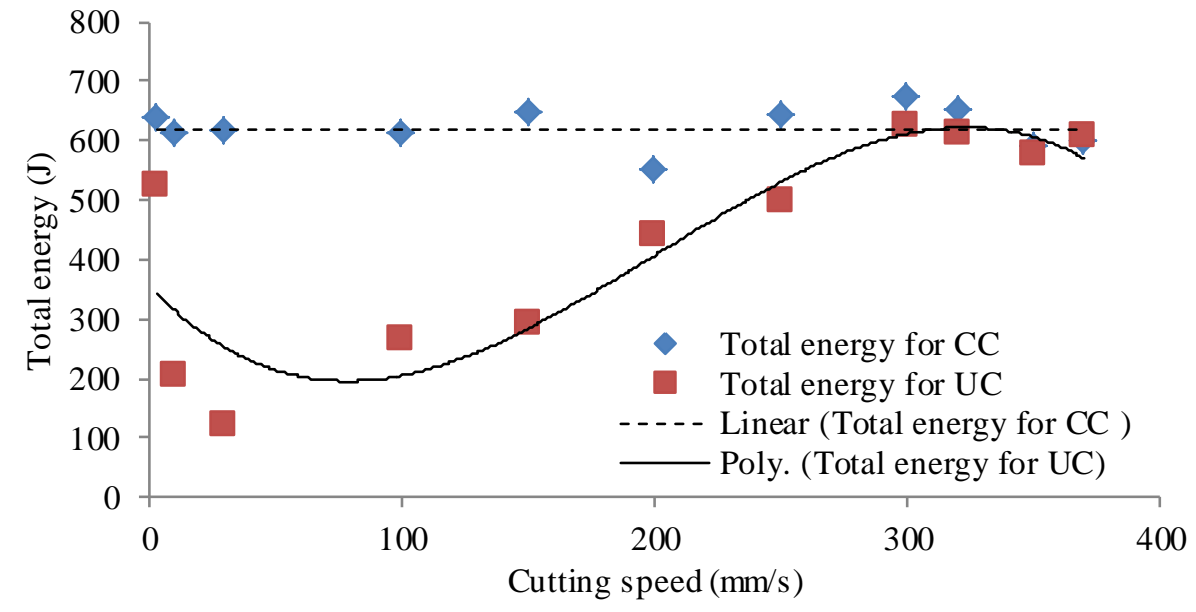

Figure 5-52. Total energy consumption of miscanthus cutting with $90^{\circ}$ cutting angle.

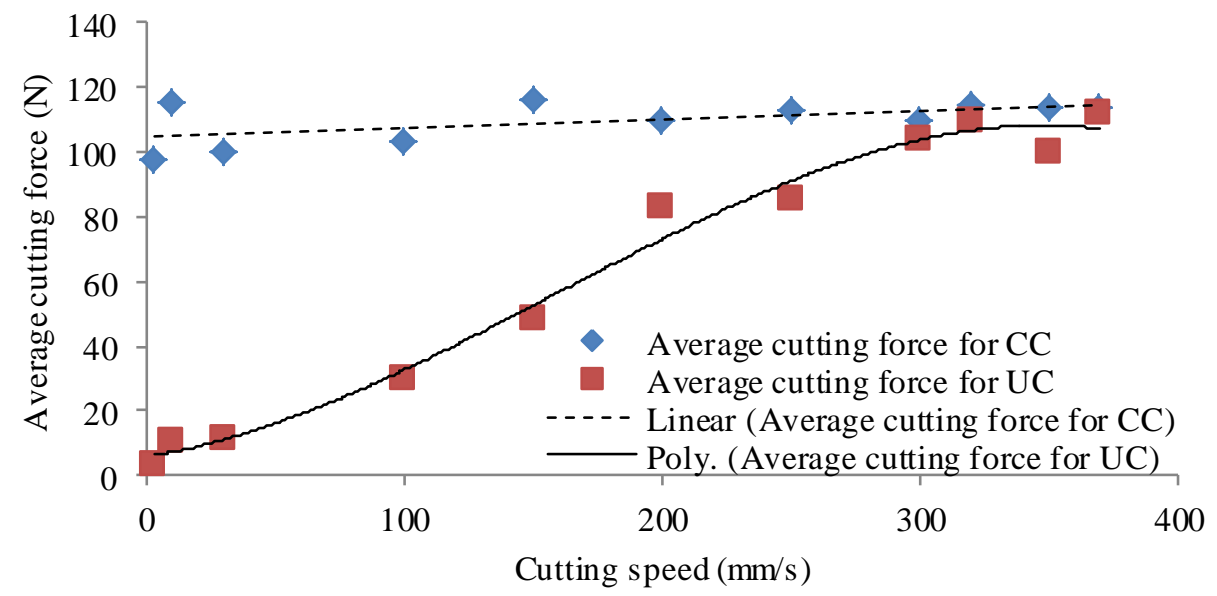

Figure 5-53. Average cutting force of miscanthus cutting with $60^{\circ}$ cutting angle. 


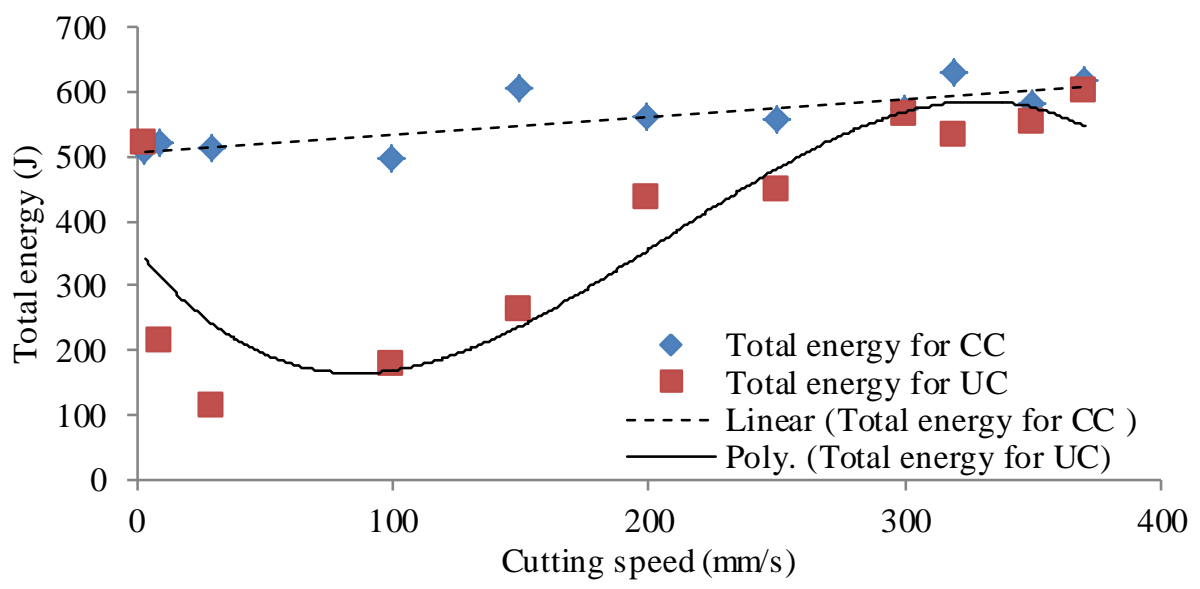

Figure 5-54. Total energy consumption of miscanthus cutting with $60^{\circ}$ cutting angle.

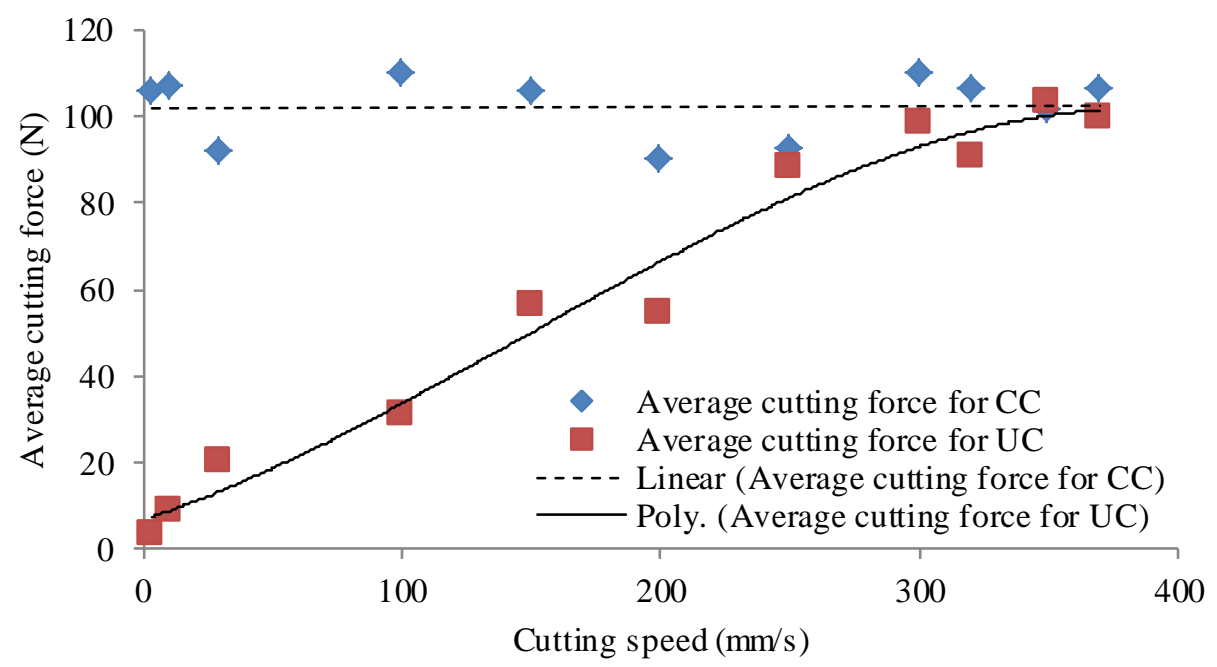

Figure 5-55. Average cutting force of miscanthus cutting with $45^{\circ}$ cutting angle.

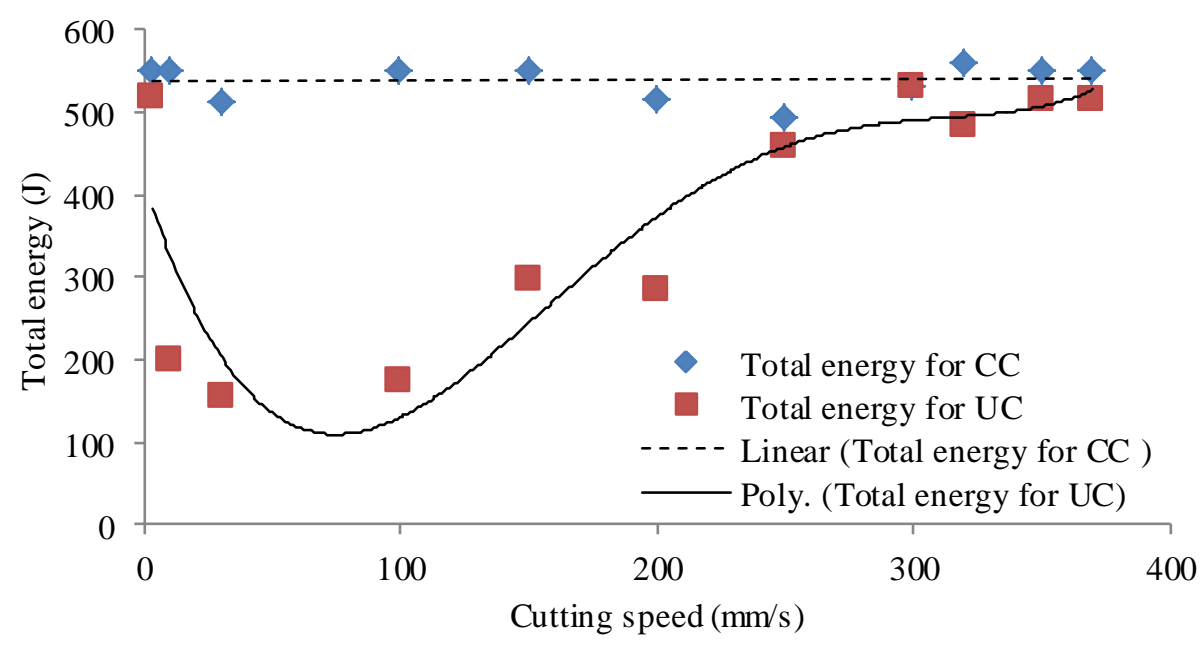

Figure 5-56. Total energy consumption of miscanthus cutting with $45^{\circ}$ cutting angle. 
For both switchgrass and miscanthus, the experimental results showed that the tested cutting speed levels did not influence the average cutting force and had critical impact on the average cutting force using ultrasonic cutting method. When the cutting speed was close to zero, the cutting force of ultrasonic cutting method was close to zero as well, and the average cutting force kept rising until the cutting speed reached about $300 \mathrm{~mm} / \mathrm{s}$. This can be interpreted that ultrasonic effect will have no impact on biomass cutting, when the cutting speed reaches a certain limit, and ultrasonic cutting method turns into conventional cutting method when the cutting speed is faster than the speed limit. The energy analysis showed that test cutting speed levels had no effect on total energy consumption of conventional cutting method. On the other hand, cutting speed played an important role on total energy consumption of biomass ultrasonic cutting. When the cutting speed was low, energy consumption of ultrasonic generator dominated the total energy use; when speed was high, the cutting energy dominated the total energy. For the energy analysis, cutting speed played an important role on total energy consumption. When the cutting speed was around $100 \mathrm{~mm} / \mathrm{s}$, ultrasonic cutting method had the least total energy use which could save about $50 \%$ energy consumption for switchgrass and $60 \%$ for miscanthus.

\subsection{Summary}

This section presented the experimental and numerical cutting force data of the conventional cutting and ultrasonic cutting of biomass. Cutting trials were experimentally performed on a linear ultrasonic cutting system and numerically simulated. The investigation presented a comparison of parametric experimental cutting tests performed on biomass for various cutting speeds, shear angle, blade designs, with and without 
ultrasonic vibrations. The experimental results were compared the results of FEA simulations which mimic the parametric experimental tests. Additional experimental investigations were performed to study the effect of shear angle, cutting speed and ultrasonication on the average cutting force and total cutting energy. For ultrasonic assisted cutting method, the blade tip vibration amplitude was $2.8 \mu \mathrm{m}$ with speed of 0.3 $\mathrm{m} / \mathrm{s}$, and at three cutting velocities, $3 \mathrm{~mm} / \mathrm{s}, 30 \mathrm{~mm} / \mathrm{s}$ and $300 \mathrm{~mm} / \mathrm{s}$ and the results were statistically analyzed by ANOVA. The predicted cutting force was higher than the force measured experimentally, which could be due to the inaccuracy of the material data included in the FEA model. In the simulation, when the elements failed due to cutting, the material properties of the elements were instantaneously ramped down to zero and removed from the solution, but this does not happen in reality. When the cutting speed was around $100 \mathrm{~mm} / \mathrm{s}$, ultrasonic cutting method had the least total energy use. The optimized total energy consumption can be achieved by adjusting the cutting speed with ultrasonication. 


\section{CHAPTER 6 CONCLUSIONS}

In this study, mechanical properties of biomass crops (miscanthus and switchgrass) were measured at two different moisture content levels. A linear cutting and data acquisition system was developed to investigate the cutting performances of conventional cutting and ultrasonic assisted cutting methods. The data acquisition system was utilized to record critical cutting performance data such as cutting force and energy consumption by the ultrasonic generator. Different cutting blade profiles were designed using FEA modal analysis to explore the cutting performances. Experimental cutting tests of different biomass crops with and without ultrasonication were carried out by using the demonstrated cutting system, and the cutting performance parameters were recorded and analyzed statistically.

Biomass mechanical properties were measured with two different controlled moisture contents for both switchgrass and miscanthus. The mechanical properties of biomass materials, specifically, miscanthus and switchgrass were determined by conducting tensile tests, compressive tests, shearing tests and friction coefficient determination tests. Biomass materials do not have uniform physical and mechanical properties and have complicated structures as shown in Figure 6-1, and these nonuniformity and anisotropic properties of biomass caused difficulties in determining mechanical properties. Specially designed testing grips were manufactured to allow biomass materials to be tested in tension, compression and shearing without damaging the sample ends.

The FEA was used to design three blade prototypes, and they were manufactured and experimentally tested by experimental modal analysis. The FEA modal analysis 
simulated the blade dynamic behaviors and made sure they were designed to work at the desired resonant frequency with ultrasonic signal applied. The amplitude of the ultrasonic blades must be sufficiently uniform to avoid damaging the cutting system and prevent heating. Grooves and slots were utilized in the blade design to achieve high uniformity. The uniformity was found to be influenced significantly by the groove depth and slot width. The inclusion of the FEA model can enhance the cutting blade design process to predict the optimum ultrasonic cutting parameters for cutting biomass prior to blade design and manufacture. This could reduce the number of design iterations in the cutting blade design process, and offer time and cost savings to the blade manufacturing.

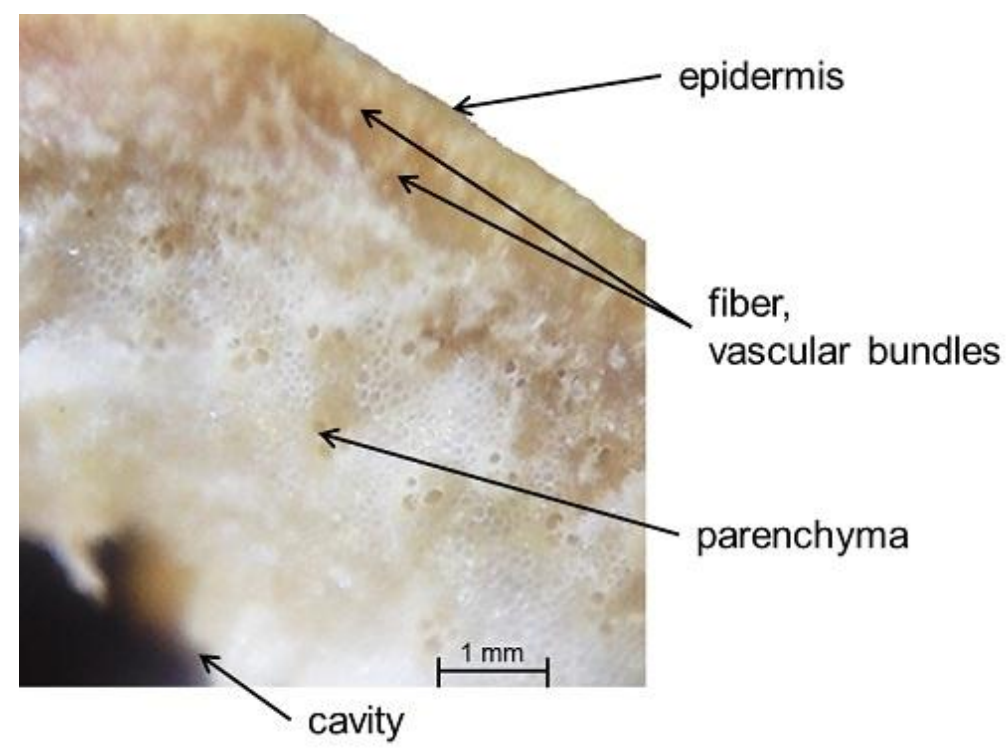

Figure 6-1. Miscanthus cross-section structure.

The studies within this dissertation illustrate how FEA modeling can be used to predict cutting parameters and subsequently can be used to optimize the cutting process. Three dimensional FEA model offers flexibility in simulating biomass cutting whereby complicated blade shapes, biomass specimens and complex cutting parameters can be simulated readily. This modeling technique is however very computationally intensive 
and usually requires a refined mesh for high accuracy analysis results. Due to the extensive computational time, fewer elements were used in the models (coarse mesh) to allow cutting predictions to be made in reasonable timescales in an attempt to validate the modeling technique. Validation of the FEA model was carried out by comparing cutting experiments performed on a specially designed linear axis cutting system with numerical simulations mimicking the experimental cutting trials. The accuracy of the results could possibly be improved by using a more refined mesh in the cutting region. During cutting the blade tip becomes slightly blunt after prolonged use but the geometry in the simulated model is always unchanged during cutting. With further work and refinement, the modeling technique could have a higher accuracy by incorporating more accurate material definitions and proper failure criteria to represent the process in more details.

In the conventional biomass cutting process, the blade first compresses a biomass stem, and then the cortex fails in the longitudinal shear, causing the longitudinal split. The biomass cortex tissues then start to fail in longitudinal tension, causing them to be severed, and this continues until the blade cuts about two-thirds of the stem diameter. Finally, the remaining part of the stem fails in shear as shown in Figure 6-2. For the ultrasonic cutting, the micro high speed vibration on the ultrasonic blade tip penetrates the biomass cortex in the initial compression and the oscillatory tip movement can reduce the blade-biomass contacting time, which can significantly reduce the friction, hence reduce cutting force. 


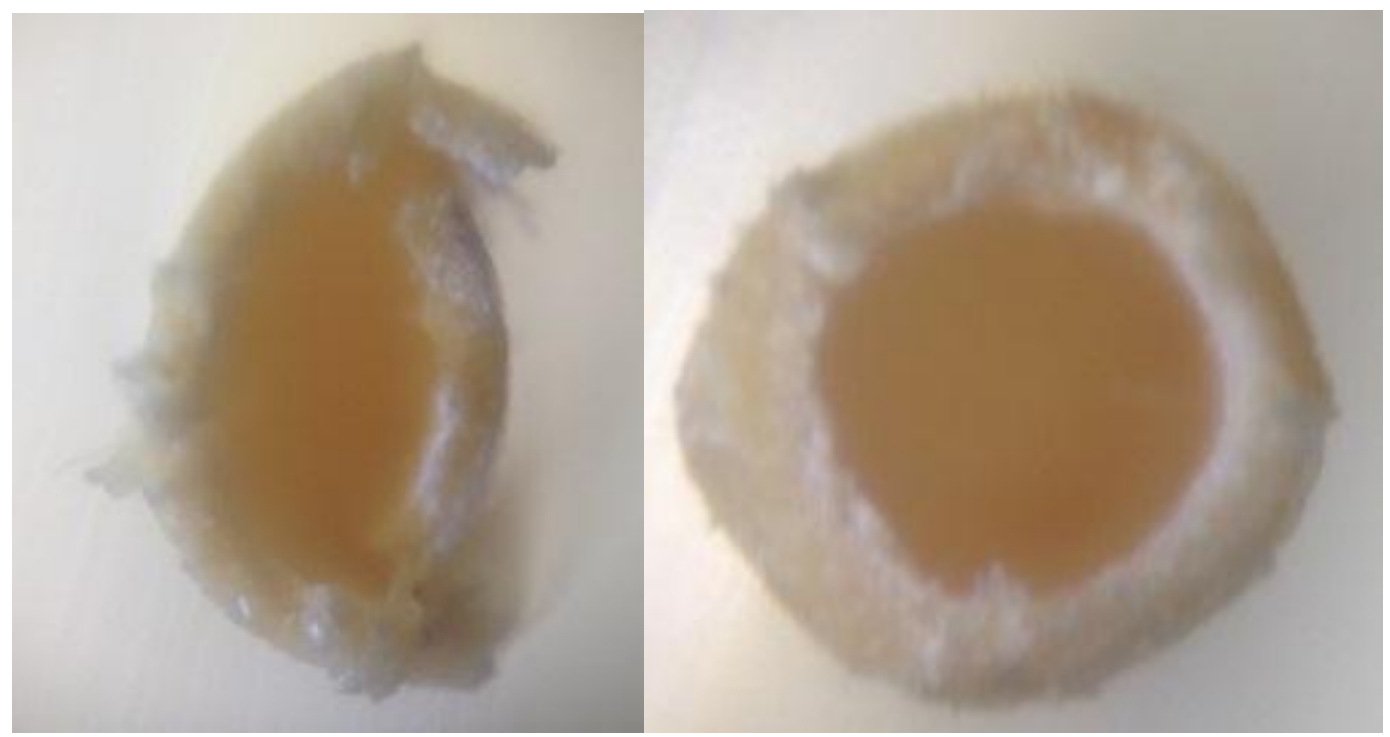

(a)

(b)

Figure 6-2. Cross section of cut switchgrass stems by: (a) conventional cutting method and (b) ultrasonic cutting method.

Biomass cutting trials were experimentally conducted on a linear ultrasonic cutting system and numerically simulated. This investigation provided a systematic way to compare the cutting performances of the conventional cutting method and the ultrasonicassisted cutting method. For ultrasonic assisted cutting method, the blade tip vibration amplitude was $2.8 \mu \mathrm{m}$ with speed of $300 \mathrm{~m} / \mathrm{s}$. The results were statistically analyzed by ANOVA. Experimental results showed that cutting speed, cutting method and shear angle had the most significant impact on cutting performances. In ultrasonic cutting tests, cutting speed around $100 \mathrm{~mm} / \mathrm{s}$ consumed the lowest total energy which saved about 50\% for switchgrass cutting and $60 \%$ for miscanthus cutting with the designed cutting parameters. The average cutting force increases as cutting speed increases, and it stops rising when it reached the ultrasonic blade vibration speed (no ultrasonic effect on biomass cutting beyond that limit). In conventional cutting tests, the tested cutting speeds did not show obvious effects on cutting performances. 
In summary, the contributions achieved in this study include:

- Determination of switchgrass and miscanthus mechanical properties along the fiber direction and cross the fiber direction. The determined mechanical properties were used in FEA simulations.

- Ultrasonic blades were designed at $20 \mathrm{kHz}$, and they successfully cut biomass stem with the designed cutting parameters. Undesired modes or mode shifting were avoided by designing the blade to be vibrated with the frequency very close to the driving frequency and far from the adjacent modes' frequencies.

- FEA ultrasonic cutting models were developed. The models enabled the biomass cutting process to be simulated and the relationship between cutting performances and cutting parameters to be predicted. Although the models need further refinement, they offer a useful tool for future blades design, cutting/grinding simulation to reduce the experimental costs.

- The simulation and experimental results indicated that ultrasonic-assisted cutting method could reduce cutting force and energy consumption of biomass preprocessing, when proper cutting parameters were chosen; the cutting speed played the most important role on cutting force and cutting energy reduction. 


\section{CHAPTER 7 FUTURE WORK}

\subsection{Determination of biomass mechanical properties}

Investigating the mechanical properties of more biomass samples using the experimental testing techniques discussed in this thesis could create a database of properties to be collated for use in FEA modeling involving biomass processing. Future research considerations can include expanding moisture contents of biomass materials. The experimental results indicate that biomass stems with low moisture contents are elastic-brittle materials, therefore special experimental tools need to be designed and used to handle the materials properly to avoid damaging them. Biomass materials also come with various physical shapes and non-uniform properties, averaging techniques should be taken to obtain the dimensions and properties.

\subsection{Ultrasonic blade design}

The research conducted in this study considered integrating the ultrasonic cutting blade design process to enhance the blade design. Several distinct areas of research have been incorporated in this dissertation and have provided a stable platform for which further exploration of the modeling of ultrasonic cutting using FEA models and determination of the thermal and mechanical properties of biomass material can be progressed.

Serrated blades, rotating blades and wider blades with ultrasonic-assisted cutting technique integrated can provide more information about the impact of blade designs on cutting and grinding performances. Other metal materials, for instance Titanium, can also be used to manufacture the blades. Fatigue and blade wear analysis can also be studied by 
both FEA and experiments in the future study to explore the blade designs and cutting methods to extend the blade life.

\subsection{Finite element analysis}

This study provided a solid base for using FEA modeling to predict the applied load during ultrasonic cutting but further work is necessary to refine the FEA model to allow future predictions about the effect of various cutting parameters on cutting temperature and applied load to be made that are more representative and indicative of the experimental results.

Further refining of the FEA cutting simulation models would provide an accurate representation of cutting force with different cutting parameters and also enhance the temperature prediction. Incorporating not only single but multi-stems of biomass in the FEA modeling technique would also be advantageous as biomass materials being cut have very complex material architectures and orientations. For FEA modeling techniques, using a larger number of frames during the cutting process would allow a more detailed and accurate capture of cutting performances. However, this is restricted to time for the solution to be completed. Further refinement of the modeling technique and the mesh in addition to advances in computational power could allow faster run times of the analys is.

Damaging temperature effects observed during ultrasonic cutting operations are typically as a result of friction between the vibrating blade and material (shown in Figure 7-1). In order to prevent the high temperatures caused damage, the ultrasonic blade has to cut with a sufficient speed. Contact areas between the blade and biomass can be reduced by new designs to minimize friction. An air or fluid cooling system can be added to the existing system. Localized temperature distribution at the blade/material interface is 
extremely useful to design ultrasonic assisted blades with no or less thermal damage on biomass materials.

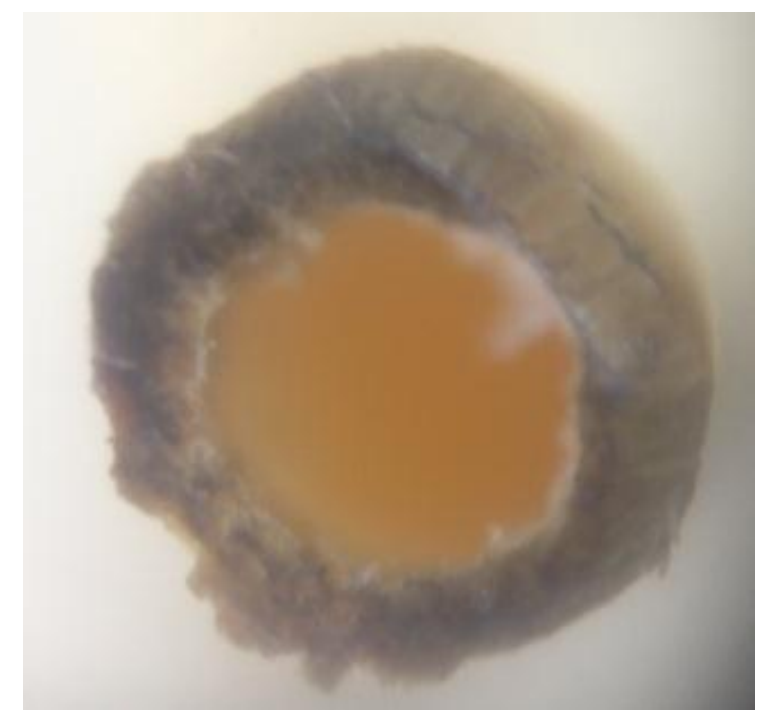

Figure 7-1. Thermal damage at biomas s cross-section area.

\subsection{Cutting experiments and equipment design}

In this study, only one ultrasonic frequency and one vibration amplitude were used in the simulation and experiments. Implementing different ultrasonic frequencies and vibration amplitudes would provide more cutting control parameters to explore their impacts on cutting performances. The linear cutting system designed and built in this study is easy to be controlled with a constant cutting speed to obtain cutting force values, but the cutting speed is limited within $0.4 \mathrm{~m} / \mathrm{s}$. For the future study, other cutting mechanisms are suggested to achieve a wider cutting speed range. Cylinder type of cutter with multiple ultrasonic blades can be designed to increase the processing rate. Experimental design of biomass bundle cutting can be achieved to best simulate the practical biomass size reduction processes. 


\section{REFERENCES}

Abdulkareem, A. (2005). Refining biogas produced from biomass: An alternative to cooking gas. Leonardo Journal of Sciences, 4(7), 1-8.

Adapa, P. K., Karunakaran, C., Tabil, L. G., \& Schoenau, G. J. (2009). Potential applications of infrared and Raman spectromicroscopy for agricultural biomass. Agricultural Engineering International: CIGR Journal.

Ahuja, D. R., Joshi, V., Smith, K. R., \& Venkataraman, C. (1987). Thermal performance and emission characteristics of unvented biomass-burning cookstoves: a proposed standard method for evaluation. Biomass, 12(4), 247-270.

Alonso, D. M., Wettstein, S. G., \& Dumesic, J. A. (2012). Bimetallic catalysts for upgrading of biomass to fuels and chemicals. Chemical Society Reviews, 41 (24), 8075-8098.

Alriols, M. G., Tejado, A., Blanco, M., Mondragon, I., \& Labidi, J. (2009). Agricultural palm oil tree residues as raw material for cellulose, lignin and hemicelluloses production by ethylene glycol pulping process. Chemical Engineering Journal, 148(1), 106-114.

Amin, S., Ahmed, M., \& Youssef, H. (1995). Computer-aided design of acoustic horns for ultrasonic machining using finite-element analysis. Journal of Materials Processing Technology, 55(3), 254-260.

Amon, T., Amon, B., Kryvoruchko, V., Zollitsch, W., Mayer, K., \& Gruber, L. (2007). Biogas production from maize and dairy cattle manure-influence of biomass composition on the methane yield. Agriculture, Ecosystems \& Environment, 118(1), 173-182.

Anderson, G. Q., \& Fergusson, M. J. (2006). Energy from biomass in the UK: sources, processes and biodiversity implications. Ibis, 148(s1), 180-183.

Angelidaki, I., Alves, M., Bolzonella, D., Borzacconi, L., Campos, J., Guwy, A., . . Van Lier, J. (2009). Defining the biomethane potential (BMP) of solid organic wastes and energy crops: a proposed protocol for batch assays. Water Science \& Technology, 59(5).

Angles, M., Ferrando, F., Farriol, X., \& Salvadó, J. (2001). Suitability of steam exploded residual softwood for the production of binderless panels. Effect of the pre-treatment severity and lignin addition. Biomass and Bioenergy, 21 (3), 211-224.

Arnold, G., Leiteritz, L., Zahn, S., \& Rohm, H. (2009). Ultrasonic cutting of cheese: Composition affects cutting work reduction and energy demand. International Dairy Journal, 19(5), 314-320.

ASAE. (2003). Moisture measurement-forage. St. Joseph, Michigan: ASAE.

Balan, V. (2014). Current challenges in commercially producing biofuels from lignocellulosic biomass. ISRN Biotechnology, 2014, 31.

BEC. What is biomass? Retrieved Janurary 2, 2014, from http://www.biomassenergycentre.org.uk/portal/page? pageid=76,15049\& dad=portal

Bisen, P. S., Debnath, M., \& Prasad, G. B. (2012). Microbes: Concepts and applications. NJ, USA: WileyBlackwell.

Bridgwater, A. (1995). The technical and economic feasibility of biomass gasification for power generation. Fuel, 74(5), 631-653.

Callé, F. R., \& Rosillo-Calle, F. (2007). The biomass assessment handbook: bioenergy for a sustainable environment. London, UK: Earthscan.

Center, J. C. P. M. (2011). Plant fact sheet for switchgrass (Panicum virgatum L.). USDA - Natural Resources Conservation Service.

Chattopadhyay, P. S., \& Pandey, K. P. (1999). Mechanical properties of sorghum stalk in relation to quasistatic deformation. Journal of Agricultural Engineering Research, 73 (2), 199-206. 
Chynoweth, D. P., Owens, J. M., \& Legrand, R. (2001). Renewable methane from anaerobic digestion of biomass. Renewable energy, 22(1), 1-8.

Ciubota-Rosie, C., Gavrilescu, M., \& Macoveanu, M. (2008). Biomass-an important renewable source of energy in romania. Environmental Engineering \& Management Journal (EEMJ), 7(5).

Clarke, K., Li, X., \& Li, K. (2011). The mechanism of fiber cutting during enzymatic hydrolysis of wood biomass. Biomass and Bioenergy, 35(9), 3943-3950.

Clough, W., R., \& Penzien, J. (1993). Dynamics of structures (2nd ed.). New York: McGraw-Hill Publishing Company.

Collinson, S., \& Thielemans, W. (2010). The catalytic oxidation of biomass to new materials focusing on starch, cellulose and lignin. Coordination Chemistry Reviews, 254(15), 1854-1870.

Collinson, S. R., \& Thielemans, W. (2010). The catalytic oxidation of biomass to new materials focusing on starch, cellulose and lignin. Coordination Chemistry Reviews, 254(15-16), 1854-1870.

Cox, P. M., Betts, R. A., Jones, C. D., Spall, S. A., \& Totterdell, I. J. (2000). Acceleration of global warming due to carbon-cycle feedbacks in a coupled climate model. Nature, 408(6809), 184-187.

Damartzis, T., \& Zabaniotou, A. (2011). Thermochemical conversion of biomass to second generation biofuels through integrated process design-A review. Renewable and Sustainable Energy Reviews, 15(1), 366-378.

Demirbas, A. (2005). Potential applications of renewable energy sources, biomass combustion problems in boiler power systems and combustion related environmental issues. Progress in Energy and Combustion Science, 31(2), 171-192.

Demirbas, A. (2008). Biofuels sources, biofuel policy, biofuel economy and global biofuel projections. Energy conversion and management, 49(8), 2106-2116.

DOE. (2014). Annual energy outlook 2014 with projections to 2040. Washington, DC U.S. Department of Energy, Energy Information Administration, Office of Integrated Analysis and Forecasting.

Eliyan, C. (2007). Anaerobic digestion of municipal solid waste in thermophilic continuous operation. Asian Institute of Technology.

Evans, A., Strezov, V., \& Evans, T. J. (2009). Assessment of sustainability indicators for renewable energy technologies. Renewable and Sustainable Energy Reviews, 13(5), 1082-1088.

Fike, J. H., Parrish, D. J., Wolf, D. D., Balasko, J. A., Green Jr, J. T., Rasnake, M., \& Reynolds, J. H. (2006). Switchgrass production for the upper southeastern USA: Influence of cultivar and cutting frequency on biomass yields. Biomass and Bioenergy, 30(3), 207-213.

Forgács, G. (2012). Biogas production from citrus wastes and chicken feather: pretreatment and codigestion. KA, Kemigården 4, Göteborg: Chalmers University of Technology.

Foston, M., \& Ragauskas, A. J. (2012). Biomass characterization: recent progress in understanding biomas s recalcitrance. Industrial Biotechnology, 8(4), 191-208.

Franco, A., Mosquera-Corral, A., Campos, J., \& Roca, E. (2007). Learning to operate anaerobic bioreactors. University of Santiago de Compostela, Available online: www. formatex. org .

Fuller, D. N., Scherer, W. T., \& Pomroy, T. A. (2003). An exploration and case study of population classification for managed healthcare within a state-based modelling framework. International Journal of Healthcare Technology and Management, 5(1-2), 123-140.

Galbe, M., Sassner, P., Wingren, A., \& Zacchi, G. (2007). Process engineering economics of bioethanol production (Vol. 108, pp. 303-327).

Gallego-Juarez, J. A. (2010). High-power ultrasonic processing: recent developments and prospective advances. Physics Procedia, 3(1), 35-47. 
Gallert, C., \& Winter, J. (2005). Bacterial metabolism in wastewater treatment systems: Wiley-VCH, Weinheim, Germany.

Gerpen, J. V. (2005). Biodiesel processing and production. Fuel processing technology, 86(10), 1097-1107.

Ghahraei, O., Ahmad, D., Khalina, A., Suryanto, H., \& Othman, J. (2011). Cutting tests of Kenaf stems. Transactions of the ASABE, 54(1), 6.

González-Montellano, C., Gómez, Á. R., Fuentes, J. M., Gallego, E., \& Ayuga, F. (2012). Determination of the mechanical properties of biomass briquettes for use in DEM simulations. SPC-07: SILOS AND GRANULAR MATERIALS (SIGMA), 100.

Goyal, H., Seal, D., \& Saxena, R. (2008). Bio-fuels from thermochemical conversion of renewable resources: a review. Renewable and Sustainable Energy Reviews, 12(2), 504-517.

Hall, D. O., Mynick, H., \& Williams, R. H. (1991). Carbon sequestration versus fossil fuel substitution: alternative roles for biomass in coping with greenhouse warming: Springer.

Hamelinck, C. N., Suurs, R. A., \& Faaij, A. P. (2005). International bioenergy transport costs and energy balance. Biomass and Bioenergy, 29(2), 114-134.

Hashin, Z. (1980). Failure criteria for unidirectional fiber composites. Journal of Applied Mechanics, 47(2), 329-334.

Humar, J. (2012). Dynamics of structures: CRC Press.

Igathinathane, C., Womac, A., Sokhansanj, S., \& Narayan, S. (2008). Knife grid size reduction to preprocess packed beds of high-and low-moisture switchgrass. Bioresource technology, 99(7), 2254-2264.

Ignaciuk, A., Vöhringer, F., Ruijs, A., \& van Ierland, E. C. (2006). Competition between biomass and food production in the presence of energy policies: A partial equilibrium analysis. Energy Policy, 34(10), 11271138.

Ikawa, N., Donaldson, R. R., Komanduri, R., König, W., Aachen, T. H., McKeown, P. A., . . Stowers, I. F. (1991). Ultraprecision metal cutting - the past, the present and the future. CIRP Annals Manufacturing Technology, 40(2), 587-594.

Ilker, R., \& Szczesniak, A. S. (1990). Structural and chemical bases for texture of plant foodstuffs. Journal of Texture Studies, 21(1), 1-36.

Jahirul, M. I., Rasul, M. G., Chowdhury, A. A., \& Ashwath, N. (2012). Biofuels production through biomass pyrolysis - a technological review. Energies, 5(12), 4952-5001.

K. Kato, K. T., I. Asano. (1971). Studies on vibration cutting of wood. I. J. Jap. Wood Res. Soc, 17(2), 5765.

Kacker, R. N., Lagergren, E. S., \& Filliben, J. J. (1991). Taguchi's orthogonal arrays are classic al designs of experiments. Journal of research of the National Institute of Standards and Technology, 96(5).

Kaletunc, G., \& Breslauer, K. J. (2003). Characterization of cereals and flours: Properties, analysis and applications (Vol. 124). NY, USA: Marcel Dekker, Inc.

Kim, J.-D., \& Lee, E.-S. (1996). A study of ultrasonic vibration cutting of carbon fibre reinforced plastics. The International Journal of Advanced Manufacturing Technology, 12 (2), 78-86.

Kitani, O. H. C. W. (1989). Biomass handbook. New York: Gordon and Breach Science Publishers.

Koike, Y., Kurosawa, M., Ueha, S., \& Adachi, K. (1991, 8-11 Dec 1991). Amplitude distribution control of ultrasonic vibration tools with a 2-D extended radiation surface. Paper presented at the Ultrasonics Symposium, 1991. Proceedings., IEEE 1991.

Kronbergs, E. (2000). Mechanical strength testing of stalk materials and compacting energy evaluation. Industrial Crops and Products, 11(2-3), 211-216.

Lazic, L., \& Mastorakis, N. (2008). Orthogonal array application for optimal combination of software defect detection techniques choices. WSEAS Transactions on Computers, 7(8), 1319-1336. 
Lehoux, N., Marier, P., D‘Amours, S., \& Beaulieu, J. (2012). The value creation network of Canadian wood fibre: CIRRELT.

Lin, Y., \& Tanaka, S. (2006). Ethanol fermentation from biomass resources: current state and prospects. Applied microbiology and biotechnology, 69(6), 627-642.

Littmann, W., Storck, H., \& Wallaschek, J. (2001). Sliding friction in the presence of ultrasonic oscillations: superposition of longitudinal os cillations. Archive of Applied Mechanics, 71 (8), 549-554.

Liu, B., \& Koc, A. (2012). Ultrasonic determination of water concentration in ethanol fuel using artificial neural networks. Transactions of the ASABE, 55(5), 1865-1872.

Liu, B., \& Koc, A. (2014). Design of an experimental system for biomass size reduction. Paper presented at the ASABE Annual International Meeting, Montreal, QC Canada.

Liu, Q., Mathanker, S. K., Zhang, Q., \& Hansen, A. C. (2012). Biomechanical properties of miscanthus stems. Transactions of the ASABE, 55(4), 1125-1131.

Lucas, M., MacBeath, A., McCulloch, E., \& Cardoni, A. (2006). A finite element model for ultrasonic cutting. Ultrasonics, 44, Supplement(0), e503-e509.

Ma, C., Shamoto, E., Moriwaki, T., \& Wang, L. (2004). Study of machining accuracy in ultrasonic elliptical vibration cutting. International Journal of Machine Tools and Manufacture, 44(12), 1305-1310.

Mam, S. (2005). A systems analysis of biomass densification process. University of British Columbia.

Markvart, T. (2000). Solar electricity (2nd ed.). England: John Wiley \& Sons.

Martini, N., \& Schell, J. S. (1998). Plant oils as fuels: present state of science and future developments : . Paper presented at the proceedings of the symposium Potsdam, Germany.

McKendry, P. (2002a). Energy production from biomass (part 1): overview of biomass. Bioresource technology, 83(1), 37-46.

McKendry, P. (2002b). Energy production from biomass (part 2): conversion technologies. Bioresource technology, 83(1), 47-54.

McLaughlin, S. B. (1992). New switchgrass biofuels research program for the Southeast. Paper presented at the Annual automotive development technology contractors`coordination meeting, Dearborn, MI.

Merkulov, L. G. (1957). Design of ultrasonic concentrations. Soviet Physics Acoustics, 3, 230-238.

Miao, Z., Grift, T. E., Hansen, A. C., \& Ting, K. (2013). An overview of lignocellulosic biomass feedstock harvest, processing and supply for biofuel production. Biofuels, 4(1), 5-8.

Mobley, A. V., Carroll, M. P., \& Canann, S. A. (1998). An Object Oriented Approach to Geometry Defeaturing for Finite Element Meshing. Paper presented at the IMR.

Monnet, F. (2003). An introduction to anaerobic digestion of organic wastes Biofuels (pp. 1-43).

Muhammad, R., Ahmed, N., Roy, A., \& Silberschmidt, V. V. (2012). Numerical modelling of vibrationassisted turning of ti-15333. Procedia CIRP, 1(0), 347-352.

Mulder, W. (2010). Proteins in biomass streams: A study commissioned by the biorenewable resources platform (platform groene grondstoffen): Wageningen UR Food \& Biobased Research.

Nad', M. (2010). Ultrasonic horn design for ultrasonic machining technologies. Applied and Computational Mechanics, 4(1).

Naik, S., Goud, V. V., Rout, P. K., \& Dalai, A. K. (2010). Production of first and second generation biofuels: a comprehensive review. Renewable and Sustainable Energy Reviews, 14(2), 578-597.

Nath, C., Rahman, M., \& Neo, K. S. (2009). A study on the effect of tool nose radius in ultrasonic elliptical vibration cutting of tungsten carbide. Journal of Materials Processing Technology, 209(17), 5830-5836.

nee'Nigam, P. S., \& Pandey, A. (2009). Solid-state fermentation technology for bioconversion of biomass and agricultural residues: Springer Netherlands. 
Nussbaumer, T. (2001). Aerosols from biomass combustion. Zurich, Switzerland: Thomas Nussbaumer (Ed.).

Nussbaumer, T. (2003). Combustion and co-combustion of biomass: fundamentals, technologies, and primary measures for emission reduction. Energy \& fuels, 17(6), 1510-1521.

O'Dogherty, M. J., \& Gale, G. E. (1991). Laboratory studies of the effect of blade parameters and stem configuration on the dynamics of cutting grass. Journal of Agricultural Engineering Research, 49(0), 99111.

Parikka, M. (2004). Global biomass fuel resources. Biomass and Bioenergy, 27(6), 613-620.

Pham, V., Holtzapple, M., \& El-Halwagi, M. (2010). Techno-economic analysis of biomass to fuel conversion via the MixAlco process. Journal of Industrial Microbiology and Biotechnology, 37(11), 11571168.

Prasad, S., Singh, A., \& Joshi, H. (2007). Ethanol as an alternative fuel from agricultural, industrial and urban residues. Resources, Conservation and Recycling, 50(1), 1-39.

Prince, R. P. W. D. D. B. J. W. (1968). Mechanical properties of corn stalks. Storrs: Storrs Agricultural Experiment Station, College of Agriculture, University of Connecticut.

Roos, C. J. (2010). Clean heat and power using biomass gasification for industrial and agricultural projects. WA, USA: Northwest CHP Application Center.

Rutz, D., \& Janssen, R. (2007). Biofuel technology handbook. Germany: Munich, Germany, WIP Renewable Energies.

Sambra, A., Sørensen, C. A. G., \& Kristensen, E. F. (2008). Optimized harvest and logistics for biomass supply chain.

Sanderson, M. A., Adler, P. R., Boateng, A. A., Casler, M. D., \& Sarath, G. (2006). Switchgrass as a biofuels feedstock in the USA. Canadian Journal of Plant Science, 86(Special Is sue), 1315-1325.

Schell, D., \& Harwood, C. (1994). Milling of lignocellulosic biomass. Applied Biochemistry and Biotechnology, 45-46(1), 159-168.

Schmer, M. R., Vogel, K. P., Mitchell, R. B., \& Perrin, R. K. (2008). Net energy of cellulosic ethanol from switchgrass. Proceedings of the National Academy of Sciences, 105(2), 464-469.

Schneider, Y., Zahn, S., \& Linke, L. (2002). Qualitative process evaluation for ultrasonic cutting of food. Engineering in Life Sciences, 2(6), 153-157.

Schneider, Y., Zahn, S., \& Rohm, H. (2008). Power requirements of the high-frequency generator in ultrasonic cutting of foods. Journal of Food Engineering, 86(1), 61-67.

Schneider, Y., Zahn, S., Schindler, C., \& Rohm, H. (2009). Ultrasonic excitation affects friction interactions between food materials and cutting tools. Ultrasonics, 49(6-7), 588-593.

Scurlock, J. M. O. (1999). Miscanthus: a review of European experience with a novel energy crop. Retrieved 01-12-2014

Searchinger, T., Heimlich, R., Houghton, R. A., Dong, F., Elobeid, A., Fabiosa, J., . . Y Yu, T.-H. (2008). Use of US croplands for biofuels increases greenhouse gases through emissions from land-use change. Science, 319(5867), 1238-1240.

Serio, M. A., Kroo, E., \& Wójtowicz, M. A. (2003). Biomass pyrolysis for distributed energy generation. Prepr. Pap.-Am. Chem. Soc., Div. Fuel Chem, 48(2), 584.

Sharma, B., Jones, C., \& Khanchi, A. (2011). Tensile strength and shear strength of switchgras s before and after frost. Biological Engineering, 4(1), 43-54.

Shi, F., Wang, P., Duan, Y., Link, D., \& Morreale, B. (2012). Recent developments in the production of liquid fuels via catalytic conversion of microalgae: Experiments and simulations. RSC Advances, 2(26), 9727-9747. 
Sim, R., \& Taylor, M. (2008). From 1st-to 2nd-generation biofuel technologies: An overview of current industry and rd\&d activities. Iea-oecd

\section{IEA Bioenergy.}

Sims, R. E., Hastings, A., Schlamadinger, B., Taylor, G., \& Smith, P. (2006). Energy crops: current status and future prospects. Global Change Biology, 12(11), 2054-2076.

Singh, S. P., \& Singh, D. (2010). Biodiesel production through the use of different sources and characterization of oils and their esters as the substitute of diesel: A review. Renewable and Sustainable Energy Reviews, 14(1), 200-216.

Sinn, G., Zettl, B., Mayer, H., \& Stanzl-Tschegg, S. (2005). Ultrasonic-assisted cutting of wood. Journal of Materials Processing Technology, 170(1-2), 42-49.

Sohi, S., Krull, E., Lopez-Capel, E., \& Bol, R. (2010). A review of biochar and its use and function in soil. Advances in agronomy, 105, 47-82.

Sokhansanj, S., Cushman, J., \& Wright, L. (2003). Collection and delivery of feedstock biomass for fuel and power production. CIGR E-Journal, 5.

Sun, R.-C. (2009). Detoxification and separation of lignocellulosic biomass prior to fermentation for bioethanol production by removal of lignin and hemicelluloses. Bioresources, 4(2).

Thomas, M., Huijnen, P. T. H. J., van Vliet, T., van Zuilichem, D. J., \& van der Poel, A. F. B. (1999). Effects of process conditions during expander processing and pelleting on starch modification and pellet quality of tapioca. Journal of the Science of Food and Agriculture, 79(11), 1481-1494.

Thomas, M., Van Vliet, T., \& Van der Poel, A. (1998). Physical quality of pelleted animal feed 3. Contribution of feedstuff components. Animal Feed Science and Technology, 70(1), 59-78.

Tilman, D., Socolow, R., Foley, J. A., Hill, J., Larson, E., Lynd, L., . . Somerville, C. (2009). Beneficial biofuels - the food, energy, and environment trilemma. Science, 325(5938), 270.

Tumuluru, J. S., Sokhansanj, S., Wright, C. T., Boardman, R. D., \& Yancey, N. A. (2011). A review on biomass classification and composition, co-firing issues and pretreatment methods. Paper presented at the Proceedings of the 2011 ASABE annual international meeting. Louis ville, Kentucky, USA.

Tumuluru, J. S., Wright, C. T., Hess, J. R., \& Kenney, K. L. (2011). A review of biomass densification systems to develop uniform feedstock commodities for bioenergy application. Biofuels, Bioproducts and Biorefining, 5(6), 683-707.

Vassilev, S. V., Baxter, D., Andersen, L. K., \& Vassileva, C. G. (2010). An overview of the chemical composition of biomass. Fuel, 89(5), 913-933.

Wang, L., Weller, C. L., Jones, D. D., \& Hanna, M. A. (2008). Contemporary issues in thermal gasification of biomass and its application to electricity and fuel production. Biomass and Bioenergy, 32 (7), 573-581.

Wang, X., Zhou, M., Gan, J. G. K., \& Ngoi, B. (2002). Theoretical and experimental studies of ultraprecision machining of brittle materials with ultrasonic vibration. The International Journal of Advanced Manufacturing Technology, 20(2), 99-102.

Welling, H., \& Shaw, T. (2004). Energy from wood biomass combustion in rural alberta applications. Agricultural Policy Framework, 19-43.

Whitmarsh, J. (1999). The photosynthetic process Concepts in Photobiology (pp. 11-51): Springer.

Wils, A., Calmano, W., Dettmann, P., Kaltschmitt, M., \& Ecke, H. (2012). Reduction of fuel side costs due to biomass co-combustion. Journal of Hazardous Materials, 207-208, 147-151.

Woldt, D., Schubert, G., \& Jäckel, H. G. (2004). Size reduction by means of low-speed rotary shears. International Journal of Mineral Processing, 74(Supplement 1), S405-S415.

Wool, R., \& Sun, X. S. (2011). Bio-based polymers and composites. MA, USA: Elsevier Science. 
Wright, C. T., Pryfogle, P. A., Stevens, N. A., Hess, J. R., \& Radtke, C. W. (2006). Value of distributed preprocessing of biomass feedstocks to a bioenergy industry: Idaho National Laboratory.

Wyman, C. E., Decker, S. R., Himmel, M. E., Brady, J. W., Skopec, C. E., \& Viikari, L. (2005). Hydrolysis of cellulose and hemicellulose. Polysaccharides: Structural diversity and functional versatility, 1, 10231062.

Yacobucci, B. D. (2007). Fuel ethanol: background and public policy issues.

Yu, M., Womac, A. R., Igathinathane, C., Ayers, P. D., \& Buschermohle, M. J. (2006). Switchgrass ultimate stresses at typical biomass conditions available for processing. Biomass and Bioenergy, 30(3), 214-219.

Zahn, S., Schneider, Y., \& Rohm, H. (2006). Ultrasonic cutting of foods: Effects of excitation magnitude and cutting velocity on the reduction of cutting work. Innovative Food Science \& Emerging Technologies, 7(4), 288-293.

Zhang, P. F., Wang, D. H., Cong, W. L., Zhang, M., Wu, X. R., Pei, Z. J., \& Deines, T. (2011). Ultrasonic vibration-assisted pelleting of cellulosic biomass for biofuel manufacturing. Journal of Manufacturing Science and Engineering, 133(1), 011012-011012.

Zhu, J. Y., \& Pan, X. J. (2010). Woody biomass pretreatment for cellulosic ethanol production: Technology and energy consumption evaluation. Bioresource technology, 101(13), 4992-5002.

Zhuang, Q., Qin, Z., \& Chen, M. (1999). Biofuel, land and water: maize, switchgrass or Miscanthus? Environmental Research Letters, 8(1). 


\section{APPENDIX I. SCHEMATIC DIAGRAM OF THE WIRELESS ENERGY MONITORING CIRCUIT}

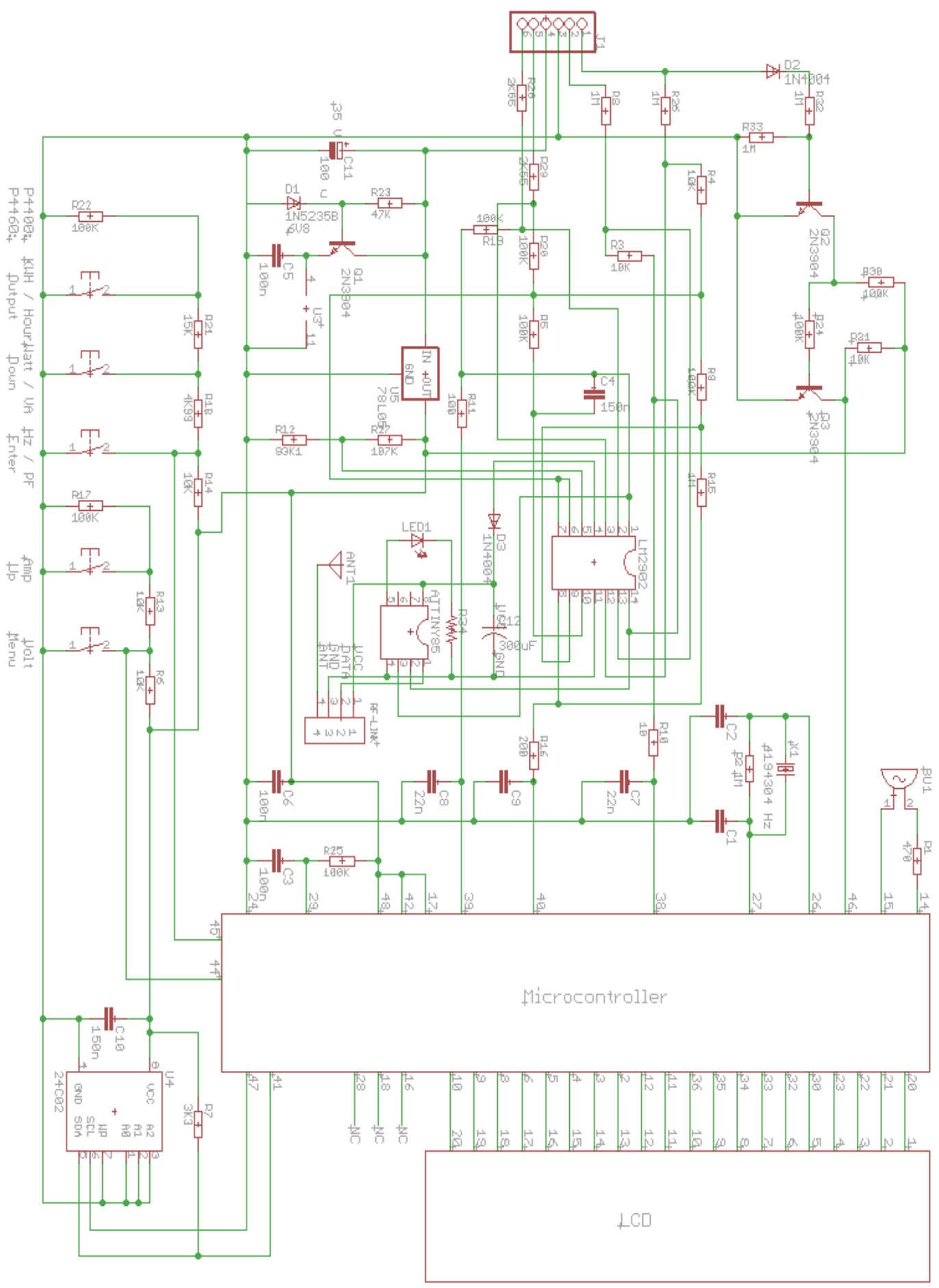




\section{VITA}

Bo Liu graduated from the Bioengineering Department of the University of Missouri Columbia in 2014. He received his Master of Science in Mechanical \& Aerospace Engineering in 2013 from the University of Missouri - Columbia under the supervision of Dr. Yuyi Lin. Bo Liu started his Ph.D. under the supervision of Dr. Ali Bulent Koc in 2011 at the University of Missouri - Columbia. His research interests include power ultrasonics, sensors and instrumentation. 